SAM GOLDY SHOYAMA ODA

ESTUDO BIOMECÂNICO DE DUAS TÉCNICAS EXTRA-CAPSULARES PARA ESTABILIZAÇÃO DO JOELHO COM RUPTURA DO LIGAMENTO CRUZADO CRANIAL EM CÃES

SÃO PAULO 


\section{ESTUDO BIOMECÂNICO DE DUAS TÉCNICAS EXTRA-CAPSULARES PARA ESTABILIZAÇÃO DO JOELHO COM RUPTURA DO LIGAMENTO CRUZADO CRANIAL EM CÃES}

Dissertação apresentada ao Programa de Pósgraduação em Clínica Cirúrgica Veterinária da Faculdade de Medicina Veterinária e Zootecnia da Universidade de São Paulo para a obtenção do título de Mestre em Medicina Veterinária

Departamento:

Cirurgia

Área de concentração:

Clínica Cirúrgica Veterinária

Orientador:

Profa Dra Julia Maria Matera 
Autorizo a reprodução parcial ou total desta obra, para fins acadêmicos, desde que citada a fonte.

DADOS INTERNACIONAIS DE CATALOGAÇÃO-NA-PUBLICAÇÃO

(Biblioteca Virginie Buff D’Ápice da Faculdade de Medicina Veterinária e Zootecnia da Universidade de São Paulo)

Oda, Sam Goldy Shoyama

Estudo biomecânico de duas técnicas extra-capsulares para estabilização do joelho com ruptura do ligamento cruzado cranial em cães / Sam Goldy Shoyama Oda. - São Paulo : S. G. S. Oda, 2008.

$113 \mathrm{f}$ : : il.

Dissertação (mestrado) - Universidade de São Paulo. Faculdade de Medicina Veterinária e Zootecnia. Departamento de Cirurgia, 2008.

Programa de Pós-Graduação: Clínica Cirúrgica Veterinária.

Área de concentração: Clínica Cirúrgica Veterinária.

Orientador: Profa. Dra. Julia Maria Matera.

1. Ruptura do ligamento cruzado cranial. 2. Extra-capsular. 3. Sutura fabelo-tibial lateral. 4. Imbricação do retináculo modificada. 5. Cães. I. Título. 


\section{UNIVERSIDADE DE SÃO PAULO \\ Faculdade de Medicina Veterinária e Zootecnia \\ Comissão Bioética}

\section{CERTIFICADO}

Certificamos que o Projeto intitulado "Avaliação e comparação por ensaio biomecânico de duas técnicas extra-capsulares para a reparação do ligamento cruzado cranial de cães", protocolado sob o n¹015/2006, utilizando 20 (vinte) cães, sob a responsabilidade da Profa. Dra. Júlia Maria Matera, está de acordo com os princípios éticos de experimentação animal da Comissão de Bioética da Faculdade de Medicina Veterinária e Zootecnia da Universidade de São Paulo e foi aprovado "ad referendum".

(We certify that the Research "Biomechanical evaluation and comparison of two extra-capsular techniques for the repair of the canine cranial cruciate ligament", protocol number 1015/2006, utilizing 20 (twenty) dogs, under the responsibility Profa. Dra. Júlia Maria Matera, agree with Ethical Principles in Animal Research adopted by Bioethic Commission of the School of Veterinary Medicine and Zootechny of University of São Paulo and was approved "ad referendum", meeting).

São Paulo, 23 de março de 2007

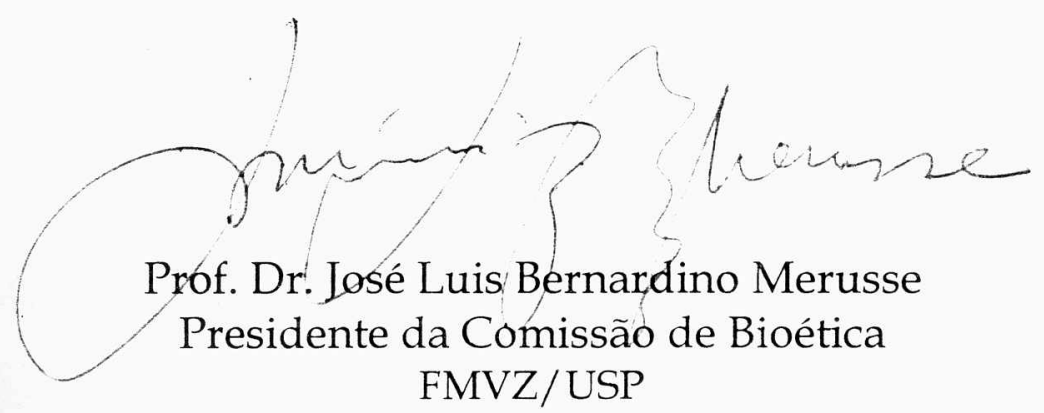

Av. Prof. Dr. Orlando Marques de Paiva, n 87 - 05508-270 - Cidade Universitária "Armando de Salles Oliveira". Fax: (11) 3032-2224 - fones: (11) 309107676/7671 - e-mail: fmvz@edu.usp.br 


\section{FOLHA DE AVALIAÇÃO}

Nome do autor: ODA, Sam Goldy Shoyama

Título: Estudo biomecânico de duas técnicas extra-capsulares para estabilização do joelho com ruptura do ligamento cruzado cranial em cães

Dissertação apresentada ao

Programa de Pós-graduação em Clínica Cirúrgica Veterinária da Faculdade de Medicina Veterinária e Zootecnia da Universidade de São Paulo para a obtenção do título de Mestre em Medicina Veterinária

Data:

Banca Examinadora

Prof. Dr.

Instituição:

Assinatura: Julgamento:

Prof. Dr. Instituição:

Assinatura: Julgamento:

Prof. Dr. Instituição:

Assinatura: Julgamento: 
Ao meu pai José Hirochi Oda por acreditar em mim e por ser um exemplo a ser seguido, “minha eterna gratidão”.

À Juliana Koszka pelo apoio e carinho em mais esta etapa de minha vida.

Aos meus amigos e familiares que direta ou indiretamente me guiam na conquista de cada dia. 


\section{DEDICATÓRIA}

À Prof. Dra. Julia Maria Matera pela orientação nesta importante etapa de minha vida.

Ao Doutor Roberto Freire da Mota e Albuquerque por viabilizar a execução deste estudo junto ao Instituto de Ortopedia e Traumatologia da Faculdade de Medicina da Universidade de São Paulo.

Ao Instituto de Ortopedia e Traumatologia da Faculdade de Medicina da Universidade de São Paulo por permitir a realização deste trabalho junto ao Laboratório de Ensaios Biomecânicos LIM-41.

Ao Tecnólogo César Augusto Martins pelo suporte no desenvolvimento e execução deste projeto de pesquisa.

À Angélica Cecília Tatarunas pela ajuda no desenvolvimento inicial deste projeto de pesquisa.

Aos Companheiros de Pós Graduação por me acompanharem em mais esta conquista, pelo carinho demonstrado e pelos conselhos e desabafos nos momentos difíceis.

Aos funcionários José Miron Oliveira da Silva, Jesus dos Anjos Vieira, Otavio Rodrigues dos Santos e Cledson Lelis dos Santos pela ajuda neste estudo e pelo indispensável suporte na rotina do Serviço de Cirurgia de Pequenos Animais da FMVZ/USP.

Aos funcionários Antonio Carlos Malaquias, Milton Gregório dos Santos e Carlito dos Santos Belauda Clínica Médica de Pequenos Animais pela ajuda no desenvolvimento deste estudo e por serem tão solícitos.

Àos Médicos Veterinários Viviane Sanchez Galeazzi, Tatiana Soares da Silva, Andressa Gianotti Campos, Patrícia Ferreira de Castro, Sandra Rosner, João Luiz Krumenerl e Rodrigo de Benedetto por contribuirem em meu desenvovimento como médico veterinário. 
À Neuza Gomes da Silva por sua amizade e conselhos que me tornam um homem melhor.

Aos Secretários Belarmino Ney Pereira e Alessandra Aparecida Araujo de Sousa da Secretaria do Departamento de Cirurgia da FMVZ/USP.

À Elza Maria Rosa Bernardo Faquim e demais funcionários da Biblioteca Virginie Buff D’Ápice pela simpatia, competência e disposição para ajudar.

À Fundação de Amparo a Pesquisa do Estado de São Paulo (FAPESP) pela bolsa concedida. 


\section{RESUMO}

ODA, S. G. S. Estudo biomecânico de duas técnicas extra-capsulares para estabilização do joelho com ruptura do ligamento cruzado cranial em cães. [Biomechanical study of two extra capsular techniques for stabilization of the knee with cranial cruciate ligament rupture in dogs]. 2008. 113 f. Dissertação (Mestrado em Medicina Veterinária) - Faculdade de Medicina Veterinária e Zootecnia, Universidade de São Paulo, São Paulo, 2008.

A instabilidade do joelho resultante da ruptura do ligamento cruzado cranial apresenta-se como sendo uma das principais causas de dor, em membro pélvico, manifestada por animais da espécie canina. Tal instabilidade pode gerar alterações como o desenvolvimento de osteoartrose e lesão de menisco, principalmente o medial. Com o intuito de restabelecer a estabilidade da articulação, muitas técnicas vêm sendo desenvolvidas de forma que as alterações provenientes de tal afecção sejam minimizadas. Com uma dimensão similar de variedades estão os materiais utilizados em diferentes técnicas ou até mesmo para o mesmo tipo de procedimento. A técnica ideal, bem como o material de escolha ainda são muito discutidos dentre os autores pesquisados. O presente trabalho avaliou a biomecânica das técnicas de sutura fabelo-tibial lateral (SFTL) e a técnica de imbricação do retináculo modificada (SFTLM), em joelhos de cadáveres de cães, na estabilização do joelho com ruptura do ligamento cruzado cranial, utilizando-se fio de náilon monofilamento leader line (60 libras). Foram avaliados rigidez articular e deslocamento craniais e caudais da tíbia em relação aos côndilos do fêmur, proporcionados pelo tipo de material e técnicas cirúrgicas, sendo os resultados obtidos comparados com os resultados do joelho íntegro e entre si. A análise estatística encontrou diferença na gaveta cranial de todos os grupos (ligamento cruzado cranial íntegro (LCCr), ligamento cruzado cranial rompido (RLCCr), SFTL e SFTLM) e na comparação da gaveta caudal entre o grupo RLCCr e SFTLM e entre o grupo SFTL e SFTLM. Outras diferenças foram encontradas na rigidez cranial dos grupos LCCr, RLCCr e reconstruído, não sendo observado diferença entre a rigidez de SFTL e SFTLM. As duas técnicas testadas diminuem a instabilidade do joelho, sendo a SFTLM mais efetiva em tal promoção, porém tal técnica influencia de forma mais evidente na biomecânica do ligamento cruzado caudal, sendo importante a avaliação de tal interferência a longo prazo. Estas duas técnicas extra-capsulares testadas, apesar de diminuirem significativamente a translação cranial da tíbia em relação ao fêmur, não restauram a rigidez articular quando comparadas com a biomecânica do joelho íntegro.

Palavras-chave: Ruptura do ligamento cruzado cranial. Extra-capsular. Sutura fabelo-tibial lateral. Imbricação do retináculo modificada. Cães. 


\begin{abstract}
ODA, S. G. S. Biomechanical study of two extra capsular techniques for stabilization of the knee with cranial cruciate ligament rupture in dogs. [Estudo biomecânico de duas técnicas extra-capsulares para estabilização do joelho com ruptura do ligamento cruzado cranial em cães]. 2008. 113 f. Dissertação (Mestrado em Medicina Veterinária) - Faculdade de Medicina Veterinária e Zootecnia, Universidade de São Paulo, São Paulo, 2008.

Knee instability resulting from an insufficient cranial cruciate ligament is the major cause of hind limb lameness in dogs. This instability can result in osteoarthrosis and medial meniscal injury. Many surgical techniques have been developed to restore knee stability and to reduce degenerative joint desease. There is a similarly huge variability in materials utilized for different or the same techniques. An ideal technique and material aren't established yet. This study analyzed the biomechanics of the lateral fabellar suture technique (SFTL) and the modified retinacular imbrication technique (SFTLM) in stabilizing cadaveric cranial cruciate ligament deficient stifles with $60 \mathrm{lb}$ nylon leader line. Articular cranio-caudal stiffness and tibial translation were evaluated and compared between different techniques and with the intact knee. The statistical analysis revealed significant differences between all groups (intact cranial cruciate ligament (LCCr), ruptured cranial cruciate ligament (RLCCr), SFTL and SFTLM) in the cranial tibial translation. In the caudal tibial translation a significant statistical difference was seen between RLCCr and SFTLM groups and between reconstructed ones. Other differences were found in the cranial stiffness between LCCr, RLCCr and reconstructed groups, but not between SFTL and SFTLM. Both techniques tested reduced joint instability but SFTLM was more efficient, although it affected the caudal cruciate ligament biomechanics more evidently when compared with the SFTL technique. This long-term evaluation of the caudal influence induced by SFTLM will be important. Despite of the reduction in the tibial cranial translation by these two different extra capsular techniques, none have maintained normal stifle stiffness.
\end{abstract}

Key words: Cranial cruciate ligament rupture. Extra capsular. Lateral fabellar suture. Modified retinacular imbrication. Dogs. 


\section{LISTA DE FIGURAS}

Figura 1 - Preparação da peça para o ensaio biomecânico destacando o joelho removido em bloco, o tensionamento do laço com auxílio de dinamômetro digital e a fixação do nó com auxílio de porta agulha São Paulo - 2007

Figura 2 - Máquina de ensaio biomecânico Kratos 5002 composta por parte eletrônica e parte mecânica - São Paulo - 2007

Figura 3 - Dispositivo de fixação do joelho à máquina de ensaios biomecânicos. A) Garra de fixação do fêmur; B) Garra de fixação da tíbia; C) Célula de carga - São Paulo - 2007. 


\section{LISTA DE TABELAS}

Tabela 1 - Tabela 1 - Peso corpóreo (quilos), sexo, raça e membro pélvico de cada cão utilizado nos ensaios biomecânicos com carga de 100 Newtons - São Paulo - 2007

Tabela 2 - Deslocamento cranial e caudal da tíbia em relação ao fêmur após carga de 100 Newtons, nas diferentes situações testadas no "joelho 01'. São Paulo, 2007

Tabela 3 - Rigidez cranial e caudal apresentada nas diferentes situações testadas no "joelho 01". São Paulo, 2007

Tabela 4 - Deslocamento cranial e caudal da tíbia em relação ao fêmur após carga de 100 Newtons, nas diferentes situações testadas no "joelho 02”. São Paulo, 2007

Tabela 5 - Rigidez cranial e caudal apresentada nas diferentes situações testadas no “joelho 02”. São Paulo, 2007.

Tabela 6 - Deslocamento cranial e caudal da tíbia em relação ao fêmur após carga de 100 Newtons, nas diferentes situações testadas no "joelho 03”. São Paulo, 2007

Tabela 7 - Rigidez cranial e caudal apresentada nas diferentes situações testadas no "joelho 03". São Paulo, 2007

Tabela 8 - Deslocamento cranial e caudal da tíbia em relação ao fêmur após carga de 100 Newtons, nas diferentes situações testadas no "joelho 04”. São Paulo, 2007

Tabela 9 - Rigidez cranial e caudal apresentada nas diferentes situações testadas no "joelho 04". São Paulo, 2007.

Tabela 10 - Deslocamento cranial e caudal da tíbia em relação ao fêmur após carga de 100 Newtons, nas diferentes situações testadas no "joelho 05”. São Paulo, 2007

Tabela 11 - Rigidez cranial e caudal apresentada nas diferentes situações testadas no “joelho 05”. São Paulo, 2007.

Tabela 12 - Deslocamento cranial e caudal da tíbia em relação ao fêmur após carga de 100 Newtons, nas diferentes situações testadas no "joelho 06”. São Paulo, 2007

Tabela 13 - Rigidez cranial e caudal apresentada nas diferentes situações testadas no "joelho 06". São Paulo, 2007 
Tabela 14 - Deslocamento cranial e caudal da tíbia em relação ao fêmur após carga de 100 Newtons, nas diferentes situações testadas no "joelho 07”. São Paulo, 2007

Tabela 15 - Rigidez cranial e caudal apresentada nas diferentes situações testadas no "joelho 07”. São Paulo, 2007

Tabela 16 - Deslocamento cranial e caudal da tíbia em relação ao fêmur após carga de 100 Newtons, nas diferentes situações testadas no "joelho 08”. São Paulo, 2007

Tabela 17 - Rigidez cranial e caudal apresentada nas diferentes situações testadas no “joelho 08". São Paulo, 2007.

Tabela 18 - Deslocamento cranial e caudal da tíbia em relação ao fêmur após carga de 100 Newtons, nas diferentes situações testadas no "joelho 09”. São Paulo, 2007

Tabela 19 - Rigidez cranial e caudal apresentada nas diferentes situações testadas no “joelho 09”. São Paulo, 2007 .....

Tabela 20 - Deslocamento cranial e caudal da tíbia em relação ao fêmur após carga de 100 Newtons, nas diferentes situações testadas no "joelho 10”. São Paulo, 2007

Tabela 21 - Rigidez cranial e caudal apresentada nas diferentes situações testadas no “joelho 10". São Paulo, 2007.

Tabela 22 - Deslocamento cranial e caudal da tíbia em relação ao fêmur após carga de 100 Newtons, nas diferentes situações testadas no "joelho 11”. São Paulo, 2007

Tabela 23 - Rigidez cranial e caudal apresentada nas diferentes situações testadas no “joelho 11”. São Paulo, 2007.

Tabela 24 - Deslocamento cranial e caudal da tíbia em relação ao fêmur após carga de 100 Newtons, nas diferentes situações testadas no "joelho 12”. São Paulo, 2007

Tabela 25 - Rigidez cranial e caudal apresentada nas diferentes situações testadas no “joelho 12”. São Paulo, 2007.

Tabela 26 - Deslocamento cranial e caudal da tíbia em relação ao fêmur após carga de 100 Newtons, nas diferentes situações testadas no "joelho 13”. São Paulo, 2007

Tabela 27 - Rigidez cranial e caudal apresentada nas diferentes situações testadas no “joelho 13". São Paulo, 2007 . 
Tabela 28 - Deslocamento cranial e caudal da tíbia em relação ao fêmur após carga de 100 Newtons, nas diferentes situações testadas no "joelho 14”. São Paulo, 2007

Tabela 29 - Rigidez cranial e caudal apresentada nas diferentes situações testadas no "joelho 14". São Paulo, 2007.

Tabela 30 - Deslocamento cranial e caudal da tíbia em relação ao fêmur após carga de 100 Newtons, nas diferentes situações testadas no "joelho 15”. São Paulo, 2007

Tabela 31 - Rigidez cranial e caudal apresentada nas diferentes situações testadas no "joelho 15". São Paulo, 2007

Tabela 32 - Deslocamento cranial e caudal da tíbia em relação ao fêmur após carga de 100 Newtons, nas diferentes situações testadas no "joelho 16”. São Paulo, 2007

Tabela 33 - Rigidez cranial e caudal apresentada nas diferentes situações testadas no "joelho 16". São Paulo, 2007 .....

Tabela 34 - Deslocamento cranial e caudal da tíbia em relação ao fêmur após carga de 100 Newtons, nas diferentes situações testadas no "joelho 17’. São Paulo, 2007

Tabela 35 - Rigidez cranial e caudal apresentada nas diferentes situações testadas no "joelho 17". São Paulo, 2007

Tabela 36 - Deslocamento cranial e caudal da tíbia em relação ao fêmur após carga de 100 Newtons, nas diferentes situações testadas no "joelho 18”. São Paulo, 2007

Tabela 37 - Rigidez cranial e caudal apresentada nas diferentes situações testadas no “joelho 18”. São Paulo, 2007.

Tabela 38 - Deslocamento cranial e caudal da tíbia em relação ao fêmur após carga de 100 Newtons, nas diferentes situações testadas no "joelho 19”. São Paulo, 2007

Tabela 39 - Rigidez cranial e caudal apresentada nas diferentes situações testadas no “joelho 19". São Paulo, 2007.

Tabela 40 - Deslocamento cranial e caudal da tíbia em relação ao fêmur após carga de 100 Newtons, nas diferentes situações testadas no "joelho 20”. São Paulo, 2007

Tabela 41 - Rigidez cranial e caudal apresentada nas diferentes situações testadas no "joelho 20". São Paulo, 2007 
Tabela 42 - Valores das forças residuais apresentadas pelos joelhos nas diferentes situações de ensaio. São Paulo, 2007

Tabela 43 - Gaveta cranial (GCRAN) em milímetros apresentada pelos diferentes grupos nos três ciclos de 100 Newtons de carga com respectivas médias, desvios padrões (DP) e probabilidades estatísticas (P). São Paulo, 2007

Tabela 44 - Gaveta caudal (GCAU) em milímetros apresentada pelos diferentes grupos nos três ciclos de 100 Newtons de carga com respectivas médias, desvios padrões (DP) e probabilidades estatísticas (P). São Paulo, 2007.

Tabela 45 - Rigidez cranial (RCRAN) em Newton/milímetro apresentada pelos diferentes grupos nos três ciclos de 100 Newtons de carga com respectivas médias, desvios padrões (DP) e probabilidades estatísticas (P). São Paulo, 2007.

Tabela 46 - Rigidez caudal (RCAU) em Newton/milímetro apresentada pelos diferentes grupos nos três ciclos de 100 Newtons de carga com respectivas médias, desvios padrões (DP) e probabilidades estatísticas (P). São Paulo, 2007.

Tabela 47 - Gaveta cranial (GCRAN) e caudal (GCAU) em milímetros e rigidez cranial (RCRAN) e caudal (RCAU) em Newton/milímetro apresentadas pelos diferentes grupos nos ensaios biomecânicos com carga de 100 Newtons com respectivas médias, desvios padrões (DP) e probabilidades estatísticas (P). São Paulo, 2007 


\section{LISTA DE GRÁFICOS}

Gráfico 1 - Exemplo de gráfico de ensaio biomecânico de inflexão realizado no experimento. São Paulo, 2007.

Gráfico 2 - Ensaios biomecânicos referentes ao "joelho 01" nas diferentes situações testadas, durante os três ciclos cranio-caudais. São Paulo, 2007.

Gráfico 3 - Ensaios biomecânicos referentes ao "joelho 02" nas diferentes situações testadas, durante os três ciclos cranio-caudais. São Paulo, 2007.

Gráfico 4 - Ensaios biomecânicos referentes ao "joelho 03" nas diferentes situações testadas, durante os três ciclos cranio-caudais. São Paulo, 2007

Gráfico 5 - Ensaios biomecânicos referentes ao "joelho 04" nas diferentes situações testadas, durante os três ciclos cranio-caudais. São Paulo, 2007

Gráfico 6 - Ensaios biomecânicos referentes ao "joelho 05" nas diferentes situações testadas, durante os três ciclos cranio-caudais. São Paulo, 2007

Gráfico 7 - Ensaios biomecânicos referentes ao "joelho 06" nas diferentes situações testadas, durante os três ciclos cranio-caudais. São Paulo, 2007.

Gráfico 8 - Ensaios biomecânicos referentes ao "joelho 07" nas diferentes situações testadas, durante os três ciclos cranio-caudais. São Paulo, 2007

Gráfico 9 - Ensaios biomecânicos referentes ao "joelho 08" nas diferentes situações testadas, durante os três ciclos cranio-caudais. São Paulo, 2007

Gráfico 10 - Ensaios biomecânicos referentes ao “joelho 09” nas diferentes situações testadas, durante os três ciclos cranio-caudais. São Paulo, 2007. 
Gráfico 11 - Ensaios biomecânicos referentes ao “joelho 10" nas diferentes situações testadas, durante os três ciclos cranio-caudais. São Paulo, 2007

Gráfico 12 - Ensaios biomecânicos referentes ao "joelho 11" nas diferentes situações testadas, durante os três ciclos cranio-caudais. São Paulo, 2007.

Gráfico 13 - Ensaios biomecânicos referentes ao "joelho 12" nas diferentes situações testadas, durante os três ciclos cranio-caudais. São Paulo, 2007.

Gráfico 14 - Ensaios biomecânicos referentes ao "joelho 13" nas diferentes situações testadas, durante os três ciclos cranio-caudais. São Paulo, 2007.

Gráfico 15 - Ensaios biomecânicos referentes ao "joelho 14" nas diferentes situações testadas, durante os três ciclos cranio-caudais. São Paulo, 2007.

Gráfico 16 - Ensaios biomecânicos referentes ao "joelho 15" nas diferentes situações testadas, durante os três ciclos cranio-caudais. São Paulo, 2007.

Gráfico 17 - Ensaios biomecânicos referentes ao "joelho 16" nas diferentes situações testadas, durante os três ciclos cranio-caudais. São Paulo, 2007

Gráfico 18 - Ensaios biomecânicos referentes ao “joelho 17" nas diferentes situações testadas, durante os três ciclos cranio-caudais. São Paulo, 2007

Gráfico 19 - Ensaios biomecânicos referentes ao “joelho 18” nas diferentes situações testadas, durante os três ciclos cranio-caudais. São Paulo, 2007

Gráfico 20 - Ensaios biomecânicos referentes ao "joelho 19" nas diferentes situações testadas, durante os três ciclos cranio-caudais. São Paulo, 2007.

Gráfico 21 - Ensaios biomecânicos referentes ao "joelho 20" nas diferentes situações testadas, durante os três ciclos cranio-caudais. São Paulo, 2007.

Gráfico 22 - Comparação gráfica dos valores médios de gaveta cranial de cada um dos grupos quando submetidos aos três ciclos de 100 Newtons. São Paulo, 2007 
Gráfico 23 - Comparação gráfica dos valores médios de gaveta caudal de cada um dos grupos quando submetidos aos três ciclos de 100 Newtons. São Paulo, 2007

Gráfico 24 - Comparação gráfica dos valores médios de rigidez cranial de cada um dos grupos quando submetidos aos três ciclos de 100 Newtons. São Paulo, 2007.

Gráfico 25 - Comparação gráfica dos valores médios de rigidez caudal de cada um dos grupos quando submetidos aos três ciclos de 100 Newtons. São Paulo, 2007

Gráfico 26 - Comparação gráfica da média e desvio padrão da gaveta cranial apresentada pelos diferentes grupos quando submetidos aos ensaios com carga de 100 Newtons. São Paulo, 2007

Gráfico 27 - Comparação gráfica da média e desvio padrão da gaveta caudal apresentada pelos diferentes grupos quando submetidos aos ensaios com carga de 100 Newtons. São Paulo, 2007.

Gráfico 28 - Comparação gráfica da média e desvio padrão da rigidez cranial apresentada pelos diferentes grupos quando submetidos aos ensaios com carga de 100 Newtons. São Paulo, 2007

Gráfico 29 - Comparação gráfica da média e desvio padrão da rigidez caudal apresentada pelos diferentes grupos quando submetidos aos ensaios com carga de 100 Newtons. São Paulo, 2007 


\section{LISTA DE ABREVIATURAS E SIGLAS}

BCM: banda crânio-medial

CSK: nó quadrado fixado com porta agulha

CT: tratamento conservador

EA: extra-articular

FHT: técnica de transposição da cabeça da fíbula

FTS: técnica de sutura fabelo-tibial padrão

HH: $\quad$ sliding half-hitch knot com total de cinco laçadas utilizando fio não estéril

HK: duplo nó quadrado com total de quatro laçadas utilizando fio não estéril e auxílio de Harris Knotter

HOVET-FMVZ/USP: Hospital Veterinário da Faculdade de Medicina Veterinária e Zootecnia da Universidade de São Paulo

IA: intra-articular

LCCr: ligamento cruzado cranial

LFS: $\quad$ sutura lateral da fabela

LGT: técnica extra-capsular com enxerto de tendão patelar e fascia lata

NFL: $\quad$ fio de náilon para pesca

NLL: $\quad$ fio de náilon leader line

PCL: porção caudo-lateral

RLCCr: ruptura do ligamento cruzado cranial

SCC: $\quad$ sistema crimp-clamp da Securos ${ }^{\circledR}$

SEC: $\quad$ sistema crimp-clamp da Securos ${ }^{\circledR}$ com fio não estéril

SFTL: $\quad$ sutura fabelo-tibial lateral

SFTLM: sutura fabelo-tibial lateral e medial

SLK: $\quad$ self-locking knot com total de cinco laçadas e fio não estéril

SQ: nó quadrado fixado após primeira laçada e mais quatro laçadas consecutivas com fio não esterilizado

SS: nó quadrado fixado após primeira laçada e mais quatro laçadas consecutivas utilizando fio esterilizado em autoclave

TPA: ângulo do platô tibial

TPLO: osteotomia de nivelamento do platô tibial

TRAP: fosfatase ácida resistente ao tartarato 


\section{SUMÁRIO}

1 INTRODUÇÃ

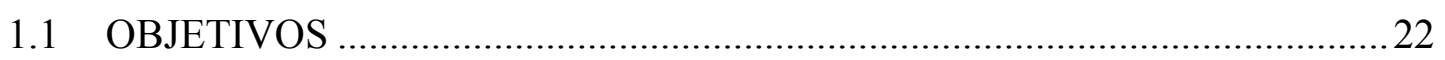

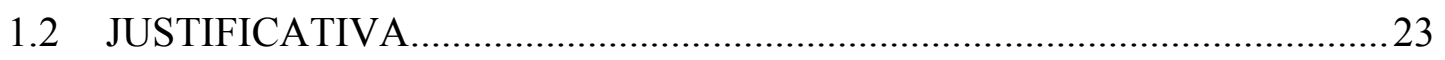

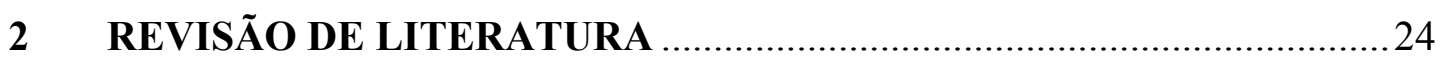

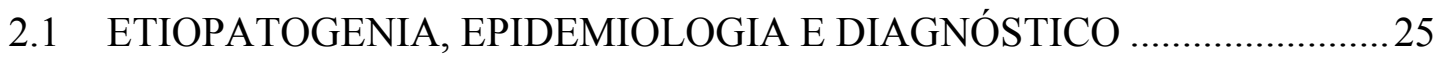

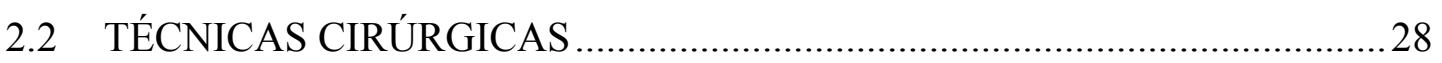

2.3 MATERIAL DOS IMPLANTES E TÉCNICAS DE FECHAMENTO DO

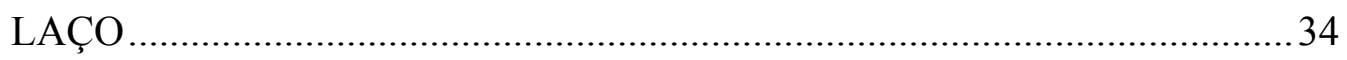

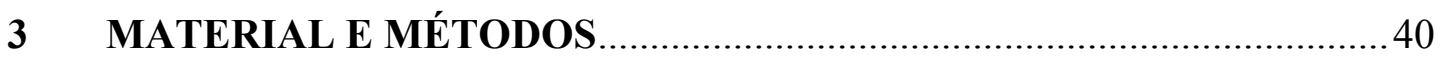

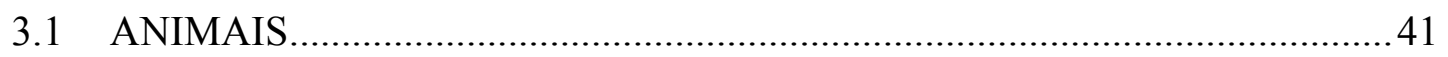

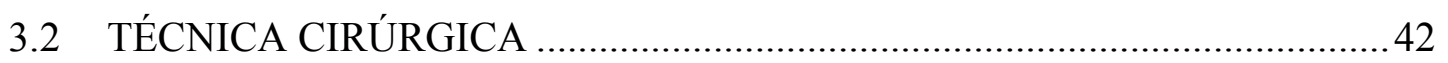

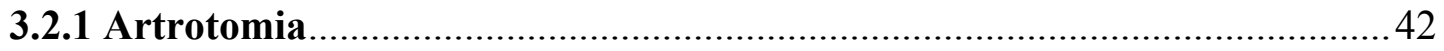

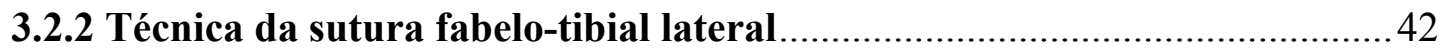

3.2.3 Técnica da sutura fabelo-tibial lateral e medial .......................................... 43

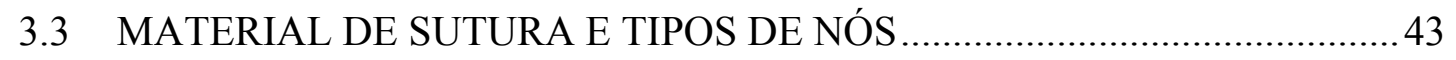

3.4 MÉTODO DE ESTERILIZAÇÃO DOS FIOS …............................................. 44

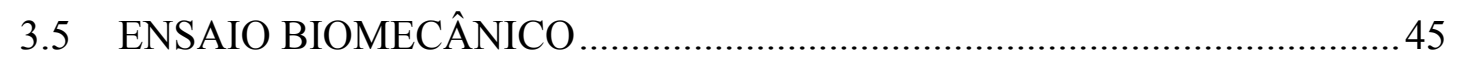

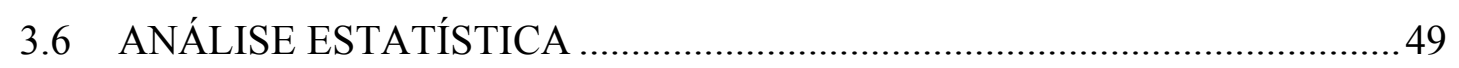

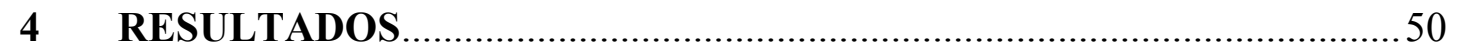

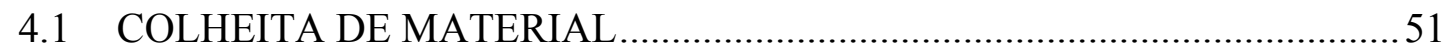

4.2 ENSAIO BIOMECÂNICO DE INFLEXÃO ...................................................53

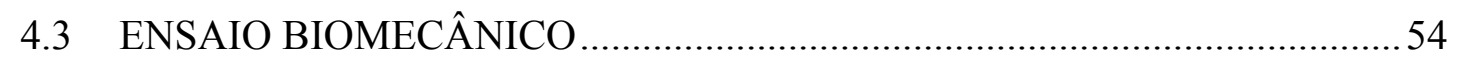

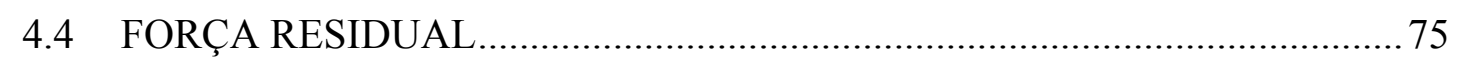

4.5 COMPARAÇÃO NO MESMO GRUPO ......................................................... 76

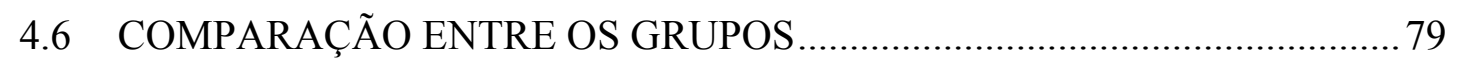

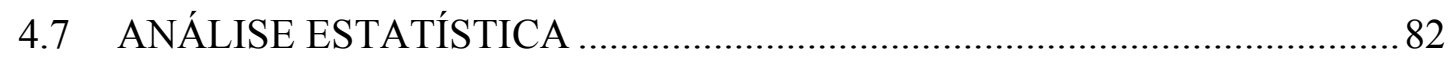

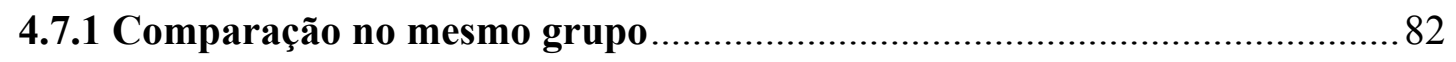

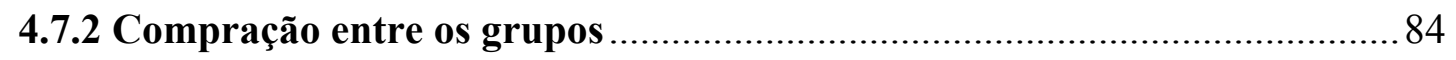

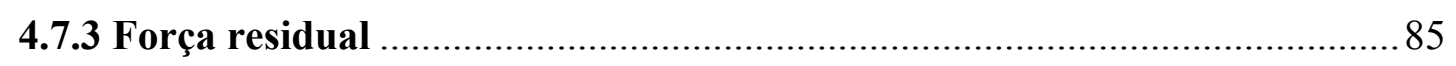

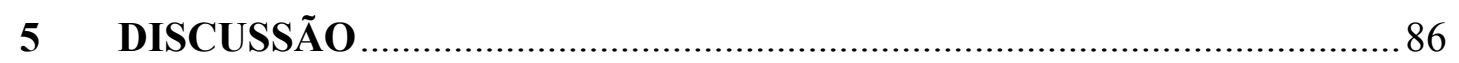

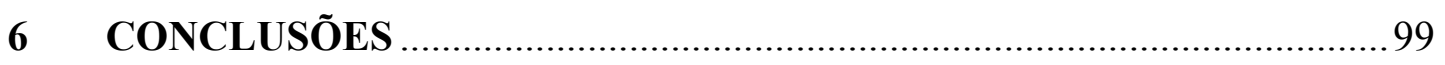

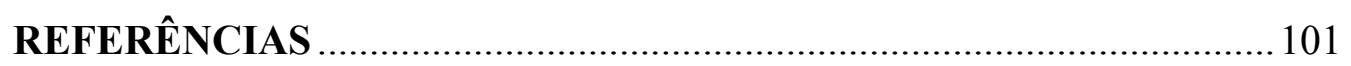


1 INTRODUCẼ̃O 


\section{INTRODUÇÃO}

O joelho do cão é uma "junta de transmissão" biarticulada, estabilizada por um sistema ligamentar e por restritores secundários que são solicitados conforme a demanda biomecânica (LEOPIZZI, 1998), ou seja, basicamente formado por um cilindro (dois côndilos), acomodado sobre uma superfície plana (platô tibial), sendo sua movimentação controlada por ligamentos e não por sua estrutura óssea (articulação ligamento-dependente). Trata-se de uma articulação com dois graus de liberdade sendo um deles a rotação em torno do eixo longo da tíbia e o segundo os movimentos que permitem a flexão e extensão no eixo transverso ao nível dos côndilos femorais (SLOCUM; SLOCUM, 1998).

A articulação femoro-tibio-patelar é formada por duas articulações funcionalmente distintas: a articulação femoro-tibial responsável pela sustentação do peso e a articulação femoro-patelar que possui como principais funções manter a patela no sulco troclear, aumentar a eficiência mecânica do grupo do músculo quadríceps e facilitar o movimento de extensão (VASSEUR, 2003).

Os meniscos são estruturas fibrocartilagíneas de configuração semilunar que se interpõe entre os côndilos femorais e o platô tibial. Possuem sua face dorsal em forma de cunha, sendo suas bordas mais espessas e sua fixação à cápsula articular; cada um deles possui dois pontos de ancoragem no platô tibial, ligamento menisco-tibial cranial e caudal, bem como um ligamento intermeniscal unindo os ligamentos menisco-tibiais craniais de ambos. Além destas estruturas o menisco lateral ainda possui o ligamento menisco-femoral que o une ao fêmur. As funções dos meniscos incluem absorção de energia e transferência de estresse através da articulação, estabilização e lubrificação da articulação, e prevenção de lesão da cápsula sinovial entre as faces articulares do fêmur e da tíbia (VASSEUR, 2003).

Os principais ligamentos responsáveis pelo suporte da estrutura do joelho são os ligamentos colaterais (medial e lateral) e os cruzados (cranial e caudal). Os ligamentos colaterais limitam os movimentos do tipo varo (ligamento colateral lateral) e valgo (ligamento colateral medial) da tíbia principalmente à extensão, já que na flexão os cruzados são mais importantes neste controle. O ligamento cruzado caudal previne a translação caudal da tíbia em relação ao fêmur (movimento de gaveta caudal) e ajuda a limitar a rotação interna da tíbia 
através de sua torção com o ligamento cruzado cranial; secundariamente o cruzado caudal auxilia a conter a hiperextensão e ajuda a limitar os movimentos tipo varo e valgo no joelho em flexão. O ligamento cruzado cranial ( $\mathrm{LCCr}$ ) é dividido em dois componentes funcionais, a banda crânio-medial (BCM) e a porção caudo-lateral (PCL) (VASSEUR, 2003), e funciona parcialmente tenso durante a flexão do joelho, onde somente as fibras da BCM estão sujeitas a solicitação de carga, mudando seu comportamento na extensão, tornando a BCM e a PCL tensas e ativas funcionalmente (LEOPIZZI, 1998). Possui uma conformação em espiral formando um ângulo de $90^{\circ}$ entre seus pontos de fixação e tem como principais funções conter o movimento de gaveta cranial e a hiperextensão do membro, assim como limitar a rotação interna da tíbia e prevenir movimento varo e valgo em excesso enquanto o joelho está fletido (VASSEUR, 2003).

A instabilidade do joelho decorrente da ruptura do ligamento cruzado cranial é uma das mais freqüentes causas de dor em membro pélvico de cães (ARNOCZKY, 1980). No ano de 2003, nos Estado Unidos, foi estimado um gasto de mais de 1,3 bilhões de dólares, pelos proprietários, no tratamento de seus cães portadores de ruptura do ligamento cruzado cranial (WILKE et al., 2005).

Trauma pode ser um dos motivos da ruptura do ligamento cruzado cranial (RLCCr), porém inúmeros autores afirmam que a RLCCr é secundária a mudanças degenerativas crônicas que ocorrem no ligamento (HOHN; NEWTON, 1975). Foi observado que o interior do ligamento e a sua porção mediana deterioram mais cedo que as camadas superficiais e as regiões próximas da inserção no osso. Em cada cão os ligamentos cruzados cranial e caudal são afetados e a severidade das alterações parece ser equivalente nos dois joelhos (VASSEUR; POOL; ARNOCZKY, 1985).

Alguns fatores como porte da raça e idade dos animais são citados como predisponentes a RLCCr. Whitehair e Vasseur (1993) referem maior freqüência de RLCCr em cães de raça grande e gigante do que em cães de raças pequenas. A força do ligamento cruzado cranial do cão reduz com a idade, sendo correlacionada com a perda da organização dos feixes de fibras e mudanças metaplásicas dos elementos celulares (VASSEUR et al., 1985). As alterações apresentam-se mais pronunciadas em cães jovens de raças de grande porte, diferentemente das raças de pequeno porte que ocorre tardiamente (VASSEUR, 2003). O maior índice de RLCCr apresentado por cães com idade superior a 5 anos está associado com as alterações 
degenerativas observadas no ligamento (HOHN; NEWTON, 1975). A influência da castração de machos e fêmeas sobre o aumento da incidência de RLCCr também foi relatada quando comparados machos inteiros com machos castrados e fêmeas inteiras com fêmeas castradas, porém a prevalência de RLCCr entre machos e fêmeas não foi constatada (VASSEUR, 2003).

Muitas são as técnicas e materiais disponíveis para a correção da instabilidade gerada pela RLCCr, sendo algumas usadas isoladamente ou em associação. Basicamente as técnicas são divididas em dois tipos: intra-articulares (IA) e extra-articulares (EA). Segundo Korvick, Johnson e Schaeffer (1994) a escolha do cirurgião pela técnica a ser utilizada depende principalmente do peso do animal e da duração do quadro de injúria.

\subsection{OBJETIVOS}

Os objetivos da pesquisa foram:

1. Avaliar a biomecânica do joelho íntegro e portador de ruptura do ligamento cruzado cranial.

2. Avaliar a biomecânica do joelho portador de ruptura do ligamento cruzado cranial submetido à técnica de estabilização retinacular lateral (HULSE; JOHNSON, 2001) utilizando fio de náilon leader line $e^{l}$ (60 libras).

3. Avaliar a biomecânica do joelho portador de ruptura do ligamento cruzado cranial submetido à técnica de imbricação do retináculo modificada (SCHAEFER; FLO, 1998), usando fio de náilon leader line $e^{1}$ (60 libras).

4. Comparar a biomecânica das técnicas com a do joelho íntegro e entre si.

\footnotetext{
${ }^{1}$ Hard Type Nylon Leader Material, Mason Tackle Co, Otisville, MI, USA
} 


\subsection{JUSTIFICATIVA}

A ruptura do ligamento cruzado cranial é a afecção que acomete a articulação do joelho do cão com maior freqüência. Dentre as formas de tratamento cirúrgico, as técnicas ditas extracapsulares, ou seja, aquelas que utilizam os tecidos periarticulares para promover a estabilidade articular são amplamente empregadas. Entre as técnicas extra-capsulares, a sutura fabelo-tibial lateral é bastante popular na ortopedia canina, havendo vários estudos pertinentes aos vários tipos de materiais utilizados e a sua biomecânica. Em literatura consultada constatou-se que alguns autores preconizam a adição de uma sutura fabelo-tibial medial. Porém não foi encontrado nenhum estudo biomecânico referente à incorporação concomitante de ambas as suturas, fabelo-tibial lateral e medial, bem como a comparação entre as duas técnicas como forma de reparação do ligamento cruzado cranial rompido. Desta forma, esta pesquisa teve por objetivo realizar o estudo biomecânico de ambas as técnicas e compará-las entre si. 
2 REVISÃO DE LITERATURA 


\section{REVISÃO DE LITERATURA}

Para uma melhor compreensão da revisão de literatura esta foi dividida em:

$\checkmark$ Etiopatogenia, epidemiologia e diagnóstico.

Técnicas cirúrgicas.

$\checkmark$ Material dos implantes e técnicas de fechamento do nó.

\subsection{ETIOPATOGENIA, EPIDEMIOLOGIA E DIAGNÓSTICO}

Vasseur et al. (1985) determinaram as propriedades mecânicas do LCCr de 65 cães de diferentes idades e pesos corporais. Observaram um decréscimo nas características do LCCr com relação à idade, bem como a influência do peso corpóreo dos animais sobre tais características. A diminuição na carga máxima e energia absorvida com a idade foi significativamente menor no LCCr de cães com peso inferior a 15 quilos quando comparadas com as observadas em cães pesando 15 quilos ou mais. Através do exame microscópico do LCCr e dos demais ligamentos femoro-tibiais coletados dos membros pélvicos contra-laterais foi constatado que os animais com mais de 15 quilos já apresentavam evidências consistentes de doença degenerativa em LCCr aos cinco anos e piorando com o avançar da idade, sendo que os cães com menos de 15 quilos em geral demonstraram menor severidade degenerativa, a qual iniciou-se mais tardiamente nesta categoria. O ligamento cruzado caudal também apresentou degeneração, porém raramente tão severa quanto a observada no LCCr e o sexo do animal não influenciou sobre o grau de degeneração.

O fato de cães mais pesados serem mais propensos a RLCCr é suportado por estudo realizado por Tatarunas et al. (2006) e Tatarunas et al. (2007) os quais constataram que as raças Rottweiler, Labrador, Boxer e Pit Bull foram as mais acometidas. 
Em estudo retrospectivo realizado no HOVET - FMVZ/USP com animais submetidos ao tratamento da RLCCr de forma conservadora, Morais, Tatarunas e Matera (2007) constataram um predomínio de fêmeas afetadas (70,9\%), sendo as raças mais acometidas o Rottweiler (19\%), Pit Bull (19\%) e o Poodle (19\%).

Moore e Read (1995) referem que 22\% dos animais estudados exibiram RLCCr do membro contralateral dentro de um período de 14 meses após a lesão inicial.

Wingfield et al. (2000) realizaram estudo comparando as propriedades biomecânicas do LCCr de cães da raça Rottweiler e Greyhound. Observaram que o Rottweiler possui uma média de área de corte transverso de LCCr maior, porém com o joelho estendido, os valores de carga máxima e rigidez foram significativamente menores. Notaram também que o mecanismo de falha apresentado com maior freqüência foi a ruptura na porção média, seguida por avulsão tibial sendo que nenhuma ruptura por avulsão femoral foi observada. Os autores, segundo os resultados obtidos, sugerem que os cães da raça Rottweiler são mais susceptíveis a RLCCr do que os cães da raça Greyhound.

A investigação das características histológicas e ultraestruturais do $\mathrm{LCCr}$ macroscopicamente íntegro de cães da raça Labrador Retriever (predisposta a RLCCr) e da raça Greyhound (não predisposta a RLCCr) demonstrou diferenças nas proporções e diâmetros das fibras de colágeno do LCCr das duas raças, bem como na predominância de tecido fibrocartilagíneo. Tal tecido, considerado por Vasseur et al. (1985) como representativo de doença degenerativa do LCCr, é sugerido como uma adaptação fisiológica às demandas físicas, tração e compressão, protegendo o $\mathrm{LCCr}$ dos cães da raça Greyhound contra fragmentação mecânica devido a compressão repetitiva (COMERFORD et al., 2006).

Leopizzi (1998) analisou as diferenças de comportamento biomecânico em relação ao ângulo de flexo-extensão articular $\left(110^{\circ}, 135^{\circ}\right.$ e $\left.155^{\circ}\right)$ através de ensaios mecânicos destrutivos, avaliando os limites de elasticidade, resistência máxima, rigidez e deformação, com a finalidade de caracterização do tecido ligamentar. Os resultados comprovados estatisticamente indicaram diferenças significativas entre os grupos de ensaio, mostrando que o LCCr torna-se mais rígido durante a extensão, e mais frouxo na flexão articular, sendo que os mecanismos de falência ligamentar mostraram-se dependentes do ângulo de ensaio.

Romano et al. (2006) avaliou a função biomecânica da articulação do joelho de cães, comparando a medida de deslocamento cranial e a rigidez articular da tíbia em relação ao fêmur em articulações íntegras e com ruptura de ligamento cruzado cranial. A análise 
estatística dos resultados encontrados revelou diferença significativa entre os dois grupos tanto para o deslocamento quanto para a rigidez. Os autores concluem que, quando comparados, a translação cranial da tíbia em relação ao fêmur é acrescida em quatro vezes e a rigidez articular é diminuída em uma vez e meia.

A importância do ângulo do platô tibial (TPA) na fisiopatologia da RLCCr não está completamente elucidada, porém é sugerido por Slocum e Slocum (1993) que quanto maior este ângulo, maior será a instabilidade do joelho com RLCCr, acarretando desta forma em evolução mais rápida e severa de osteoartrose. Tal teoria não foi confirmada por Havig et al. (2007), os quais avaliaram o efeito da sutura fabelo-tibial lateral sobre o TPA e correlacionaram-no com a evolução clínica dos cães tratados por esta técnica. Observaram que o TPA não foi alterado após tratamento com a sutura fabelo-tibial lateral e que não houve correlação entre TPA e a evolução clínica dos pacientes. Desta forma os autores referem que o TPA não possui valor preditivo sobre a evolução clínica de cães tratados por esta técnica de estabilização do joelho com LCCr deficiente.

Smith (2000) refere a importância do LCCr não apenas como restritor primário, mas também como mecanoreceptor para a função normal do membro. Comenta que a falha no seu papel como mecanoreceptor, devido a sua degeneração, tem influência no modo de atuação da musculatura, levando a diminuição da carga a que o membro é exposto.

As proporções, dos cirurgiões quanto ao método diagnóstico utilizado para a RLCCr, observadas foram: $98 \%$ dos cirurgiões usam o teste de gaveta cranial com joelho flexionado em $140^{\circ}$ e a radiografia do joelho afetado é requisitada principalmente nos casos crônicos (81\%) (KORVICK; JOHNSON; SCHAEFFER, 1994).

Recentemente tem-se observado crescente atenção aos mediadores e células relacionados a inflamação gerada pela RLCCr em busca de um melhor entendimento do processo de lesão ligamentar, bem como seus possíveis papéis na degeneração articular progressiva. Muir et al. (2005) observaram aumento na expressão de metaloproteases 2 e 9, bem como catepsina $S$ associados a RLCCr, sendo estes possíveis e importantes mediadores da degeneração progressiva da articulação do joelho. Tais mediadores podem ser possíveis alvos para futura terapia antiinflamatória.

Comerford et al. (2005) sugere que o aumento da expressão de pro-metaloproteinase-2 encontrado em cães com predisposição a RLCCr pode ser resultado de uma maior amplitude 
de movimento cranio-caudal do joelho e maior taxa de renovação do colágeno do LCCr, quando comparados com cães que não possuem tal predisposição.

Muir, Manley e Hao (2006) sugerem envolvimento de células mononucleares com receptores para catepsina K e TRAP (fostase ácido resistente ao tartarato) na degeneração do LCCr. Tais células foram observadas infiltradas nos LCCr rompidos e foram relacionadas com a colagenólise local.

\subsection{TÉCNICAS CIRÚRGICAS}

Flo (1975) desenvolveu a técnica de imbricação do retináculo modificada que consiste em suturas fabelo-tibiais lateral e medial adicionadas de uma terceira sutura fabelo-patelar com o intuito de promover a estabilização do joelho com RLCCr, porém Schaefer e Flo (1998) descrevem a mesma técnica sem a terceira sutura (sutura fabelo-patelar) pois esta é raramente incorporada na técnica, permanecendo apenas as suturas fabelo-tibiais lateral e medial.

Korvick, Johnson e Schaeffer (1994) caracterizaram a preferência de cirurgiões veterinários com relação a técnica cirúrgica utilizada e observaram que para cães com menos de 11 quilos, 80\% dos cirurgiões usam técnicas extra-articulares; para cães que pesam entre 11 e 29 quilos, $52 \%$ dos cirurgiões utilizam técnicas extra-articulares; já para cães acima de 29 quilos, $52 \%$ preferiram a técnica extra-articular para os casos crônicos. Dentre as técnicas extra-articulares utilizadas a mais comum foi a sutura fabelo-tibial lateral.

Em estudo prospectivo realizado através do Colégio Americano de Cirurgiões Veterinários com 755 cães totalizando 861 joelhos com RLCCr, Lampman, Lund e Lipowitz (2003) constataram que a técnica de sutura fabelo-tibial lateral para correção do LCCr rompido foi a mais comumente utilizada, perfazendo $57 \%$ dos joelhos operados pelos diferentes cirugiões.

A sutura fabelo-tibial lateral é composta por um laço de fio ancorado proximal ao ligamento fabelo-femoral e distal a um túnel na tuberosidade tibial (KORVICK; JOHNSON; SCHAEFFER, 1994; LAMPMAN; LUND; LIPOWITZ, 2003; ARTHURS; LANGLEYHOBBS, 2007). Trata-se de uma variação da técnica descrita por DeAngelis e Lau (1970) 
onde uma sutura era realizada entre a fabela lateral e a porção mais distal do ligamento patelar.

Guénégo et al. (2007) observaram um índice de $91 \%$ de sucesso no retorno a função normal do membro em cães de porte grande e gigante com RLCCr estabilizados por uma variação da técnica extra-capsular de SFTL, a qual baseia-se na utilização de âncora óssea no ponto de fixação femoral e túnel duplo na tuberosidade tibial com fio de poliéster misto, siliconizado, multifilamento $\left(V\right.$ itafil ${ }^{\circledR}$ ) fechado com nó. Apesar do bom resultado clínico, os autores citam $21 \%$ de falha na fixação da âncora óssea e dois casos de ruptura do fio utilizado. Comparando a biomecânica de diferentes tipos de âncoras ósseas para a sua utilização nesta mesma variação da técnica extra-capsular, Giles et al. (2008) referem melhor posicionamento da âncora na porção caudal do côndilo femoral e viabilidade de sua utilização com NLL de 60 libras.

Moore e Read (1995) através de um estudo retrospectivo em um período de quatro anos e quatro meses compararam a evolução clínica de cães com LCCr insuficientes operados por técnicas intra-capsulares, extra-capsulares ou por transposição da cabeça da fíbula. O estudo retrospectivo demonstrou que indiferentemente da técnica utilizada 85,7 a $91 \%$ dos cães apresentaram melhora clínica após a cirurgia, porém menos de $50 \%$ dos cães apresentaram-se clinicamente sãos do membro operado e 9 a 14,3\% mantiveram dor persistente do membro. Nenhuma associação estatística foi encontrada entre o resultado após a cirurgia e a idade, peso corporal, sexo, período de lesão antes da cirurgia, causa da lesão, ângulo do platô tibial, grau de osteoartrite antes da cirurgia e lesão concorrente de menisco medial. Ao exame físico, as técnicas extra-capsulares aparentaram superioridade quando comparadas com a transposição da cabeça da fíbula em termos de estabilidade da articulação e função do membro.

Patterson et al. (1991) compararam por biomecânica quatro técnicas comumente utilizadas na reparação de RLCCr de cães. Avaliaram a frouxidão (gaveta cranial) e rigidez através de joelho de cadáveres de cães no pós-operatório imediato. Quanto às técnicas testadas a transposição da cabeça da fíbula resultou em maior rigidez e menor frouxidão quando comparada com as demais, já a técnica de imbricação lateral apresentou menor frouxidão e maior rigidez que as técnicas de tendão patelar e enxerto de fascia. De acordo com estes resultados, eles sugerem que dentre os métodos reconstrutivos testados a transposição da cabeça da fíbula é a técnica que possui propriedades biomecânicas superiores no pósoperatório imediato. Tal sugestão pode ser discutida ao avaliarmos os resultados encontrados 
por Dupuis et al. (1994) em estudo realizado com esta mesma técnica de estabilização do joelho com RLCCr, onde os autores afirmam que a técnica de transposição da cabeça da fíbula não controla o movimento de gaveta cranial e a instabilidade rotacional, não sendo bem sucedida na restauração da função normal do membro e na prevenção de degeneração articular e de lesões de menisco.

Chauvet et al. (1996) realizaram um estudo retrospectivo avaliando a função do membro e a progressão de osteoartrose em joelhos de cães de grande porte (peso corpóreo maior ou igual a 22,7 quilos) tratados para RLCCr com a técnica de transposição da cabeça da fíbula (FHT), sutura lateral da fabela (LFS) e tratamento conservador (CT). De acordo com a avaliação da recuperação dos animais pelos proprietários a LFS foi a que apresentou melhores resultados clínicos quando comparada aos demais tratamentos, sendo que a pontuação da avaliação da recuperação para CT não diferiu estatisticamente de FHT. Após avaliação por veterinários não foram encontradas diferenças significativas na pontuação para dor, instabilidade do joelho e análise em placa de força entre os diferentes tipos de tratamento. Os autores citam que aparentemente os sinais de gaveta, crepitação e espessamento de cápsula não são correlacionados com a piora clínica do animal e que a progressão de doença degenerativa articular ocorreu independentemente do tratamento realizado. Vasseur e Berry (1992) chegaram a mesma conclusão em estudo realizado com progressão da osteoartrose após reconstrução intra-capsular em cães com RLCCr.

Harper et al. (2004) realizaram trabalho comparando a estabilidade do joelho normal com a estabilidade proporcionada pela técnica extra-capsular com enxerto de tendão patelar e fascia lata (LGT) no joelho com deficiência do LCCr. Determinaram se diferentes pontos de ancoragem na tíbia proporcionariam um aumento na estabilidade do joelho com LCCr deficiente quando comparado com a técnica de sutura fabelo-tibial padrão (FTS). Após analise dos resultados observaram que a técnica de enxerto LGT utilizada apresentou rigidez e deformação similares às apresentadas por FTS em ensaio in vitro, e citam como vantagens da LGT o uso de material biológico que elimina a possibilidade de reação ao corpo estranho, além de possível remodelamento do enxerto in vivo proporcionando um menor índice de rotação externa, comumente gerada pelas técnicas extra-capsulares. Com relação à mudança dos pontos de ancoragem na tíbia nenhuma melhora do ponto de vista funcional em relação a FTS foi observada. Concluem que das diferentes técnicas testadas nenhuma delas apresentou 
rigidez similar à do LCCr intacto e que seria importante um estudo clínico com a técnica LGT de tendão patelar e fascia lata.

Romano (2006) realizou ensaios biomecânicos em joelhos de cães e não encontrou diferença estatísticamente significativa entre o movimento de gaveta cranial do joelho com LCCr íntegro e estabilizado por SFTL com fio de náilon fechado com anel de aço. Observou também que tal técnica não recupera a rigidez articular quando comparada com a rigidez da articulação com o LCCr íntegro.

Selmi et al. (2003) refere a alteração dos vetores de força e do centro instantâneo de movimento em alguns joelhos reconstruídos pela técnica SFTL sugerindo compressão das superfícies articulares, fato também sugerido por Smith (2000).

Chailleux et al. (2007), através de análise cinemática tridimensional, avaliaram a técnica de imbricação do retináculo modificada segundo sua influência durante a flexo-extensão do joelho. Observaram grande restrição da amplitude de movimento, com aumento significativo da rotação externa da tibia e abdução do joelho, não sendo observado movimento de gaveta cranial. Referem que a rotação externa e abdução elas são decorrentes da fixação do fio lateral, e que devido a esta sua predominância o uso do fio medial é questionável. Sugerem também que tal diminuição da amplitude de movimento deva ser resultante da fixação dos fios em pontos não isométricos, podendo ser justificada também pela inibição do movimento de translação caudal normal do côndilo femoral lateral sobre o platô tibial resultante da restrição da rotação axial normal da tibia (ARNOCZKY; MARSHALL, 1977).

Baraúna Júnior et al. (2007) descrevem a técnica de interligação extra-capsular femorofabelo-tibial e seu uso com sucesso na restrição do movimento de gaveta cranial e rotação interna excessiva da tibia em cães com RLCCr.

Lopez et al. (2006) descrevem a utilização de prótese intra-articular em rupturas parciais do LCCr com bons resultados. A aplicação de tal implante tem como objetivo diminuir a carga sobre o LCCr permitindo a cicatrização da lesão.

Budsberg et al. (1988) realizou exame com placa de força em nove cães com ruptura de ligamento cruzado cranial antes e após a realização da técnica de imbricação do retináculo. No exame pré-operatório todos os animais apresentaram pico de força vertical, impulsos associados e distribuição do peso significativamente menor no membro afetado quando comparados com o membro clinicamente sadio. Aos sete meses de pós-operatório os animais já apresentavam um aumento em todas as forças verticais e crânio-caudais do membro 
operado, o qual com o passar do tempo não apresentou diferenças significativas ao exame em placa de força quando comparado com o outro membro. Os resultados encontrados indicam restauração da função do membro afetado quando comparado com o membro clinicamente sadio através de placa de força durante o período de estudo.

Através de estudo prospectivo a longo prazo, Innes et al. (2000) avaliaram resposta funcional do membro pélvico com RLCCr em um período de três a cinco anos de pósoperatório. Segundo avaliação dos proprietários seus animais apresentaram melhora da função do membro na avaliação de um ano após a intervenção cirúrgica, porém vinham apresentando piora gradativa no decorrer do tempo. Ao exame físico sinais de doença articular degenerativa foram observados, porém os autores discutem o resultado da avaliação dos proprietários, já que grande parte dos animais apresentavam alterações sugestivas de quadro inicial de RLCCr no membro contralateral. Desta forma uma possível alteração do membro não operado poderia ter influenciado a avaliação dos proprietários do membro tratado com técnica de estabilização.

A determinação da evolução e o efeito de três diferentes técnicas para reparação do $\mathrm{LCCr}$ rompido sobre a função do membro em cães da raça Labrador foi realizada por Conzemius et al. (2005). Em seu estudo os autores constataram que independente da técnica utilizada, a taxa de retorno a função normal do membro é baixa e que, segundo os resultados obtidos foram semelhantes, entre a técnica de sutura fabelo-tibial lateral e a osteotomia para nivelamento do platô tibial e as duas foram superiores a técnica intra-capsular over-the-top.

Em estudo retrospectivo, comparando as técnicas de osteotomia de nivelamento do platô tibial (TPLO) e extra-capsular através de análise radiográfica a longo prazo, não pôde ser observado diferença significativa entre a evolução da osteoartrose, porém através de modelo de regressão observou-se uma maior probabilidade de evolução desfavorável da osteoartrose nos cães submetidos a estabilização extra-capsular quando comparados com a TPLO (LAZAR et al., 2005).

Francis, Millis e Head (2006) avaliaram a quantidade de massa muscular e densidade óssea do membro pélvico de cães portadores de RLCCr submetidos a estabilização por SFTL em diferentes períodos do pós-operatório. Observaram perda significativa de tecido muscular e diminuição da densidade óssea, sendo esta mais pronunciada nas regiões metafisárias da tibia. O contrário foi observado no membro contralateral, o qual teve aumento das duas variáveis analisadas, resultado do aumento compensatório de carga sobre o membro não afetado. 
Arthurs e Langley-Hobbs (2007) descrevem a luxação de patela, tanto medial quanto lateral, como complicação da intervenção cirúrgica para reparo da RLCCr, quer esta seja intra-capsular, extra-capsular ou TPLO. Em seu estudo retrospectivo, os autores citam a técnica extra-capsular como a mais utilizada para o reparo da RLCCr e relatam uma incidência de $0,18 \%$ de luxação de patela após realização de procedimento cirúrgico para reparo do LCCr, sendo a luxação de patela medial em $94 \%$ dos casos e lateral nos $6 \%$ restantes. Na maior parte dos casos os autores não conseguiram identificar a causa da luxação de patela, porém sugerem a falha imediata ou tardia da sutura da cápsula articular, excesso de tensão na sutura do retináculo, atrofia muscular, flacidez das estruturas periarticulares e instabilidade de patela como as principais causas da luxação de patela como complicação da cirurgia de reparo do LCCr.

Tem-se dado crescente importância aos estudos relacionados a medicina baseada em evidências por se tratar de uma avaliação sistemática de pesquisas, cujo objetivo é auxiliar no processo de decisão dos clínicos e cirurgiões sobre sua variedade de problemas clínicocirúrgicos. Um estudo utilizando a medicina baseada em evidências para avaliar as técnicas cirúrgicas disponíveis para estabilização do joelho com RLCCr em cães constatou uma ausência de estudos de maior nível de evidência (níveis I e II), dificultando o estabelecimento de uma técnica cirúrgica superior dentre as mais estudadas (TPLO, estabilização por sutura extra-capsular, transposição da cabeça da fíbula e técnica intra-capsular) (ARAGON; BUDSBERG, 2005). Fato também observado por Kim et al. (2008), os quais compararam as osteotomias de nivelamento do platô tibial e técnicas mais tradicionais de estabilização do joelho e concluiram não haver dados disponíveis suficientes para uma adequada comparação entre as técnicas estudadas. 


\subsection{MATERIAL DOS IMPLANTES E TÉCNICAS DE FECHAMENTO DO NÓ}

O náilon e o polipropileno são os materiais mais comumente utilizados, e quando do uso das técnicas extra-articulares, os cirurgiões utilizam com freqüência o fio de náilon leader line de 60 libras (KORVICK;JOHNSON; SCHAEFFER, 1994).

Selmi et al. (2003) comparou a utilização de fio de aço e polipropileno na confecção da SFTL segundo o centro instantâneo de movimento e direção do vetor de velocidade. Observou manutenção das duas características nos joelhos reconstruídos com polipropileno, sendo este material sugerido pelos autores como de características mais favoráveis do que o fio de aço.

Muitos tipos de materiais para sutura são utilizados na estabilização de LCCr pela técnica extra-capsular. Embora o fio de náilon leader line seja considerado por alguns o mais apropriado material para este tipo de procedimento, o fio de náilon monofilamento para pesca é muito utilizado. O estudo avalia quatro marcas de fios de pesca monofilamento com o intuito de determinar a superioridade do material bem como o método de esterilização de escolha. As marcas utilizadas foram "Ande ${ }^{\circledR}$, Berkley $^{\circledR}$, Hi-Seas $^{\circledR}$ e Maxima ${ }^{\circledR}$ " todas de 36 quilos/teste. Antes da esterilização as marcas "Ande ${ }^{\circledR}$ e Maxima ${ }^{\circledR}$ " apresentaram maior força. Com a esterilização sendo realizada por óxido de etileno, mínima deformação dos fios foi observada, porém três das marcas testadas (Ande ${ }^{\circledR}$, Hi-Seas ${ }^{\circledR}$ e Maxima ${ }^{\circledR}$ ) obtiveram significativa queda na força quando comparadas com os resultados apresentados previamente à esterilização ou após esterilização em autoclave. A esterilização em autoclave por sua vez, resultou em significativa deformação dos materiais testados e efeito sobre a força demonstrou-se variado. Considerando todos os materiais testados a marca "Ande" ${ }^{\circledR}$ " como sendo a de escolha quando o método de esterilização a ser utilizado for o óxido de etileno e as marcas “Ande ${ }^{\circledR}$ ou Maxima ${ }^{\circledR}$ " quando o método de esterilização for a autoclave (SICARD et al., 1999).

Ensaio mecânico comparou duas marcas de fio de náilon para pesca "Ande ${ }^{\circledR}$ e Sufix ${ }^{\circledR}$ " e três marcas de fio de náilon leader line "Ande ${ }^{\circledR}$, Mason ${ }^{\circledR}$ e Jinkai ${ }^{\circledR}$ " todas de 36 quilos/teste, e avaliou o efeito da esterilização por autoclave e por óxido de etileno sobre suas propriedades, bem como as propriedades mecânicas do sistema crimp-clamp desenvolvido comercialmente para o reparo extra-articular do joelho canino. De acordo com os resultados obtidos o método 
de esterilização deve ser preferencialmente o óxido de etileno o qual preservou a força e minimizou a deformação dos materiais testados. Dentre os materiais testados o fio de náilon leader line da marca "Mason ${ }^{\circledR}$ " foi o que apresentou menor deformação e maior preservação de sua força quando submetido à esterilização por óxido de etileno. Já quando o método de esterilização a ser utilizado é a autoclave o fio de náilon leader line da marca "Mason ${ }^{\circledR}$ " e o fio de náilon para pesca da marca "Sufix ${ }^{\circledR}$ ", apresentaram características semelhantes. Quanto ao sistema crimp-clamp com o fio da "Mason ${ }^{\circledR} "$ este apresentou deformação significativamente menor do que a apresentada pelo fio da "Mason" ${ }^{\circledR}$ " fechado com nó (SICARD; HAYASHI; MANLEY, 2002).

Lewis, Milthorpe e Bellenger (1997) determinaram as propriedades mecânicas de três materiais (polipropileno $\mathrm{n}^{\mathrm{o}} 2$, poliéster multifilamentoso revestido com polibutilato $\mathrm{n}^{0} 5$ e 18 , 27, 36 quilos/teste fio de náilon leader line da marca "Mason ${ }^{\circledR}$ ") comumente utilizados na estabilização extra-capsular do joelho de cães com RLCCr. Compararam a eficiência da estabilização do joelho com RLCCr de cães com o fio de náilon leader line (36 quilos/teste) e poliéster multifilamentoso revestido com polibutilato $\mathrm{n}^{\circ} 5$ e avaliaram os efeitos dos diferentes tipos de esterilização sobre o fio de náilon leader line. Segundo as propriedades mecânicas observadas para os diferentes materiais os autores relatam a fraqueza apresentada pelo polipropileno $\mathrm{n}^{\mathrm{o}} 2$ e não recomendam este tipo de material para o uso clínico. Já o poliéster multifilamentoso revestido com polibutilato $\mathrm{n}^{0} 5$ e o 18 quilos/teste náilon leader line apresentaram carga à falha equivalentes, ressaltando que quanto maior for o calibre do fio de náilon leader line, maior resistência a carga ele possui. Concluíram que dos materiais testados o fio de náilon monofilamento leader line é o melhor para estabilização extra-capsular do joelho com RLCCr por ter apresentado características biomecânicas satisfatórias, devendo ser esterilizado preferencialmente por óxido de etileno.

Caporn e Roe (1996) realizaram estudo com o objetivo de avaliar o comportamento mecânico de dois tipos de fio de náilon monofilamento de 27 e 36 quilos/teste (fio de náilon para pesca da marca "Ande Premium ${ }^{\circledR}$ " NFL e fio de náilon leader line da marca "Mason" NLL) e a influência da esterilização sobre suas características, bem como o desempenho mecânico do local de fixação na fabela lateral utilizado na técnica de sutura fabelo-tibial lateral. Os laços de NLL não tiveram suas características afetadas pela esterilização (óxido de etileno e autoclave) e apresentaram maiores cargas à falha e rigidez quando comparados com os laços de NFL, os quais foram significativamente afetados pela esterilização apresentando 
diminuição da carga máxima, rigidez e aumento da deformação. O NLL de 27 quilos/teste apresentou características que o tornam o mais habilitado para o uso na técnica de sutura fabelo-tibial lateral, já que o efeito apresentado por um nó mais volumoso do NLL de 36 quilos/teste e a dificuldade de manuseio do fio mais calibroso não demonstrou ser vantajoso. Os autores constataram também que ao contrário do que foi observada em outros estudos, a fixação do NLL com o auxílio de porta-agulha no momento da confecção do nó não enfraqueceu o laço, ao contrário, permitiu confecção de um nó mais justo, o qual apresentou menor deformação, maior carga máxima e rigidez. Comparando os laços testados com fixação em parafuso e com fixação na fabela lateral, estes demonstraram desempenho melhor quando ciclados com carga de 50 Newton e inferiores quando ciclados com carga de 100 Newton.

As características biomecânicas do fio de náilon leader line de 27,3 quilos/teste da marca "Mason ${ }^{\circledR}$ " não estéril e esterilizado (por autoclave ou óxido de etileno) utilizando no fechamento do fio o sistema crimp-clamp ou nó quadrado totalizando cinco laçadas foram comparadas. Os laços fechados com o sistema crimp-clamp foram superiores aos laços fechados com nó em todos os parâmetros testados (carga à falha, tensão inicial do laço e deformação do laço) independente do método de esterilização. Os autores concluíram que o sistema crimp-clamp proporciona características superiores quando comparado com o método de fixação por nó em ensaio in vitro utilizando-se fio de náilon leader line da marca "Mason ${ }^{\circledR}$, de 27,3 quilos/teste (ANDERSON et al., 1998).

As propriedades mecânicas do sistema de reparo de 18 e 36 quilos para ligamento cruzado cranial da empresa "Securos ${ }^{\circledR}$ " foram avaliadas. Dois métodos de fechamento do fio foram utilizados, sistema crimp-clamp da "Securos ${ }^{\circledR}$ " (SCC) e o nó quadrado fixado com porta agulha (CSK). Os autores também testaram o fio de 27 quilos com o sistema crimp-clamp para fio de 36 quilos. Os resultados observados em SCC para 27 e 36 quilos foram iguais ou melhores que os observados em CSK com os mesmos fios, porém os SCC para 18 quilos demonstraram eficiência inferior aos CSK. Em todos os testes a ruptura do fio ocorreu próximo do nó ou anel de aço, sendo que apenas o SCC para fio de 18 quilos falhou por deslizamento do fio pelo anel de aço, apresentando desta forma considerável variabilidade na deformação e carga à falha. Os autores recomendam o uso do sistema crimp-clamp para fios de náilon leader line de 27 e 36 quilos (BANWELL et al., 2005).

Peycke et al. (2002) compararam mecanicamente seis métodos de fechamento do fio utilizando o náilon monofilamento leader line (NLL) da marca "Mason ${ }^{\circledR}$ " de 27,3 e 36,4 
quilos/teste comumente utilizados por cirurgiões veterinários no reparo extra-capsular da RLCCr. Os seis métodos utilizados foram: nó quadrado fixado após primeira laçada e mais quatro laçadas consecutivas utilizando fio esterilizado em autoclave (SS); nó quadrado fixado após primeira laçada e mais quatro laçadas consecutivas com fio não esterilizado (SQ); sliding half-hitch knot com total de cinco laçadas utilizando fio não estéril (HH); self-locking knot com total de cinco laçadas e fio não estéril (SLK); sistema crimp-clamp da "Securos ${ }^{\circledR}$ " com fio não estéril (SEC) e duplo nó quadrado com total de quatro laçadas empregando fio não estéril e auxílio de Harris Knotter (HK). Todos os laços testados falharam por quebra do fio em até três milímetros de distância do nó ou anel de aço. O método HK apresentou maior deformação que os demais métodos, exceto pela deformação apresentada por SLK. Já o método SEC apresentou força equivalente aos métodos tradicionais (SQ e HH) utilizando-se o fio de 27,3 quilos/teste e mais forte que estes se utilizando o fio de 36,4 quilos/teste.

Nwadike e Roe (1998) compararam a influência do tipo de nó sobre a performance mecânica de dois tipos de material de náilon monofilamento (fio de pesca "Ande Premium ${ }^{\circledR}$ ", e o fio leader line "Mason ${ }^{\circledR}$ "), ambos de 27 quilos/teste, quando submetidos à carga continua até a falha e ciclos de carga e posterior carga até a falha. Os tipos de nós testados foram o nó quadrado fixado após a primeira laçada e mais quatro laçadas consecutivas e o slip knot com três laçadas consecutivas. Os resultados obtidos demonstraram que determinado tipo de nó pode melhorar o desempenho mecânico de diferentes tipos de náilon monofilamento, desta forma os autores sugerem o uso do nó slip knot para o fio de náilon leader line e o nó quadrado fixado após primeira laçada para o fio de náilon para pesca com intuito de otimizar o desempenho mecânico do laço na sutura fabelo-tibial.

Huber, Egger e James (1999) avaliaram os efeitos dos diferentes tipos de nós sobre as propriedades mecânicas de fios monofilamento não absorvíveis e de grande diâmetro comumente utilizados na estabilização extra-capsular de joelhos instáveis. Os tipos de nós testados foram nó quadrado, nó de cirurgião, sliding half-hitch e nó quadrado fixado após a primeira laçada e os tipos de fios foram náilon $n^{\circ} 2$ USP, polipropileno $n^{\circ} 2$, polybutester $n^{0} 2$, náilon de pesca monofilamento "Ande Premium ${ }^{\circledR}$ ", e náilon leader line "Mason ${ }^{\circledR}$,, ambos de 27 quilos/teste. Levando em conta os parâmetros clinicamente importantes (rigidez e ponto de deformação permanente) os autores referem que o tipo de nó não gera efeitos significativamente diferentes para os fios náilon $\mathrm{n}^{\mathrm{0}} 2$ e polybutester $\mathrm{n}^{\circ} 2$; o nó de cirurgião não é recomendado para o polipropileno $\mathrm{n}^{\mathrm{0}} 2,27$ quilos/teste náilon de pesca e leader line; o nó 
sliding half-hitch diminuiu a força necessária para que o fio de náilon leader line apresentasse deformação permanente e o nó quadrado fixado após a primeira laçada não demonstrou efeitos adversos imediatos sobre as propriedades dos materiais testados como sugerido por outros autores. Os autores concluem de seu estudo que os diferentes tipos de nós geram influência sobre as características dos diferentes tipos de material e devem ser considerados.

Moores et al. (2006) descreveram uma variação da técnica de fechamento do fio pelo sistema crimp-clamp da "Securos ${ }^{\circledR}$ " para fio de náilon leader line de 80 libras. Nesta técnica descrita, os autores utilizaram o alicate do sistema, mas não usaram o dispositivo de tensionamento do laço. Ela baseia-se na plissagem do anel de aço em seu ponto médio e posterior tração manual do fio, desta forma o anel mantém o fio tensionado mesmo após a liberação de suas pontas livres. Com o laço já tensionado duas plissagens são acrescentadas nas extremidades do anel de aço. Comparando-se mecanicamente a técnica descrita com a recomendada pelo fabricante não foram observadas diferenças estatísticas significativas quanto a carga máxima e rígidez dos laços testados. Os autores ressaltam que uma das vantagens da técnica descrita é a facilidade de execução sem a necessidade de um auxiliar.

Laços de NLL de 27 quilos/teste $\left(\right.$ Mason $^{\circledR}$ e Securos ${ }^{\circledR}$ ) fechados por dois tipos diferentes de nó e dois sistemas de anel de aço foram comparados mecanicamente. Ao teste de carga à falha foi observada mais na tensão inicial do laço e rigidez nos sistemas de anel de aço quando comparados com o fechamento por nó verdadeiro fixado após a primeira laçada totalizando cinco laçadas. Ao teste cíclico os laços fechados por nó apresentaram maior deformação e queda mais rápida da tensão. Desta forma concluiu-se que os sistemas de anel de aço apresentam maior rigidez e resistem de forma mais efetiva, em ambos os testes, antes de se deformarem permanentemente (VIANNA; ROE, 2006).

Moores et al. (2006) constataram que a variação individual da força aplicada ao anel de aço, tanto no sistema da Securos ${ }^{\circledR}$, quanto no sistema da Veterinary Instrumentation ${ }^{\circledR}$, tem relação direta com a carga máxima suportada pelo laço antes da falha.

McCartney, O'Connor e McCann (2007) em estudo com 110 casos de animais submetidos a estabilização do joelho com RLCCr através da técnica de SFTL encerrada com o sistema crimp-clamp relatam uma taxa de $8 \%$ de falha prematura e um índice de $9 \%$ de infecção cirúrgica quando da utilização deste sistema.

Olmstead (1993) utilizou fio ortopédico como sutura lateral na estabilização do joelho com RLCCr. O autor refere que a técnica é simples e pouco traumática, promove boa estabilidade 
e pode ser usada para animais de diferentes tamanhos mudando-se apenas o diâmetro do fio ortopédico. Alguns pontos negativos da técnica utilizada são a formação de trajetos com exsudato na região do fio ortopédico, quebra do fio entre dois e 12 meses e dor gerada pelo fio rompido. Apesar da quebra do fio, o autor cita que até este período a fibrose periarticular já foi promovida e quase toda estabilidade do joelho está estabelecida. Refere algumas complicações com a técnica, porém todas de fácil solução.

A utilização de fio de poliéster misto, siliconizado, multifilamento (Vitafil ${ }^{\circledR)}$ fechado com nó, diferentemente de outros estudos (SMITH, 2000), não gerou áreas de seroma e sinais de infecção, quando utilizados em uma variação da técnica de sutura fabelo-tibial lateral (GUÉNÉGO et al., 2007).

Buquera et al. (2002) compararam por Raio-X e aspectos macroscópicos a técnica extracapsular de SFTL com fio de poliamida ou poliéster trançado, sendo observado sinais de efusão, distensão e espessamento da cápsula articular, erosão da cartilagem do côndilo femoral lateral e perda da tensão do laço, nos dois grupos até a última avaliação de 60 dias de pós-operatório. 
3 MATERIAL E MÉTODOS 


\section{MATERIAL E MÉTODOS}

O presente trabalho foi realizado na Faculdade de Medicina Veterinária e Zootecnia da Universidade de São Paulo no Laboratório do Aparelho Locomotor e o ensaio biomecânico no Instituto de Ortopedia e Traumatologia do Hospital das Clinicas no Laboratório de Ensaios Biomecânicos LIM-41.

\subsection{ANIMAIS}

Foram utilizados 20 joelhos de cadáveres de cães que pesavam entre 20 e 30 quilos.

A integridade do sistema locomotor do membro utilizado foi realizada analisando a amplitude articular, estabilidade (teste de gaveta), aumento de volume de partes moles e presença de crepitação da articulação do joelho.

Os membros pélvicos dos cadáveres foram retirados por desarticulação da cabeça do fêmur, embrulhados em papel toalha umedecido com solução fisiológica $\mathrm{NaCl} 0,9 \%$, acondicionados em sacos plásticos e armazenados a $-20^{\circ} \mathrm{C}$ (PATTERSON et al., 1991; LEWIS; MILTHORPE; BELLENGER, 1997).

O material foi descongelado à temperatura ambiente apenas no dia do ensaio biomecânico. Após o descongelamento do membro, sua musculatura foi dissecada, permanecendo intacta a cápsula articular, bem como os músculos de origem ou inserção próxima a ela (PATTERSON et al., 1991). 


\subsection{TÉCNICA CIRÚRGICA}

As descrições das técnicas cirúrgicas de estabilização extra-capsulares utilizadas neste estudo estão dispostas nos itens:

Artrotomia.

$\checkmark$ Técnica de sutura fabelo-tibial lateral.

$\checkmark$ Técnica de sutura fabelo-tibial lateral e medial.

\subsubsection{Artrotomia}

Inicialmente foi realizada uma artrotomia parapatelar lateral (PIERMATTEI, 1993) com inspeção do espaço articular e de suas estruturas, visando verificar a presença de sinais de doença articular. Articulações com sinais de doença foram descartadas.

Após a inspeção, o ligamento cruzado cranial foi seccionado cuidadosamente para evitar possíveis lesões às estruturas adjacentes. A síntese da capsular articular foi realizada com fio sintético absorvível poliglactina 910 (Vicryl ${ }^{\circledR}$ 3-0) em pontos simples separados não contaminantes. Para o retináculo foi utilizado fio de náilon 2-0 com sutura do tipo imbricação lateral.

\subsubsection{Técnica de sutura fabelo-tibial lateral}

Por meio da palpação a fabela lateral foi localizada e o fio passado ao seu redor com o auxílio de agulha de ligamento cruzado (agulha em "J"). A agulha foi passada no sentido crânio-caudal proporcionando ao fio um ponto de ancoragem no ligamento fabelo-femoral. Em seguida foi realizado um túnel na tuberosidade da tíbia, caudal e distal a inserção do ligamento patelar, no sentido latero-medial com o auxílio de furadeira, e a ponta distal do fio foi passada pelo orifício sem que a configuração em oito fosse formada. A ponta proximal do fio foi passada por baixo do ligamento patelar no sentido latero-medial e em direção a outra 
extremidade do fio (próximo ao orifício na tuberosidade da tíbia) com o auxílio de pinça hemostática, reta de Kelly. Após estas etapas, o membro foi estendido, a tíbia mantida em direção caudal em relação ao fêmur, excluindo o movimento de gaveta cranial, e uma leve rotação externa a tíbia foi aplicada. Neste momento o fio foi tracionado e o nó confeccionado de forma que se localizasse próximo à face medial do orifício na tuberosidade da tíbia.

\subsubsection{Técnica de sutura fabelo-tibial lateral e medial}

Por meio da palpação as fabelas lateral e medial foram identificadas. O fio foi ancorado no ligamento fabelo-femoral da mesma forma que foi descrito anteriormente, porém em ambas as fabelas. $\mathrm{O}$ orifício na tuberosidade da tíbia foi confeccionado da mesma forma e no mesmo local do utilizado para a sutura fabelo-tibial lateral, porém suficientemente calibroso para permitir a passagem dos fios simultaneamente. A ponta distal do fio da fabela medial foi passada pelo orifício no sentido medio-lateral e a ponta distal do fio da fabela lateral no sentido latero-medial. Após estas etapas, o membro foi posicionado como descrito anteriormente, e os nós confeccionados de forma que se situassem próximos à tuberosidade da tíbia; sendo que o nó do fio proveniente da face lateral foi confeccionado primeiro.

\subsection{MATERIAL DE SUTURA E TIPOS DE NÓS}

Utilizou-se fio de náilon leader line (NLL) monofilamento da marca Mason Hard Type 60 libras (equivalente a 27 quilos/teste).

No momento da confecção do nó, anterior a sua fixação com porta agulha, manteve-se uma tensão no laço de aproximadamente 100 Newtons com o auxílio de dinamômetro digital ${ }^{1}$ (Figura 1).

O nó empregado foi constituído por um nó simples e dois nós verdadeiros consecutivos, sendo que a primeira laçada foi fixada com porta agulha, deixando três milímetros de fio (CAPORN; ROE, 1996).

\footnotetext{
${ }^{1}$ Kern CH15K20, Kern \& Sohn GmbH, Balingen-Frommern, Germany
} 


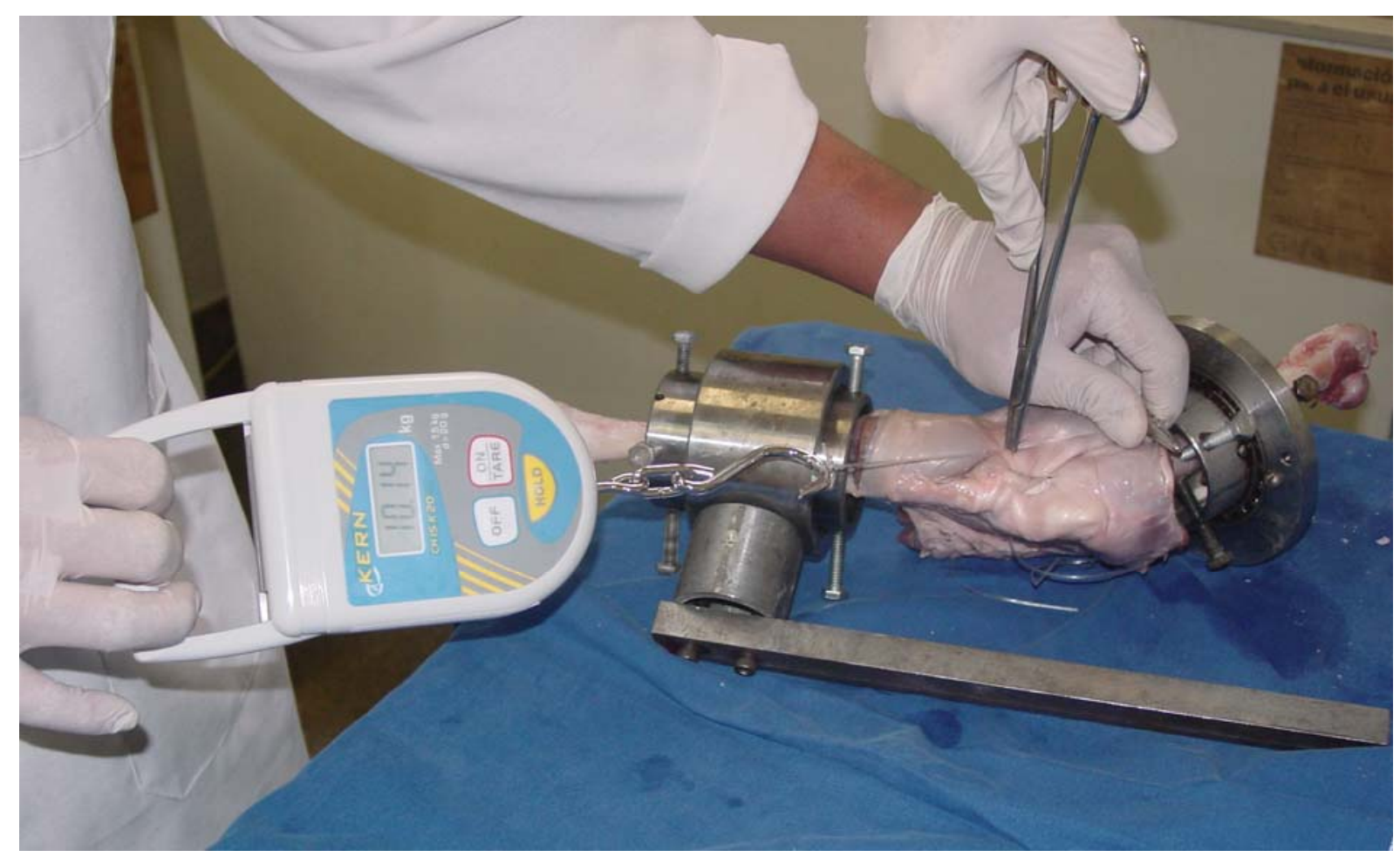

Figura 1 - Preparação da peça para o ensaio biomecânico destacando o joelho removido em bloco, o tensionamento do laço com auxílio de dinamômetro digital e a fixação do nó com auxílio de porta agulha - São Paulo - 2007

\subsection{MÉTODO DE ESTERILIZAÇÃO DOS FIOS}

O náilon leader line foi esterilizado em autoclave ${ }^{2}$ com capacidade de 21 litros a uma temperatura de $121,0{ }^{\circ} \mathrm{C}$, pressão de $103,4 \mathrm{kPa}$, durante 20 minutos.

\footnotetext{
${ }^{2}$ Sercon AHMC 5, Sercon, Mogi das Cruzes, SP, Brasil
} 


\subsection{ENSAIO BIOMECÂNICO}

O ensaio biomecânico foi realizado no Instituto de Ortopedia e Traumatologia do Hospital das Clínicas no Laboratório de Biomecânica (LIM-41).

Cada joelho foi submetido a quatro ensaios consecutivos:

1. joelho com LCCr íntegro (grupo LCCr);

2. joelho estabilizado pela sutura fabelo-tibial lateral (grupo SFTL);

3. joelho estabilizado pelas suturas fabelo-tibiais lateral e medial (grupo SFTLM), e

4. joelho com RLCCr sem nenhuma estabilização extra-capsular (grupo RLCCr).

A coleta de dados de um mesmo joelho sob diferentes condições experimentais possibilitou eliminar a interferência da variação individual sobre a comparação dos resultados obtidos (YAMAMOTO et al., 2004).

Primeiramente o teste foi realizado com o LCCr intacto. Posteriormente, seccionou-se cirurgicamente o LCCr e o joelho foi estabilizado pela técnica SFTL e novamente testado. Após este segundo ensaio, o material utilizado na primeira técnica foi retirado e novos fios foram posicionados para o teste da técnica SFTLM. Por último foi realizado o ensaio do joelho com RLCCr sem nenhuma estabilização extra-capsular.

Utilizou-se, para a realização dos testes, uma máquina de ensaios mecânicos (KRATOS 5002), dotada de célula de carga de $100 \mathrm{Kgf}$ e conectada a um computador com sistema de aquisição de dados (Figura 2).

O fêmur foi fixado ao braço hidráulico superior da máquina e a tíbia à plataforma inferior. Estas duas extremidades foram fixadas à máquina por meio de garras constituidas de cilindros metálicos pelos quais passam parafusos de orientação radial e que se fixão aos ossos perpendicularmente ao eixo longo da diáfise óssea. O cilindro de fixação do fêmur é fixo e o de fixação da tíbia permitiu sua rotação, tanto interna quanto externa, movimentos do tipo valgo e varo, e movimentos de aproximação e distanciamento da tíbia em relação ao fêmur, no momento dos ensaios biomecânicos. As articulações testadas foram mantidas em ângulo de 135 graus de flexão (HARPER et al., 2004) (Figura 3).

Após a fixação adequada do joelho, um ensaio de translação com carga parcial de 50 Newtons no sentido cranial e caudal foi realizado para que se pudesse, através do gráfico gerado, encontrar o ponto de inflexão. Tal ponto caracterizou-se pelo momento em que as 
estruturas responsáveis pela estabilidade da articulação do joelho estavam sob menor tensão, sendo este o nosso ponto inicial para o restante dos ensaios biomecânicos.

Descobrindo-se o ponto de inflexão, três mensurações tinham que ser realizadas: distância da tíbia, ângulo de rotação e paquímetro inicial. Estes três valores permitiram posteriormente que o joelho, sempre que fosse retirado da máquina de ensaios biomecânicos, pudesse ser reposicionado nesta mesma posição. A "distância da tíbia" foi medida com paquímetro ${ }^{3}$ e permitia reposicionar a garra distal sempre na mesma posição inicial, e o "ângulo de rotação" e o "paquímetro inicial”" permitiam o reposicionamento, na mesma posição inicial, da garra proximal.

A partir da fixação inicial da peça anatômica ao dispositivo de ensaio biomecânico, o joelho pôde ser removido da máquina em bloco (joelho, garra da tíbia e garra do fêmur) para a preparação da peça para os ensaios seguintes (Figura 1). A remoção em bloco permitiu que o joelho pudesse ser reposicionado na mesma posição para todos os ensaios, uma vez que as mensurações iniciais fossem respeitadas, de forma que a comparação das técnicas fosse mais fidedigna.

Este ponto de partida do joelho íntegro tornou-se nosso ponto de referência para o inicio dos demais ensaios da mesma articulação em diferentes situações, sendo ele representado pela ausência de carga na célula de força da máquina de ensaios mecânicos. Esta força foi denominada de força residual, a qual sempre foi zero para o joelho íntegro, nosso ponto de referência, e foi registrada sempre que o joelho era recolocado na máquina em diferentes situações.

Foi utilizada uma aplicação de carga de 100 Newtons (PATTERSON et al., 1991; HARPER et al., 2004; ROMANO, 2006) a uma velocidade constante de 20 milímetros por minuto (ROMANO, 2006), intercalando-se o sentido de gaveta cranial e caudal, totalizando três ciclos em cada sentido. Nos ensaios biomecânicos foram avaliados rigidez articular e deslocamento cranial e caudal da tíbia em relação aos côndilos do fêmur.

\footnotetext{
${ }^{3}$ Paquímetro universal 530-104B , Mitutoyo, São Paulo, SP, Brasil

${ }^{4}$ Paquímetro digital 500-171, Mitutoyo, São Paulo, SP, Brasil
} 


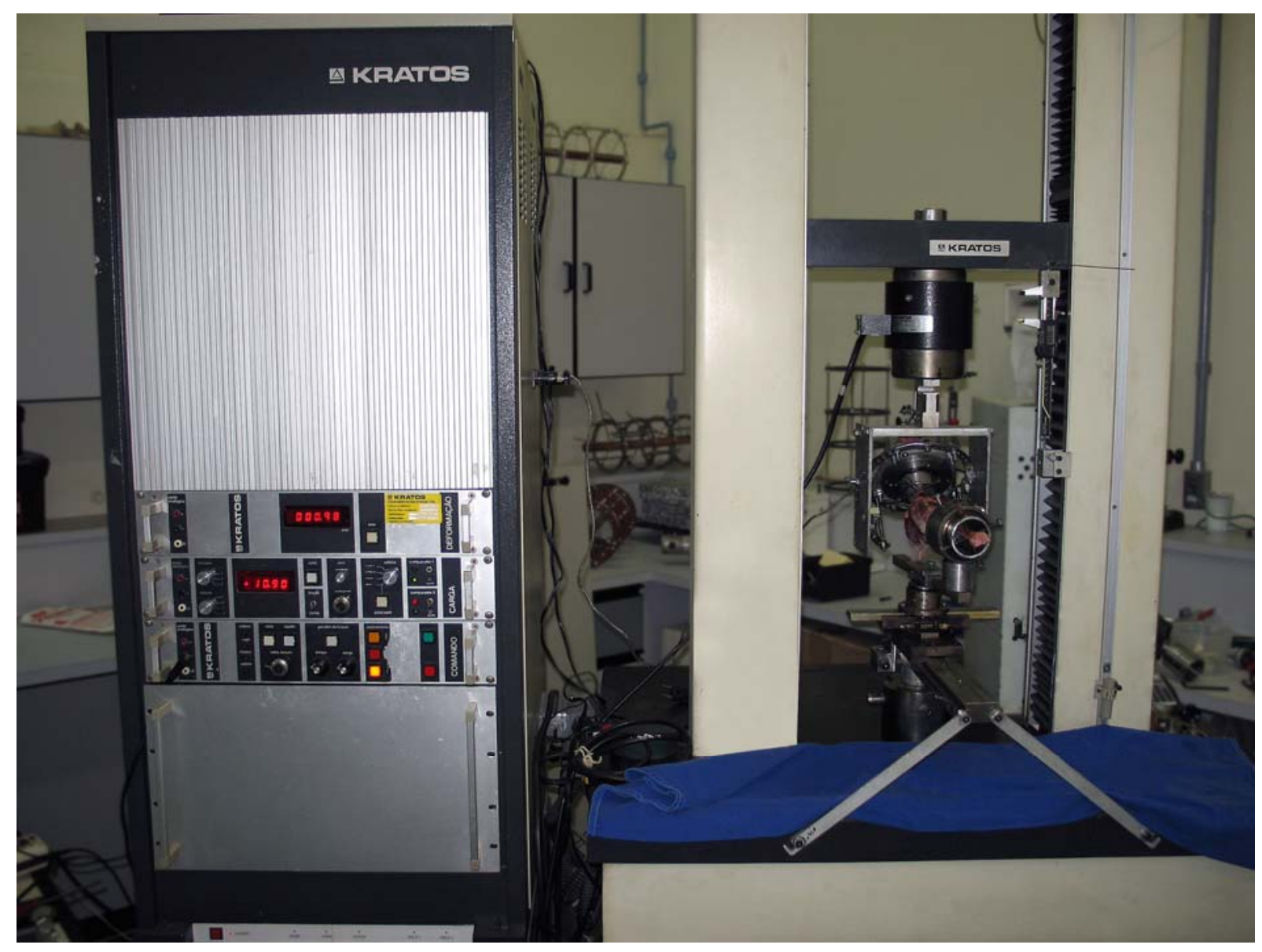

Figura 2 - Máquina de ensaio biomecânico Kratos 5002 composta por parte eletrônica e parte mecânica - São Paulo - 2007 


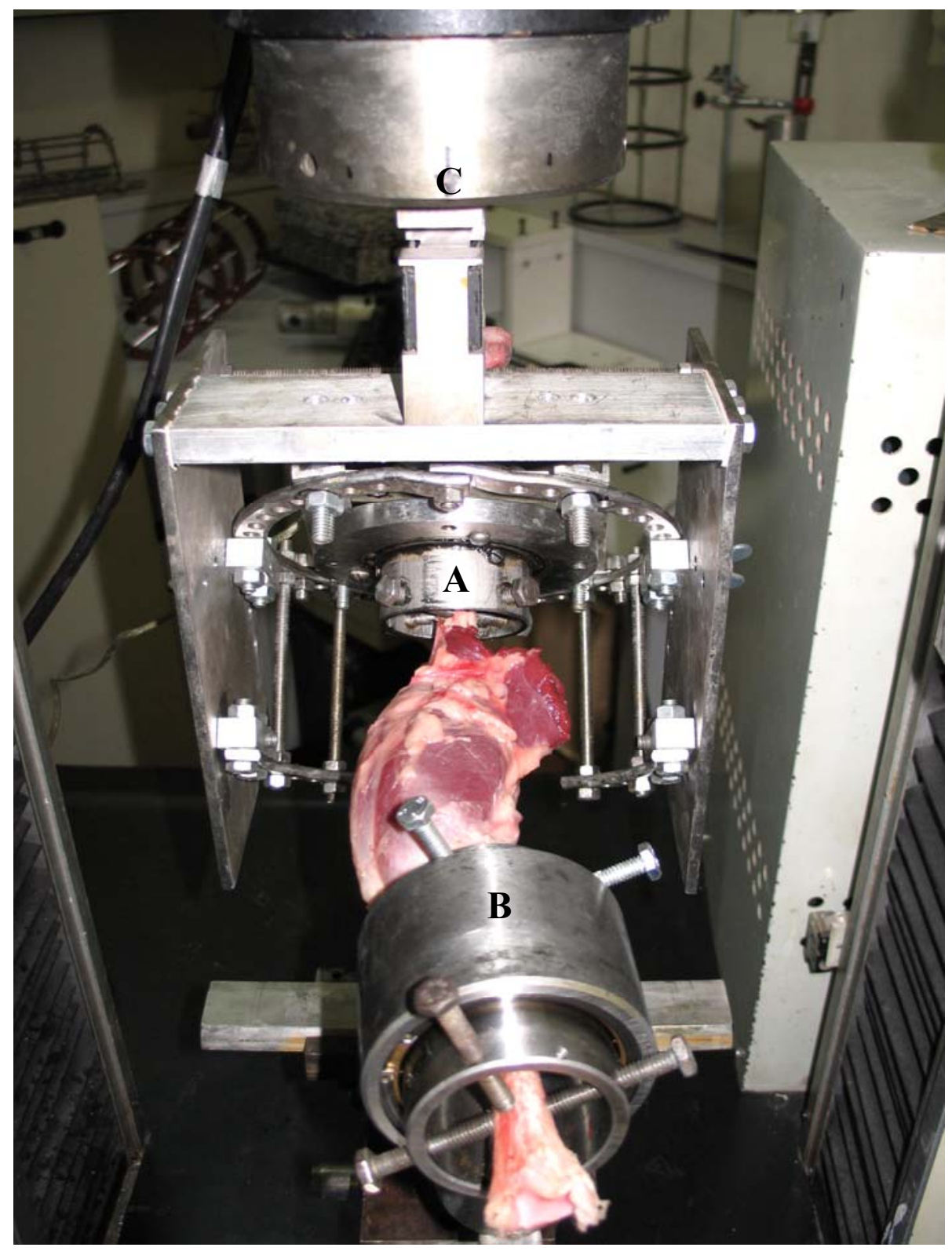

Figura 3 - Dispositivo de fixação do joelho à máquina de ensaios biomecânicos. A) Garra de fixação do fêmur; B) Garra de fixação da tíbia; C) Célula de carga - São Paulo 2007 


\subsection{ANÁLISE ESTATÍSTICA}

Os resultados foram analisados através do programa computacional Statistical Analysis System (SAS, 2001) sendo anteriormente verificada a normalidade dos resíduos pelo Teste de Shapiro-Wilk (PROC UNIVARIATE) e a homogeneidade das variâncias comparadas pelo Teste de Hartley (OTT, 1993).

Os dados (variável dependente) atenderam a estas premissas sendo submetidos à análise de variância que separou como única causa de variação o efeito de tratamento.

O efeito de tratamento foi separado através do teste de média Tukey-Kramer e tal análise foi realizada utilizando-se o procedimento General Linear Model (PROC GLM do SAS).

Para a correlação das forças residuais os dados foram analisados por correlação linear para obter o valor de $\mathrm{r}$ (rho) e a probabilidade entre os dados obtidos neste trabalho. Como todos os dados possuem distribuição normal e homogeneidade das variâncias, utilizou-se a correlação de Pearson (PROC CORR do SAS).

Foi utilizado o nível de significância de 5\% para todos os testes realizados. 
4 RESULTADOS 


\section{RESULTADOS}

Os resultados obtidos dos ensaios biomecânicos realizados nos joelhos em diferentes condições estão dispostos a seguir.

\subsection{COLHEITA DE MATERIAL}

A média e desvio padrão do peso dos animais utilizados foi de $23,42 \pm 2,83$ quilos, dos quais nove eram machos e onze eram fêmeas, doze eram membros pélvicos direitos e oito eram esquerdos, com predomínio de animais sem raça definida (Tabela 1). 
Tabela 1 - Peso corpóreo (quilos), sexo, raça e membro pélvico de cada cão utilizado nos ensaios biomecânicos com carga de 100 Newtons - São Paulo - 2007

\begin{tabular}{clclc}
\hline JOELHO & MEMBRO & PESO $(\mathrm{Kg})$ & SEXO & RAÇA \\
\hline 1 & Direito & 28,0 & Macho & SRD \\
\hline 2 & Esquerdo & 28,0 & Macho & SRD \\
\hline 3 & Direito & 22,0 & Fêmea & SRD \\
\hline 4 & Esquerdo & 22,0 & Macho & SRD \\
\hline 5 & Esquerdo & 20,0 & Fêmea & SRD \\
\hline 6 & Direito & 20,0 & Fêmea & SRD \\
\hline 7 & Esquerdo & 20,0 & Macho & SRD \\
\hline 8 & Direito & 20,0 & Fêmea & SRD \\
\hline 9 & Direito & 20,0 & Fêmea & SRD \\
\hline 10 & Direito & 25,0 & Macho & SRD \\
\hline 11 & Direito & 26,0 & Macho & Pit Bull \\
\hline 12 & Esquerdo & 20,0 & Fêmea & SRD \\
\hline 13 & Direito & 24,0 & Fêmea & SRD \\
\hline 14 & Esquerdo & 24,0 & Macho & SRD \\
\hline 15 & Esquerdo & 26,0 & Macho & SRD \\
\hline 16 & Direito & 22,0 & Fêmea & SRD \\
\hline 17 & Direito & 26,0 & Macho & Pit Bull \\
\hline 18 & Direito & 24,0 & Fêmea & SRD \\
\hline 19 & Esquerdo & 25,7 & Fêmea & Pit Bull \\
\hline 20 & Direito & Fêmea & Pit Bull \\
\hline
\end{tabular}

SRD: sem raça definida; Kg: quilo

Todos os membros utilizados apresentavam-se sem alterações da articulação femoro-tibiopatelar. 


\subsection{ENSAIO BIOMECÂNICO DE INFLEXÃO}

O ensaio biomecânico de inflexão foi realizado com carga parcial de 50 Newtons no sentido cranial e caudal em cada joelho com o LCCr íntegro.

Seu objetivo foi o de estabelecer o ponto de inflexão do joelho a ser testado, ou seja, o ponto de menor tensionamento de suas estruturas estabilizadoras, sendo este o nosso ponto inicial para os demais ensaios para o mesmo joelho em diferentes situações (Gráfico - 1).

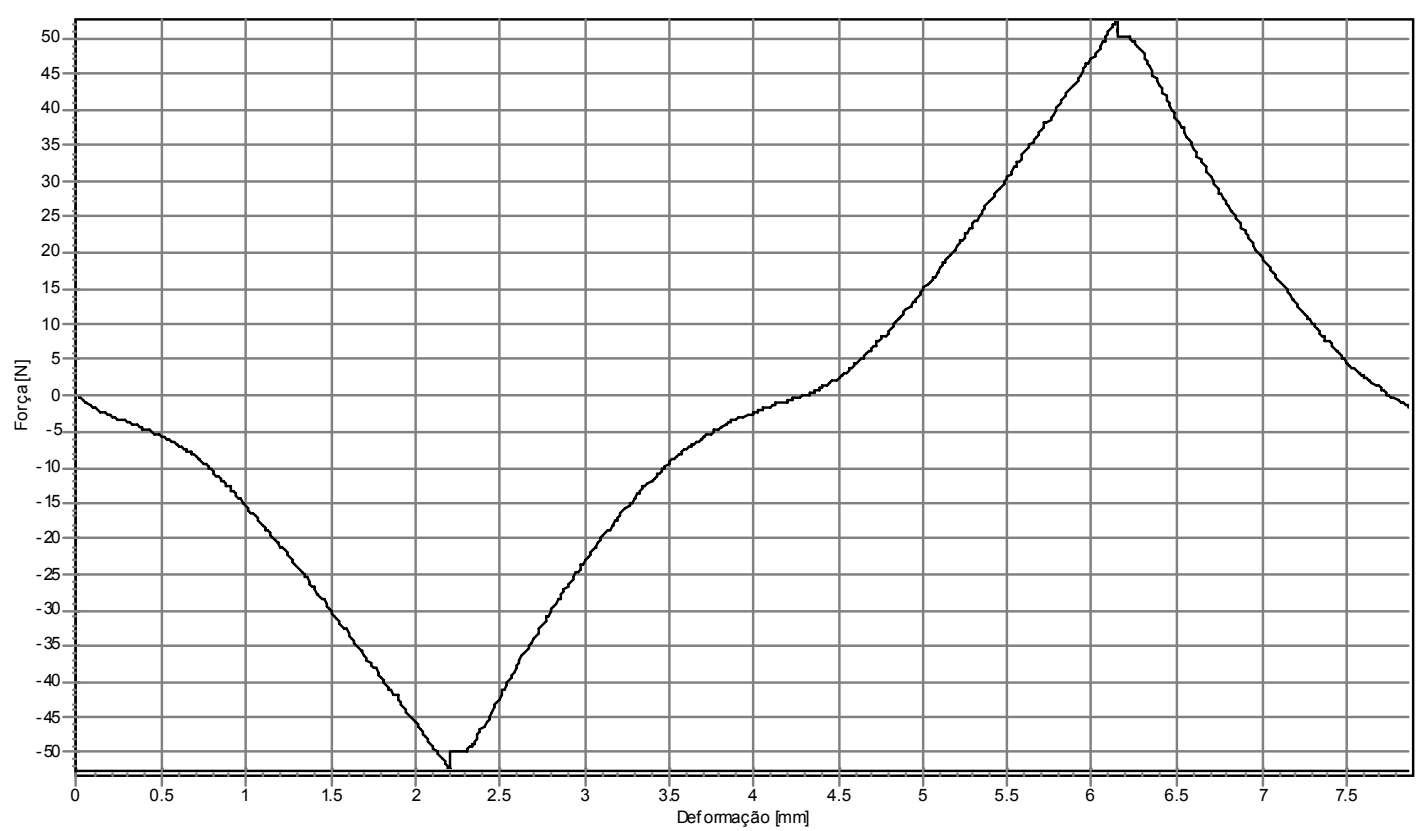

$\mathrm{N}$ : Newton; mm: milímetro

Gráfico 1 - Exemplo de gráfico de ensaio biomecânico de inflexão realizado no experimento - São Paulo - 2007 


\subsection{ENSAIO BIOMECÂNICO}

Os valores de gaveta obtidos são correspondentes ao deslocamento em milímetro no sentido cranial e caudal e a rígidez é a relação entre carga e deformação calculada nas regiões craniais e caudais mais retilíneas dos gráficos dos ensaios biomecânicos.

Os dados de gaveta e rigidez craniais e caudais, bem como os gráficos dos ensaios biomecânicos de cada um dos 20 joelhos estão dispostos nas páginas seguintes, sendo os dados de cada joelho apresentados separadamente por página (Tabela 2 a 41 e Gráfico 2 a 21). 
Tabela 2 - Deslocamento cranial e caudal da tíbia em relação ao fêmur após carga de 100 Newtons, nas diferentes situações testadas no “joelho 01" - São Paulo - 2007

\begin{tabular}{lcccccc}
\hline \multicolumn{7}{c}{ GAVETA (mm) } \\
\hline Situação & Cranial 1 & Cranial 2 & Cranial 3 & Caudal 1 & Caudal 2 & Caudal 3 \\
\hline LCCr & 2,95 & 2,94 & 2,94 & 3,95 & 4,18 & 4,26 \\
\hline RLCCr & 11,81 & 11,88 & 12,06 & 5,12 & 5,34 & 5,36 \\
\hline SFTL & 5,9 & 6,12 & 6,25 & 4,57 & 4,54 & 4,55 \\
\hline SFTLM & 4,36 & 4,54 & 4,69 & 3,42 & 3,42 & 3,41 \\
\hline LCCr: ligamento cruzado cranial íntegro; RLCCr: ligamento cruzado cranial rompido; SFTL: sutura fabelo-tibial
\end{tabular}

lateral; SFTLM: suturas fabelo-tibiais lateral e medial; mm: milímetro.

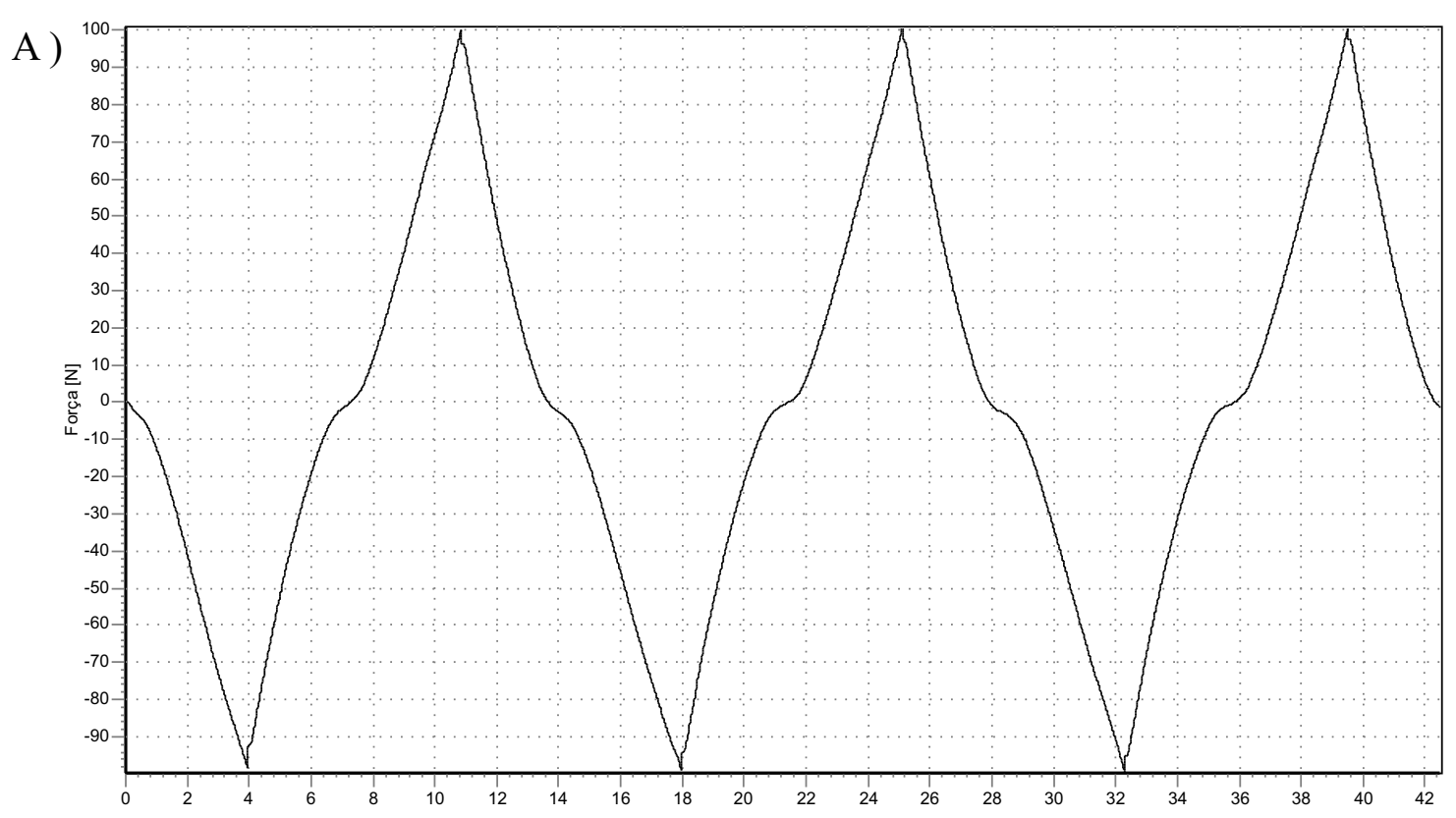

C

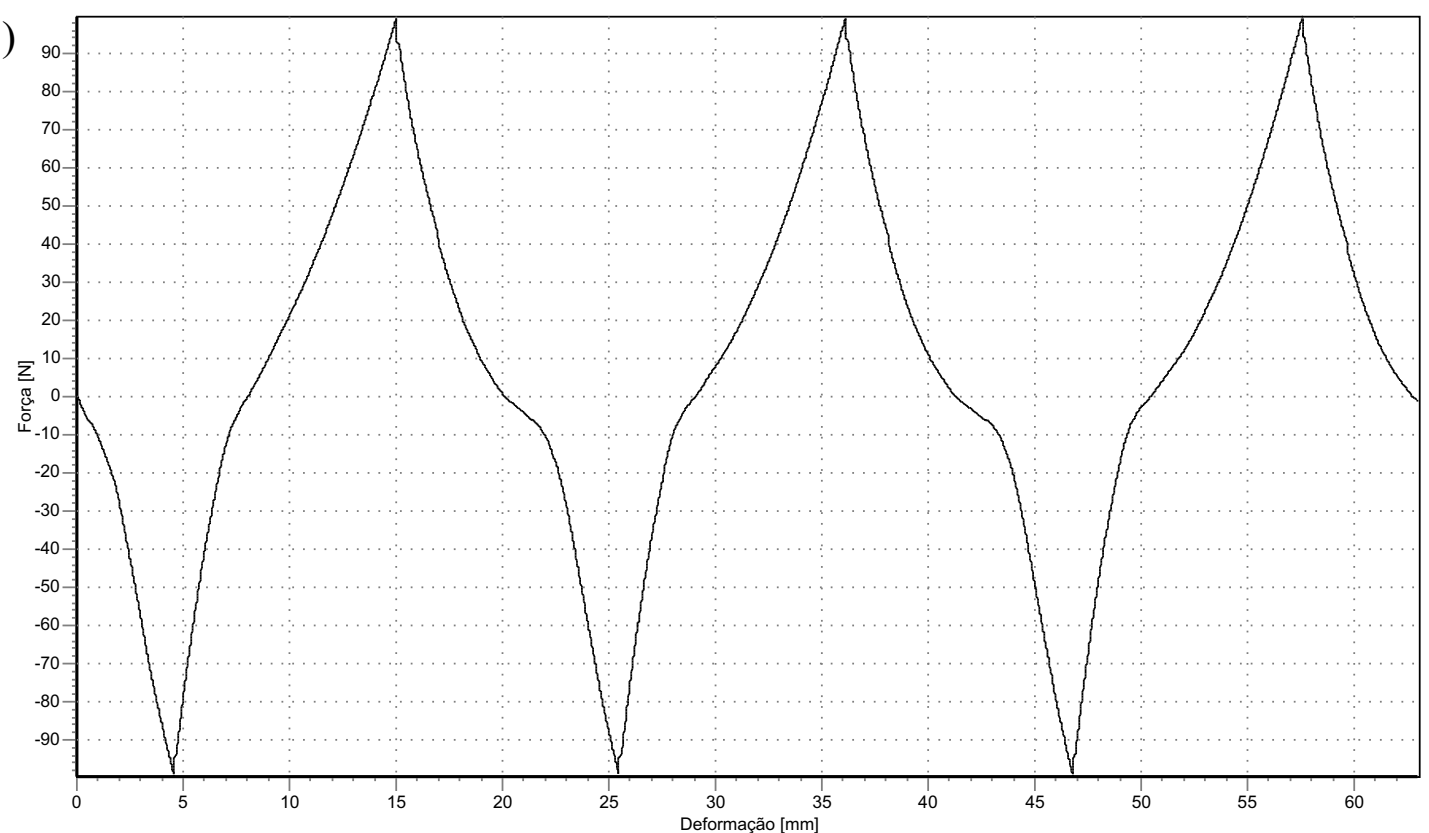

Tabela 3 - Rigidez cranial e caudal apresentadas nas diferentes situacões testadas no “joelho 01" - São Paulo - 2007

\begin{tabular}{ccccccc}
\hline \multicolumn{7}{c}{ RIGIDEZ (N/mm) } \\
\hline Situação & Cranial 1 & Cranial 2 & Cranial 3 & Caudal 1 & Caudal 2 & Caudal 3 \\
\hline LCCr & 31,91 & 32,79 & 32,98 & 27,81 & 25,79 & 27,25 \\
\hline RLCCr & 25,10 & 26,17 & 26,87 & 28,28 & 27,35 & 27,78 \\
\hline SFTL & 17,73 & 19,30 & 19,76 & 26,12 & 27,26 & 27,50 \\
\hline SFTLM & 18,33 & 20,71 & 21,11 & 33,02 & 32,03 & 31,85 \\
\hline LCCr: ligamento cruzado cranial íntegro; RLCCr: ligamento cruzado cranial rompido; SFTL: sutura fabelo-tibial
\end{tabular}

lateral; SFTLM: suturas fabelo-tibiais lateral e medial; mm: milímetro.
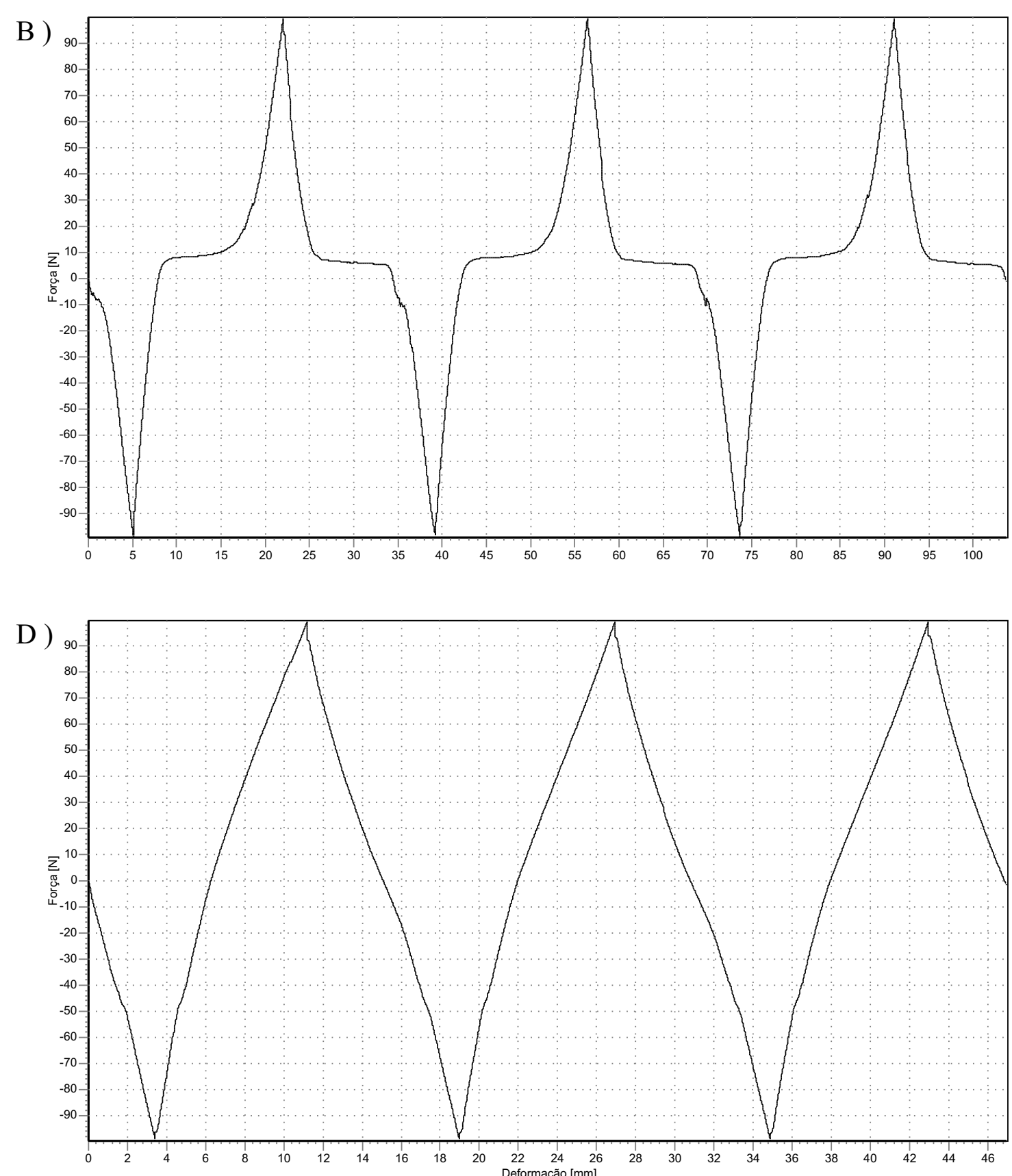

A) LCCr (ligamento íntegro); B) RLCCr (ligamento rompido); C) Joelho reparado por sutura fabelo-tibial lateral; D) Joelho reparado por suturas fabelo-tibiais lateral e medial; N: Newton; mm: milímetro.

Gráficos 2 - Ensaios biomecânicos referentes ao “joelho 01” nas diferentes situações testadas, durante os três ciclos cranio-caudais - São Paulo - 2007 
Tabela 4 - Deslocamento cranial e caudal da tíbia em relação ao fêmur após carga de 100 Newtons, nas diferentes situações testadas no "joelho 02" - São Paulo - 2007

\begin{tabular}{ccccccc}
\hline \multicolumn{7}{c}{ GAVETA (mm) } \\
\hline Situação & Cranial 1 & Cranial 2 & Cranial 3 & Caudal 1 & Caudal 2 & Caudal 3 \\
\hline LCCr & 3,71 & 3,72 & 3,74 & 4,88 & 4,84 & 4,91 \\
\hline RLCCr & 12,40 & 12,68 & 12,70 & 5,60 & 5,79 & 5,90 \\
\hline SFTL & 5,71 & 5,95 & 6,10 & 5,62 & 5,62 & 5,64 \\
\hline SFTLM & 4,69 & 4,93 & 5,09 & 4,05 & 3,93 & 3,88 \\
\hline LCCr: ligamento cruzado cranial integro; RLCCr: ligamento cruzado cranial rompido; SFTL: sutura fabelo-tibial
\end{tabular}

LCCr: ligamento cruzado cranial íntegro; RLCCr: ligamento cruzado cranial rompido; SFTL: sutura fabelo-tibial lateral; SFTLM: suturas fabelo-tibiais lateral e medial; mm: milímetro.

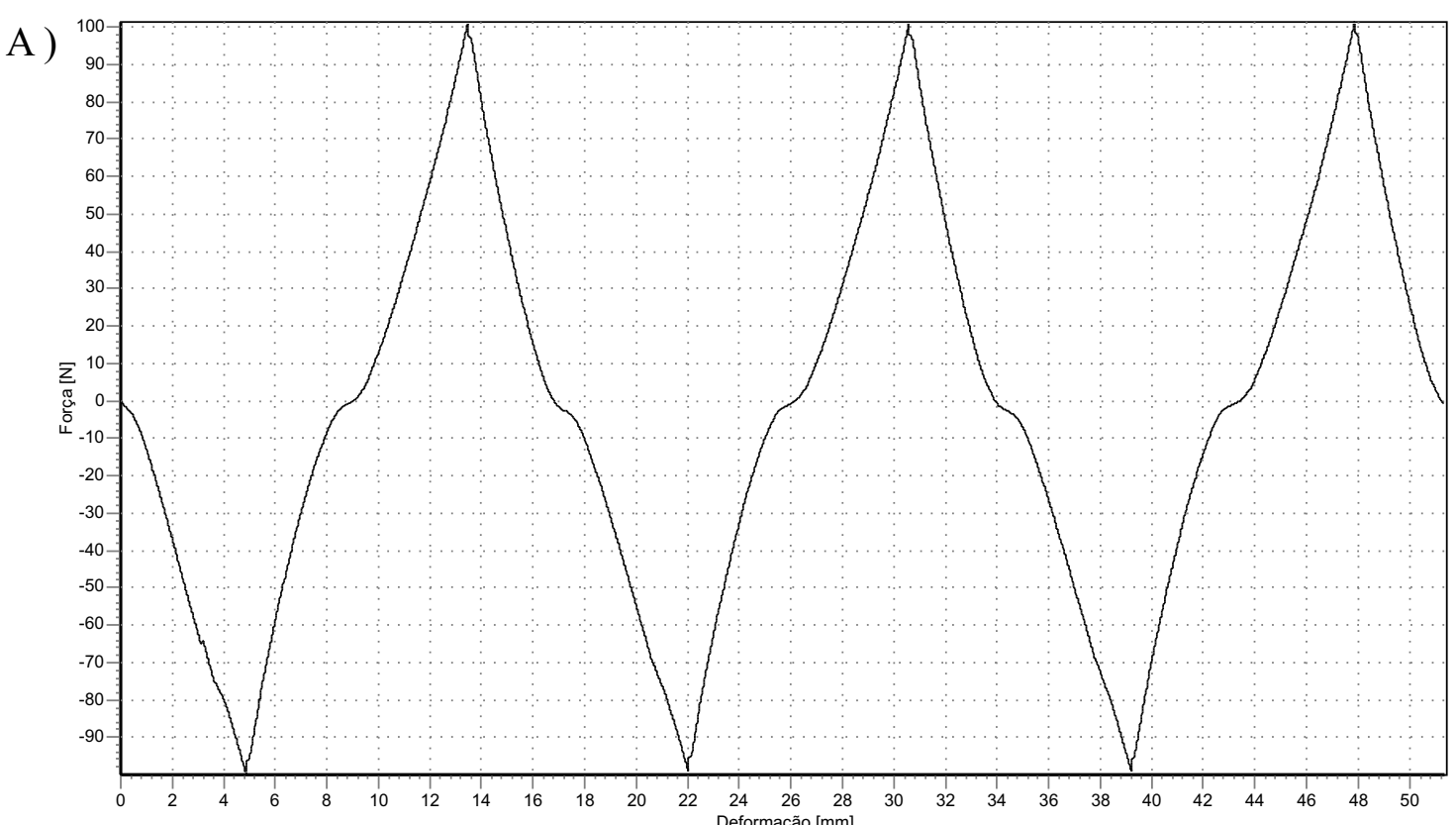

C

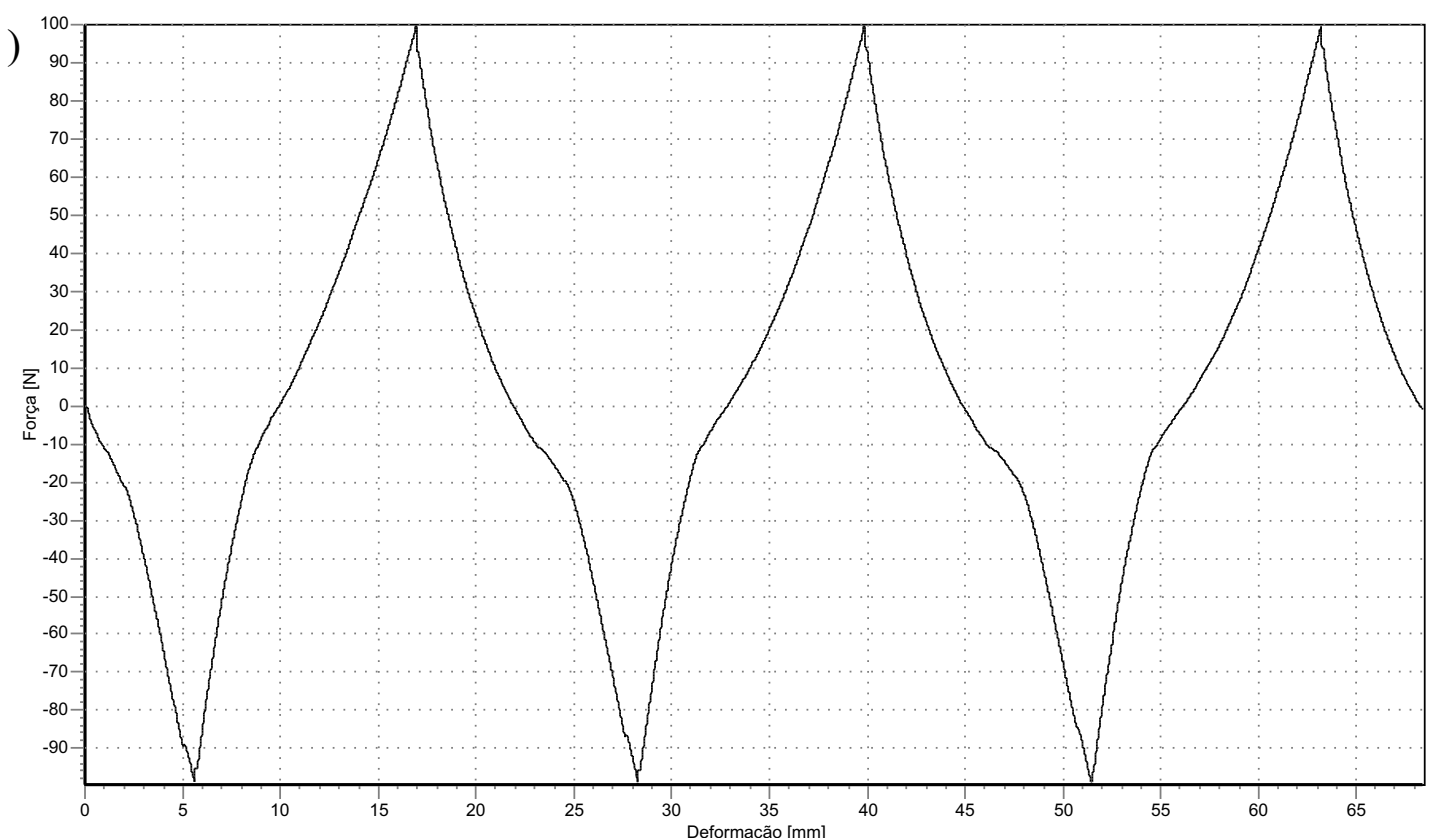

Tabela 5 - Rigidez cranial e caudal apresentadas nas diferentes situacões testadas no “joelho 02" - São Paulo - 2007

\begin{tabular}{ccccccc}
\hline \multicolumn{7}{c}{ RIGIDEZ (N/mm) } \\
\hline Situação & Cranial 1 & Cranial 2 & Cranial 3 & Caudal 1 & Caudal 2 & Caudal 3 \\
\hline LCCr & 29,06 & 29,40 & 29,71 & 19,58 & 20,80 & 21,23 \\
\hline RLCCr & 20,18 & 21,30 & 21,45 & 23,26 & 24,80 & 21,68 \\
\hline SFTL & 17,92 & 19,70 & 20,03 & 21,56 & 21,98 & 21,70 \\
\hline SFTLM & 18,09 & 20,70 & 21,21 & 26,53 & 25,91 & 25,85 \\
\hline LCCr: ligamento cruzado cranial íntegro; RLCCr: ligamento cruzado cranial rompido; SFTL: sutura fabelo-tibial
\end{tabular}

LCCr: ligamento cruzado cranial íntegro; RLCCr: ligamento cruzado cranial rompido; SFTL: sutura fabelo-tibial lateral; SFTLM: suturas fabelo-tibiais lateral e medial; mm: milímetro,
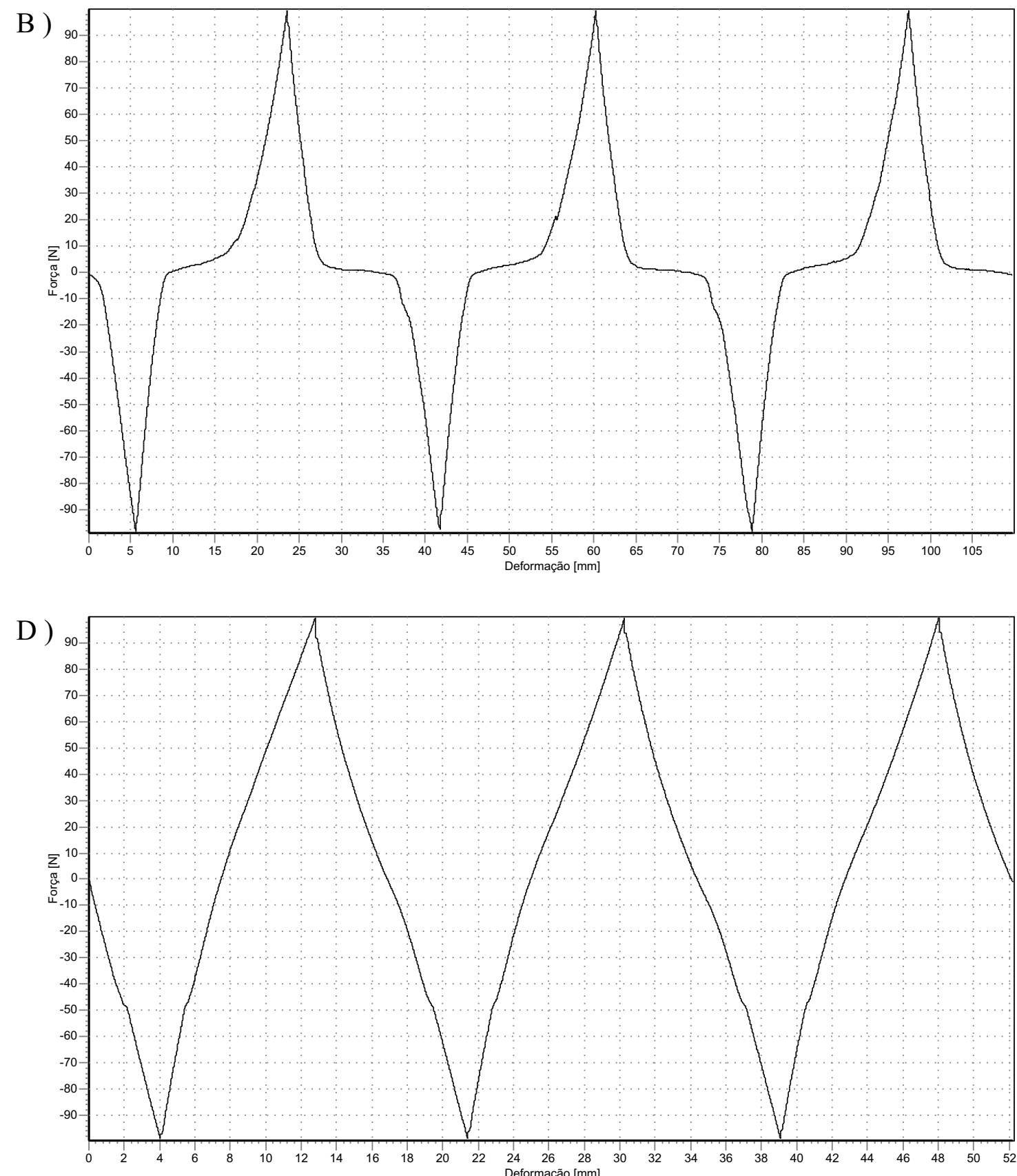

A) LCCr (ligamento íntegro); B) RLCCr (ligamento rompido); C) Joelho reparado por sutura fabelo-tibial lateral; D) Joelho reparado por suturas fabelo-tibiais lateral e medial; N: Newton; mm: milímetro.

Gráficos 3 - Ensaios biomecânicos referentes ao “joelho 02" nas diferentes situações testadas, durante os três ciclos cranio-caudais - São Paulo - 2007 
Tabela 6 - Deslocamento cranial e caudal da tíbia em relação ao fêmur após carga de 100 Newtons, nas diferentes situações testadas no "joelho 03" - São Paulo - 2007

\begin{tabular}{ccccccc}
\hline \multicolumn{7}{c}{ GAVETA ( mm) } \\
\hline Situação & Cranial 1 & Cranial 2 & Cranial 3 & Caudal 1 & Caudal 2 & Caudal 3 \\
\hline LCCr & 2,89 & 2,96 & 3,00 & 3,93 & 4,03 & 4,09 \\
\hline RLCCr & 12,46 & 12,74 & 12,84 & 3,95 & 3,94 & 3,98 \\
\hline SFTL & 4,21 & 4,35 & 4,44 & 4,23 & 4,22 & 4,23 \\
\hline SFTLM & 4,96 & 5,18 & 5,28 & 3,45 & 3,53 & 3,54 \\
\hline LCCr: ligamento cruzado cranial integro; RLCCr: ligamento cruzado cranial rompido; SFTL: sutura fabelo-tibial
\end{tabular}

LCCr: ligamento cruzado cranial integro; RLCCr: ligamento cruzado cranial rompido; SFTL: sutura fabelo-tibial lateral; SFTLM: suturas fabelo-tibiais lateral e medial; mm: milímetro.
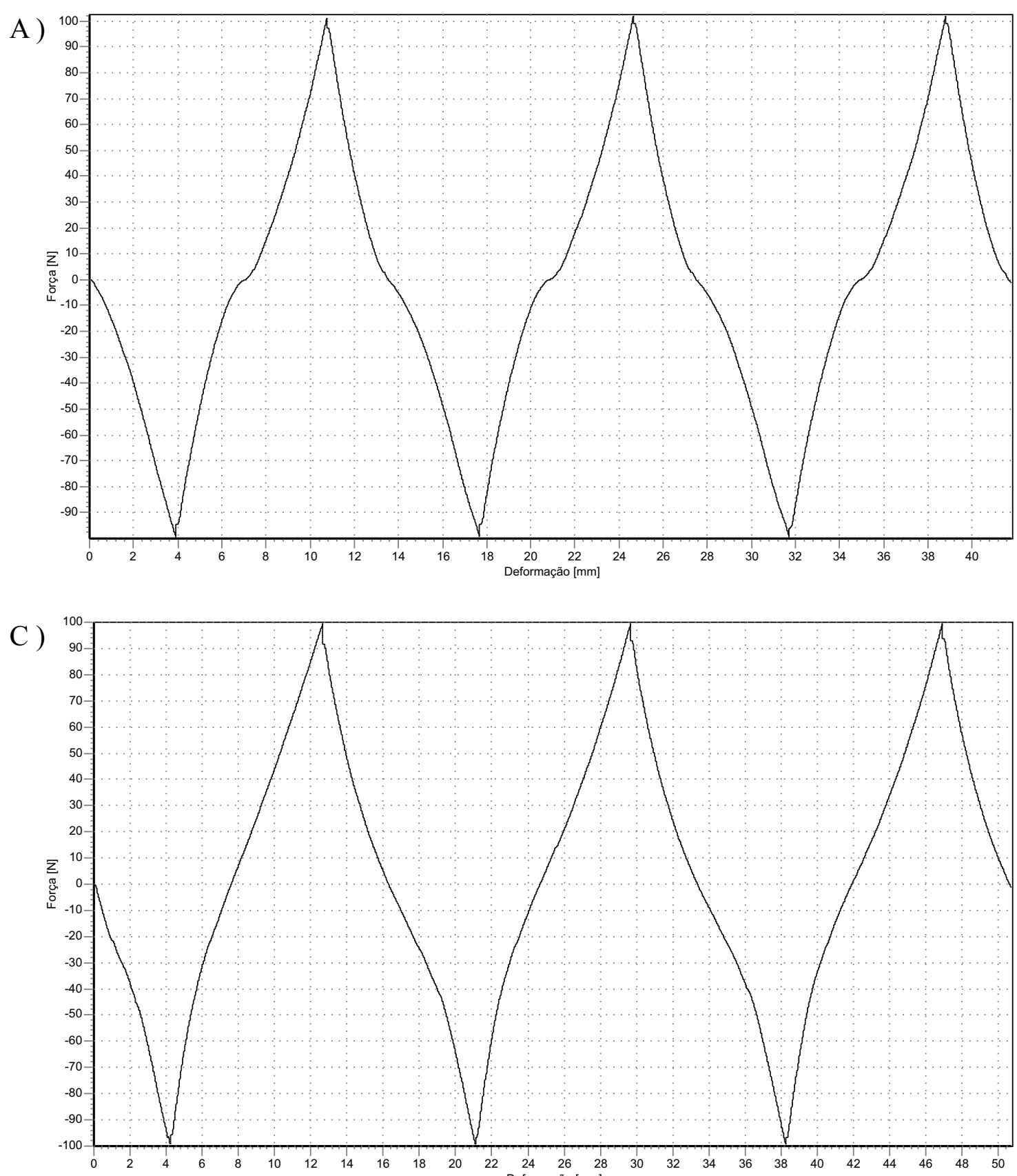

Tabela 7 - Rigidez cranial e caudal apresentadas nas diferentes situações testadas no “joelho 03"-São Paulo - 2007

\begin{tabular}{ccccccc}
\hline \multicolumn{7}{c}{ RIGIDEZ (N/mm) } \\
\hline Situação & Cranial 1 & Cranial 2 & Cranial 3 & Caudal 1 & Caudal 2 & Caudal 3 \\
\hline LCCr & 37,03 & 37,96 & 38,55 & 31,08 & 30,27 & 29,17 \\
\hline RLCCr & 28,47 & 31,18 & 32,37 & 33,36 & 32,93 & 31,58 \\
\hline SFTL & 21,34 & 24,05 & 24,68 & 31,36 & 32,15 & 31,86 \\
\hline SFTLM & 20,71 & 22,63 & 22,93 & 31,26 & 32,24 & 32,39 \\
\hline LCCr: ligamento cruzado cranial íntegro; RLCCr: ligamento cruzado cranial rompido; SFTL: sutura fabelo-tibial
\end{tabular}

lateral; SFTLM: suturas fabelo-tibiais lateral e medial; mm: milímetro.
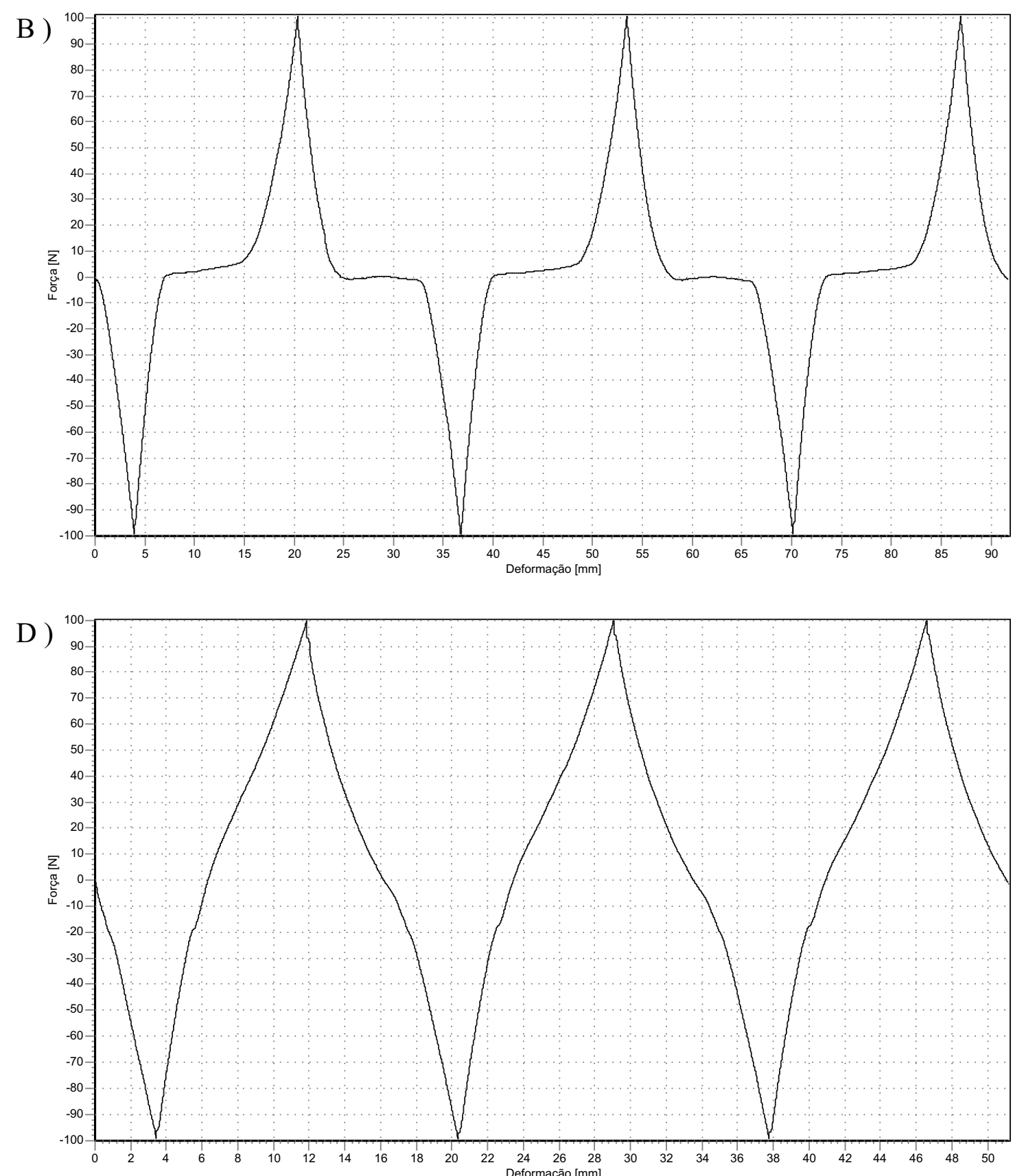

A) LCCr (ligamento íntegro); B) RLCCr (ligamento rompido); C) Joelho reparado por sutura fabelo-tibial lateral; D) Joelho reparado por suturas fabelo-tibiais lateral e medial; N: Newton; mm: milímetro.

Gráficos 4 - Ensaios biomecânicos referentes ao “joelho 03" nas diferentes situações testadas, durante os três ciclos cranio-caudais - São Paulo - 2007 
Tabela 8 - Deslocamento cranial e caudal da tíbia em relação ao fêmur após carga de 100 Newtons, nas diferentes situações testadas no “joelho 04" - São Paulo - 2007

\begin{tabular}{ccccccc}
\hline \multicolumn{7}{c}{ GAVETA (mm) } \\
\hline Situação & Cranial 1 & Cranial 2 & Cranial 3 & Caudal 1 & Caudal 2 & Caudal 3 \\
\hline LCCr & 3,65 & 3,64 & 3,69 & 5,01 & 5,09 & 5,12 \\
\hline RLCCr & 11,17 & 11,40 & 11,49 & 6,08 & 6,13 & 6,15 \\
\hline SFTL & 5,54 & 5,79 & 5,95 & 5,69 & 5,67 & 5,65 \\
\hline SFTLM & 4,67 & 4,88 & 5,03 & 5,03 & 5,07 & 5,02 \\
\hline LCCr: ligamento cruzado cranial integro; RLCCr: ligamento cruzado cranial rompido; SFTL: sutura fabelo-tibial
\end{tabular}

lateral; SFTLM: suturas fabelo-tibiais lateral e medial; mm: milímetro.

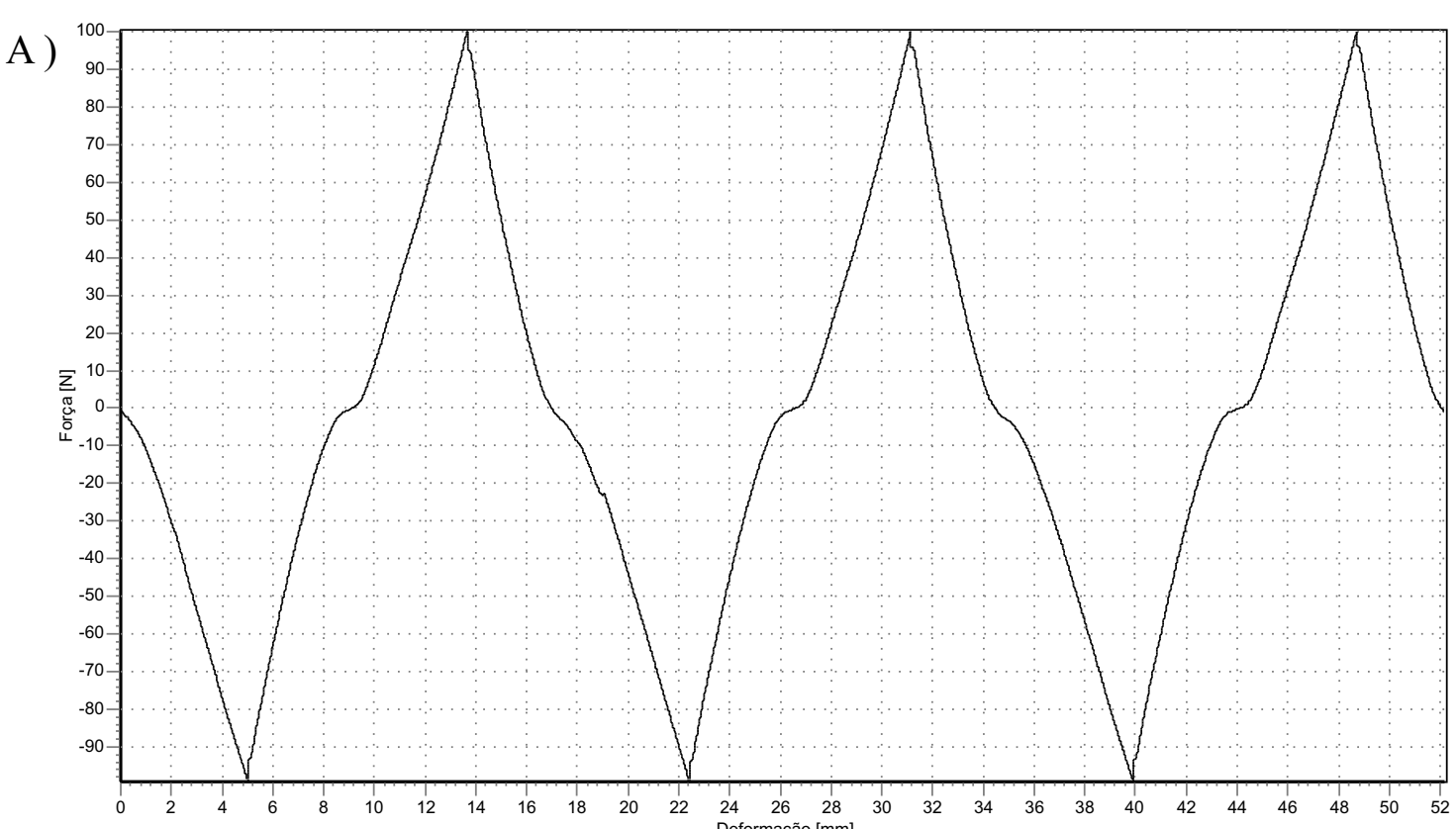

C )

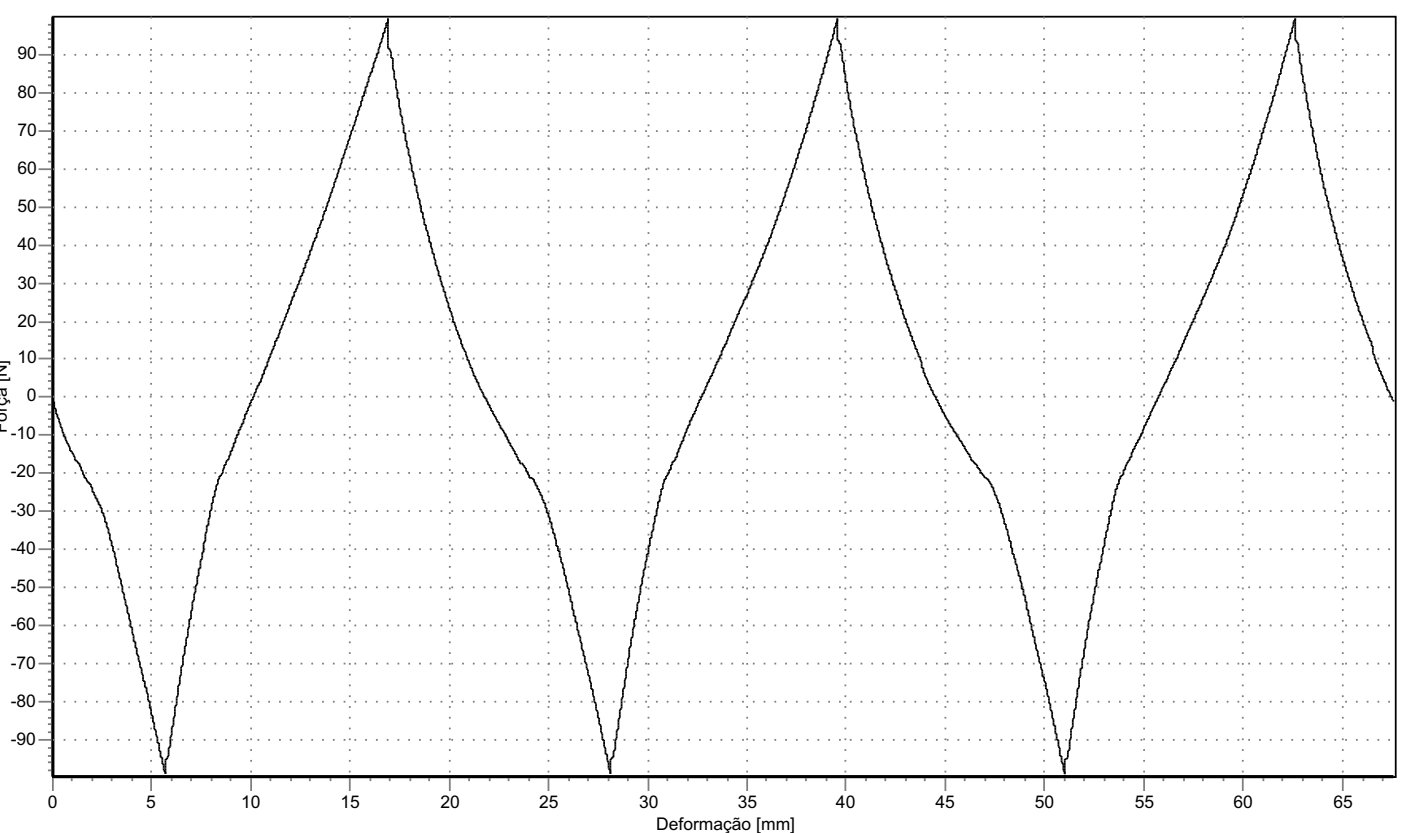

Tabela 9 - Rigidez cranial e caudal apresentadas nas diferentes situações testadas no “joelho 04" - São Paulo - 2007

\begin{tabular}{ccccccc}
\hline \multicolumn{7}{c}{ RIGIDEZ (N/mm) } \\
\hline Situação & Cranial 1 & Cranial 2 & Cranial 3 & Caudal 1 & Caudal 2 & Caudal 3 \\
\hline LCCr & 26,39 & 26,99 & 26,55 & 22,47 & 23,03 & 22,26 \\
\hline RLCCr & 20,77 & 22,38 & 23,06 & 22,70 & 22,60 & 22,15 \\
\hline SFTL & 15,92 & 17,77 & 18,15 & 22,50 & 22,93 & 23,10 \\
\hline SFTLM & 15,74 & 16,93 & 17,20 & 23,94 & 23,83 & 23,85 \\
\hline LCCr: ligamento cruzado cranial íntegro; RLCCr: ligamento cruzado cranial rompido; SFTL: sutura fabelo-tibial
\end{tabular}

LCCr: ligamento cruzado cranial integro; RLCCr: ligamento cruzado cranial rompido; SFTL: sutura fabelo-tibial lateral; SFTLM: suturas fabelo-tibiais lateral e medial; mm: milímetro.
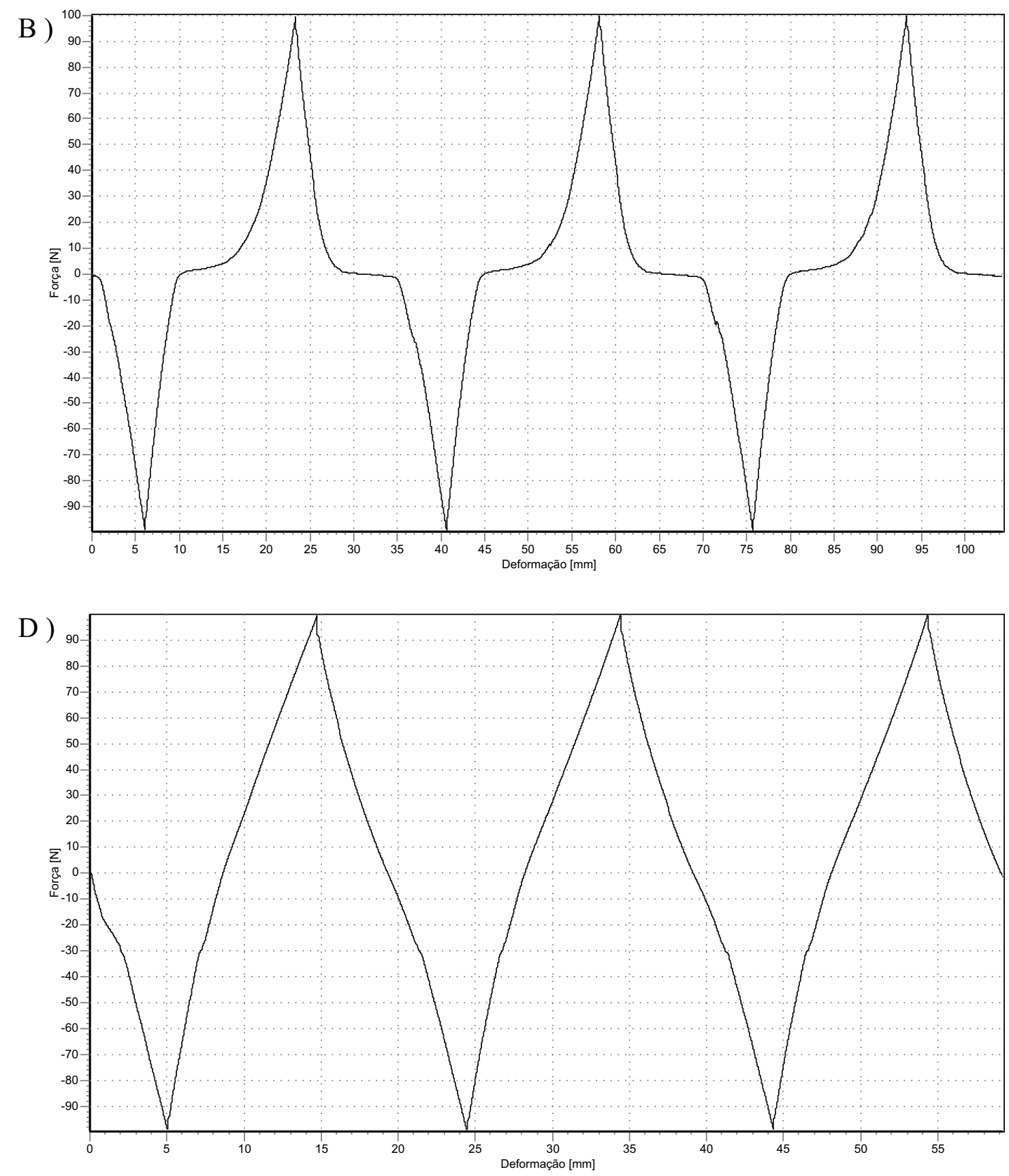

A) LCCr (ligamento íntegro); B) RLCCr (ligamento rompido); C) Joelho reparado por sutura fabelo-tibial lateral; D) Joelho reparado por suturas fabelo-tibiais lateral e medial; N: Newton; mm: milímetro.

Gráficos 5 - Ensaios biomecânicos referentes ao "joelho 04" nas diferentes situações testadas, durante os três ciclos cranio-caudais - São Paulo - 2007 
Tabela 10 - Deslocamento cranial e caudal da tíbia em relação ao fêmur após carga de 100 Newtons, nas diferentes situações testadas no “joelho 05” - São Paulo - 2007

\begin{tabular}{ccccccc}
\hline \multicolumn{7}{c}{ GAVETA $(\mathbf{m m})$} \\
\hline Situação & Cranial 1 & Cranial 2 & Cranial 3 & Caudal 1 & Caudal 2 & Caudal 3 \\
\hline LCCr & 2,95 & 2,96 & 3,02 & 4,07 & 4,08 & 4,10 \\
\hline RLCCr & 13,66 & 13,88 & 13,97 & 4,99 & 4,79 & 4,71 \\
\hline SFTL & 4,99 & 5,11 & 5,19 & 5,20 & 5,22 & 5,25 \\
\hline SFTLM & 3,47 & 3,66 & 3,75 & 3,70 & 3,64 & 3,58 \\
\hline
\end{tabular}

LCCr: ligamento cruzado cranial íntegro; RLCCr: ligamento cruzado cranial rompido; SFTL: sutura fabelo-tibial lateral; SFTLM: suturas fabelo-tibiais lateral e medial; mm: milímetro.

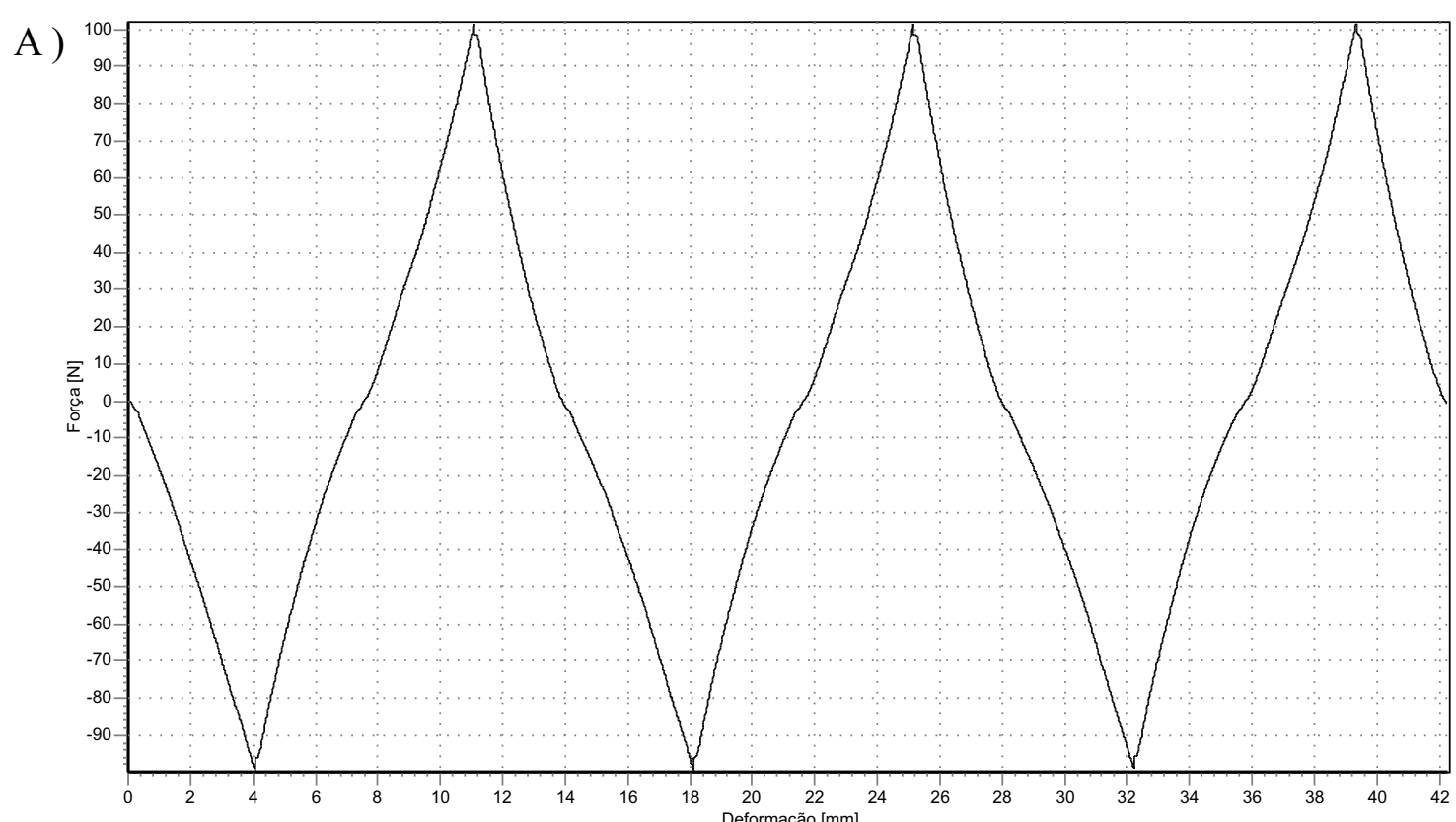

C

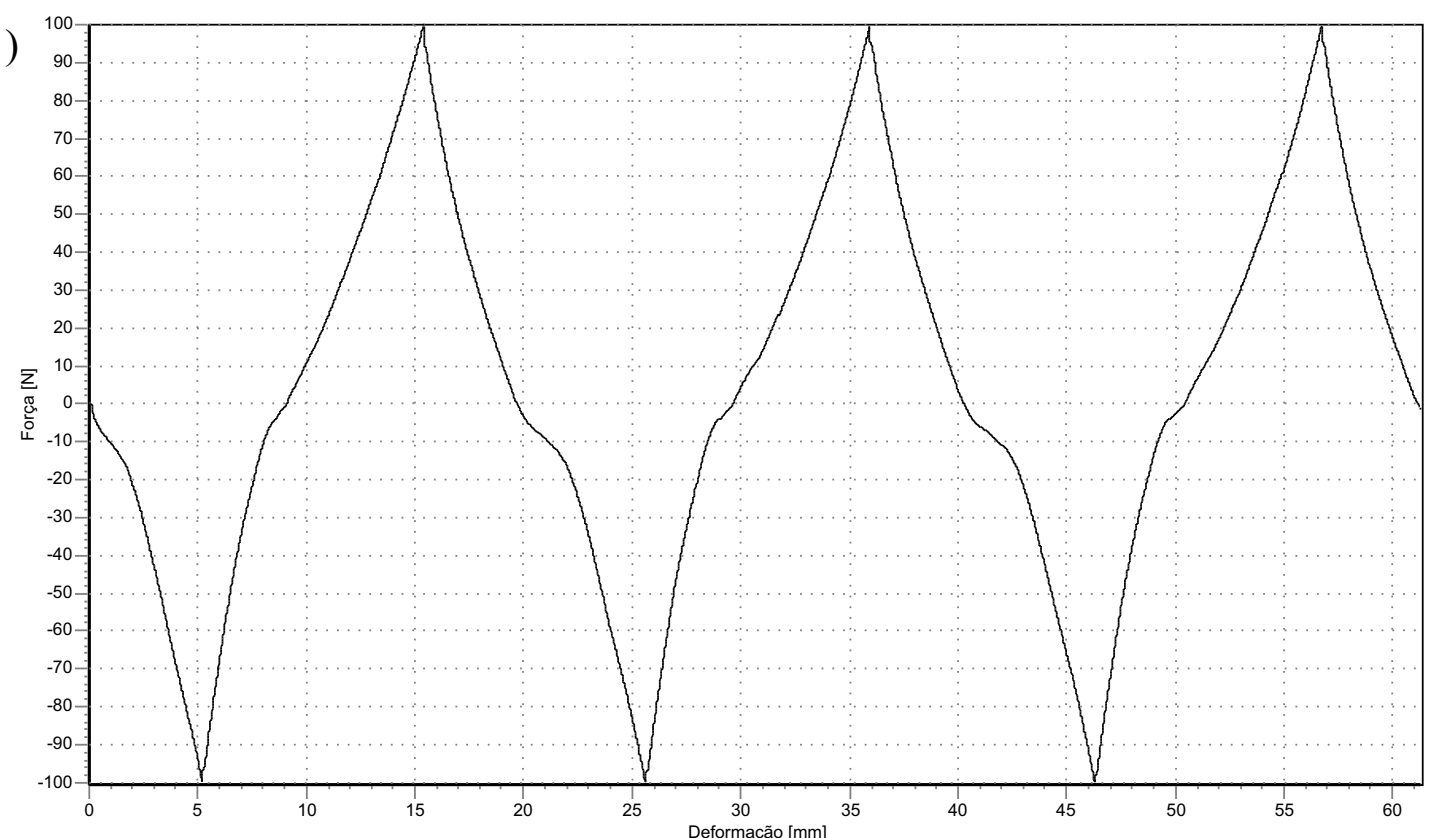

Tabela 11 - Rigidez cranial e caudal apresentadas nas diferentes situações testadas no “joelho 05” - São Paulo - 2007

\begin{tabular}{ccccccc}
\hline \multicolumn{7}{c}{ RIGIDEZ (N/mm) } \\
\hline Situação & Cranial 1 & Cranial 2 & Cranial 3 & Caudal 1 & Caudal 2 & Caudal 3 \\
\hline LCCr & 35,45 & 36,70 & 36,82 & 27,58 & 27,87 & 27,53 \\
\hline RLCCr & 26,55 & 28,95 & 29,75 & 24,90 & 22,13 & 21,99 \\
\hline SFTL & 19,69 & 21,36 & 21,64 & 25,01 & 25,25 & 25,67 \\
\hline SFTLM & 23,79 & 25,07 & 25,52 & 27,89 & 27,30 & 26,90 \\
\hline LCCr: ligamento cruzado cranial íntegro; RLCCr: ligamento cruzado cranial rompido; SFTL: sutura fabelo-tibial
\end{tabular}

LCCr: ligamento cruzado cranial íntegro; RLCCr: ligamento cruzado cranial rompido; SFTL: sutura fabelo-tibial lateral; SFTLM: suturas fabelo-tibiais lateral e medial; mm: milímetro.
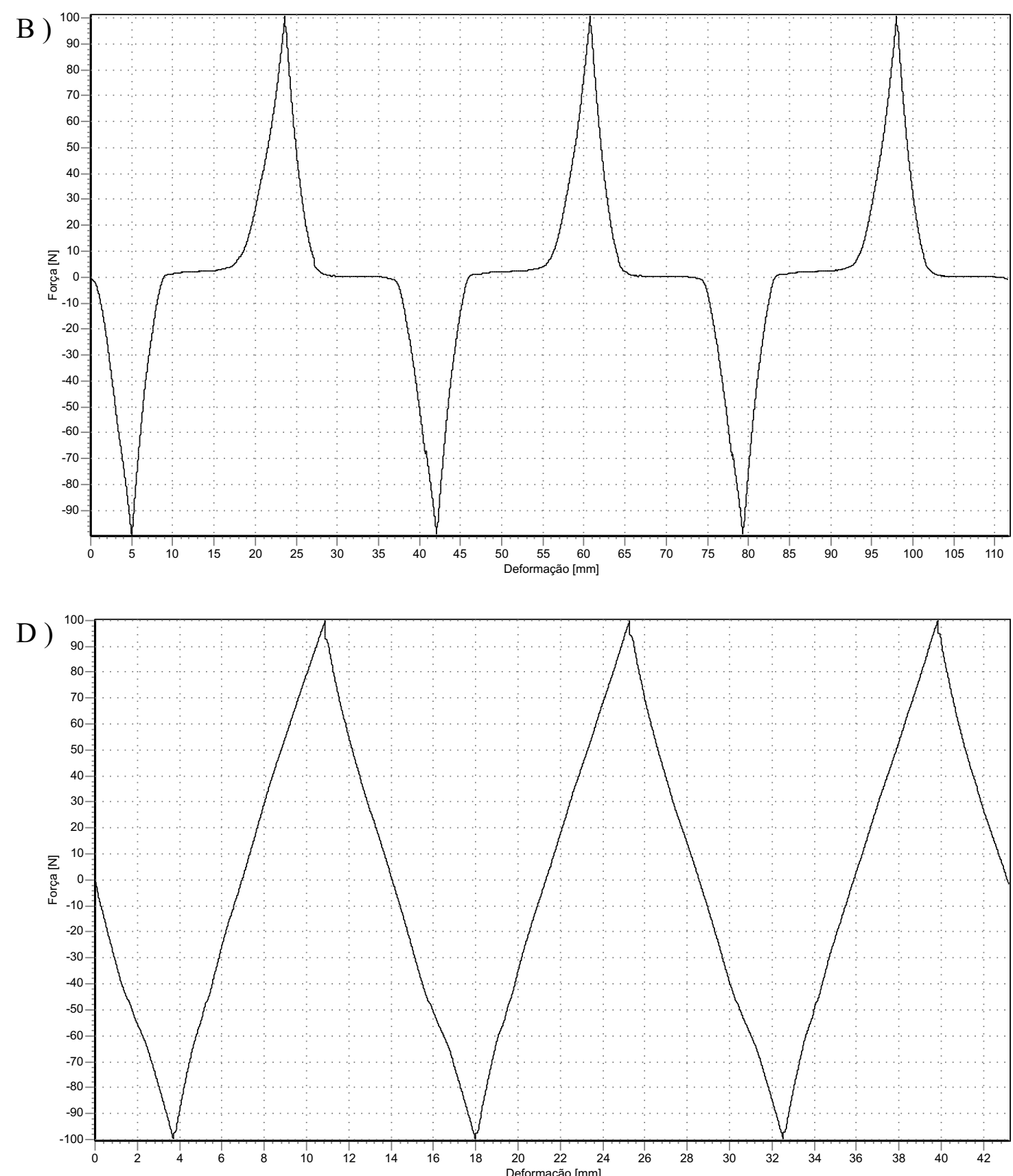

A) LCCr (ligamento íntegro); B) RLCCr (ligamento rompido); C) Joelho reparado por sutura fabelo-tibial lateral; D) Joelho reparado por suturas fabelo-tibiais lateral e medial; N: Newton; mm: milímetro.

Gráficos 6 - Ensaios biomecânicos referentes ao “joelho 05” nas diferentes situações testadas, durante os três ciclos cranio-caudais - São Paulo - 2007 
Tabela 12 - Deslocamento cranial e caudal da tíbia em relação ao fêmur após carga de 100 Newtons, nas diferentes situações testadas no “joelho 06" - São Paulo - 2007

\begin{tabular}{ccccccc}
\hline \multicolumn{7}{c}{ GAVETA (mm) } \\
\hline Situação & Cranial 1 & Cranial 2 & Cranial 3 & Caudal 1 & Caudal 2 & Caudal 3 \\
\hline LCCr & 3,88 & 3,92 & 3,96 & 4,3 & 4,3 & 4,31 \\
\hline RLCCr & 12,26 & 12,58 & 12,69 & 4,48 & 4,43 & 4,4 \\
\hline SFTL & 5,89 & 6,02 & 6,12 & 4,64 & 4,64 & 4,66 \\
\hline SFTLM & 4,13 & 4,22 & 4,31 & 4,3 & 4,35 & 4,35 \\
\hline
\end{tabular}

LCCr: ligamento cruzado cranial íntegro; RLCCr: ligamento cruzado cranial rompido; SFTL: sutura fabelo-tibia lateral; SFTLM: suturas fabelo-tibiais lateral e medial; mm: milímetro.

A )

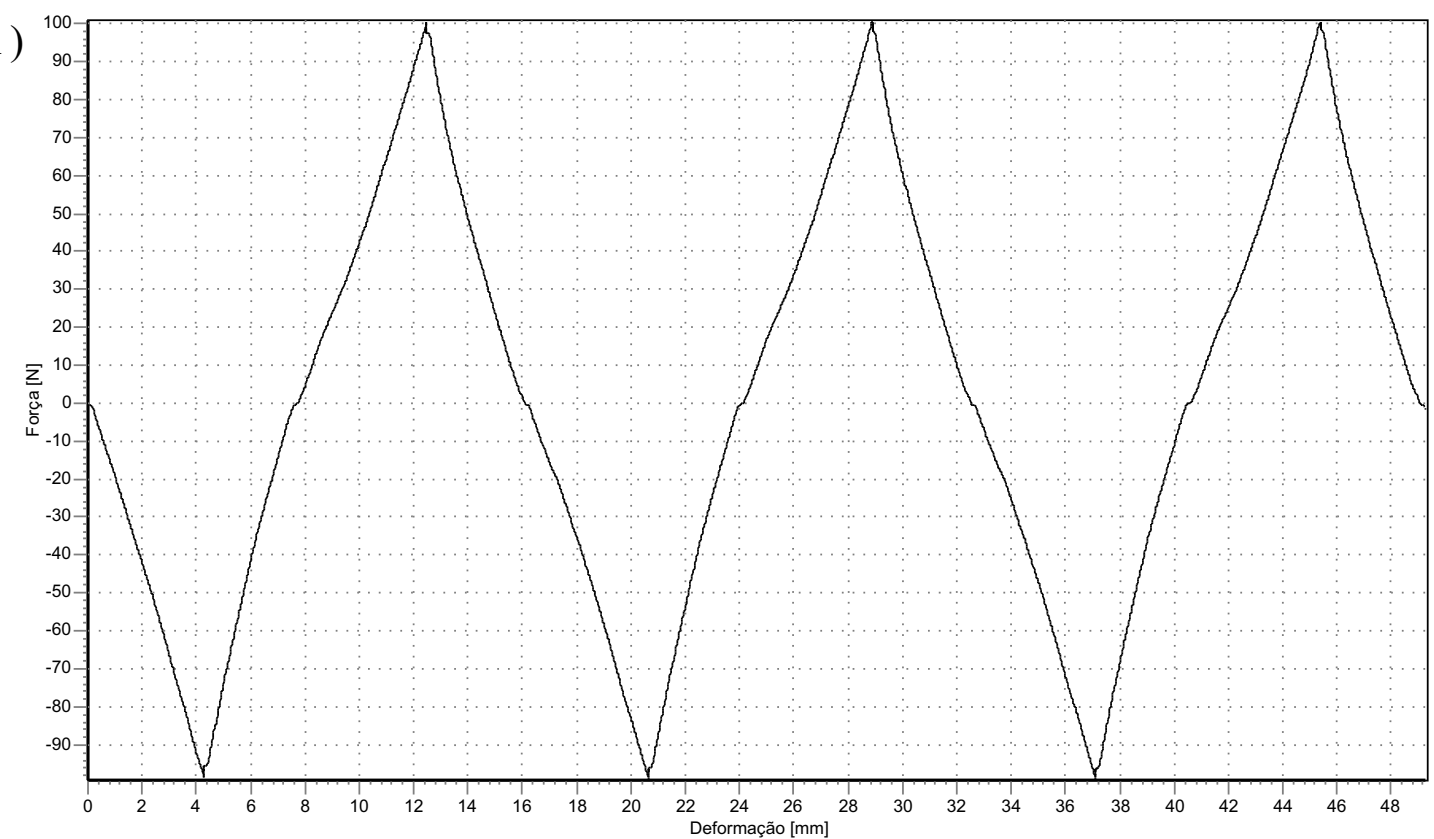

C )

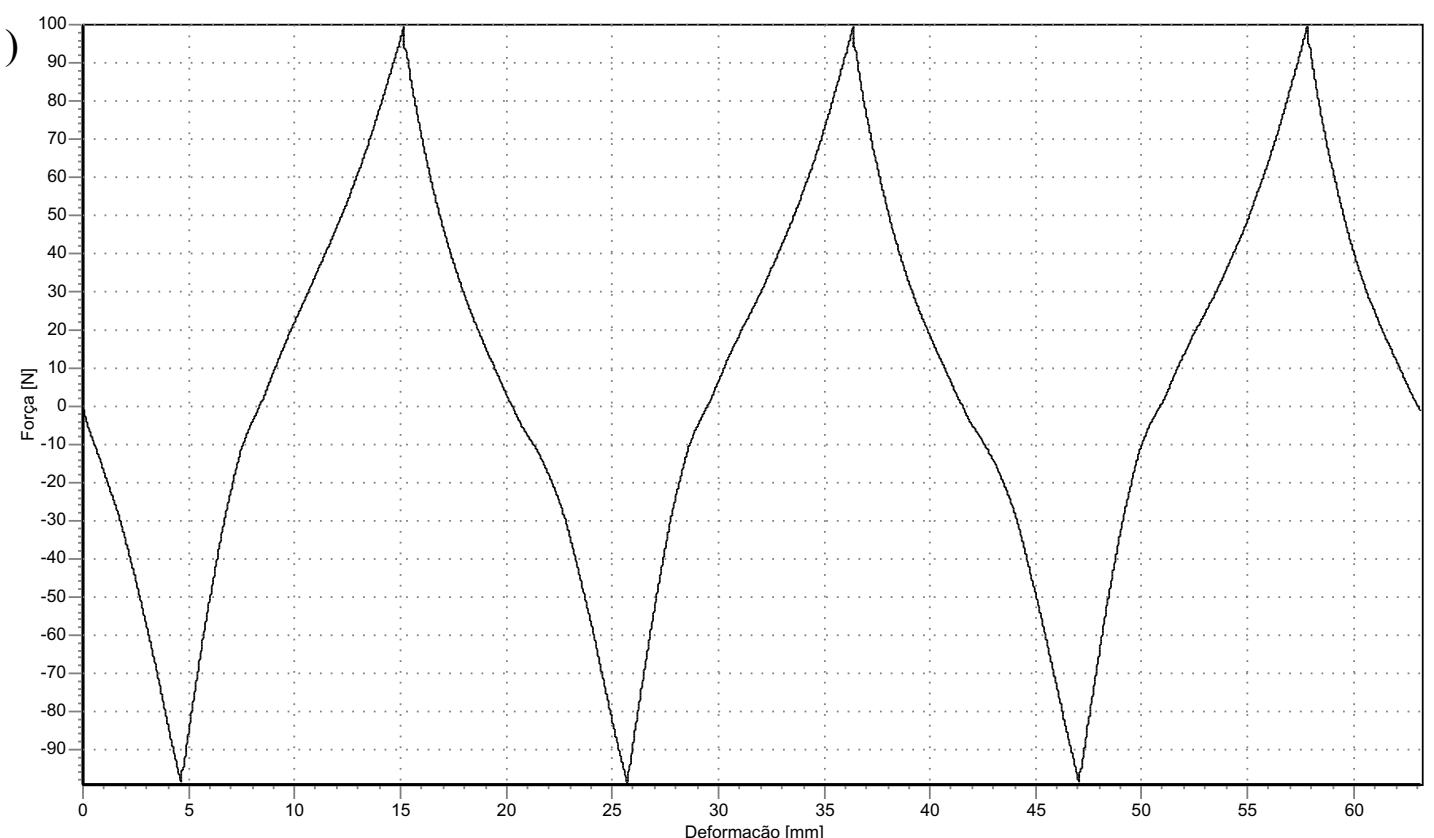

Tabela 13 - Rigidez cranial e caudal apresentadas nas diferentes situações testadas no “joelho 06” - São Paulo - 2007

\begin{tabular}{ccccccc}
\hline \multicolumn{7}{c}{ RIGIDEZ (N/mm) } \\
\hline Situação & Cranial 1 & Cranial 2 & Cranial 3 & Caudal 1 & Caudal 2 & Caudal 3 \\
\hline LCCr & 24,00 & 24,20 & 24,21 & 25,37 & 24,65 & 24,54 \\
\hline RLCCr & 18,57 & 19,96 & 20,30 & 25,10 & 25,12 & 24,69 \\
\hline SFTL & 17,70 & 18,80 & 19,14 & 25,86 & 24,78 & 24,35 \\
\hline SFTLM & 17,72 & 18,38 & 18,44 & 26,75 & 26,90 & 26,87 \\
\hline LCCr: ligamento cruzado cranial íntegro; RLCCr: ligamento cruzado cranial rompido; SFTL: sutura fabelo-tibial
\end{tabular}

LCCr: ligamento cruzado cranial íntegro; RLCCr: ligamento cruzado cranial rompido; SFTL: sutura fabelo-tibial lateral; SFTLM: suturas fabelo-tibiais lateral e medial; mm: milímetro.
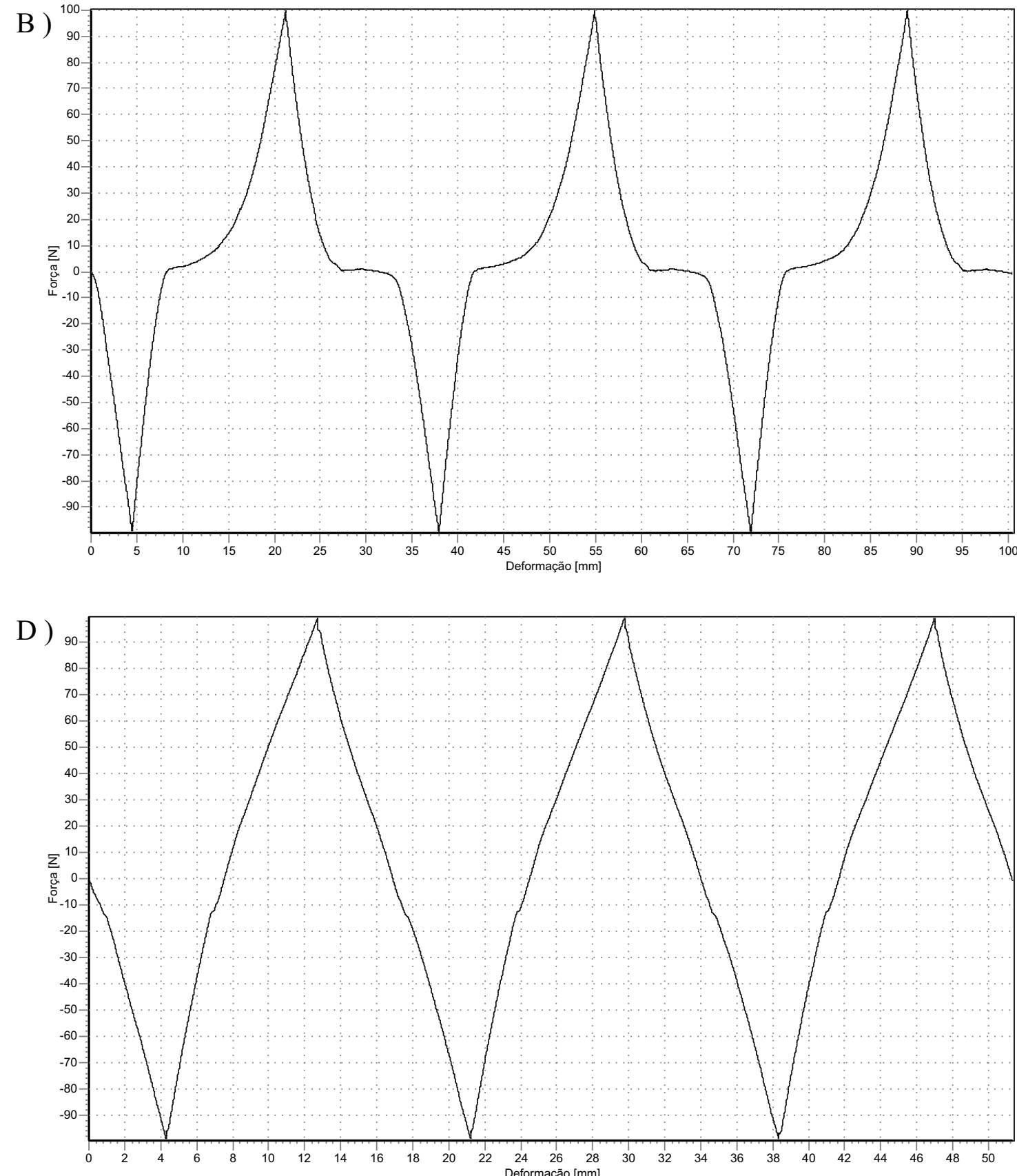

A) LCCr (ligamento íntegro); B) RLCCr (ligamento rompido); C) Joelho reparado por sutura fabelo-tibial lateral; D) Joelho reparado por suturas fabelo-tibiais lateral e medial; N: Newton; mm: milímetro.

Gráficos 7 - Ensaios biomecânicos referentes ao "joelho 06” nas diferentes situações testadas, durante os três ciclos cranio-caudais - São Paulo - 2007 
Tabela 14 - Deslocamento cranial e caudal da tíbia em relação ao fêmur após carga de 100 Newtons, nas diferentes situações testadas no "joelho 07" - São Paulo - 2007

\begin{tabular}{ccccccc}
\hline \multicolumn{7}{c}{ GAVETA (mm) } \\
\hline Situação & Cranial 1 & Cranial 2 & Cranial 3 & Caudal 1 & Caudal 2 & Caudal 3 \\
\hline LCCr & 3,39 & 3,46 & 3,45 & 4,30 & 4,35 & 4,37 \\
\hline RLCCr & 12,86 & 13,21 & 13,39 & 4,29 & 4,20 & 4,17 \\
\hline SFTL & 6,19 & 6,36 & 6,46 & 4,46 & 4,39 & 4,39 \\
\hline SFTLM & 4,01 & 4,13 & 4,26 & 3,85 & 3,82 & 3,81 \\
\hline LCCr: ligamento cruzado cranial integro; RLCCr: ligamento cruzado cranial rompido; SFTL: sutura fabelo-tibial
\end{tabular}

lateral; SFTLM: suturas fabelo-tibiais lateral e medial; mm: milímetro.

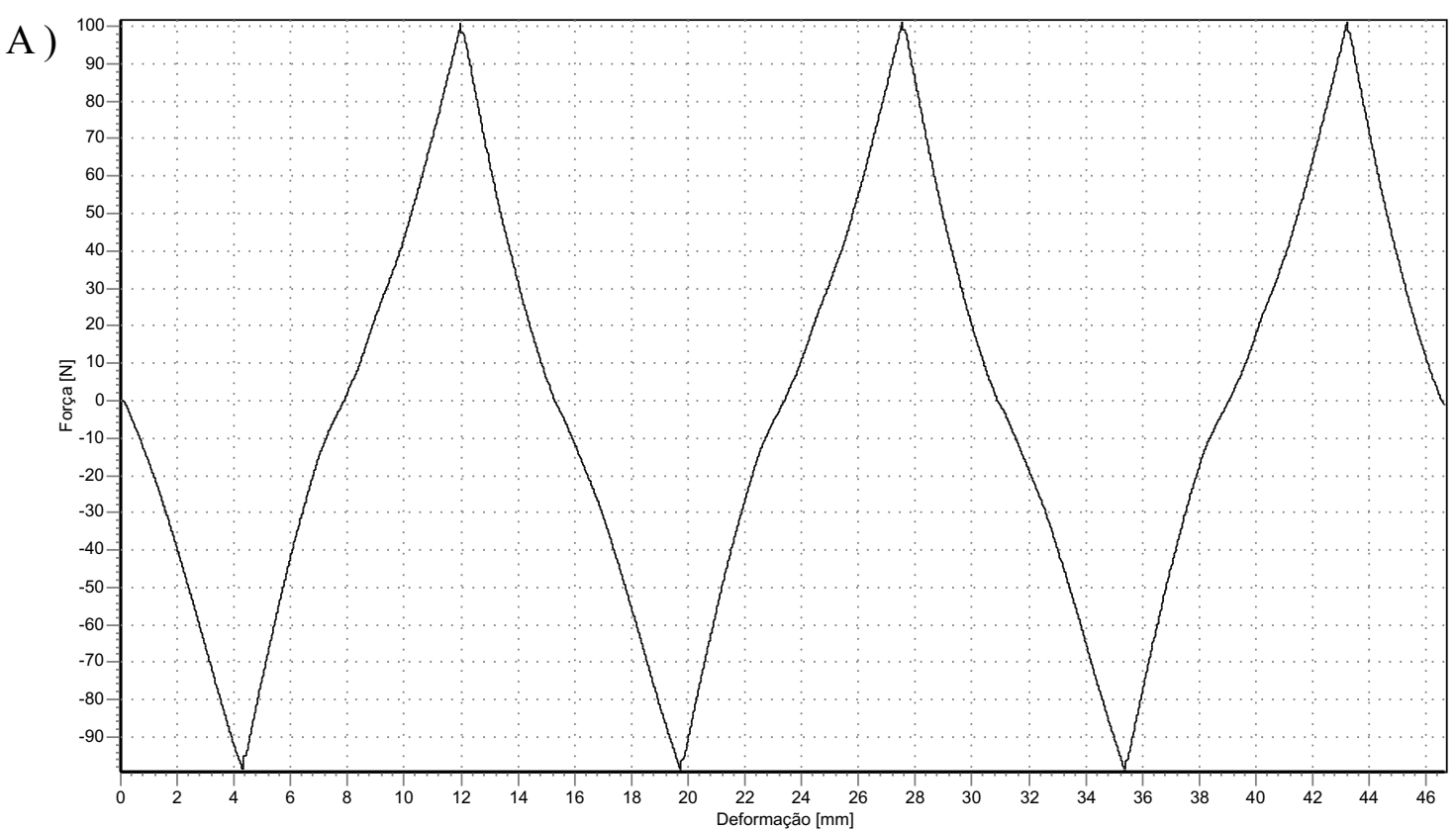

C

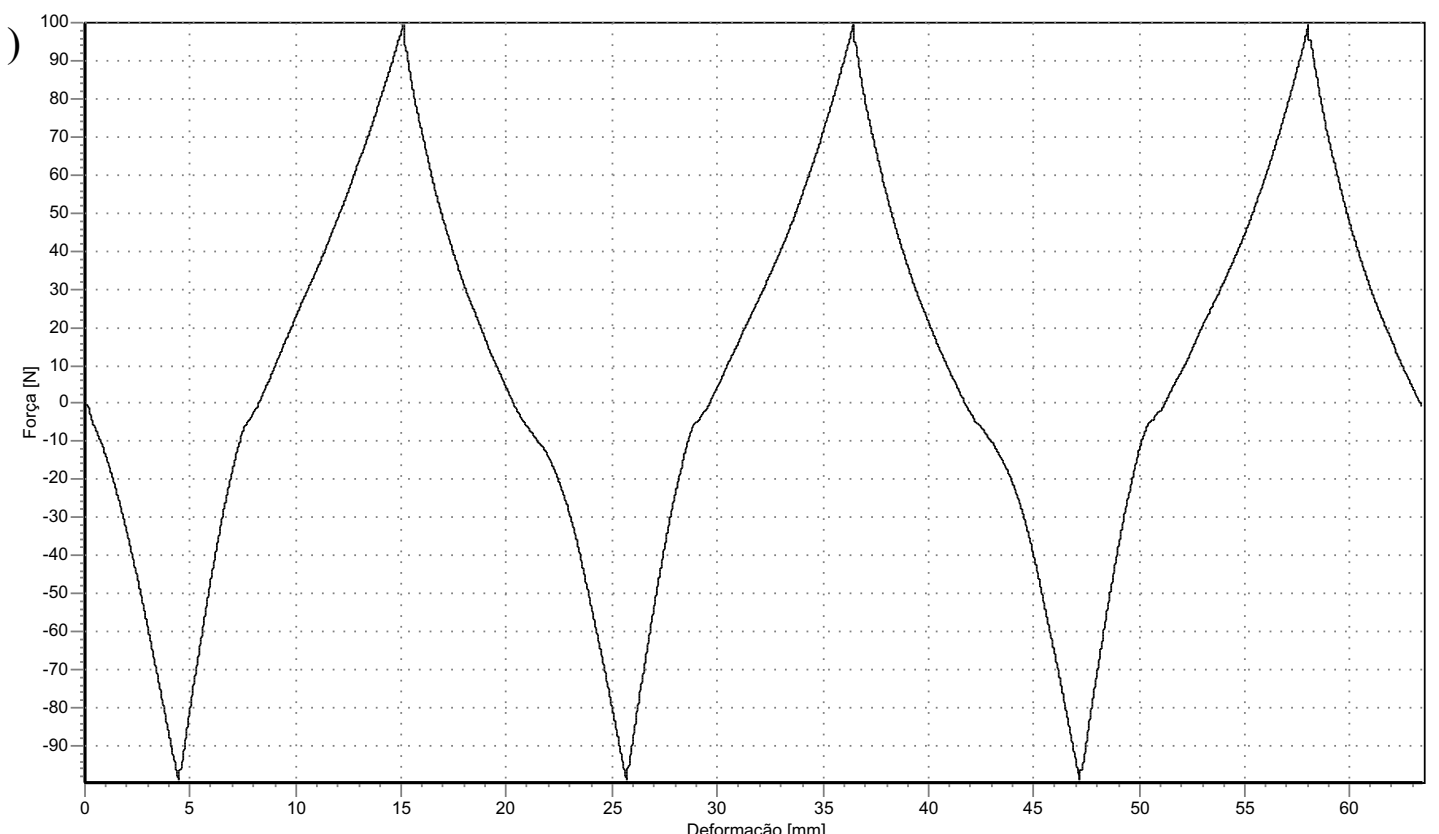

Tabela 15 - Rigidez cranial e caudal apresentadas nas diferentes situaç̃es testadas no “joelho 07” - São Paulo - 2007

\begin{tabular}{ccccccc}
\hline \multicolumn{7}{c}{ RIGIDEZ (N/mm) } \\
\hline Situação & Cranial 1 & Cranial 2 & Cranial 3 & Caudal 1 & Caudal 2 & Caudal 3 \\
\hline LCCr & 29,79 & 30,20 & 30,42 & 25,63 & 25,10 & 25,08 \\
\hline RLCCr & 19,36 & 21,68 & 22,16 & 27,78 & 27,84 & 28,04 \\
\hline SFTL & 16,96 & 18,89 & 19,59 & 27,76 & 27,85 & 27,89 \\
\hline SFTLM & 19,10 & 19,79 & 19,78 & 28,82 & 28,69 & 28,54 \\
\hline LCCr: ligamento cruzado cranial íntegro; RLCCr: ligamento cruzado cranial rompido; SFTL: sutura fabelo-tibial
\end{tabular}

LCCr: ligamento cruzado cranial integro; RLCCr: ligamento cruzado cranial rompido; SFTL: sutura fabelo-tibial lateral; SFTLM: suturas fabelo-tibiais lateral e medial; $\mathrm{mm}$ : milímetro.
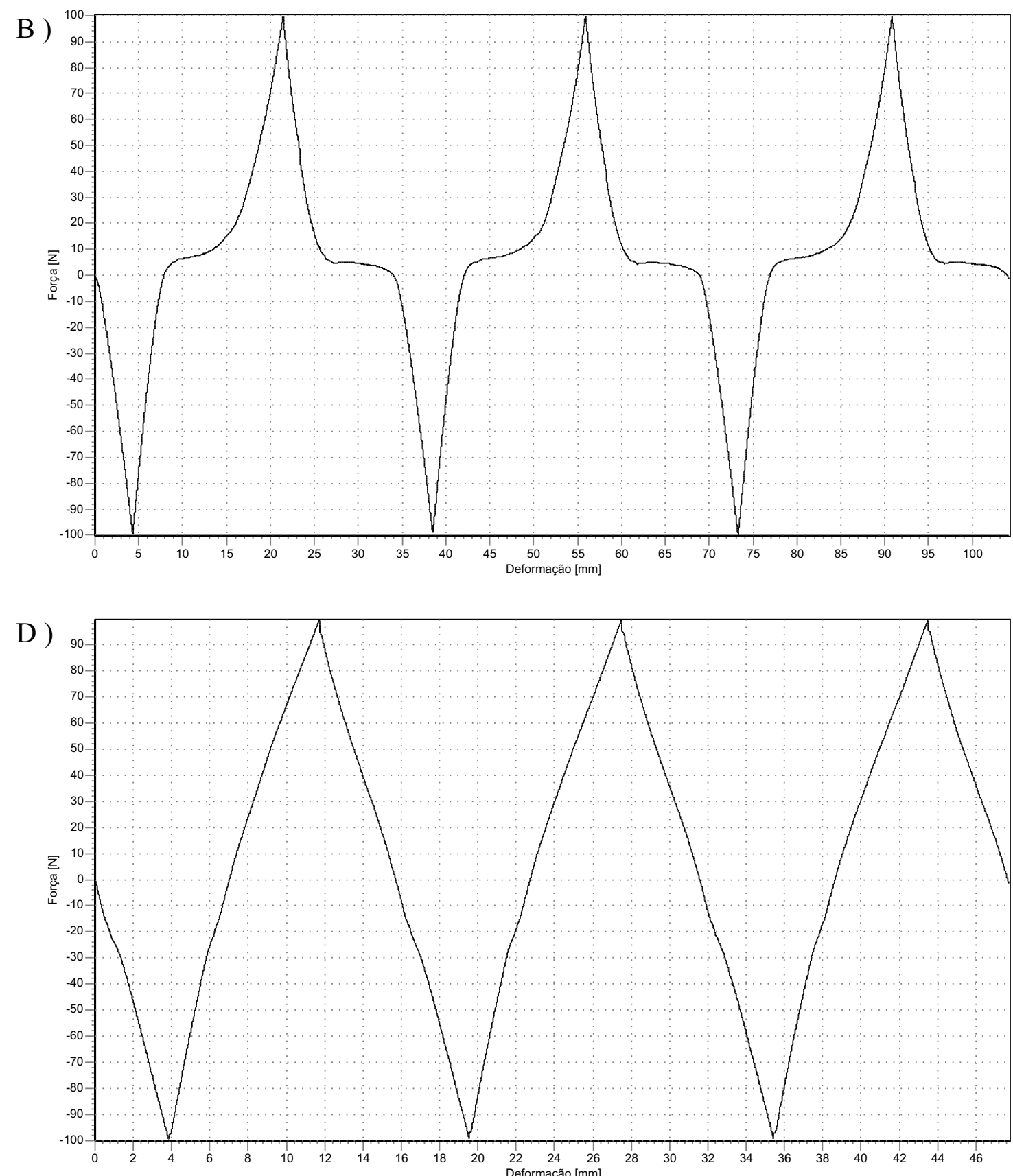

A) LCCr (ligamento íntegro); B) RLCCr (ligamento rompido); C) Joelho reparado por sutura fabelo-tibial lateral; D) Joelho reparado por suturas fabelo-tibiais lateral e medial; N: Newton; mm: milímetro.

Gráficos 8 - Ensaios biomecânicos referentes ao “joelho 07” nas diferentes situações testadas, durante os três ciclos cranio-caudais - São Paulo - 2007 
Tabela 16 - Deslocamento cranial e caudal da tíbia em relação ao fêmur após carga de 100 Newtons, nas diferentes situações testadas no “joelho 08” - São Paulo - 2007

\begin{tabular}{ccccccc}
\hline \multicolumn{7}{c}{ GAVETA (mm) } \\
\hline Situação & Cranial 1 & Cranial 2 & Cranial 3 & Caudal 1 & Caudal 2 & Caudal 3 \\
\hline LCCr & 3,67 & 3,64 & 3,66 & 4,77 & 4,80 & 4,83 \\
\hline RLCCr & 13,80 & 14,32 & 14,45 & 5,69 & 5,33 & 5,22 \\
\hline SFTL & 5,95 & 6,17 & 6,25 & 5,43 & 5,39 & 5,38 \\
\hline SFTLM & 4,13 & 4,33 & 4,51 & 4,31 & 4,29 & 4,30 \\
\hline
\end{tabular}

LCCr: ligamento cruzado cranial íntegro; RLCCr: ligamento cruzado cranial rompido; SFTL: sutura fabelo-tibial lateral; SFTLM: suturas fabelo-tibiais lateral e medial; mm: milímetro

A )

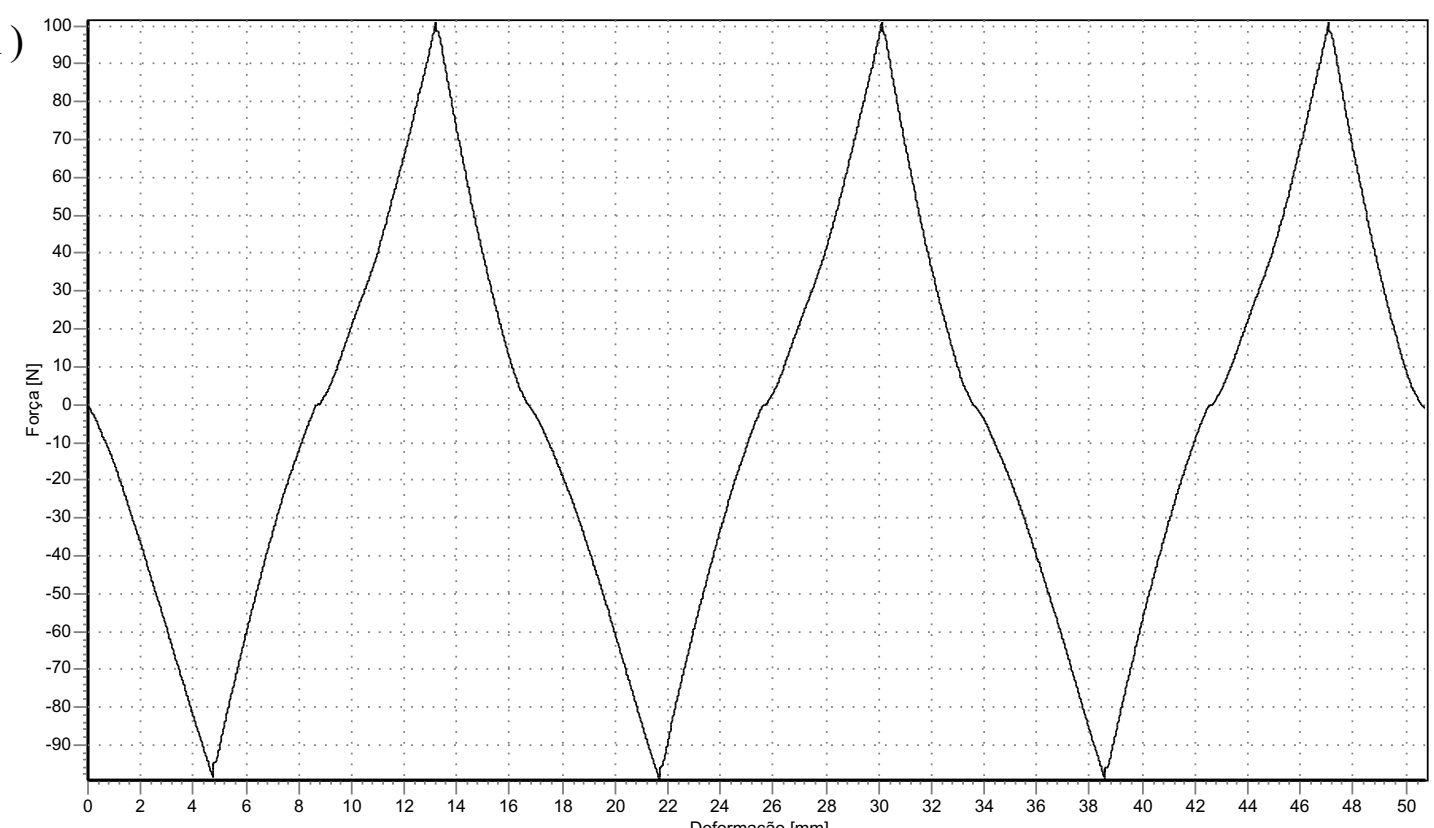

C )

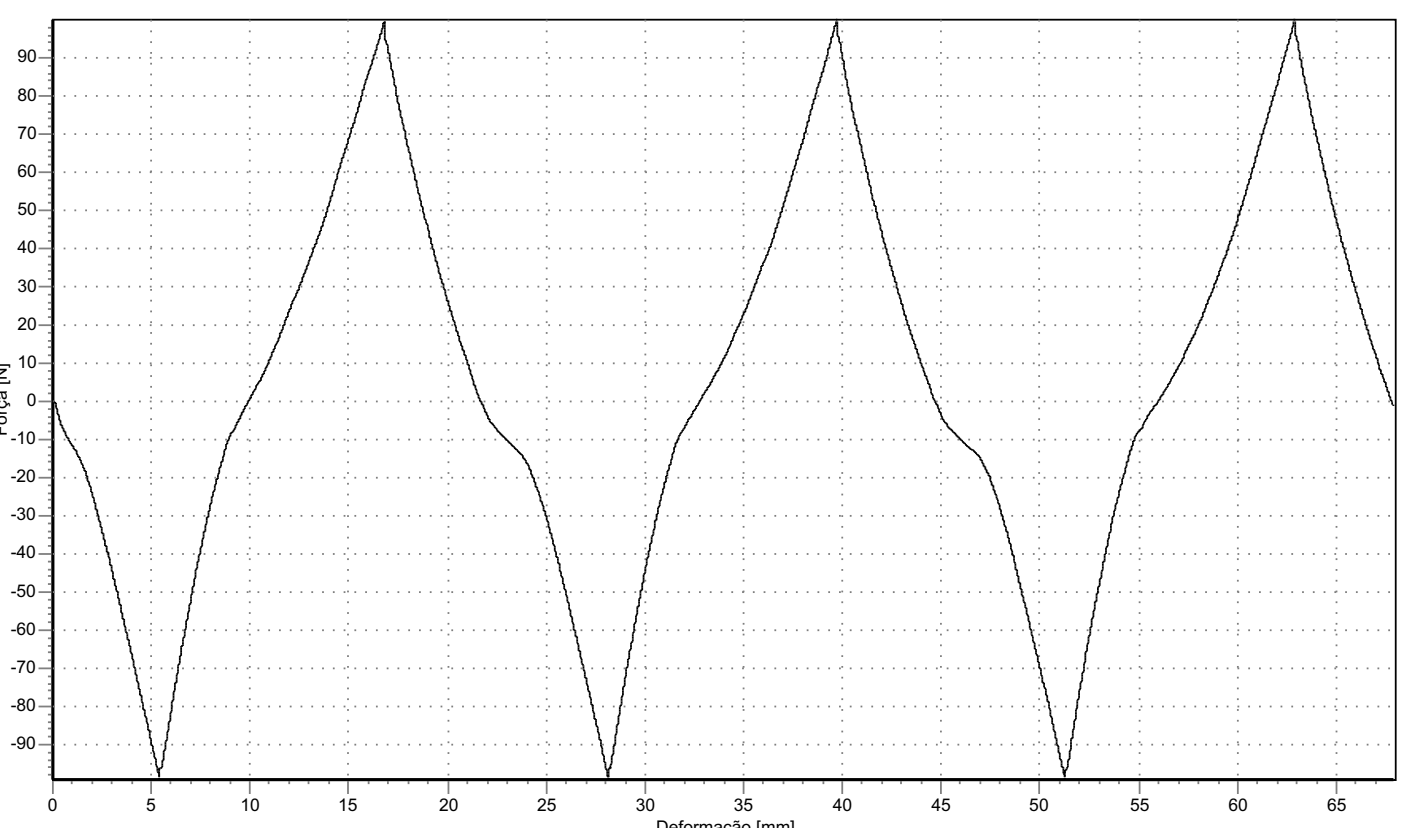

Tabela 17 - Rigidez cranial e caudal apresentadas nas diferentes situações testadas no “joelho 08”- São Paulo - 2007

\begin{tabular}{ccccccc}
\hline \multicolumn{7}{c}{ RIGIDEZ (N/mm) } \\
\hline Situação & Cranial 1 & Cranial 2 & Cranial 3 & Caudal 1 & Caudal 2 & Caudal 3 \\
\hline LCCr & 28,88 & 29,41 & 29,82 & 22,27 & 23,21 & 23,31 \\
\hline RLCCr & 23,90 & 25,57 & 25,64 & 21,74 & 22,01 & 22,17 \\
\hline SFTL & 16,92 & 18,07 & 18,30 & 22,81 & 22,65 & 22,55 \\
\hline SFTLM & 19,66 & 19,85 & 19,75 & 23,57 & 23,83 & 23,65 \\
\hline LCCr: ligamento cruzado cranial íntegro; RLCCr: ligamento cruzado cranial rompido; SFTL: sutura fabelo-tibial
\end{tabular}
lateral; SFTLM: suturas fabelo-tibiais lateral e medial; mm: milímetro
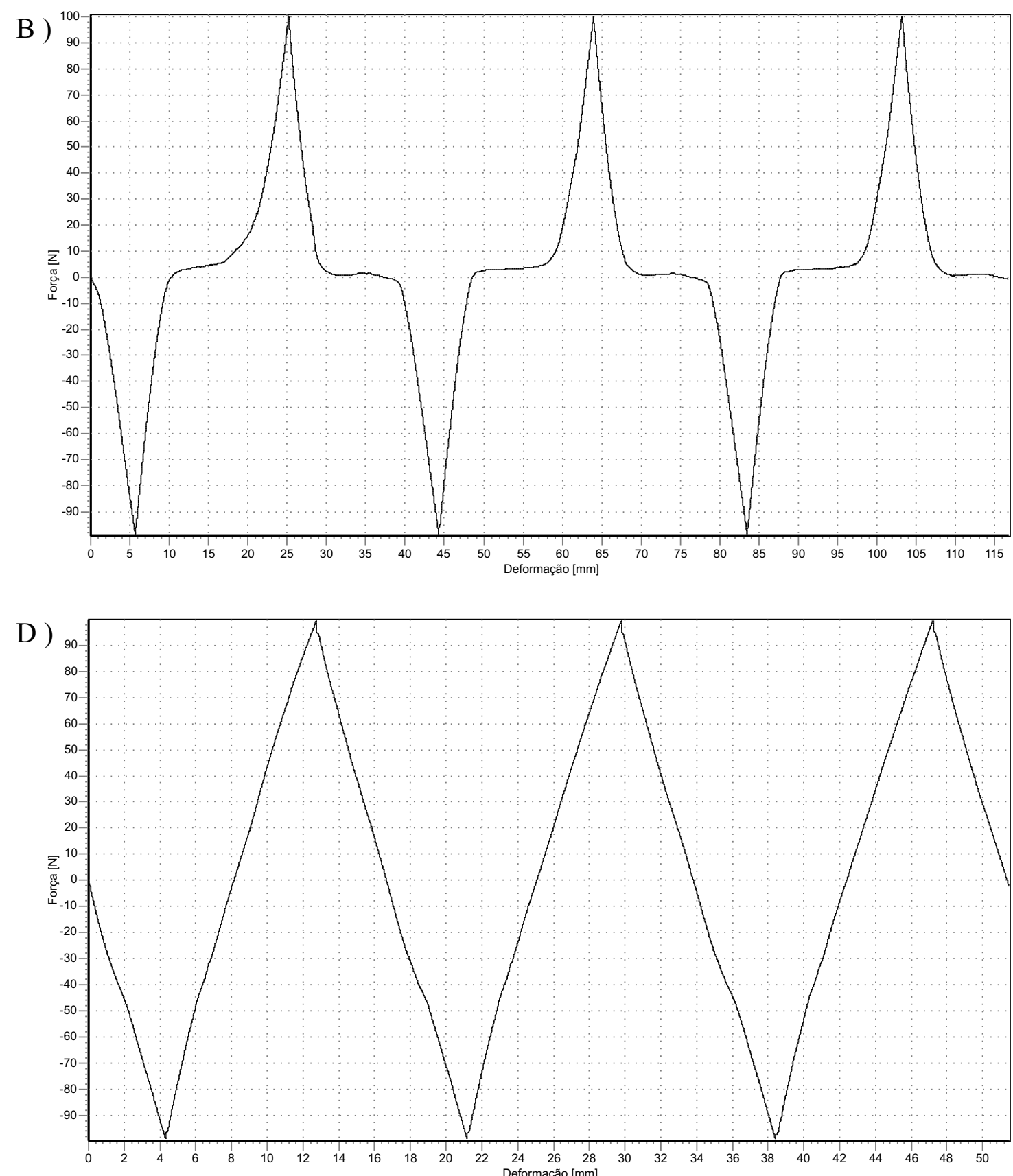

A) LCCr (ligamento íntegro); B) RLCCr (ligamento rompido); C) Joelho reparado por sutura fabelo-tibial lateral; D) Joelho reparado por suturas fabelo-tibiais lateral e medial; N: Newton; mm: milímetro.

Gráficos 9 - Ensaios biomecânicos referentes ao "joelho 08” nas diferentes situações testadas, durante os três ciclos cranio-caudais - São Paulo - 2007 
Tabela 18 - Deslocamento cranial e caudal da tíbia em relação ao fêmur após carga de 100 Newtons, nas diferentes situações testadas no “joelho 09” - São Paulo - 2007

\begin{tabular}{ccccccc}
\hline \multicolumn{7}{c}{ GAVETA ( mm) } \\
\hline Situação & Cranial 1 & Cranial 2 & Cranial 3 & Caudal 1 & Caudal 2 & Caudal 3 \\
\hline LCCr & 3,16 & 3,21 & 3,23 & 4,01 & 4,10 & 4,21 \\
\hline RLCCr & 11,20 & 11,38 & 11,45 & 4,33 & 4,33 & 4,29 \\
\hline SFTL & 5,09 & 5,31 & 5,43 & 4,20 & 4,16 & 4,14 \\
\hline SFTLM & 3,04 & 3,10 & 3,16 & 3,18 & 3,18 & 3,18 \\
\hline LCCr: ligamento cruzado cranial integro; RLCCr: ligamento cruzado cranial rompido; SFTL: sutura fabelo-tibial
\end{tabular}

LCCr: ligamento cruzado cranial íntegro; RLCCr: ligamento cruzado cranial rompido; SFTL: sutura fabelo-tibial lateral; SFTLM: suturas fabelo-tibiais lateral e medial; mm: milímetro.

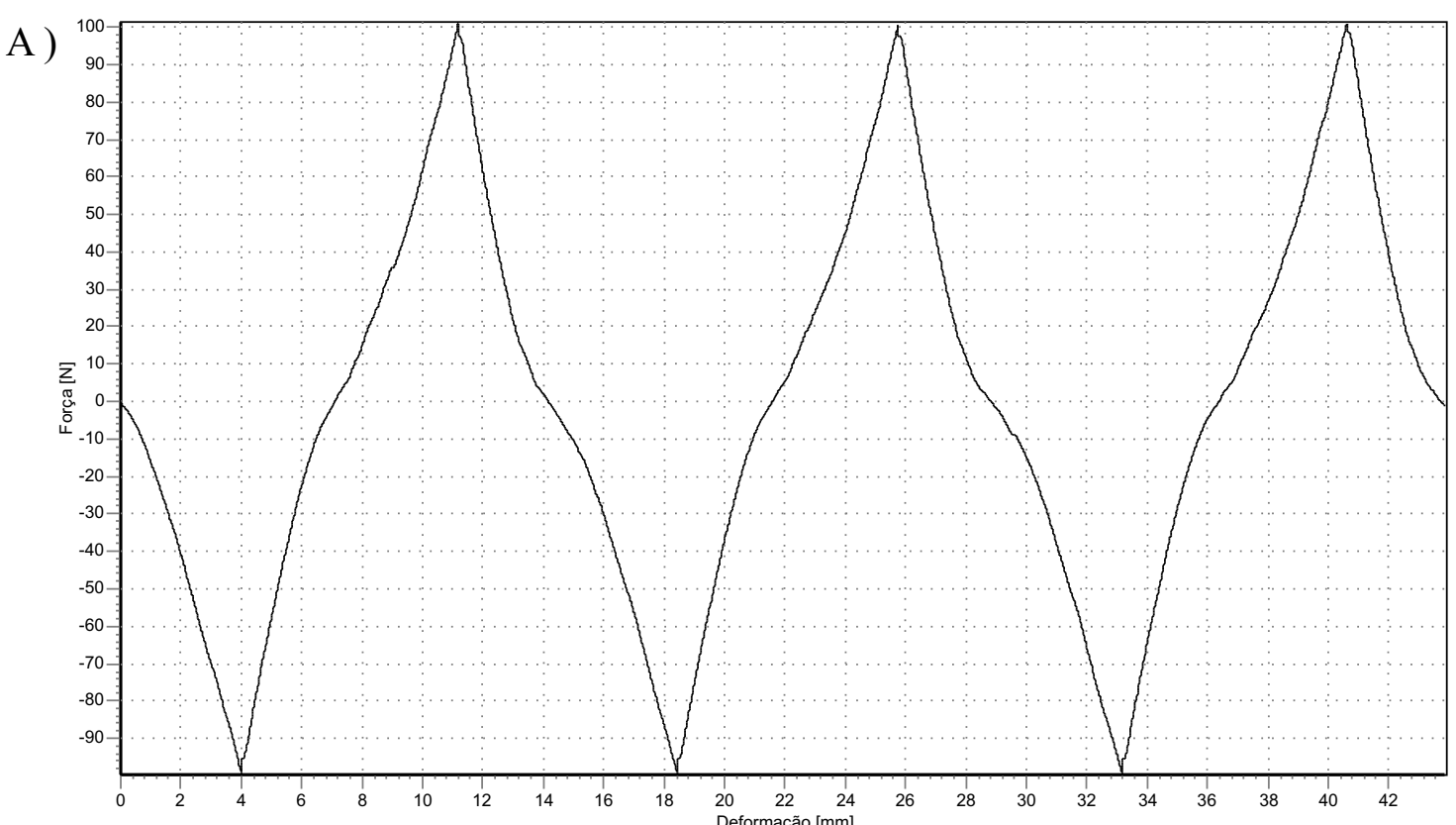

C)

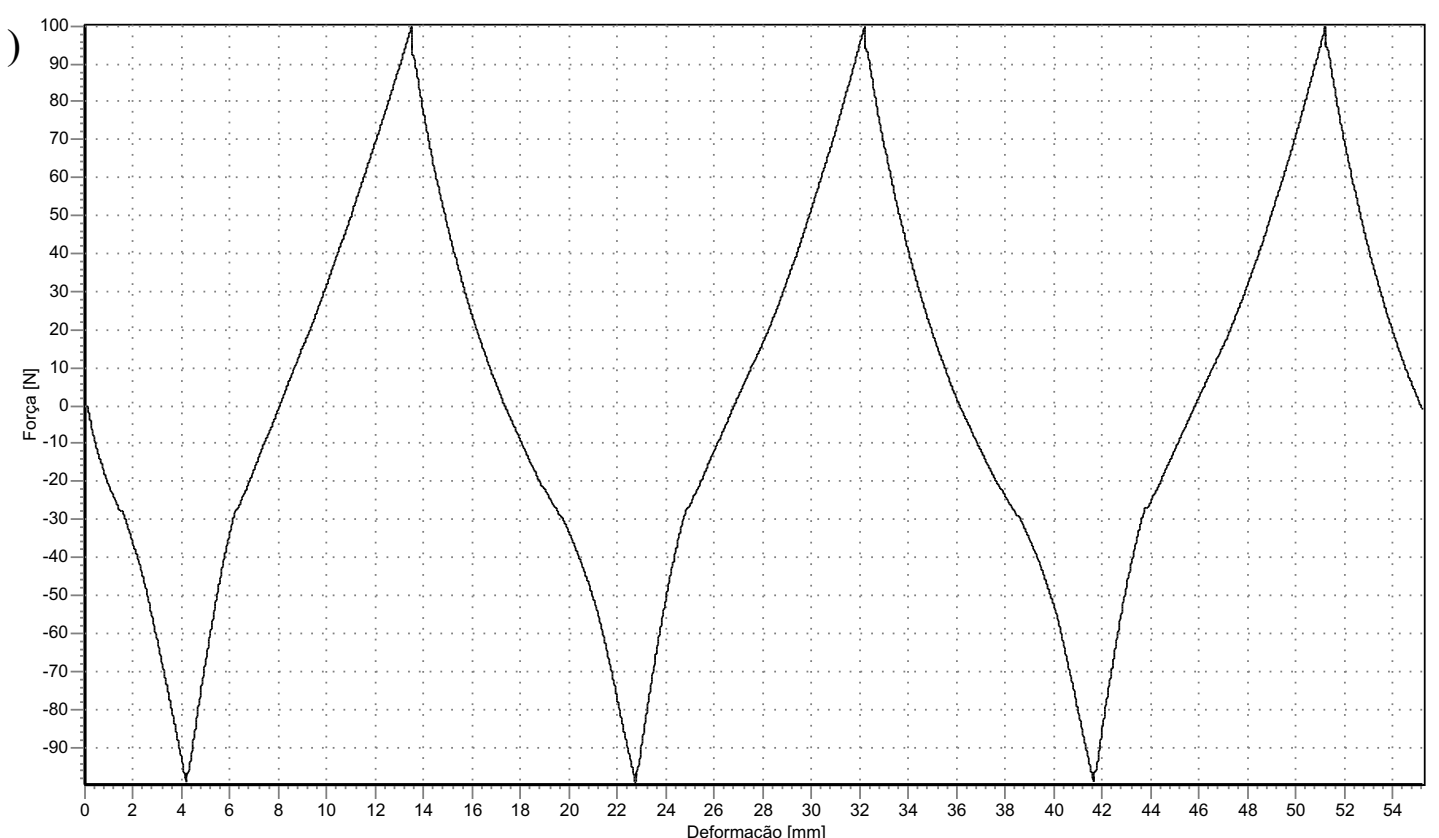

Tabela 19 - Rigidez cranial e caudal apresentadas nas diferentes situações testadas no “joelho 09" - São Paulo - 2007

\begin{tabular}{ccccccc}
\hline \multicolumn{7}{c}{ RIGIDEZ (N/mm) } \\
\hline Situação & Cranial 1 & Cranial 2 & Cranial 3 & Caudal 1 & Caudal 2 & Caudal 3 \\
\hline LCCr & 32,31 & 32,90 & 32,20 & 28,29 & 29,84 & 28,73 \\
\hline RLCCr & 27,08 & 28,10 & 28,44 & 27,88 & 29,32 & 29,84 \\
\hline SFTL & 20,08 & 22,43 & 22,93 & 31,28 & 29,58 & 29,46 \\
\hline SFTLM & 27,49 & 28,23 & 28,26 & 32,10 & 30,90 & 31,16 \\
\hline LCCr: ligamento cruzado cranial íntegro; RLCCr: ligamento cruzado cranial rompido; SFTL: sutura fabelo-tibial
\end{tabular}

LCCr: ligamento cruzado cranial íntegro; RLCCr: ligamento cruzado cranial rompido; SFTL: sutura fabelo-tibial lateral; SFTLM: suturas fabelo-tibiais lateral e medial; $\mathrm{mm}$ : milimetro.
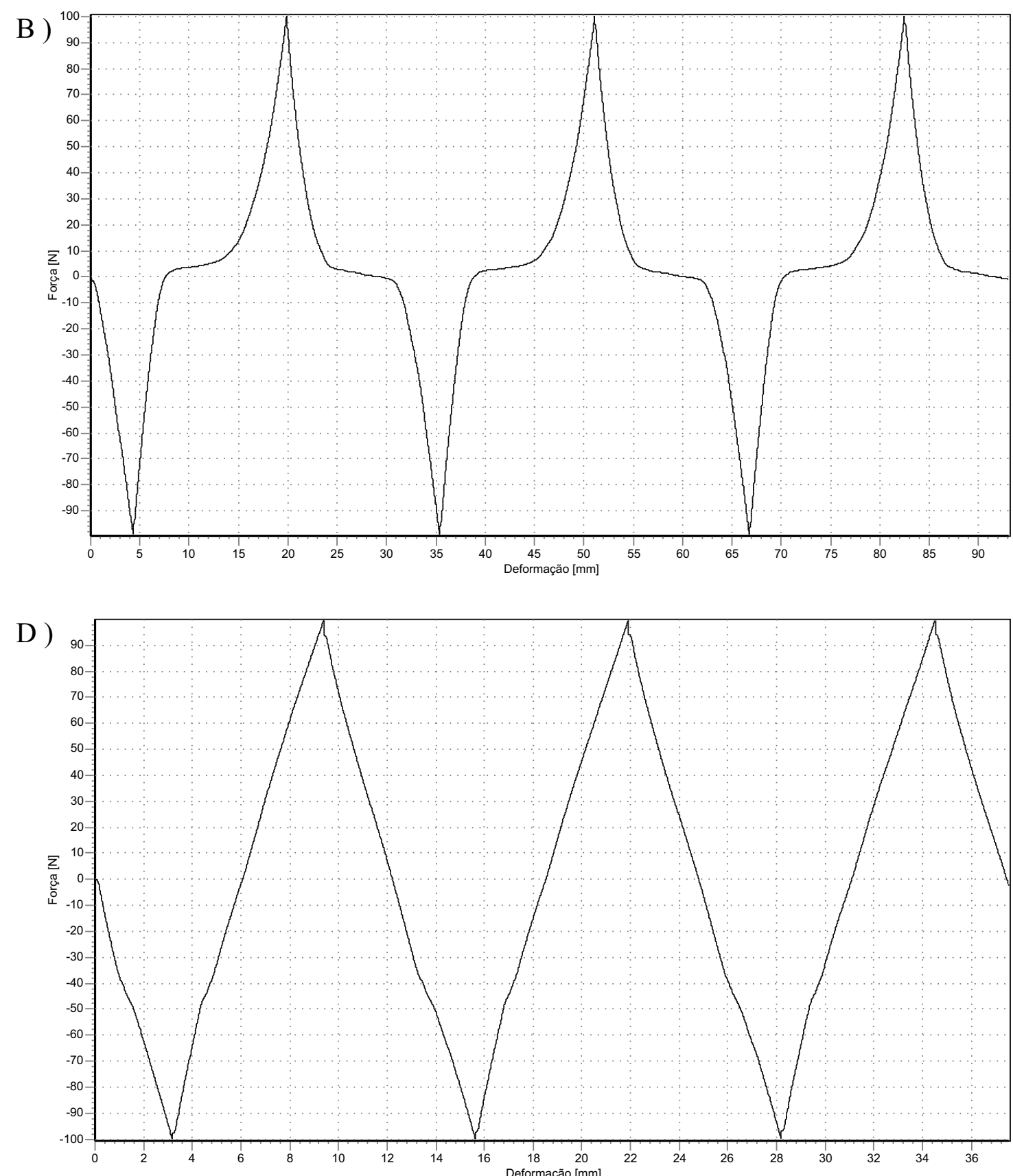

A) LCCr (ligamento íntegro); B) RLCCr (ligamento rompido); C) Joelho reparado por sutura fabelo-tibial lateral; D) Joelho reparado por suturas fabelo-tibiais lateral e medial; N: Newton; mm: milímetro.

Gráficos 10 - Ensaios biomecânicos referentes ao "joelho 09” nas diferentes situações testadas, durante os três ciclos cranio-caudais - São Paulo - 2007 
Tabela 20 - Deslocamento cranial e caudal da tíbia em relação ao fêmur após carga de 100 Newtons, nas diferentes situações testadas no "joelho 10" - São Paulo - 2007

\begin{tabular}{ccccccc}
\hline \multicolumn{7}{c}{ GAVETA (mm) } \\
\hline Situação & Cranial 1 & Cranial 2 & Cranial 3 & Caudal 1 & Caudal 2 & Caudal 3 \\
\hline LCCr & 4,41 & 4,22 & 4,27 & 3,86 & 3,41 & 3,66 \\
\hline RLCCr & 13,47 & 13,95 & 14,12 & 4,28 & 4,41 & 4,41 \\
\hline SFTL & 5,82 & 6,09 & 6,23 & 4,03 & 4,05 & 4,12 \\
\hline SFTLM & 4,32 & 4,62 & 4,78 & 3,06 & 2,93 & 2,88 \\
\hline LCCr: ligamento cruzado cranial integro; RLCCr: ligamento cruzado cranial rompido; SFTL: sutura fabelo-tibial
\end{tabular}

LCCr: ligamento cruzado cranial íntegro; RLCCr: ligamento cruzado cranial rompido; SFTL: sutura fabelo-tibia lateral; SFTLM: suturas fabelo-tibiais lateral e medial; mm: milímetro.

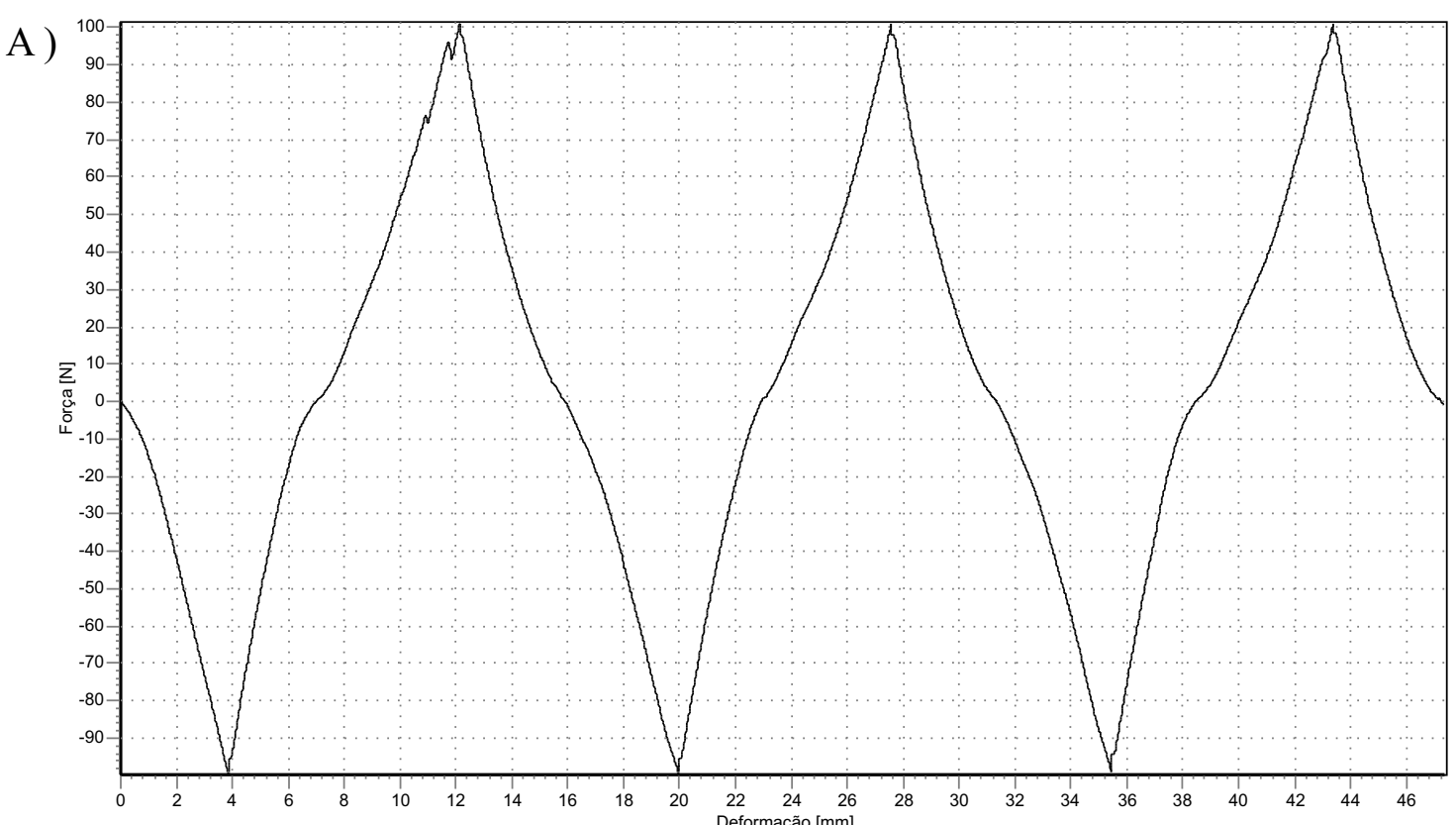

C

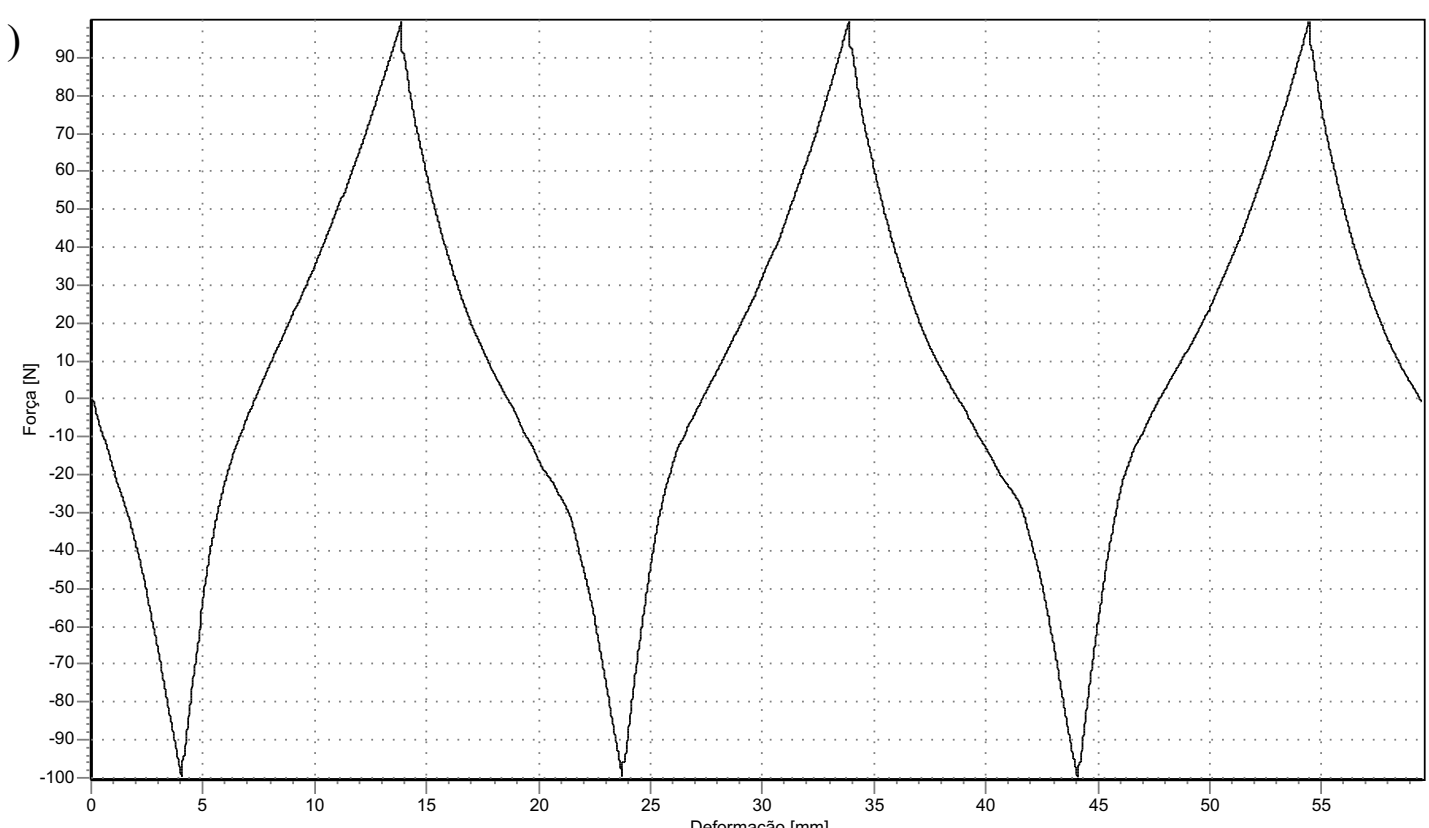

Tabela 21 - Rigidez cranial e caudal apresentadas nas diferentes situações testadas no “joelho 10" - São Paulo - 2007

\begin{tabular}{ccccccc}
\hline \multicolumn{7}{c}{ RIGIDEZ (N/mm) } \\
\hline Situação & Cranial 1 & Cranial 2 & Cranial 3 & Caudal 1 & Caudal 2 & Caudal 3 \\
\hline LCCr & 21,50 & 30,37 & 27,27 & 30,99 & 28,83 & 29,00 \\
\hline RLCCr & 18,99 & 23,23 & 24,46 & 30,82 & 29,70 & 30,94 \\
\hline SFTL & 17,97 & 19,45 & 19,72 & 31,99 & 33,66 & 33,08 \\
\hline SFTLM & 19,70 & 22,76 & 23,69 & 32,53 & 27,36 & 27,28 \\
\hline LCCr: ligamento cruzado cranial íntegro; RLCCr: ligamento cruzado cranial rompido; SFTL: sutura fabelo-tibial
\end{tabular}

LCCr: ligamento cruzado cranial integro; RLCCr: ligamento cruzado cranial rompido; SFTL: sutura fabelo-tibial lateral; SFTLM: suturas fabelo-tibiais lateral e medial; mm: milimetro.
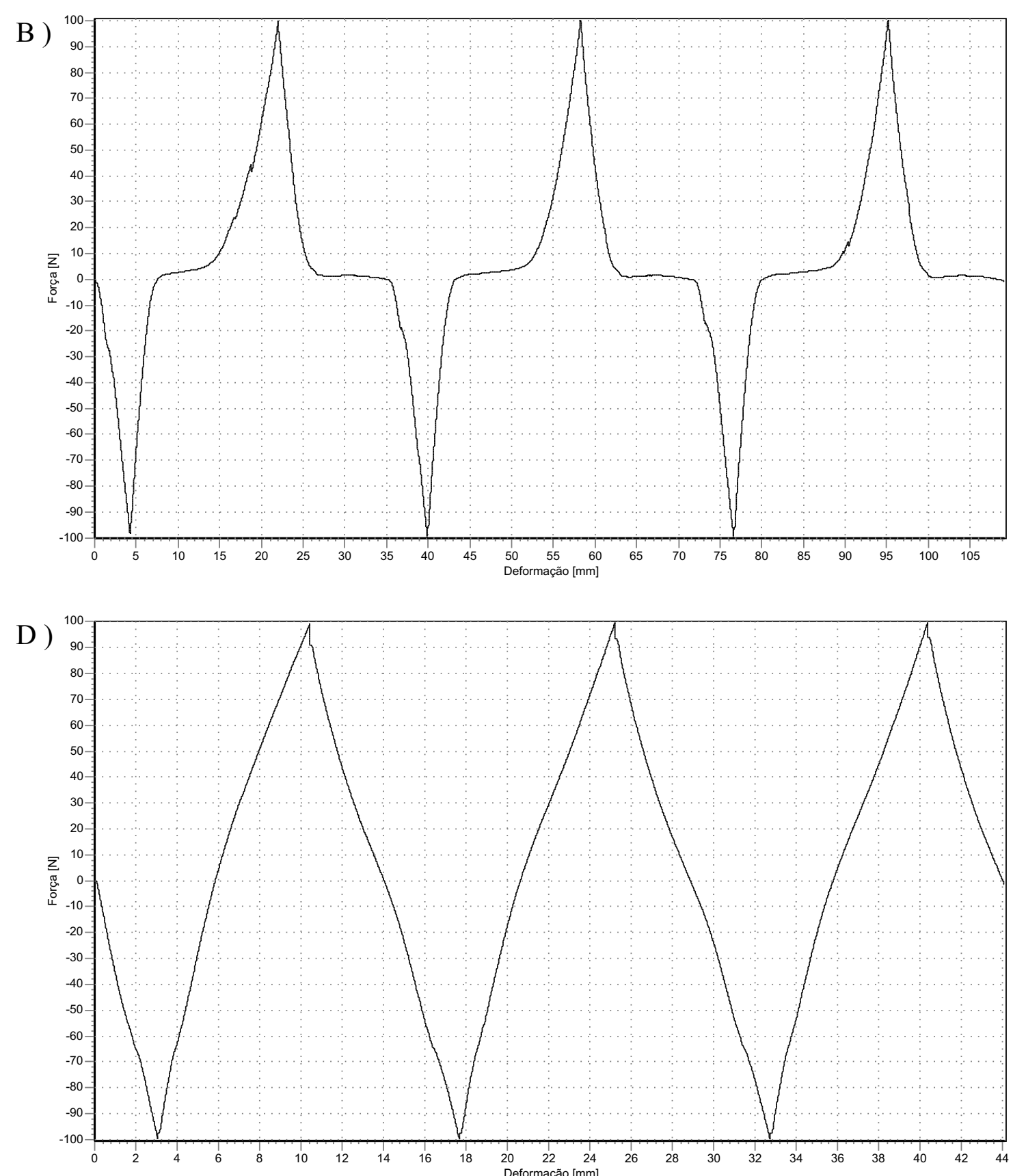

A) LCCr (ligamento íntegro); B) RLCCr (ligamento rompido); C) Joelho reparado por sutura fabelo-tibial lateral; D) Joelho reparado por suturas fabelo-tibiais lateral e medial; N: Newton; mm: milímetro.

Gráficos 11 - Ensaios biomecânicos referentes ao "joelho 10" nas diferentes situações testadas, durante os três ciclos cranio-caudais - São Paulo - 2007 
Tabela 22 - Deslocamento cranial e caudal da tíbia em relação ao fêmur após carga de 100 Newtons, nas diferentes situações testadas no "joelho 11" - São Paulo - 2007

\begin{tabular}{ccccccc}
\hline \multicolumn{7}{c}{ GAVETA $(\mathbf{m m})$} \\
\hline Situação & Cranial 1 & Cranial 2 & Cranial 3 & Caudal 1 & Caudal 2 & Caudal 3 \\
\hline LCCr & 3,36 & 3,46 & 3,52 & 3,13 & 2,98 & 2,95 \\
\hline RLCCr & 11,94 & 11,92 & 11,84 & 3,57 & 3,39 & 3,34 \\
\hline SFTL & 5,73 & 6,03 & 6,14 & 3,94 & 3,90 & 3,94 \\
\hline SFTLM & 3,78 & 4,08 & 4,29 & 2,76 & 2,65 & 2,62 \\
\hline
\end{tabular}

LCCr: ligamento cruzado cranial íntegro; RLCCr: ligamento cruzado cranial rompido; SFTL: sutura fabelo-tibial lateral; SFTLM: suturas fabelo-tibiais lateral e medial; mm: milímetro,
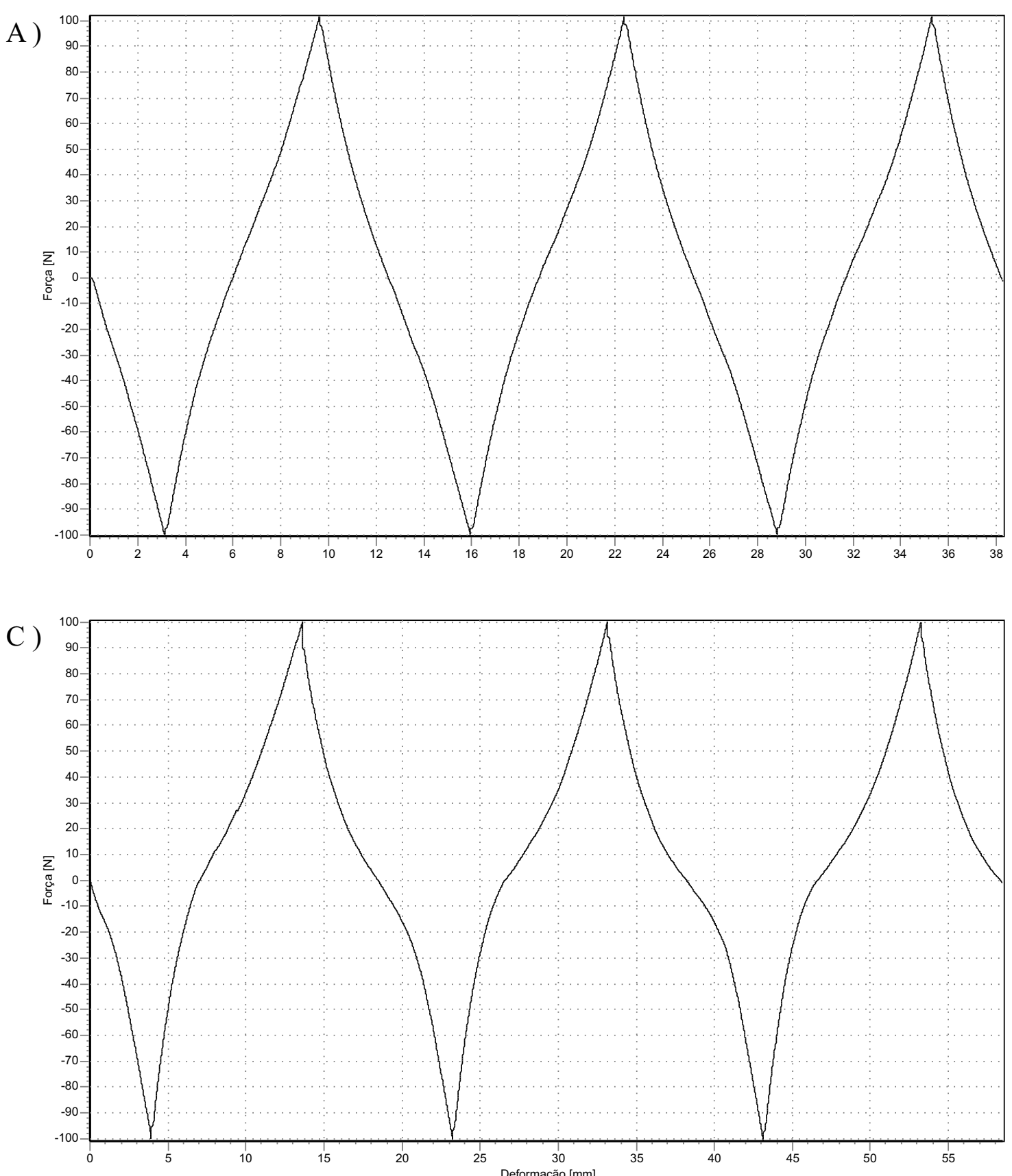

Tabela 23 - Rigidez cranial e caudal apresentadas nas diferentes situaçoes testadas no “joelho 11"-São Paulo - 2007

\begin{tabular}{ccccccc}
\hline \multicolumn{7}{c}{ RIGIDEZ (N/mm) } \\
\hline Situação & Cranial 1 & Cranial 2 & Cranial 3 & Caudal 1 & Caudal 2 & Caudal 3 \\
\hline LCCr & 32,91 & 35,92 & 36,12 & 36,55 & 34,03 & 33,17 \\
\hline RLCCr & 27,32 & 28,37 & 28,50 & 32,22 & 33,77 & 34,03 \\
\hline SFTL & 19,83 & 22,69 & 23,04 & 33,35 & 34,10 & 34,16 \\
\hline SFTLM & 23,84 & 26,07 & 26,36 & 35,83 & 32,24 & 32,35 \\
\hline LCCr: ligamento cruzado cranial íntegro; RLCCr: ligamento cruzado cranial rompido; SFTL: sutura fabelo-tibial
\end{tabular}

lateral; SFTLM: suturas fabelo-tibiais lateral e medial; mm: milímetro
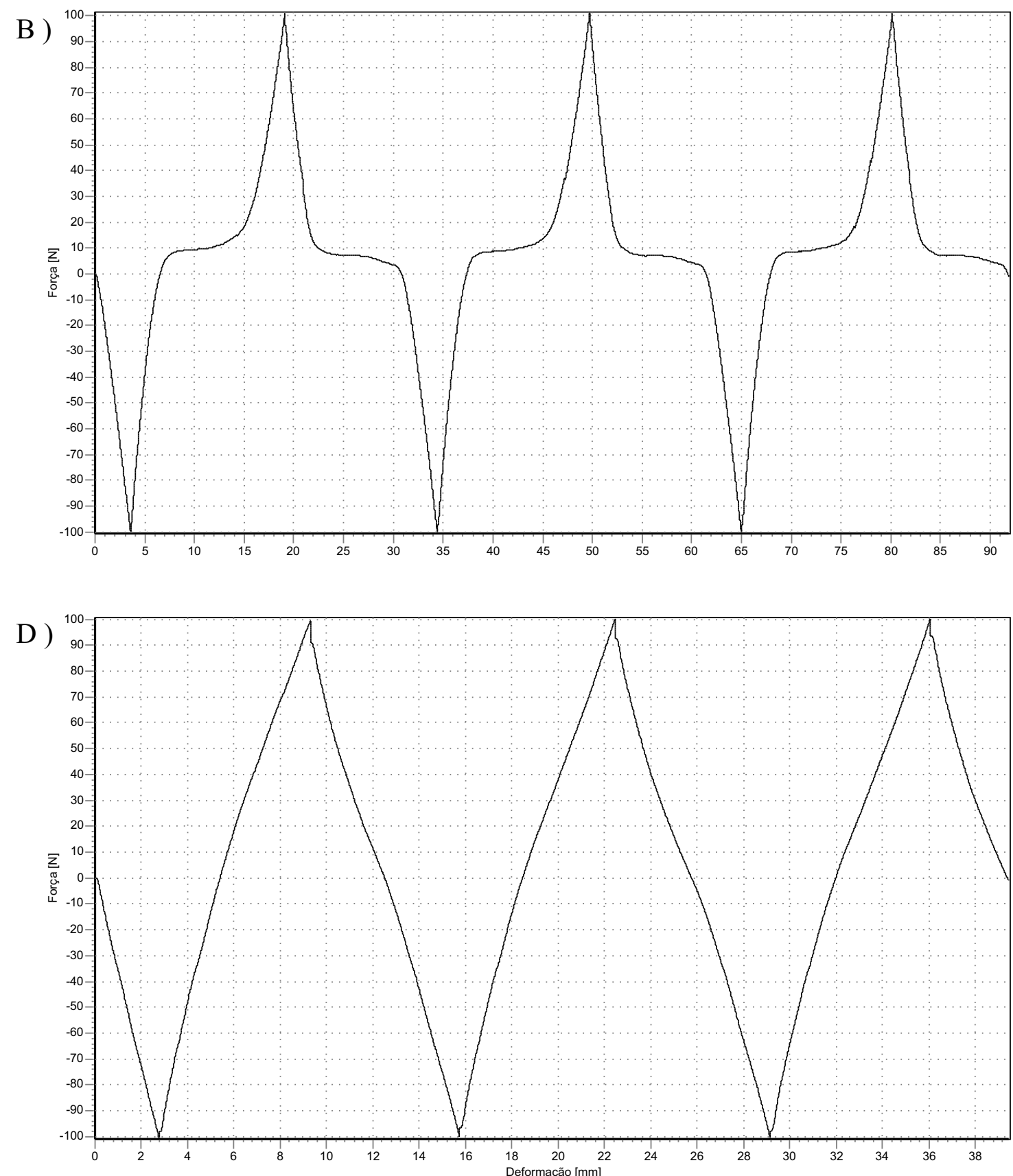

A) LCCr (ligamento íntegro); B) RLCCr (ligamento rompido); C) Joelho reparado por sutura fabelo-tibial lateral; D) Joelho reparado por suturas fabelo-tibiais lateral e medial; N: Newton; mm: milímetro.

Gráficos 12 - Ensaios biomecânicos referentes ao "joelho 11" nas diferentes situações testadas, durante os três ciclos cranio-caudais - São Paulo - 2007 
Tabela 24 - Deslocamento cranial e caudal da tíbia em relação ao fêmur após carga de 100 Newtons, nas diferentes situações testadas no "joelho 12" - São Paulo - 2007

\begin{tabular}{ccccccc}
\hline \multicolumn{7}{c}{ GAVETA ( mm) } \\
\hline Situação & Cranial 1 & Cranial 2 & Cranial 3 & Caudal 1 & Caudal 2 & Caudal 3 \\
\hline LCCr & 3,42 & 3,44 & 3,45 & 3,62 & 3,65 & 3,66 \\
\hline RLCCr & 10,86 & 11,21 & 11,27 & 4,32 & 4,26 & 4,22 \\
\hline SFTL & 5,20 & 5,40 & 5,49 & 4,08 & 4,11 & 4,14 \\
\hline SFTLM & 3,59 & 3,79 & 3,89 & 3,08 & 2,98 & 2,96 \\
\hline LCCr: ligamento cruzado cranial integro; RLCCr: ligamento cruzado cranial rompido; SFTL: sutura fabelo-tibial
\end{tabular}

LCCr: ligamento cruzado cranial íntegro; RLCCr: ligamento cruzado cranial rompido; SFTL: sutura fabelo-tibia lateral; SFTLM: suturas fabelo-tibiais lateral e medial; mm: milímetro.

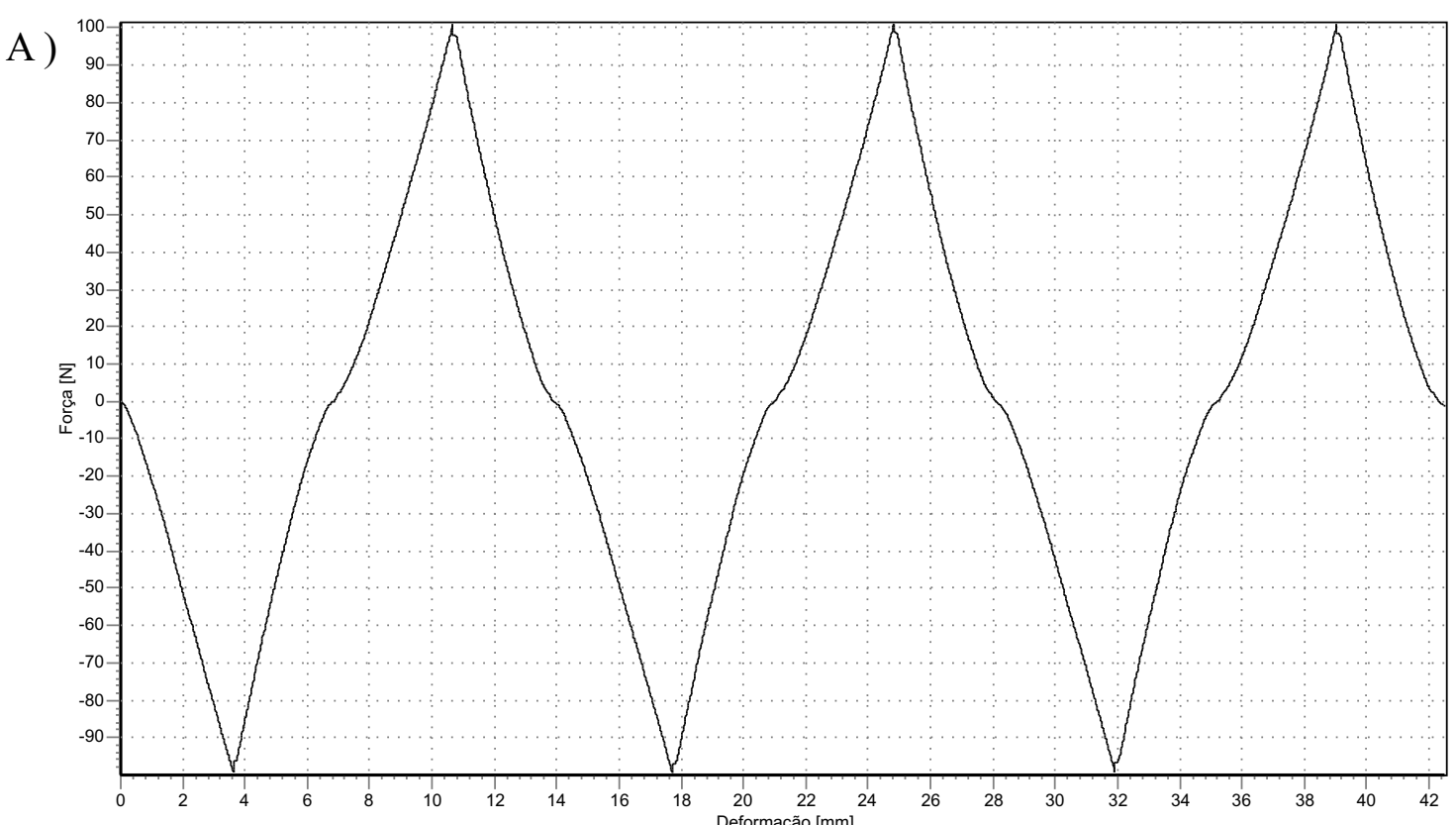

C)

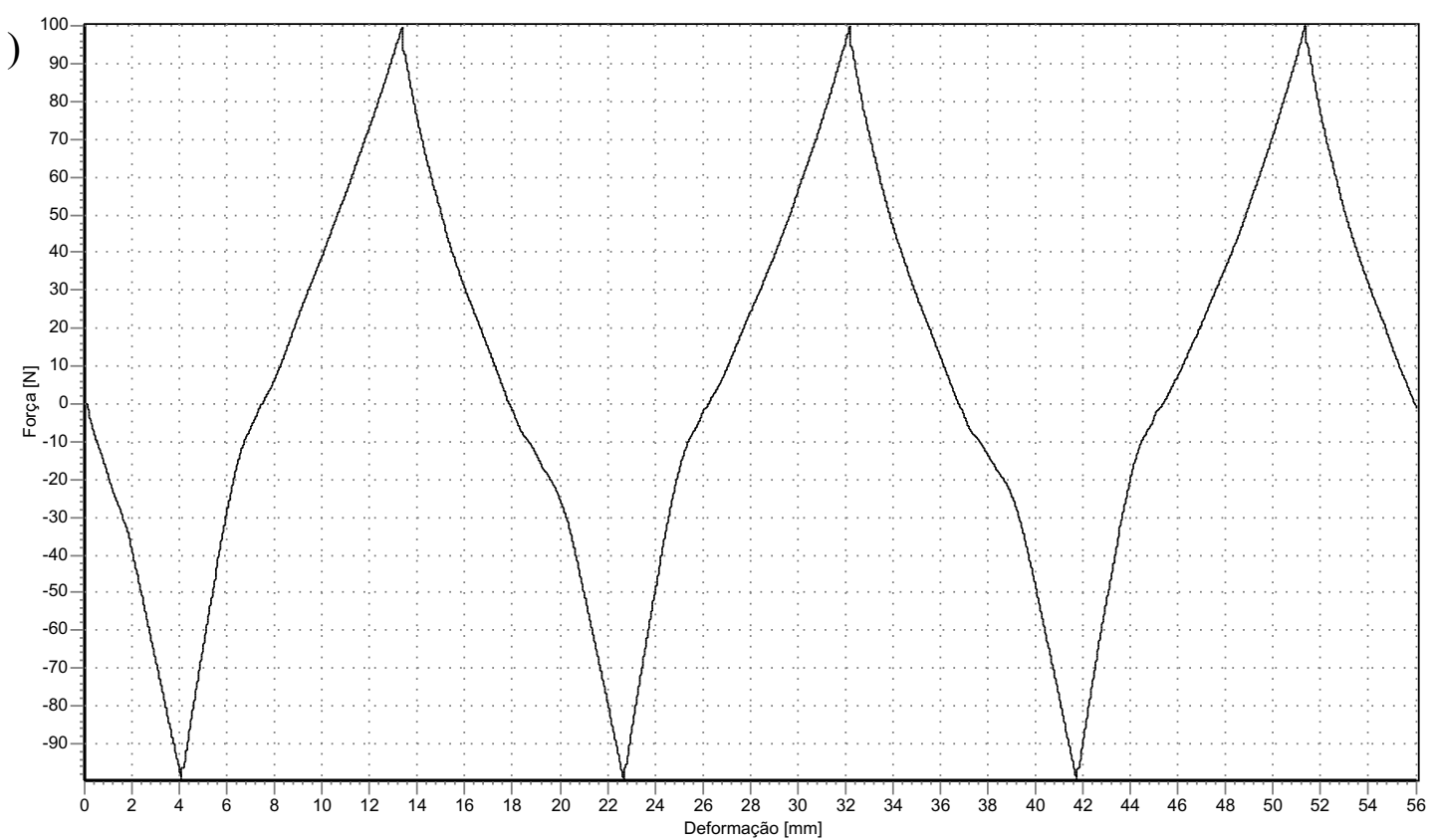

Tabela 25 - Rigidez cranial e caudal apresentadas nas diferentes situações testadas no “joelho 12”- São Paulo - 2007

\begin{tabular}{ccccccc}
\hline \multicolumn{7}{c}{ RIGIDEZ (N/mm) } \\
\hline Situação & Cranial 1 & Cranial 2 & Cranial 3 & Caudal 1 & Caudal 2 & Caudal 3 \\
\hline LCCr & 31,46 & 32,15 & 32,78 & 29,79 & 29,42 & 29,74 \\
\hline RLCCr & 25,14 & 26,81 & 27,81 & 26,64 & 28,94 & 28,86 \\
\hline SFTL & 18,67 & 20,24 & 20,66 & 29,18 & 29,89 & 29,88 \\
\hline SFTLM & 22,89 & 24,50 & 24,72 & 30,57 & 29,41 & 29,28 \\
\hline LCCr: ligamento cruzado cranial íntegro; RLCCr: ligamento cruzado cranial rompido; SFTL: sutura fabelo-tibial
\end{tabular}

LCCr: ligamento cruzado cranial íntegro; RLCCr: ligamento cruzado cranial rompido; SFTL: sutura fabelo-tibial lateral; SFTLM: suturas fabelo-tibiais lateral e medial; mm: milimetro.

B )
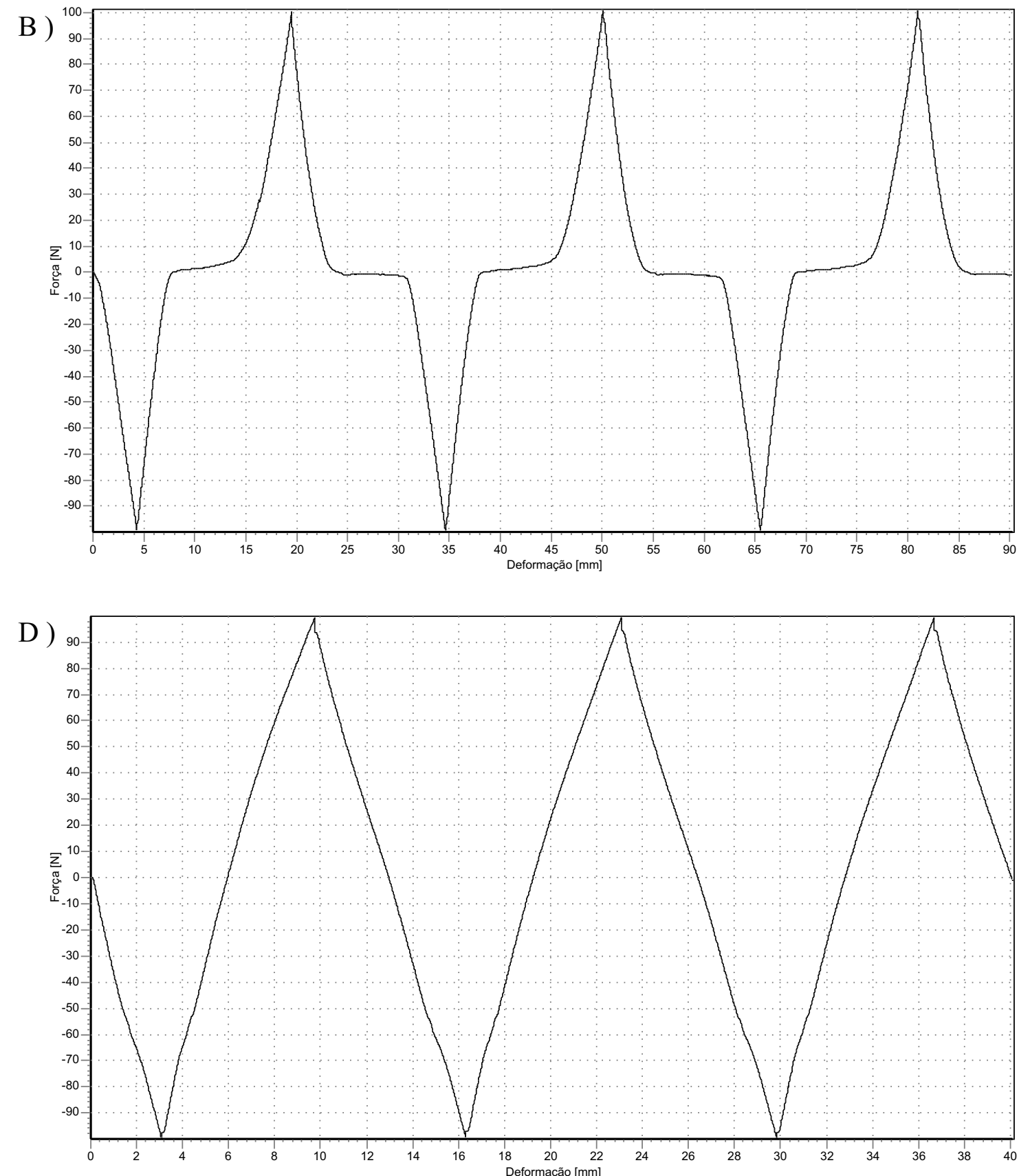

A) LCCr (ligamento íntegro); B) RLCCr (ligamento rompido); C) Joelho reparado por sutura fabelo-tibial lateral; D) Joelho reparado por suturas fabelo-tibiais lateral e medial; N: Newton; mm: milímetro.

Gráficos 13 - Ensaios biomecânicos referentes ao "joelho 12" nas diferentes situações testadas, durante os três ciclos cranio-caudais - São Paulo - 2007 
Tabela 26 - Deslocamento cranial e caudal da tíbia em relação ao fêmur após carga de 100 Newtons, nas diferentes situações testadas no "joelho 13" - São Paulo - 2007

\begin{tabular}{ccccccc}
\hline \multicolumn{7}{c}{ GAVETA (mm) } \\
\hline Situação & Cranial 1 & Cranial 2 & Cranial 3 & Caudal 1 & Caudal 2 & Caudal 3 \\
\hline LCCr & 3,33 & 3,38 & 3,41 & 4,17 & 4,23 & 4,30 \\
\hline RLCCr & 14,68 & 14,93 & 15,14 & 5,54 & 5,38 & 5,30 \\
\hline SFTL & 6,21 & 6,39 & 6,48 & 5,72 & 5,64 & 5,66 \\
\hline SFTLM & 4,67 & 5,04 & 5,27 & 3,71 & 3,61 & 3,57 \\
\hline LCCr: ligamento cruzado cranial íntegro; RLCCr: ligamento cruzado cranial rompido; SFTL: sutura fabelo-tibial
\end{tabular}

lateral; SFTLM: suturas fabelo-tibiais lateral e medial; mm: milímetro

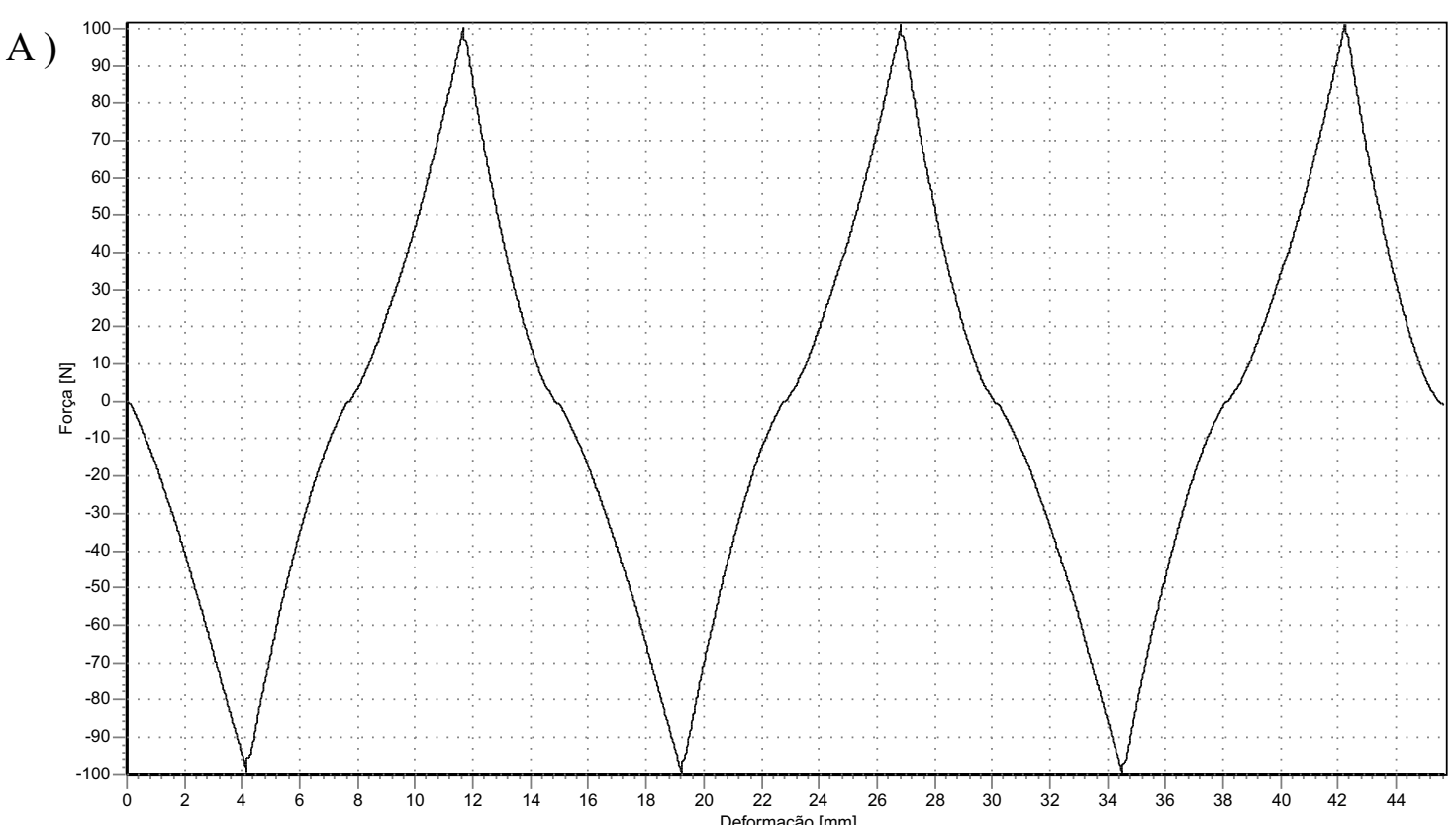

C )

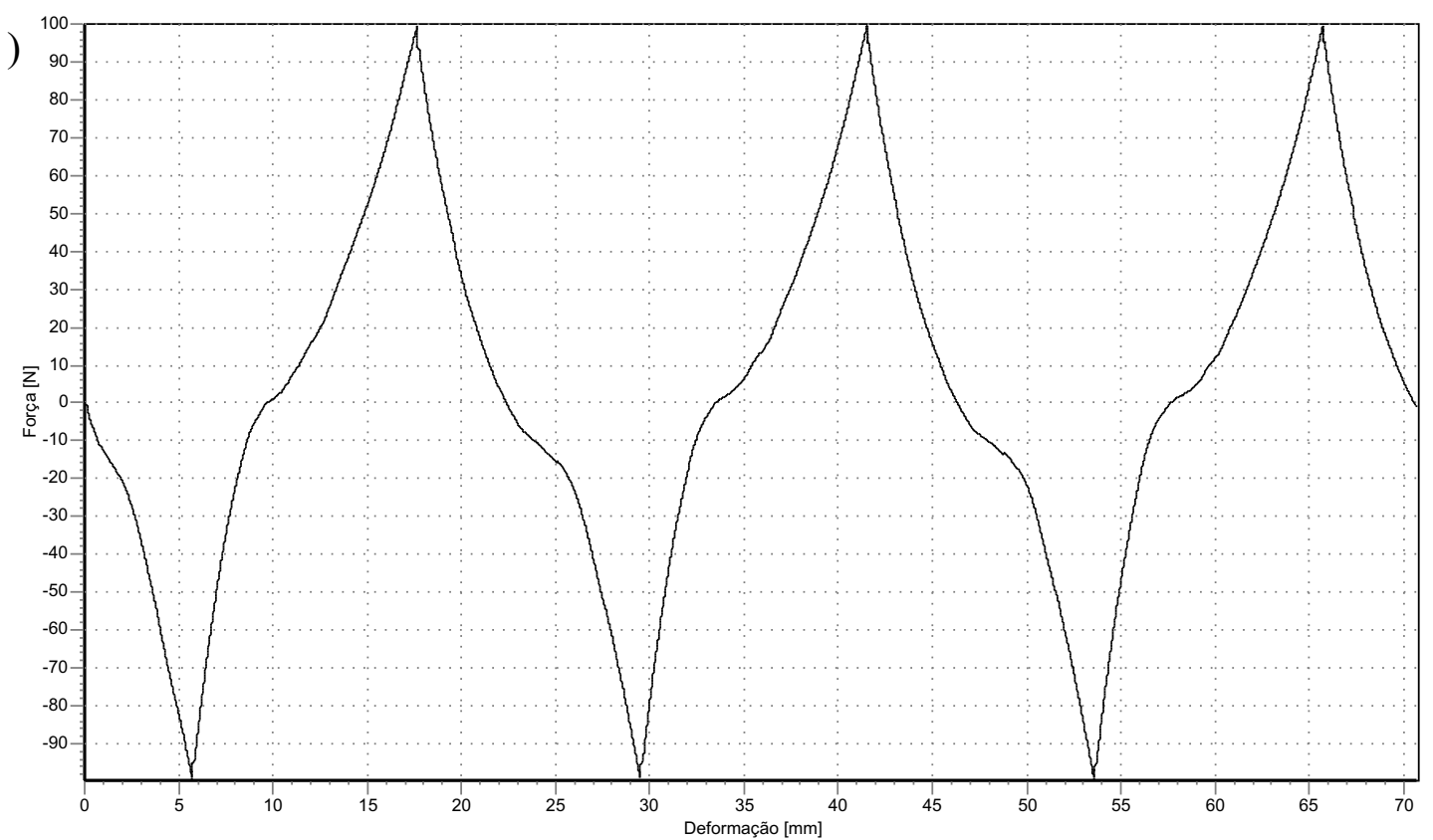

Tabela 27 - Rigidez cranial e caudal apresentadas nas diferentes situações testadas no “joelho 13" - São Paulo - 2007

\begin{tabular}{ccccccc}
\hline \multicolumn{7}{c}{ RIGIDEZ (N/mm) } \\
\hline Situação & Cranial 1 & Cranial 2 & Cranial 3 & Caudal 1 & Caudal 2 & Caudal 3 \\
\hline LCCr & 33,09 & 33,87 & 33,85 & 27,37 & 27,93 & 27,64 \\
\hline RLCCr & 21,81 & 23,02 & 23,65 & 23,02 & 24,69 & 24,69 \\
\hline SFTL & 18,76 & 20,22 & 20,47 & 22,68 & 25,02 & 25,37 \\
\hline SFTLM & 17,96 & 19,76 & 20,21 & 23,96 & 23,72 & 23,70 \\
\hline LCCr: ligamento cruzado cranial íntegro; RLCCr: ligamento cruzado cranial rompido; SFTL: sutura fabelo-tibial
\end{tabular}

LCCr: ligamento cruzado cranial íntegro; RLCCr: ligamento cruzado cranial rompido; SFTL: sutura fabelo-tibial lateral; SFTLM: suturas fabelo-tibiais lateral e medial; mm: milímetro.
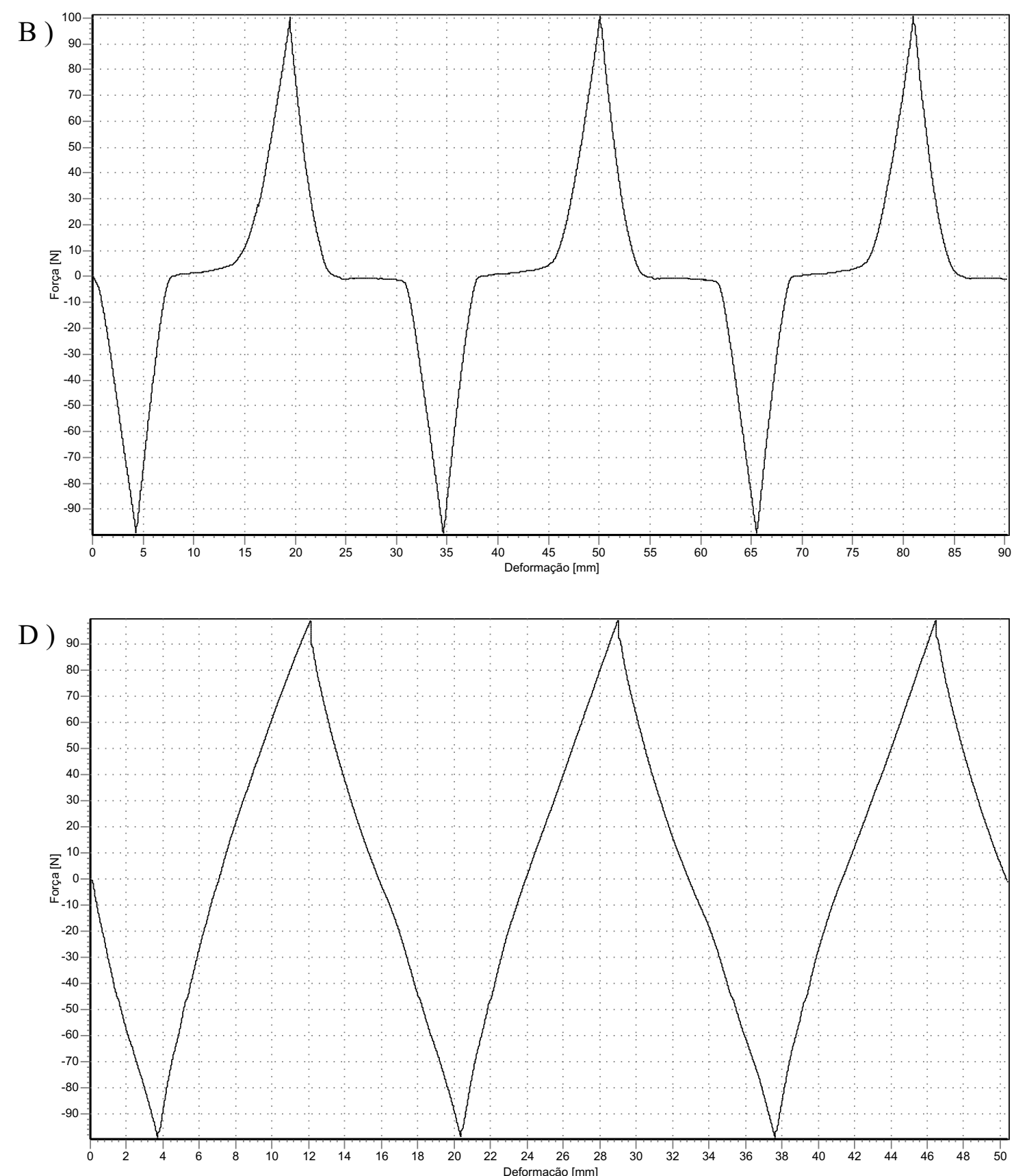

A) LCCr (ligamento íntegro); B) RLCCr (ligamento rompido); C) Joelho reparado por sutura fabelo-tibial lateral; D) Joelho reparado por suturas fabelo-tibiais lateral e medial; N: Newton; mm: milímetro.

Gráficos 14 - Ensaios biomecânicos referentes ao "joelho 13" nas diferentes situações testadas, durante os três ciclos cranio-caudais - São Paulo - 2007 
Tabela 28 - Deslocamento cranial e caudal da tíbia em relação ao fêmur após carga de 100 Newtons, nas diferentes situações testadas no "joelho 14" - São Paulo - 2007

\begin{tabular}{ccccccc}
\hline \multicolumn{7}{c}{ GAVETA (mm) } \\
\hline Situação & Cranial 1 & Cranial 2 & Cranial 3 & Caudal 1 & Caudal 2 & Caudal 3 \\
\hline LCCr & 2,84 & 2,94 & 2,95 & 3,58 & 3,65 & 3,68 \\
\hline RLCCr & 14,61 & 15,12 & 15,23 & 4,97 & 5,09 & 5,10 \\
\hline SFTL & 5,02 & 5,21 & 5,33 & 4,43 & 4,43 & 4,45 \\
\hline SFTLM & 4,20 & 4,54 & 4,75 & 3,23 & 3,14 & 3,05 \\
\hline LCCr: ligamento cruzado cranial integro; RLCCr: ligamento cruzado cranial rompido; SFTL: sutura fabelo-tibial
\end{tabular}

lateral; SFTLM: suturas fabelo-tibiais lateral e medial; mm: milímetro.

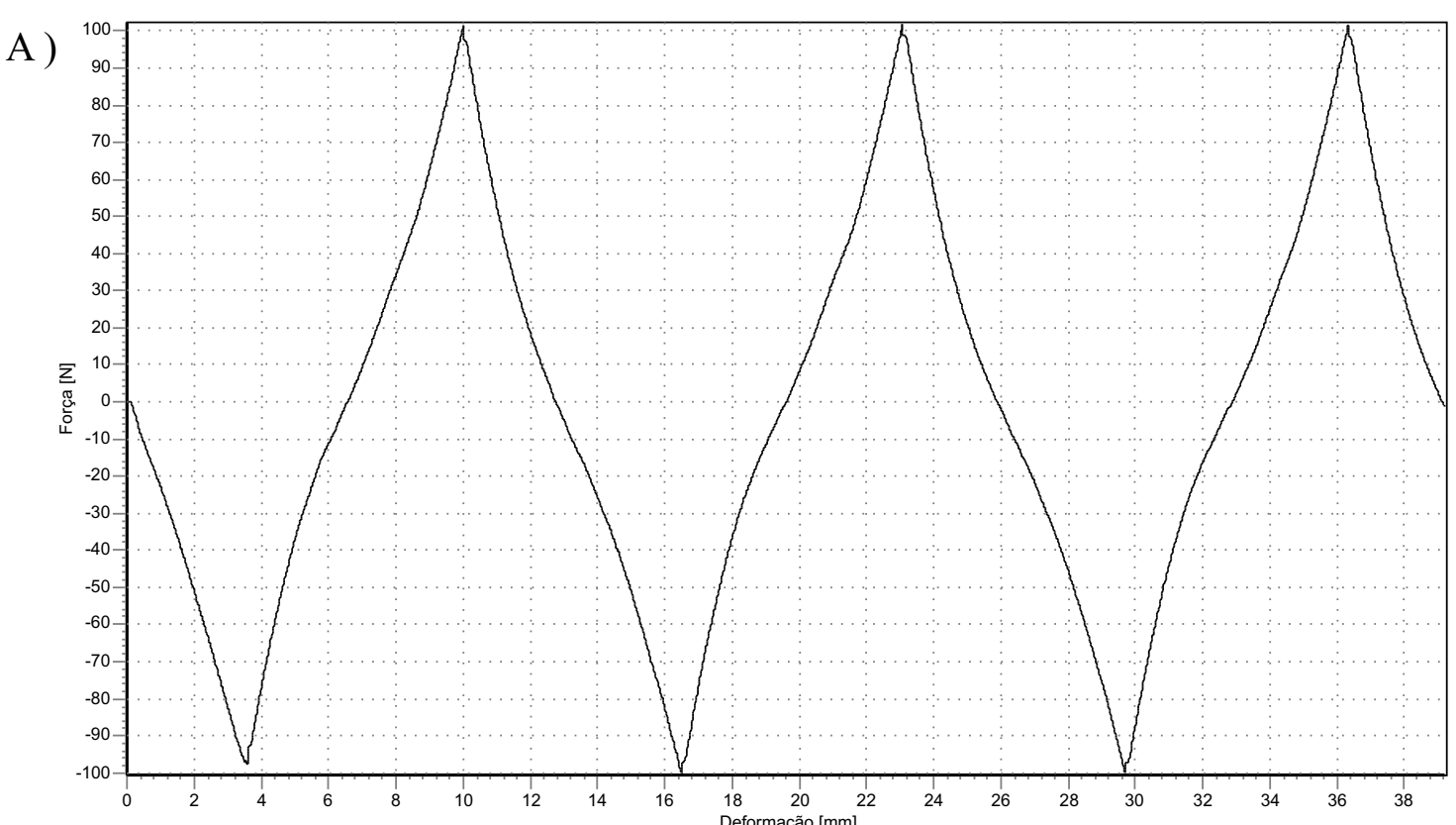

C )

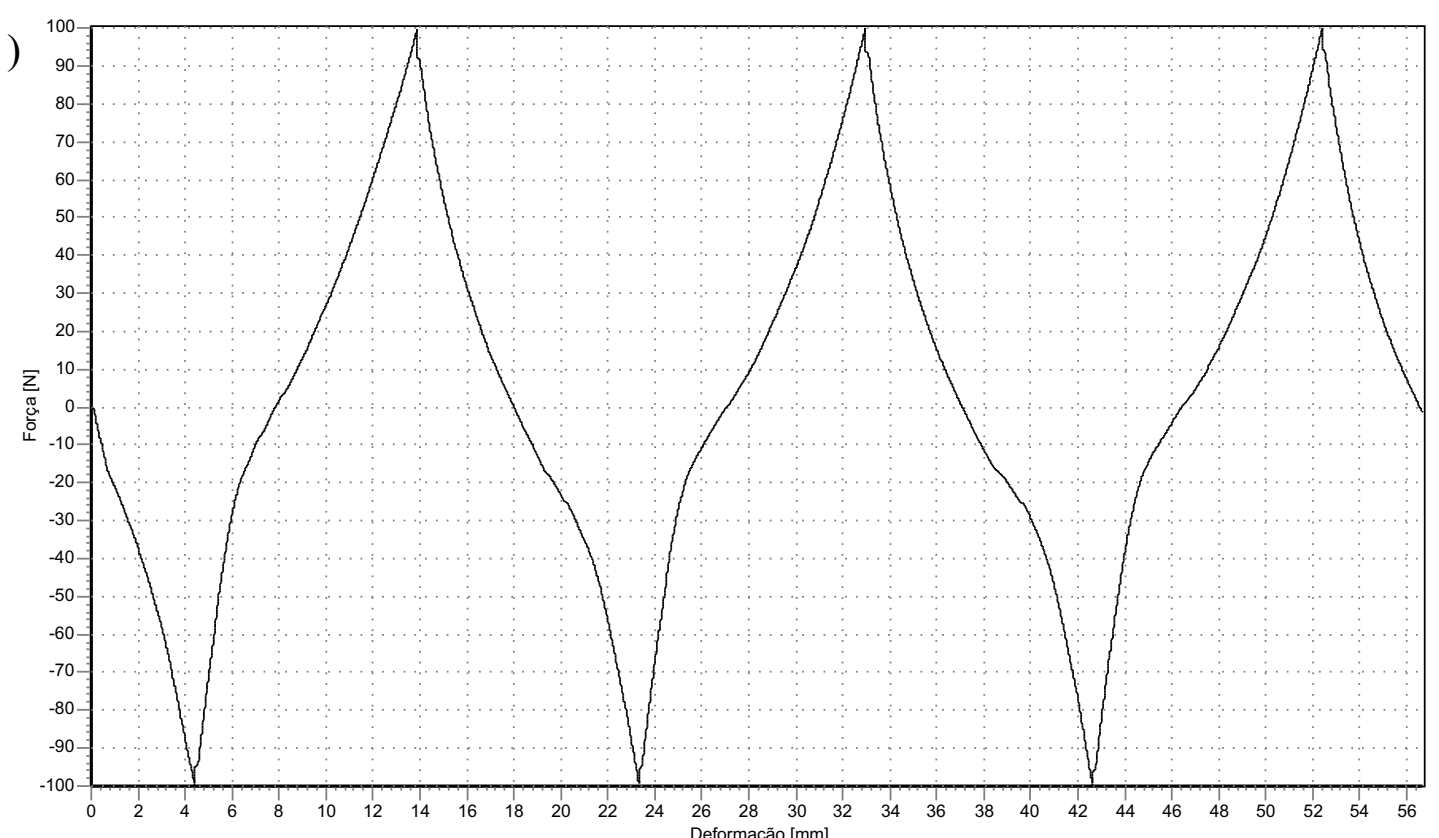

Tabela 29 - Rigidez cranial e caudal apresentadas nas diferentes situações testadas no “joelho 14" - São Paulo - 2007

\begin{tabular}{ccccccc}
\hline \multicolumn{7}{c}{ RIGIDEZ (N/mm) } \\
\hline Situação & Cranial 1 & Cranial 2 & Cranial 3 & Caudal 1 & Caudal 2 & Caudal 3 \\
\hline LCCr & 38,45 & 39,18 & 38,79 & 30,79 & 33,30 & 33,66 \\
\hline RLCCr & 25,03 & 28,69 & 28,44 & 30,74 & 28,03 & 28,87 \\
\hline SFTL & 20,78 & 23,75 & 24,48 & 30,39 & 32,65 & 34,12 \\
\hline SFTLM & 21,85 & 24,66 & 25,46 & 27,94 & 26,38 & 25,47 \\
\hline LCCr: ligamento cruzado cranial íntegro; RLCCr: ligamento cruzado cranial rompido; SFTL: sutura fabelo-tibial
\end{tabular}

lateral; SFTLM: suturas fabelo-tibiais lateral e medial; mm: milímetro
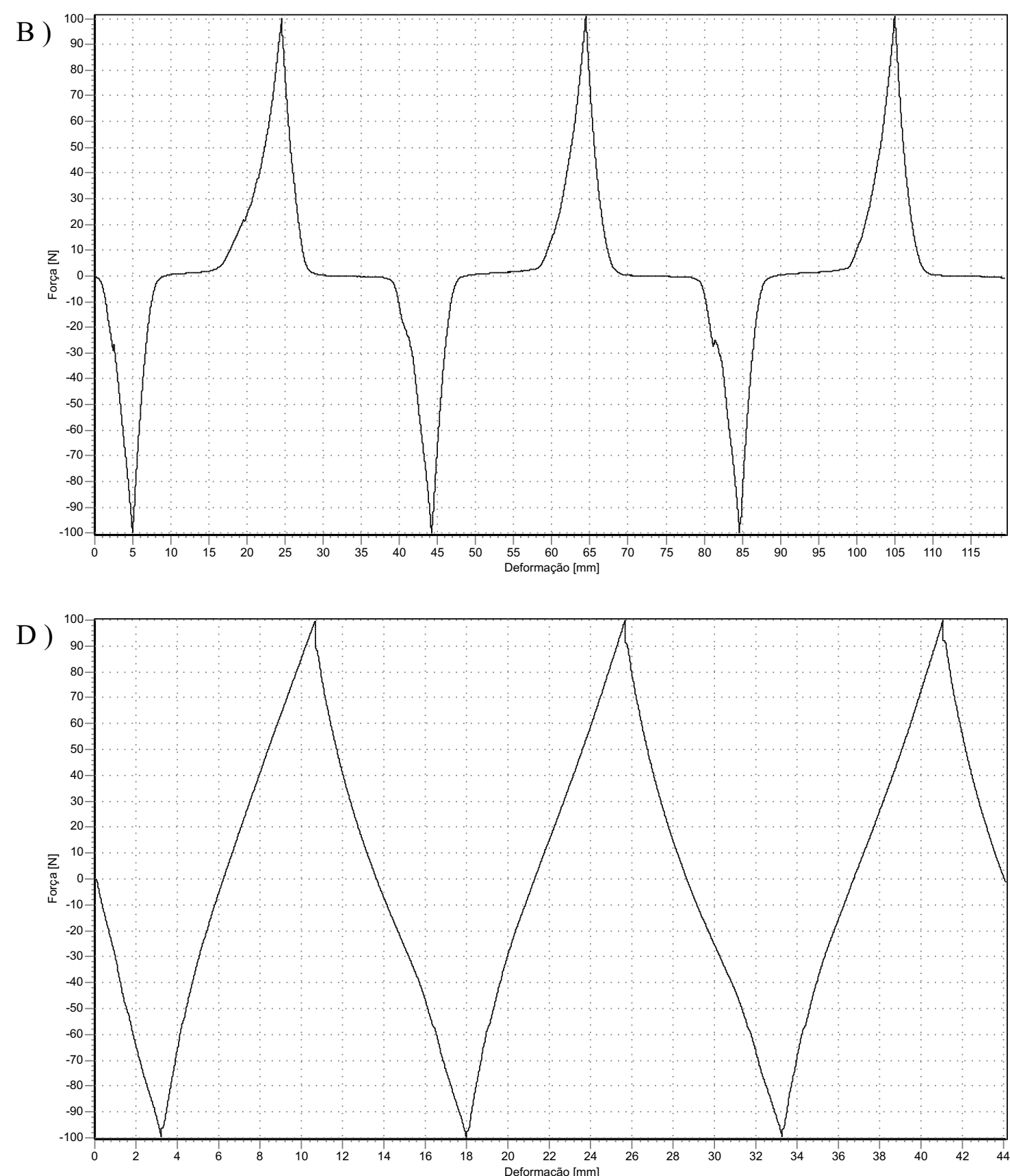

A) LCCr (ligamento íntegro); B) RLCCr (ligamento rompido); C) Joelho reparado por sutura fabelo-tibial lateral; D) Joelho reparado por suturas fabelo-tibiais lateral e medial; N: Newton; mm: milímetro.

Gráficos 15 - Ensaios biomecânicos referentes ao "joelho 14" nas diferentes situações testadas, durante os três ciclos cranio-caudais - São Paulo - 2007 
Tabela 30 - Deslocamento cranial e caudal da tíbia em relação ao fêmur após carga de 100 Newtons, nas diferentes situações testadas no “joelho 15" - São Paulo - 2007

\begin{tabular}{ccccccc}
\hline \multicolumn{7}{c}{ GAVETA (mm) } \\
\hline Situação & Cranial 1 & Cranial 2 & Cranial 3 & Caudal 1 & Caudal 2 & Caudal 3 \\
\hline LCCr & 2,90 & 2,94 & 2,98 & 4,60 & 4,60 & 4,63 \\
\hline RLCCr & 14,39 & 14,69 & 14,82 & 4,97 & 4,85 & 4,79 \\
\hline SFTL & 5,10 & 5,29 & 5,41 & 4,82 & 4,78 & 4,81 \\
\hline SFTLM & 4,64 & 4,98 & 5,13 & 3,96 & 3,93 & 3,90 \\
\hline
\end{tabular}

LCCr: ligamento cruzado cranial íntegro; RLCCr: ligamento cruzado cranial rompido; SFTL: sutura fabelo-tibia lateral; SFTLM: suturas fabelo-tibiais lateral e medial; mm: milímetro.

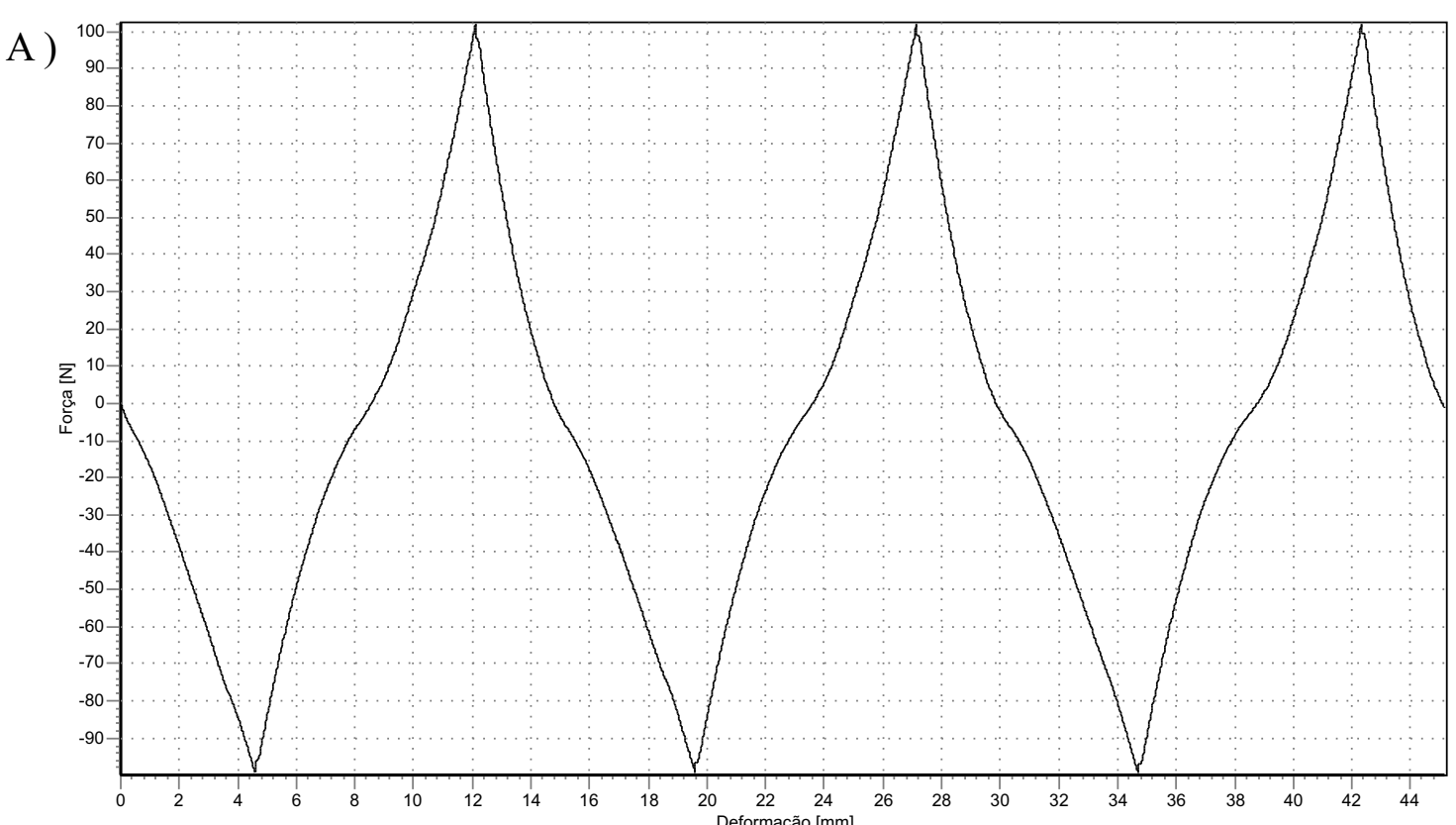

C)

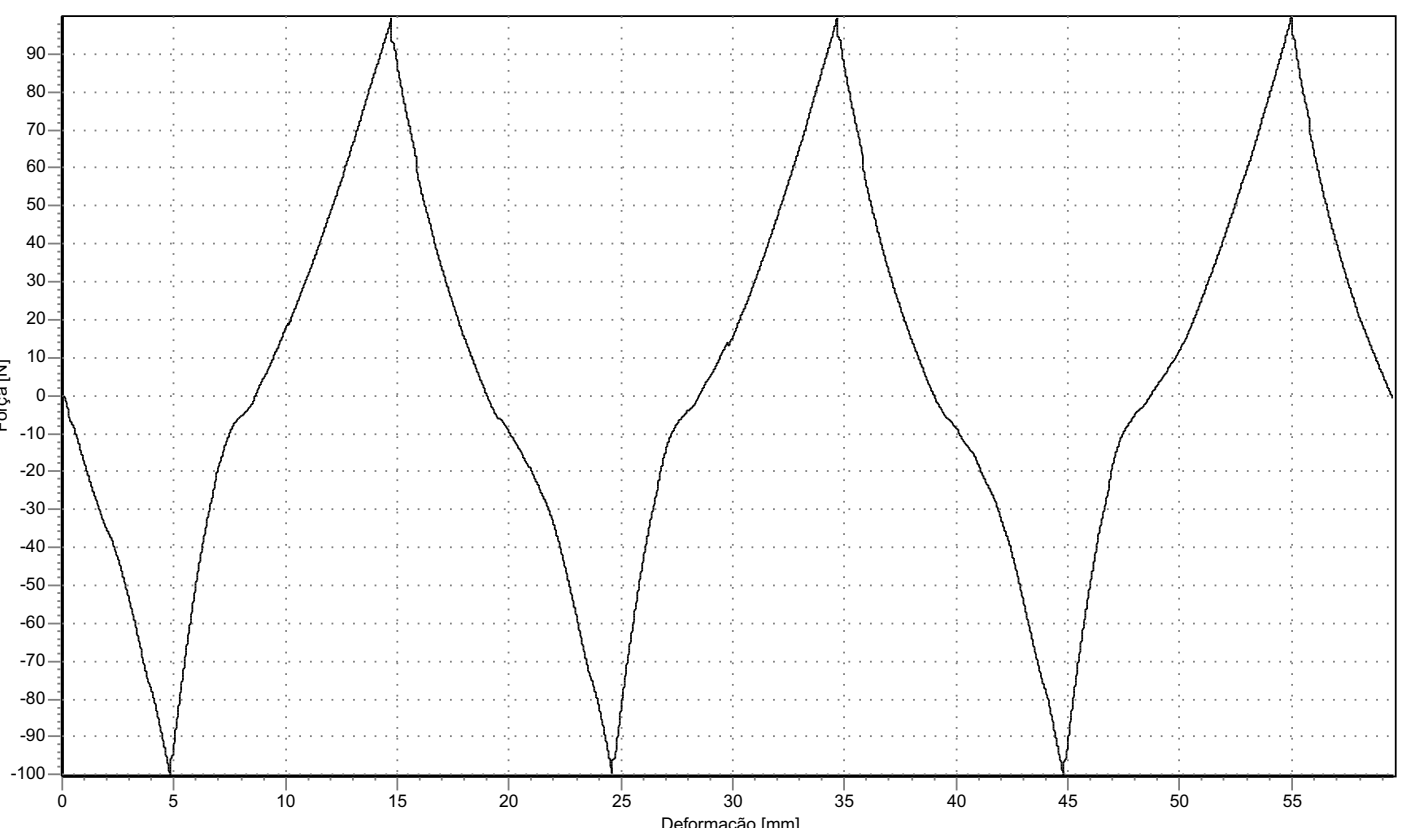

Tabela 31 - Rigidez cranial e caudal apresentadas nas diferentes situações testadas no “joelho 15" - São Paulo - 2007

\begin{tabular}{ccccccc}
\hline \multicolumn{7}{c}{ RIGIDEZ (N/mm) } \\
\hline Situação & Cranial 1 & Cranial 2 & Cranial 3 & Caudal 1 & Caudal 2 & Caudal 3 \\
\hline LCCr & 38,96 & 39,96 & 40,07 & 22,90 & 23,58 & 24,25 \\
\hline RLCCr & 26,47 & 28,67 & 29,53 & 24,10 & 23,35 & 23,50 \\
\hline SFTL & 19,09 & 20,16 & 20,25 & 24,61 & 24,63 & 24,79 \\
\hline SFTLM & 17,25 & 18,95 & 19,23 & 27,86 & 27,74 & 27,81 \\
\hline LCCr: ligamento cruzado cranial íntegro; RLCCr: ligamento cruzado cranial rompido; SFTL: sutura fabelo-tibial
\end{tabular}

LCCr: ligamento cruzado cranial íntegro; RLCCr: ligamento cruzado cranial rompido; SFTL: sutura fabelo-tibial lateral; SFTLM: suturas fabelo-tibiais lateral e medial; $\mathrm{mm}$ : milimetro.
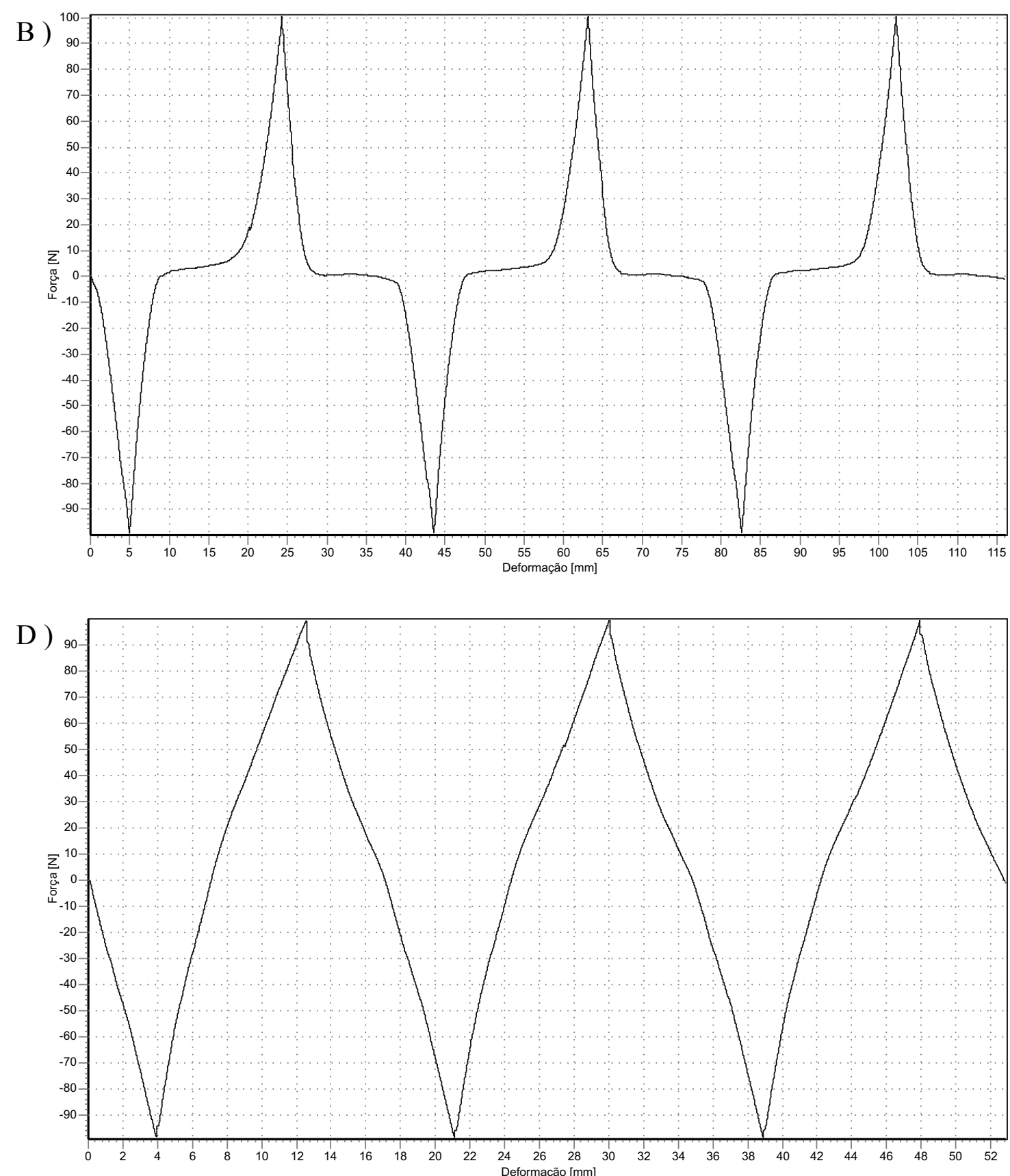

A) LCCr (ligamento íntegro); B) RLCCr (ligamento rompido); C) Joelho reparado por sutura fabelo-tibial lateral; D) Joelho reparado por suturas fabelo-tibiais lateral e medial; N: Newton; mm: milímetro.

Gráficos 16 - Ensaios biomecânicos referentes ao "joelho 15" nas diferentes situações testadas, durante os três ciclos cranio-caudais - São Paulo - 2007 
Tabela 32 - Deslocamento cranial e caudal da tíbia em relação ao fêmur após carga de 100 Newtons, nas diferentes situações testadas no "joelho 16" - São Paulo - 2007

\begin{tabular}{ccccccc}
\hline \multicolumn{7}{c}{ GAVETA (mm) } \\
\hline Situação & Cranial 1 & Cranial 2 & Cranial 3 & Caudal 1 & Caudal 2 & Caudal 3 \\
\hline LCCr & 4,18 & 4,32 & 4,32 & 4,40 & 3,99 & 3,97 \\
\hline RLCCr & 12,50 & 12,71 & 12,76 & 4,26 & 4,43 & 4,48 \\
\hline SFTL & 6,15 & 6,39 & 6,55 & 3,95 & 3,99 & 4,02 \\
\hline SFTLM & 5,26 & 5,55 & 5,71 & 3,73 & 3,67 & 3,61 \\
\hline LCCr: ligamento cruzado cranial integro; RLCCr: ligamento cruzado cranial rompido; SFTL: sutura fabelo-tibial
\end{tabular}

LCCr: ligamento cruzado cranial íntegro; RLCCr: ligamento cruzado cranial rompido; SFTL: sutura fabelo-tibial lateral; SFTLM: suturas fabelo-tibiais lateral e medial; $\mathrm{mm}$ : milímetro.

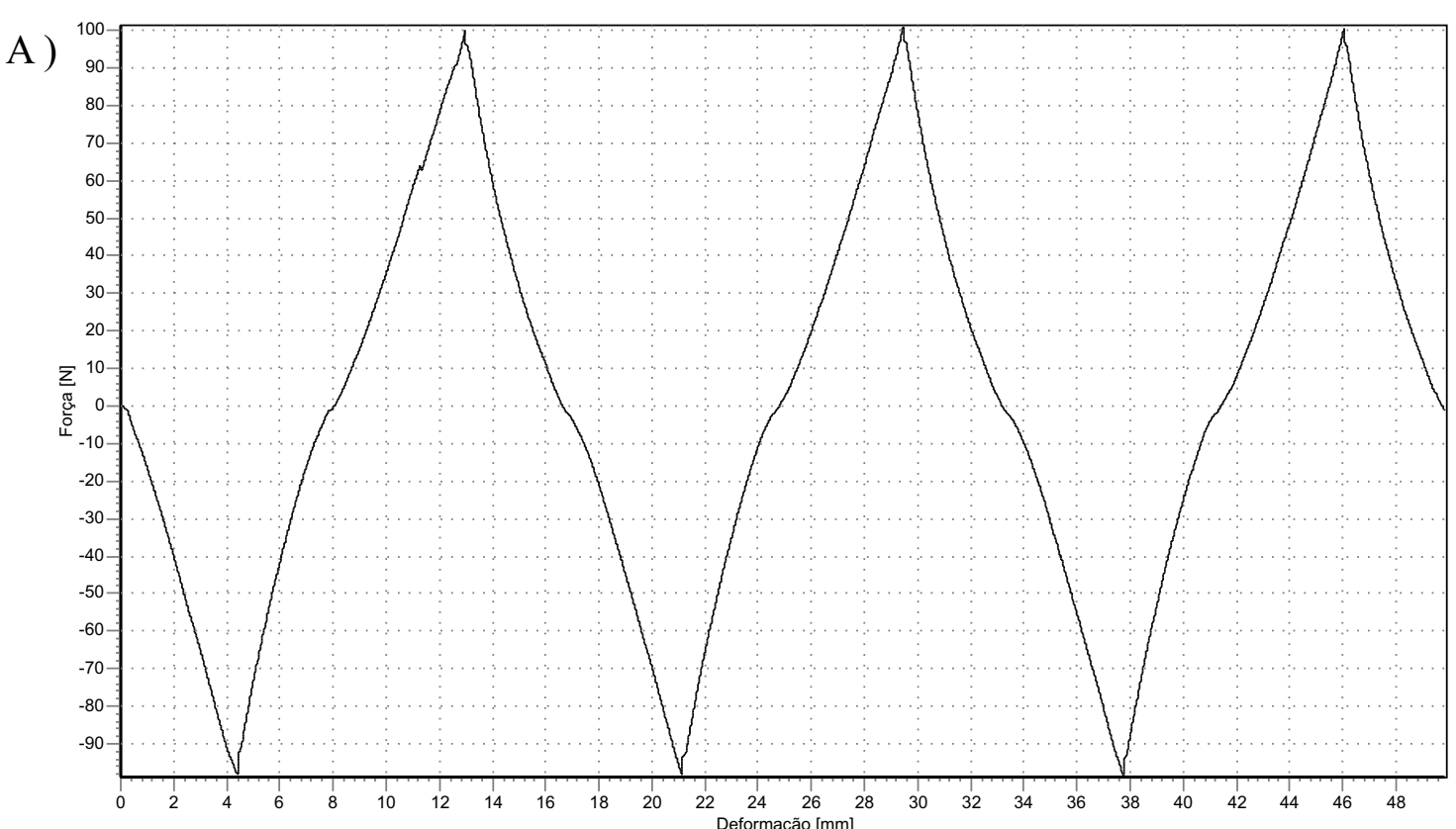

C)

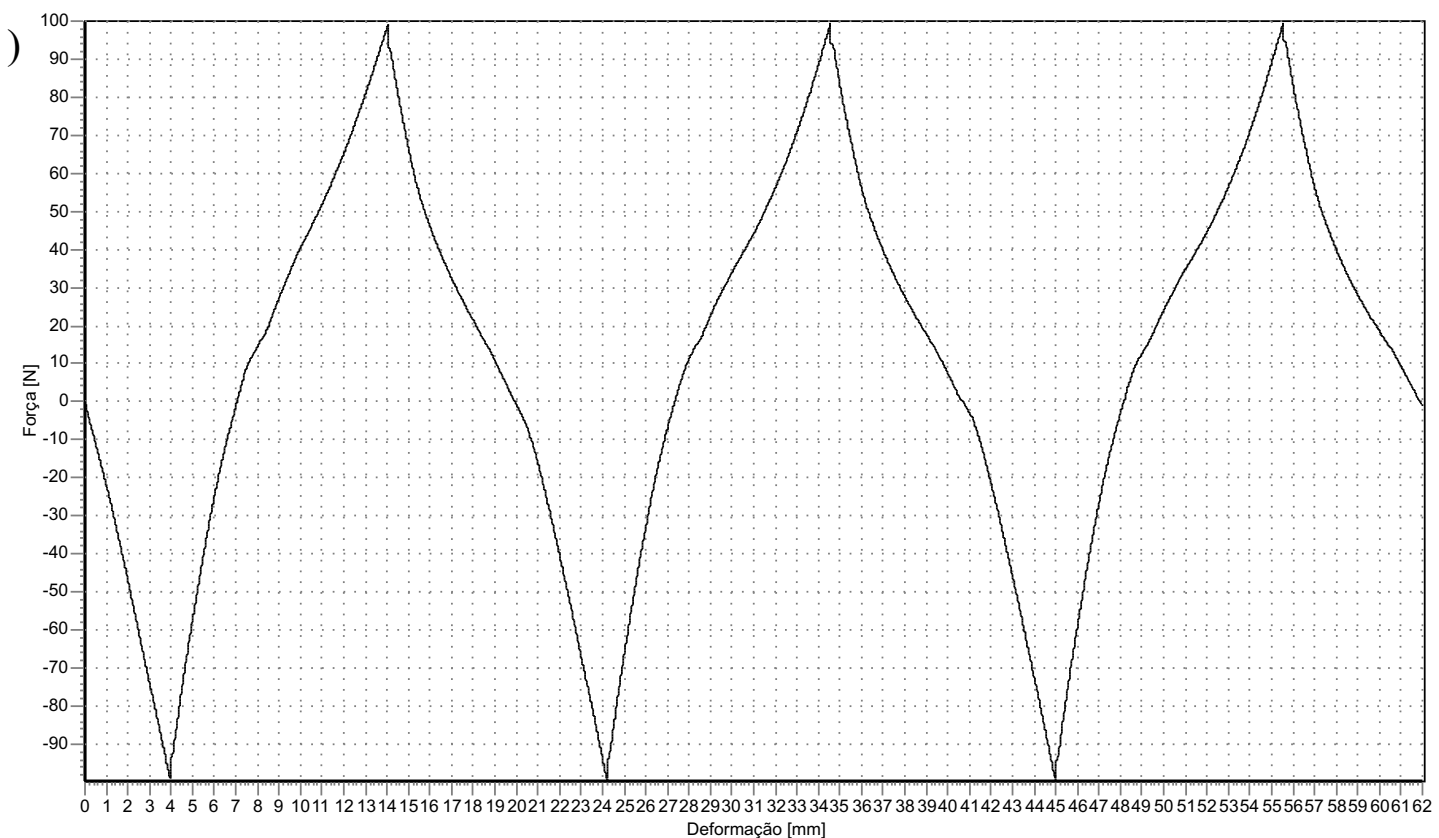

Tabela 33 - Rigidez cranial e caudal apresentadas nas diferentes situações testadas no “joelho 16" - São Paulo - 2007

\begin{tabular}{ccccccc}
\hline \multicolumn{7}{c}{ RIGIDEZ (N/mm) } \\
\hline Situação & Cranial 1 & Cranial 2 & Cranial 3 & Caudal 1 & Caudal 2 & Caudal 3 \\
\hline LCCr & 21,26 & 24,73 & 25,74 & 24,76 & 25,66 & 25,23 \\
\hline RLCCr & 26,12 & 28,05 & 28,22 & 25,47 & 23,36 & 22,95 \\
\hline SFTL & 16,25 & 17,44 & 17,52 & 26,32 & 27,20 & 27,31 \\
\hline SFTLM & 17,57 & 19,09 & 19,56 & 27,53 & 26,77 & 26,57 \\
\hline LCCr: ligamento cruzado cranial íntegro; RLCCr: ligamento cruzado cranial rompido; SFTL: sutura fabelo-tibial
\end{tabular}

LCCr: ligamento cruzado cranial íntegro; RLCCr: ligamento cruzado cranial rompido; SFTL: sutura fabelo-tibial lateral; SFTLM: suturas fabelo-tibiais lateral e medial; mm: milímetro.
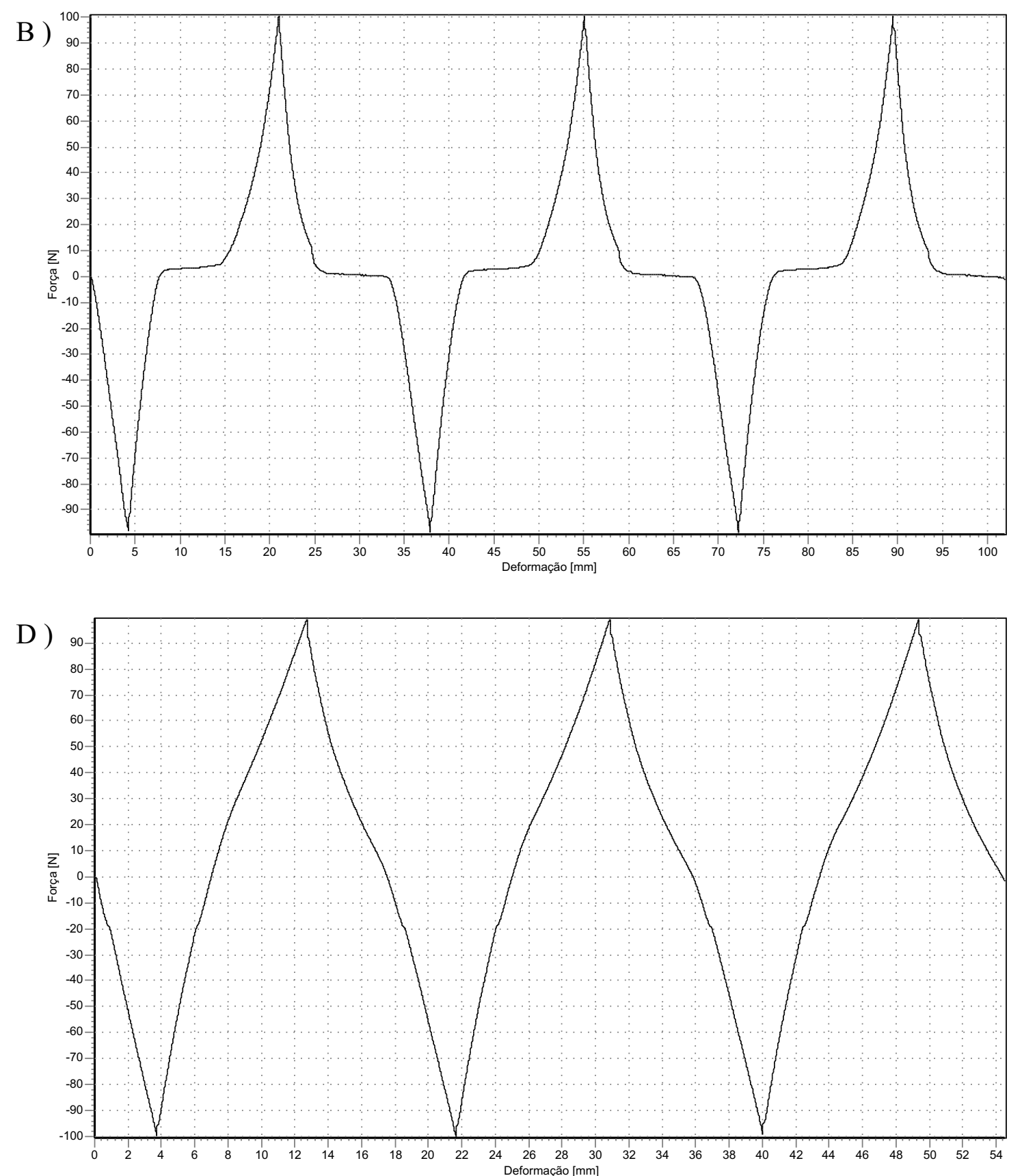

A) LCCr (ligamento íntegro); B) RLCCr (ligamento rompido); C) Joelho reparado por sutura fabelo-tibial lateral; D) Joelho reparado por suturas fabelo-tibiais lateral e medial; N: Newton; mm: milímetro.

Gráficos 17 - Ensaios biomecânicos referentes ao "joelho 16" nas diferentes situações testadas, durante os três ciclos cranio-caudais - São Paulo - 2007 
Tabela 34 - Deslocamento cranial e caudal da tíbia em relação ao fêmur após carga de 100 Newtons, nas diferentes situações testadas no "joelho 17" - São Paulo - 2007

\begin{tabular}{ccccccc}
\hline \multicolumn{7}{c}{ GAVETA (mm) } \\
\hline Situação & Cranial 1 & Cranial 2 & Cranial 3 & Caudal 1 & Caudal 2 & Caudal 3 \\
\hline LCCr & 2,48 & 2,49 & 2,48 & 3,70 & 3,72 & 3,78 \\
\hline RLCCr & 14,10 & 14,29 & 14,45 & 4,31 & 4,41 & 4,39 \\
\hline SFTL & 4,45 & 4,61 & 4,69 & 3,89 & 3,89 & 3,94 \\
\hline SFTLM & 3,51 & 3,73 & 3,86 & 3,18 & 3,09 & 3,05 \\
\hline
\end{tabular}

LCCr: ligamento cruzado cranial íntegro; RLCCr: ligamento cruzado cranial rompido; SFTL: sutura fabelo-tibial lateral; SFTLM: suturas fabelo-tibiais lateral e medial; mm: milímetro.
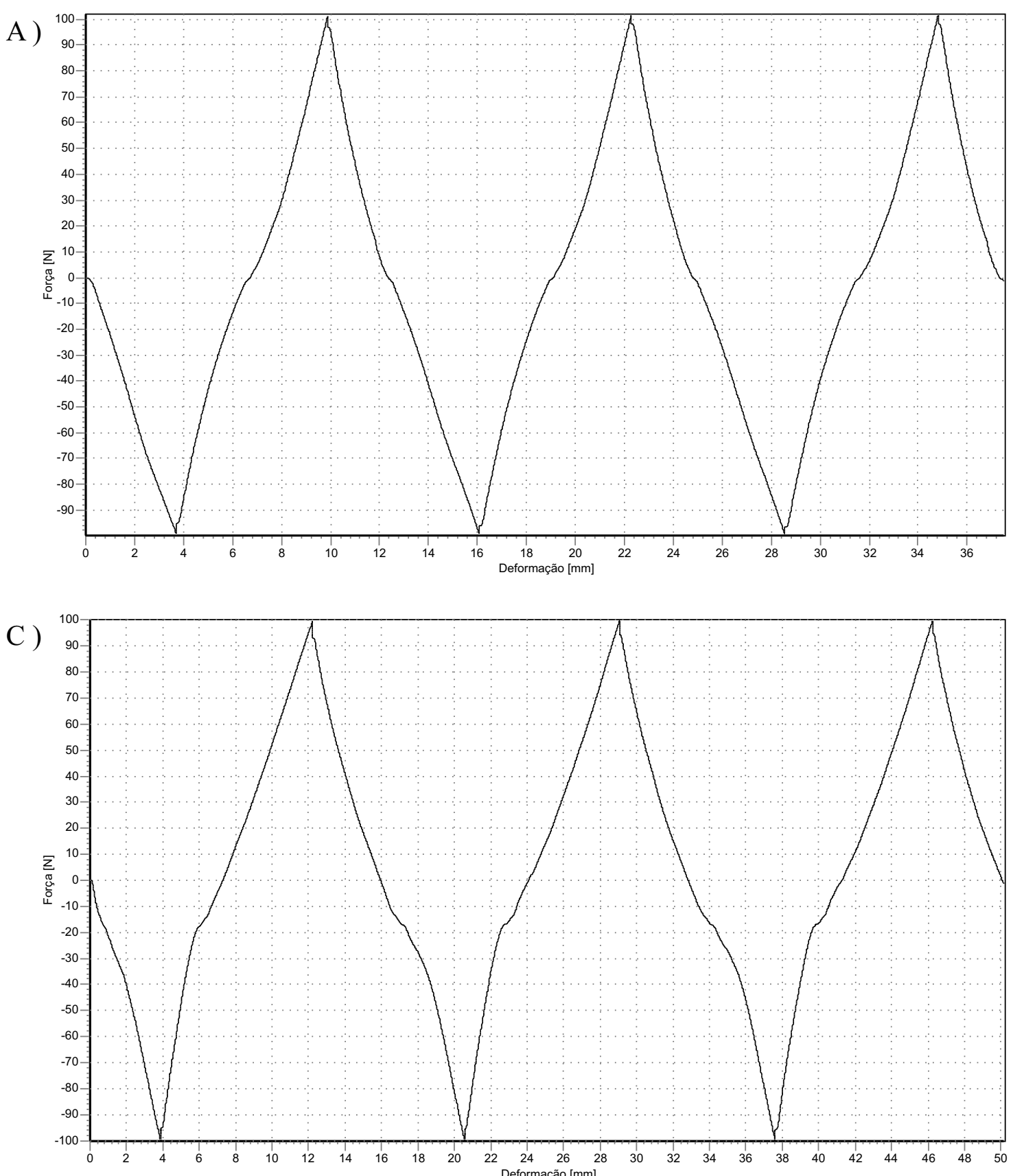

Tabela 35 - Rigidez cranial e caudal apresentadas nas diferentes situações testadas no “joelho 17” - São Paulo - 2007

\begin{tabular}{ccccccc}
\hline \multicolumn{7}{c}{ RIGIDEZ (N/mm) } \\
\hline Situação & Cranial 1 & Cranial 2 & Cranial 3 & Caudal 1 & Caudal 2 & Caudal 3 \\
\hline LCCr & 39,70 & 40,09 & 40,25 & 25,68 & 26,41 & 26,84 \\
\hline RLCCr & 28,31 & 30,07 & 30,67 & 28,68 & 30,79 & 30,25 \\
\hline SFTL & 21,42 & 23,24 & 23,35 & 33,24 & 34,29 & 34,33 \\
\hline SFTLM & 24,30 & 26,53 & 26,59 & 37,75 & 36,62 & 36,09 \\
\hline
\end{tabular}

LCCr: ligamento cruzado cranial íntegro; RLCCr: ligamento cruzado cranial rompido; SFTL: sutura fabelo-tibial lateral; SFTLM: suturas fabelo-tibiais lateral e medial; mm: milímetro.
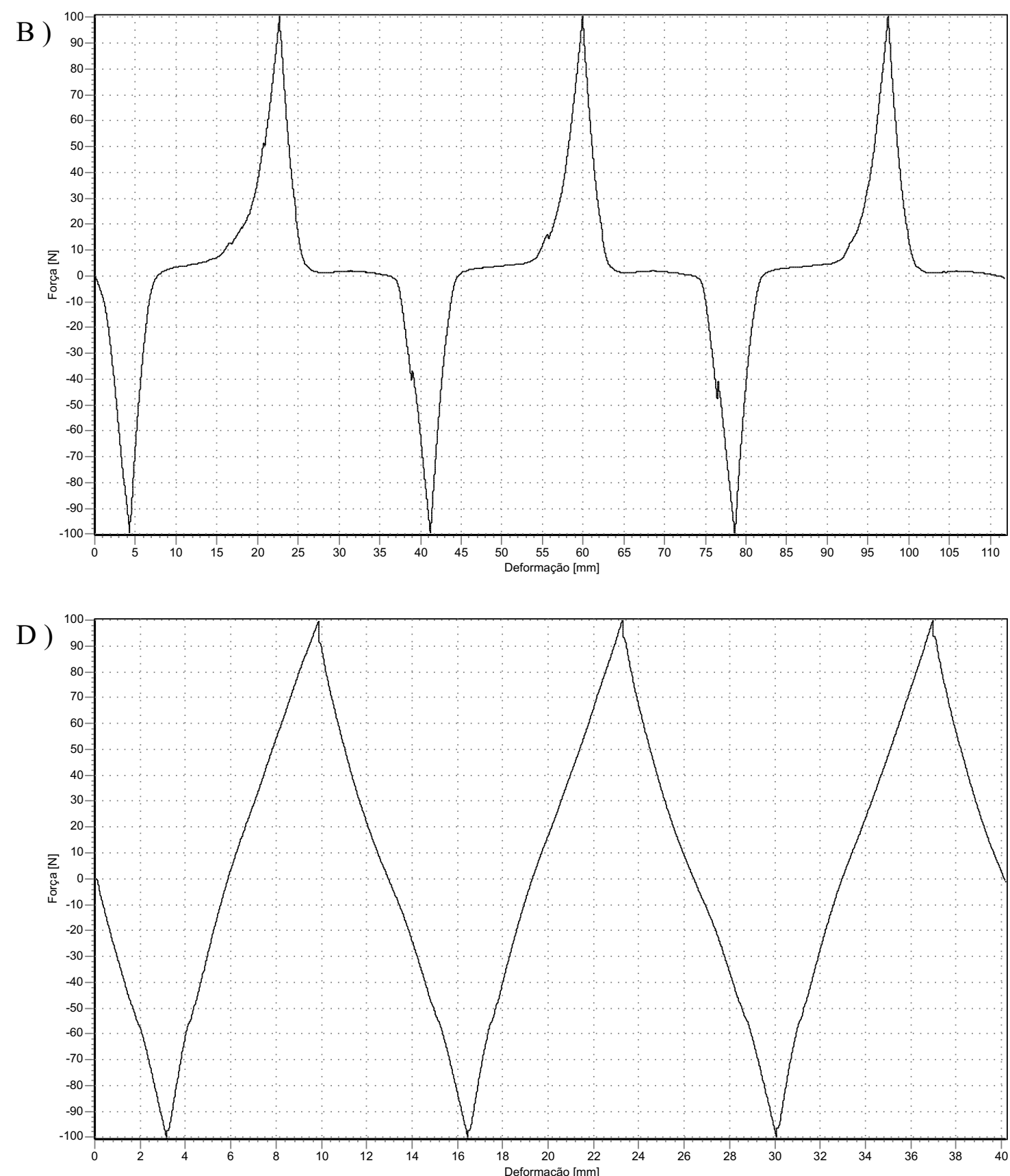

A) LCCr (ligamento íntegro); B) RLCCr (ligamento rompido); C) Joelho reparado por sutura fabelo-tibial lateral; D) Joelho reparado por suturas fabelo-tibiais lateral e medial; N: Newton; mm: milímetro.

Gráficos 18 - Ensaios biomecânicos referentes ao "joelho 17" nas diferentes situações testadas, durante os três ciclos cranio-caudais - São Paulo - 2007 
Tabela 36 - Deslocamento cranial e caudal da tíbia em relação ao fêmur após carga de 100 Newtons, nas diferentes situações testadas no “joelho 18 ” - São Paulo - 2007

\begin{tabular}{ccccccc}
\hline \multicolumn{7}{c}{ GAVETA ( mm) } \\
\hline Situação & Cranial 1 & Cranial 2 & Cranial 3 & Caudal 1 & Caudal 2 & Caudal 3 \\
\hline LCCr & 2,45 & 2,46 & 2,49 & 2,54 & 2,58 & 2,66 \\
\hline RLCCr & 11,78 & 12,07 & 12,18 & 2,43 & 2,49 & 2,52 \\
\hline SFTL & 4,35 & 4,48 & 4,57 & 2,36 & 2,39 & 2,38 \\
\hline SFTLM & 3,62 & 3,91 & 4,07 & 2,05 & 1,95 & 1,95 \\
\hline LCCr: ligamento cruzado cranial integro; RLCCr: ligamento cruzado cranial rompido; SFTL: sutura fabelo-tibial
\end{tabular}

LCCr: ligamento cruzado cranial integro; RLCCr: ligamento cruzado cranial rompido; SFTL: sutura fabelo-tibial lateral; SFTLM: suturas fabelo-tibiais lateral e medial; mm: milímetro.

A)

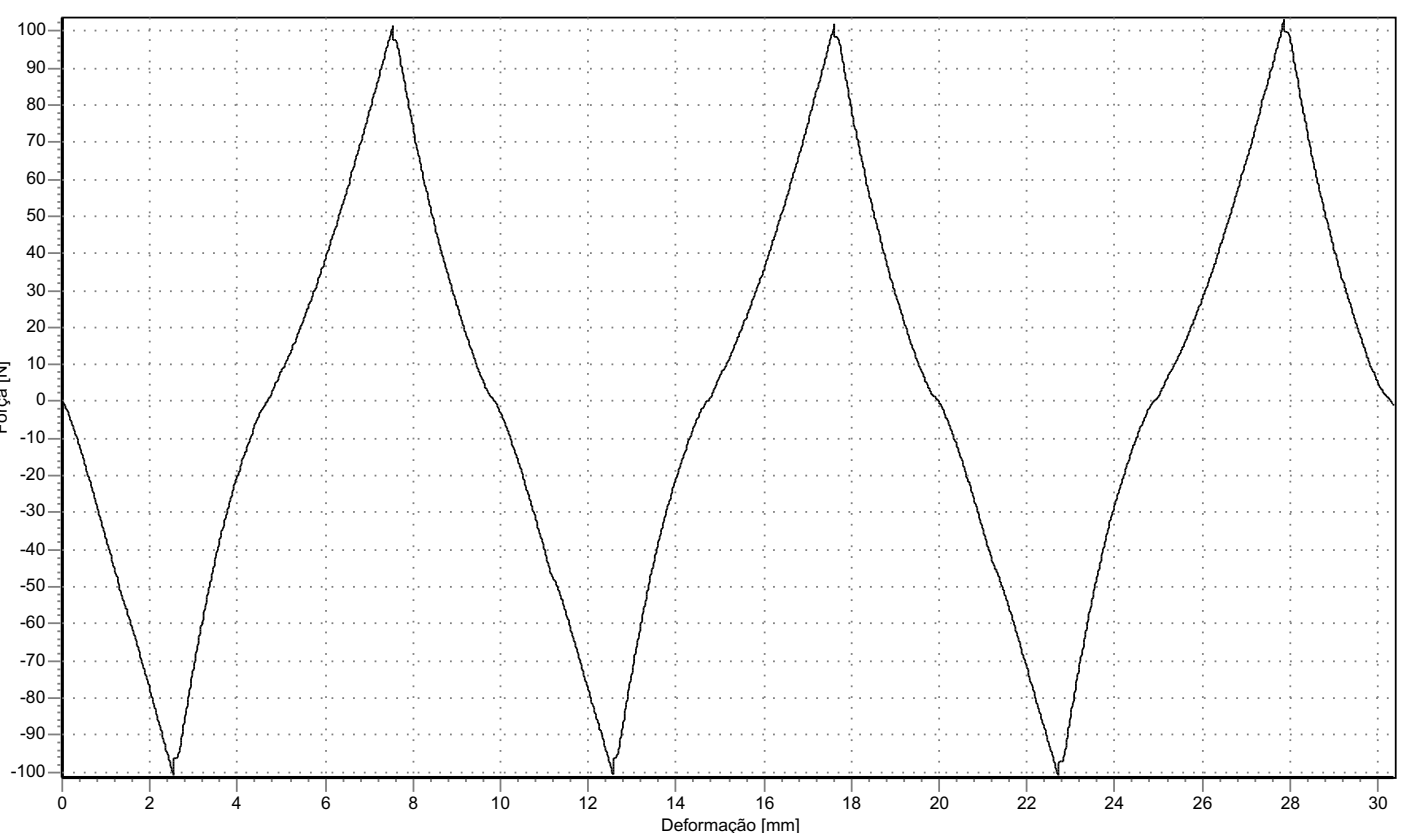

C

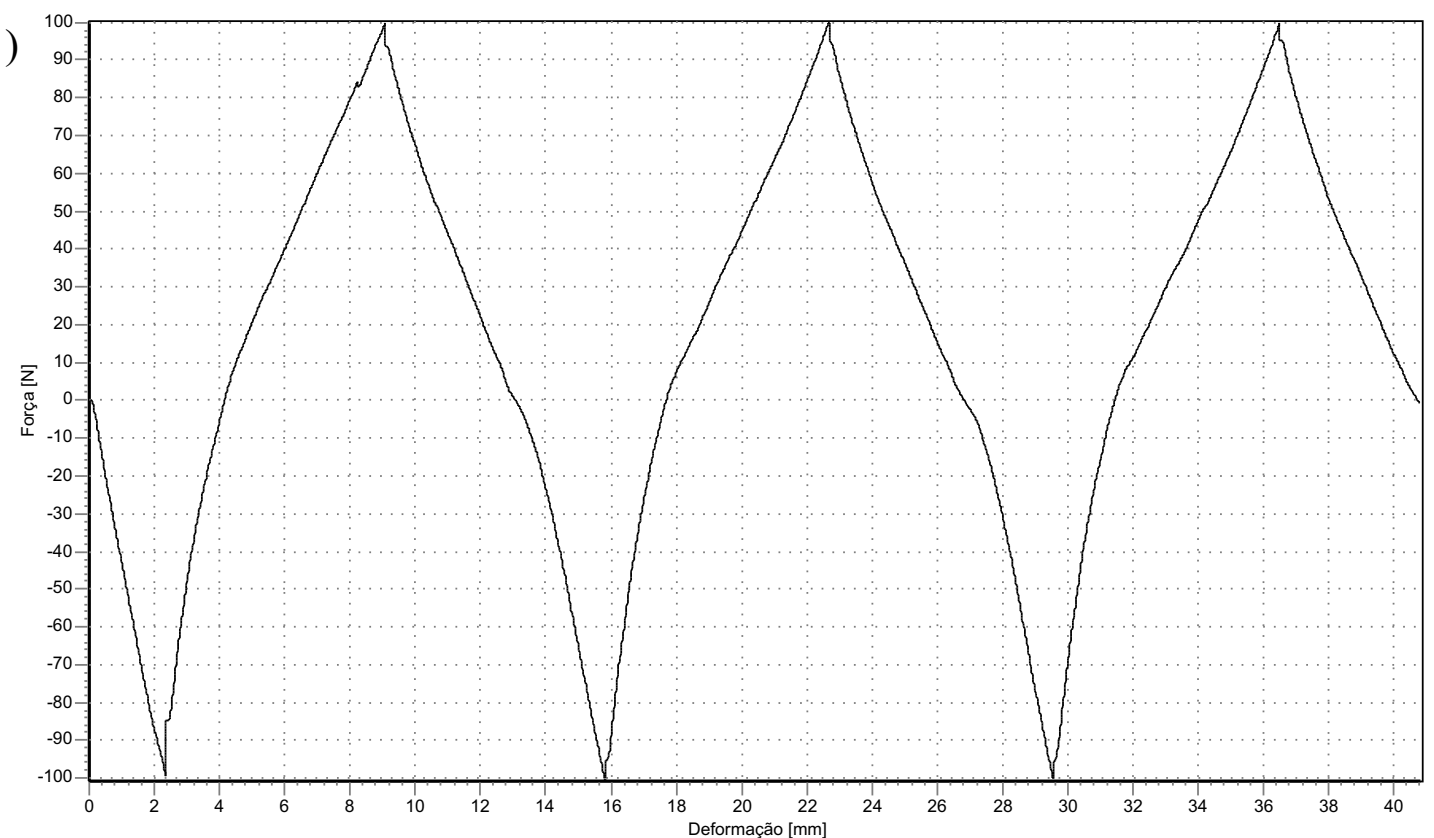

Tabela 37 - Rigidez cranial e caudal apresentadas nas diferentes situações testadas no “joelho 18" - São Paulo - 2007

\begin{tabular}{ccccccc}
\hline \multicolumn{7}{c}{ RIGIDEZ (N/mm) } \\
\hline Situação & Cranial 1 & Cranial 2 & Cranial 3 & Caudal 1 & Caudal 2 & Caudal 3 \\
\hline LCCr & 42,73 & 43,25 & 43,69 & 42,53 & 40,37 & 40,50 \\
\hline RLCCr & 34,42 & 37,16 & 37,67 & 40,57 & 43,13 & 43,18 \\
\hline SFTL & 18,64 & 21,48 & 22,27 & 39,71 & 43,67 & 44,68 \\
\hline SFTLM & 22,08 & 24,36 & 24,63 & 54,53 & 49,23 & 48,72 \\
\hline LCCr: ligamento cruzado cranial íntegro; RLCCr: ligamento cruzado cranial rompido; SFTL: sutura fabelo-tibial
\end{tabular}

lateral; SFTLM: suturas fabelo-tibiais lateral e medial; mm: milímetro
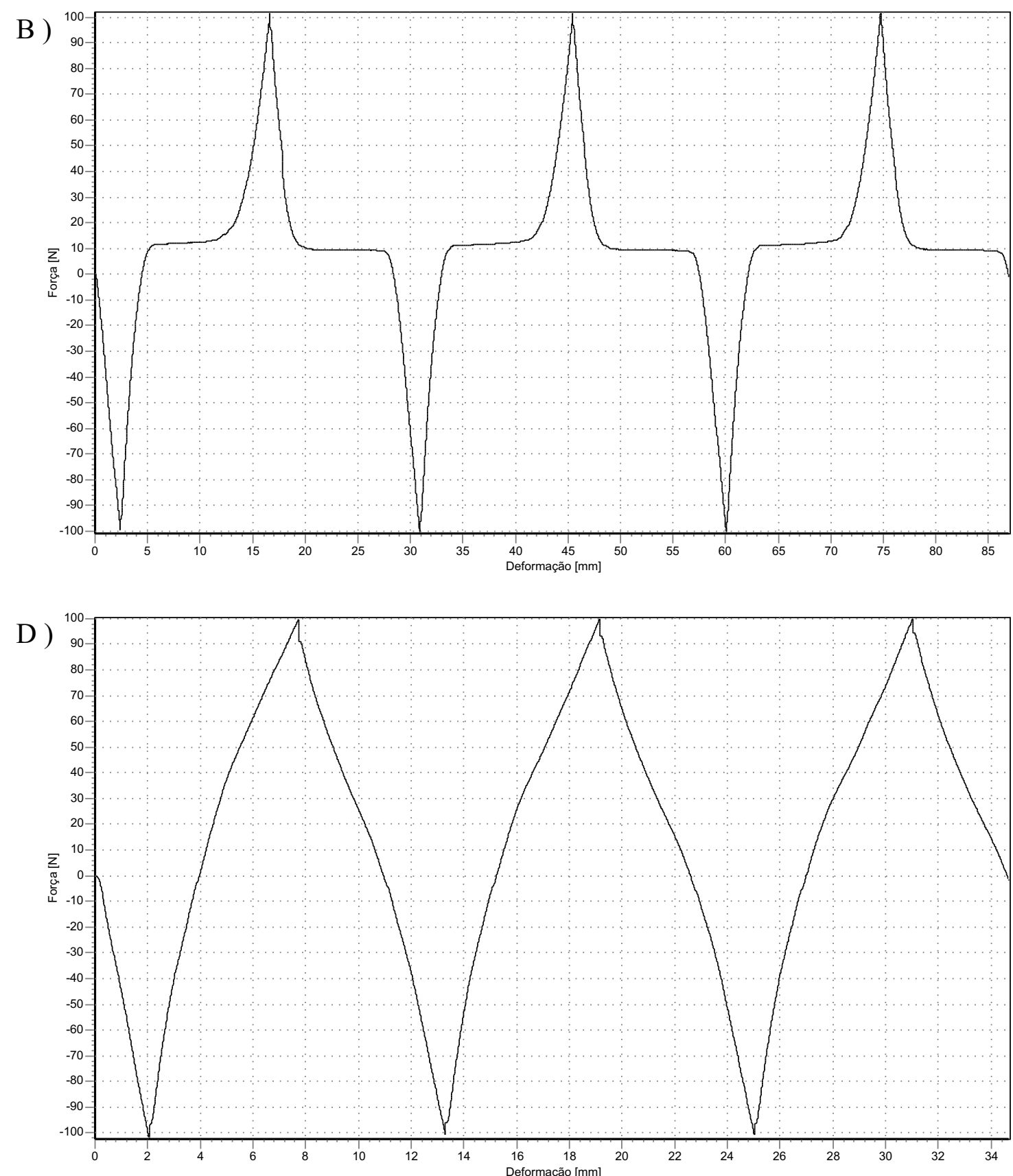

A) LCCr (ligamento íntegro); B) RLCCr (ligamento rompido); C) Joelho reparado por sutura fabelo-tibial lateral; D) Joelho reparado por suturas fabelo-tibiais lateral e medial; N: Newton; mm: milímetro.

Gráficos 19 - Ensaios biomecânicos referentes ao "joelho 18” nas diferentes situações testadas, durante os três ciclos cranio-caudais - São Paulo - 2007 
Tabela 38 - Deslocamento cranial e caudal da tíbia em relação ao fêmur após carga de 100 Newtons, nas diferentes situações testadas no “joelho 19”- São Paulo - 2007

\begin{tabular}{ccccccc}
\hline \multicolumn{7}{c}{ GAVETA (mm) } \\
\hline Situação & Cranial 1 & Cranial 2 & Cranial 3 & Caudal 1 & Caudal 2 & Caudal 3 \\
\hline LCCr & 2,72 & 2,62 & 2,64 & 4,93 & 4,93 & 4,93 \\
\hline RLCCr & 14,06 & 14,19 & 14,25 & 4,97 & 4,85 & 4,83 \\
\hline SFTL & 4,66 & 4,86 & 4,97 & 4,24 & 4,19 & 4,16 \\
\hline SFTLM & 3,45 & 3,59 & 3,72 & 3,53 & 3,55 & 3,57 \\
\hline LCC
\end{tabular}

LCCr: ligamento cruzado cranial íntegro; RLCCr: ligamento cruzado cranial rompido; SFTL: sutura fabelo-tibia lateral; SFTLM: suturas fabelo-tibiais lateral e medial; mm: milímetro.

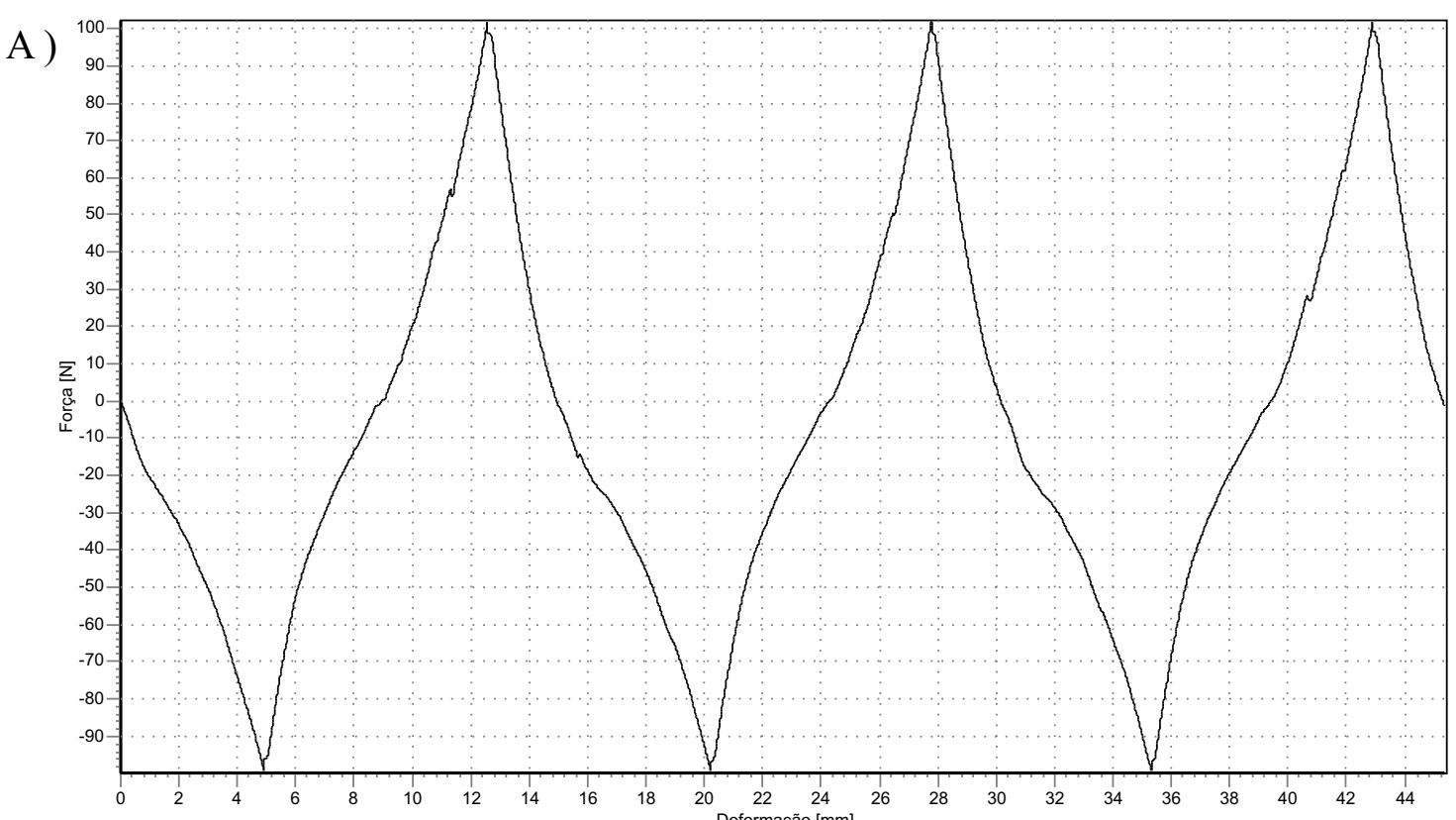

C

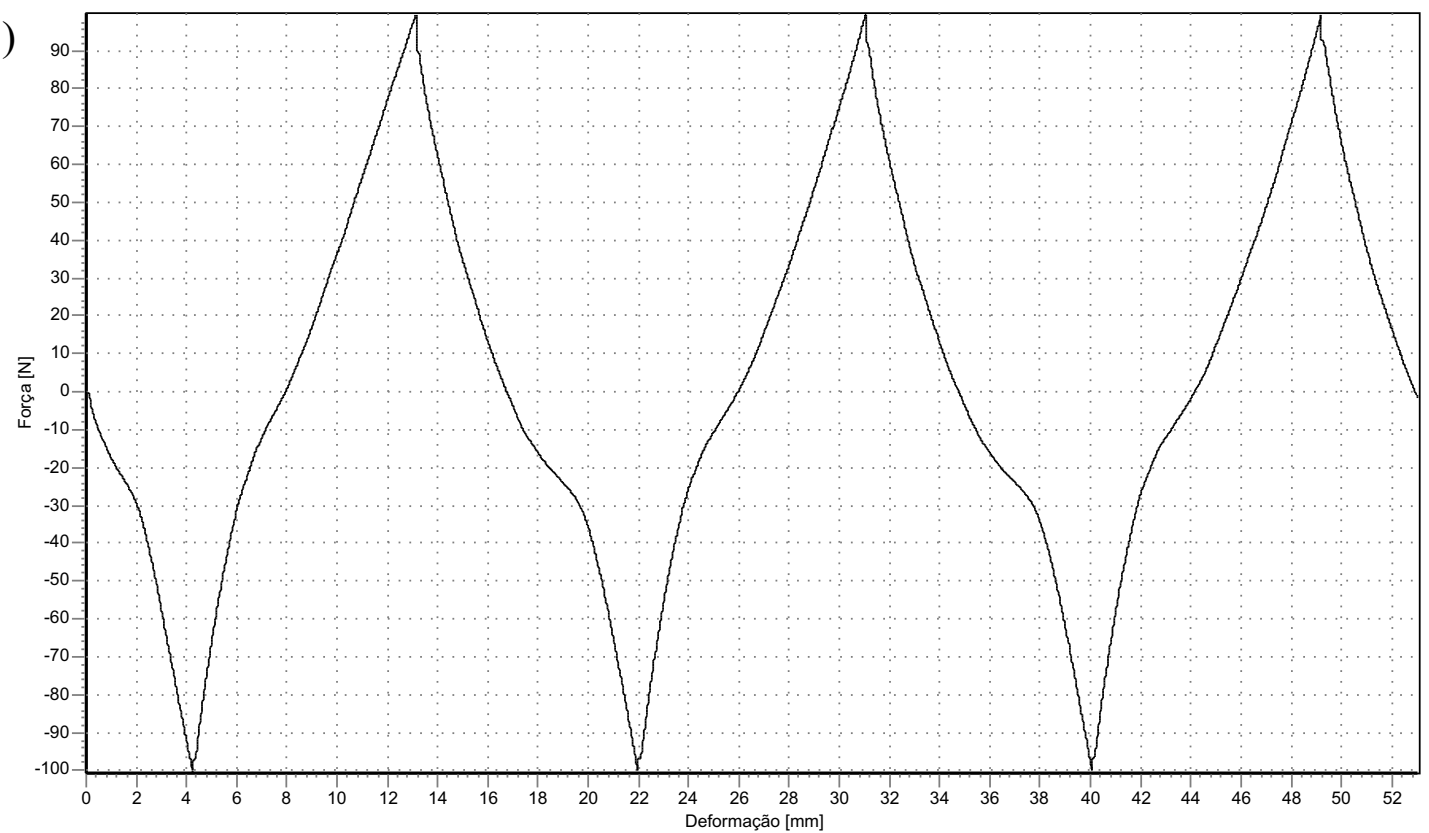

Tabela 39 - Rigidez cranial e caudal apresentadas nas diferentes situacões testadas no “joelho 19" - São Paulo - 2007

\begin{tabular}{ccccccc}
\hline \multicolumn{7}{c}{ RIGIDEZ (N/mm) } \\
\hline Situação & Cranial 1 & Cranial 2 & Cranial 3 & Caudal 1 & Caudal 2 & Caudal 3 \\
\hline LCCr & 37,82 & 41,38 & 39,55 & 26,55 & 25,97 & 26,38 \\
\hline RLCCr & 13,95 & 22,40 & 21,94 & 27,32 & 27,30 & 27,02 \\
\hline SFTL & 20,11 & 22,49 & 23,51 & 34,20 & 35,48 & 35,81 \\
\hline SFTLM & 20,45 & 21,55 & 21,83 & 30,43 & 30,79 & 30,04 \\
\hline LCCr: ligamento cruzado cranial íntegro; RLCCr: ligamento cruzado cranial rompido; SFTL: sutura fabelo-tibial
\end{tabular}

LCCr: ligamento cruzado cranial íntegro; RLCCr: ligamento cruzado cranial rompido; SFTL: sutura fabelo-tibial lateral; SFTLM: suturas fabelo-tibiais lateral e medial; mm: milímetro.
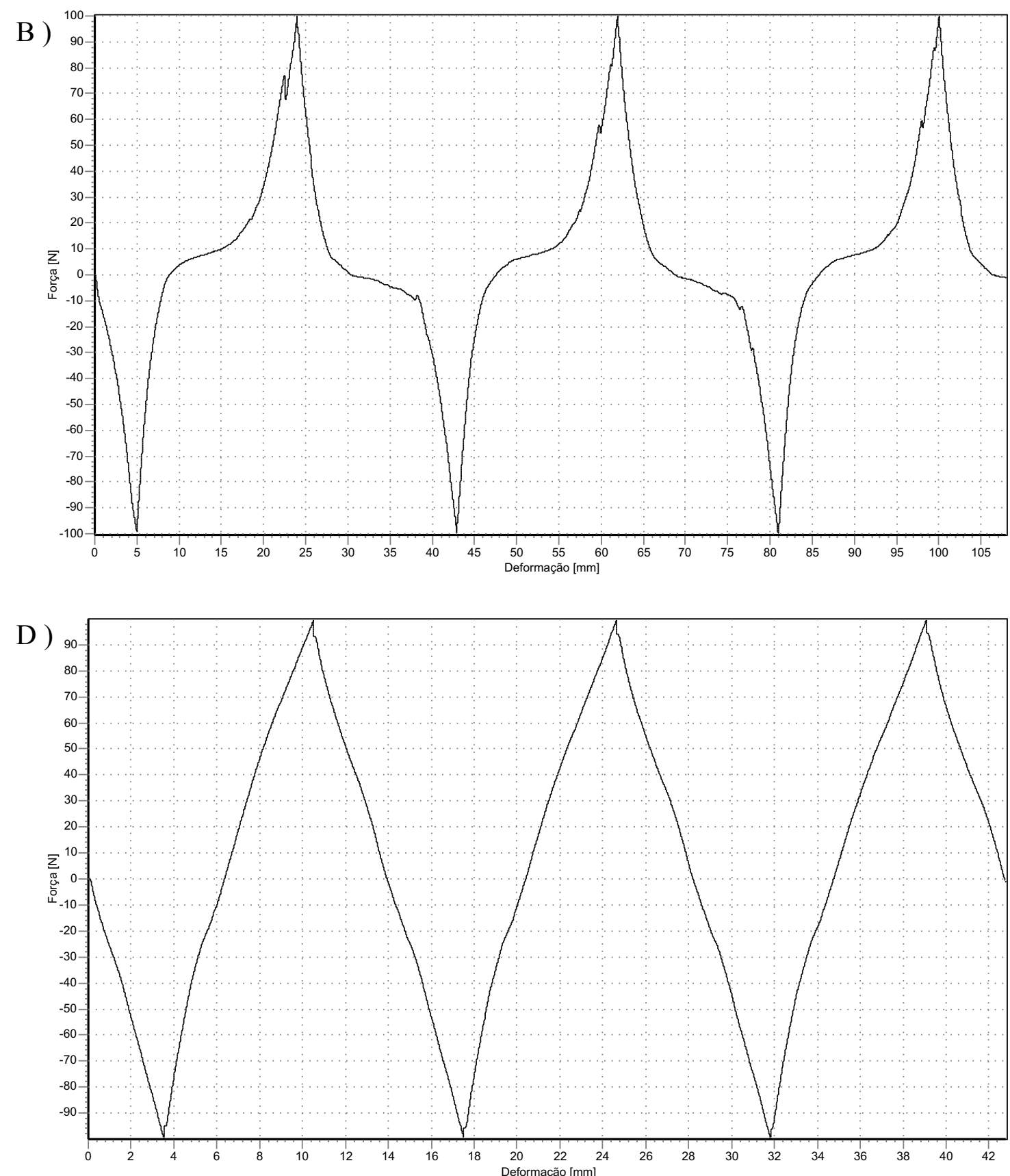

A) LCCr (ligamento íntegro); B) RLCCr (ligamento rompido); C) Joelho reparado por sutura fabelo-tibial lateral; D) Joelho reparado por suturas fabelo-tibiais lateral e medial; N: Newton; mm: milímetro.

Gráficos 20 - Ensaios biomecânicos referentes ao "joelho 19” nas diferentes situações testadas, durante os três ciclos cranio-caudais - São Paulo - 2007 
Tabela 40 - Deslocamento cranial e caudal da tíbia em relação ao fêmur após carga de 100 Newtons, nas diferentes situações testadas no "joelho 20" - São Paulo - 2007

\begin{tabular}{ccccccc}
\hline \multicolumn{7}{c}{ GAVETA (mm) } \\
\hline Situação & Cranial 1 & Cranial 2 & Cranial 3 & Caudal 1 & Caudal 2 & Caudal 3 \\
\hline LCCr & 2,50 & 2,55 & 2,57 & 2,58 & 2,57 & 2,56 \\
\hline RLCCr & 13,61 & 13,85 & 13,87 & 3,60 & 3,00 & 3,03 \\
\hline SFTL & 5,24 & 5,45 & 5,57 & 3,48 & 3,46 & 3,46 \\
\hline SFTLM & 2,88 & 3,07 & 3,15 & 2,55 & 2,53 & 2,50 \\
\hline LCCr: ligamento cruzado cranial integro; RLCCr: ligamento cruzado cranial rompido; SFTL: sutura fabelo-tibial
\end{tabular}

lateral; SFTLM: suturas fabelo-tibiais lateral e medial; mm: milímetro.

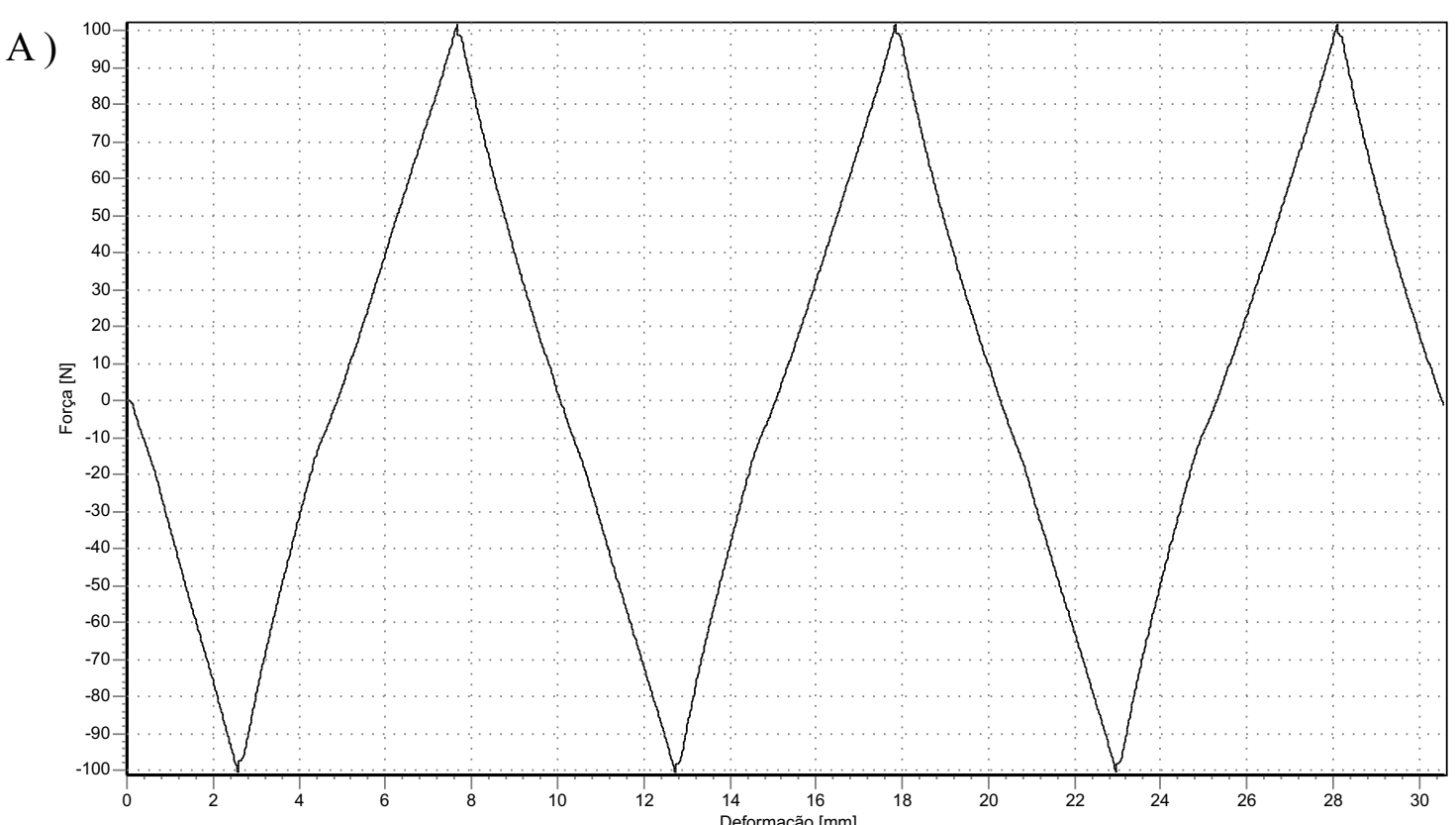

C

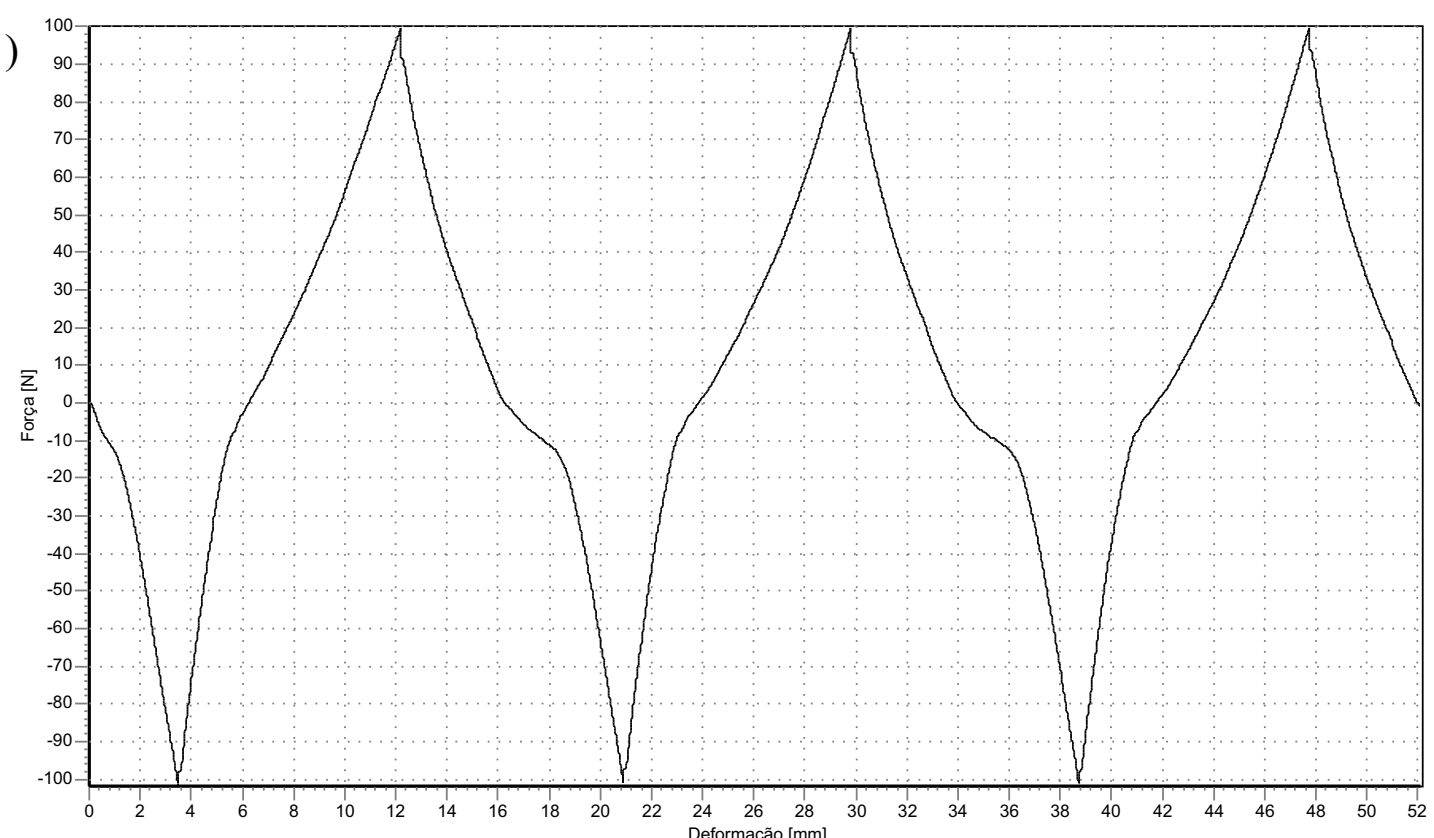

Tabela 41 - Rigidez cranial e caudal apresentadas nas diferentes situações testadas no “joelho 20" - São Paulo - 2007

\begin{tabular}{ccccccc}
\hline \multicolumn{7}{c}{ RIGIDEZ (N/mm) } \\
\hline Situação & Cranial 1 & Cranial 2 & Cranial 3 & Caudal 1 & Caudal 2 & Caudal 3 \\
\hline LCCr & 37,22 & 38,27 & 38,68 & 41,83 & 38,88 & 38,76 \\
\hline RLCCr & 26,34 & 31,20 & 31,41 & 37,83 & 40,53 & 36,53 \\
\hline SFTL & 19,82 & 22,40 & 22,65 & 40,91 & 41,60 & 41,87 \\
\hline SFTLM & 24,22 & 24,40 & 24,86 & 44,18 & 43,62 & 42,93 \\
\hline LCCr: ligamento cruzado cranial íntegro; RLCCr: ligamento cruzado cranial rompido; SFTL: sutura fabelo-tibial
\end{tabular}

LCCr: ligamento cruzado cranial íntegro; RLCCr: ligamento cruzado cranial rompido; SFTL: sutura fabelo-tibial lateral; SFTLM: suturas fabelo-tibiais lateral e medial; $\mathrm{mm}$ : milímetro.
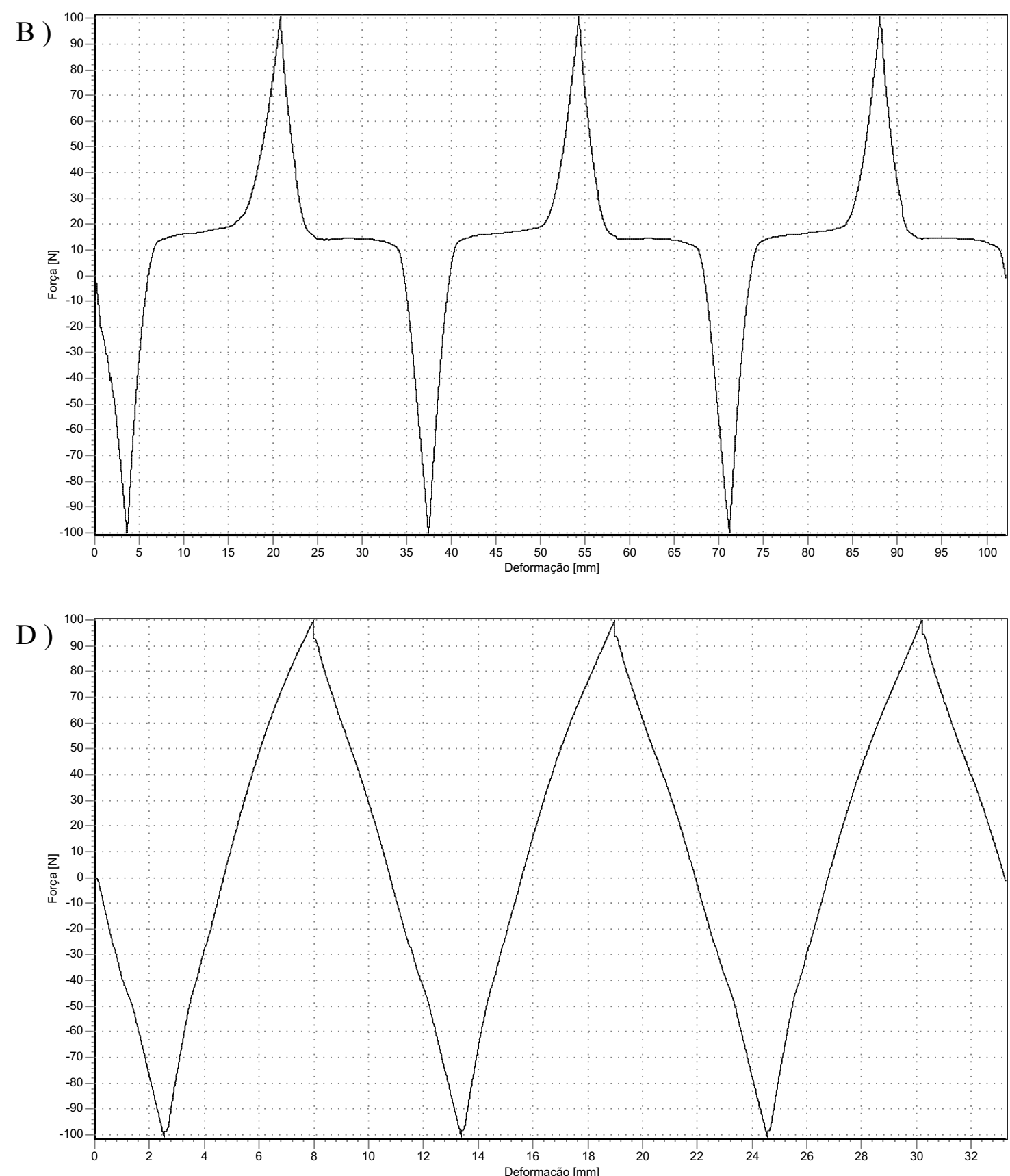

A) LCCr (ligamento íntegro); B) RLCCr (ligamento rompido); C) Joelho reparado por sutura fabelo-tibial lateral; D) Joelho reparado por suturas fabelo-tibiais lateral e medial; N: Newton; mm: milímetro.

Gráficos 21 - Ensaios biomecânicos referentes ao "joelho 20" nas diferentes situações testadas, durante os três ciclos cranio-caudais - São Paulo - 2007 


\subsection{FORÇA RESIDUAL}

A força residual é correspondente a resultante dos vetores de força verticais apresentada pelo joelho antes de se iniciar o seu ensaio nas diferentes situações.

O ponto de referência para todos os joelhos foi a sua situação íntegra, onde a força residual era zero Newton.

Os valores das forças residuais obtidos para cada joelho nas diferentes situações estão dispostos a seguir na Tabela 42 .

Tabela 42 - Valores das forças residuais apresentadas pelos joelhos nas diferentes situações de ensaio - São Paulo - 2007

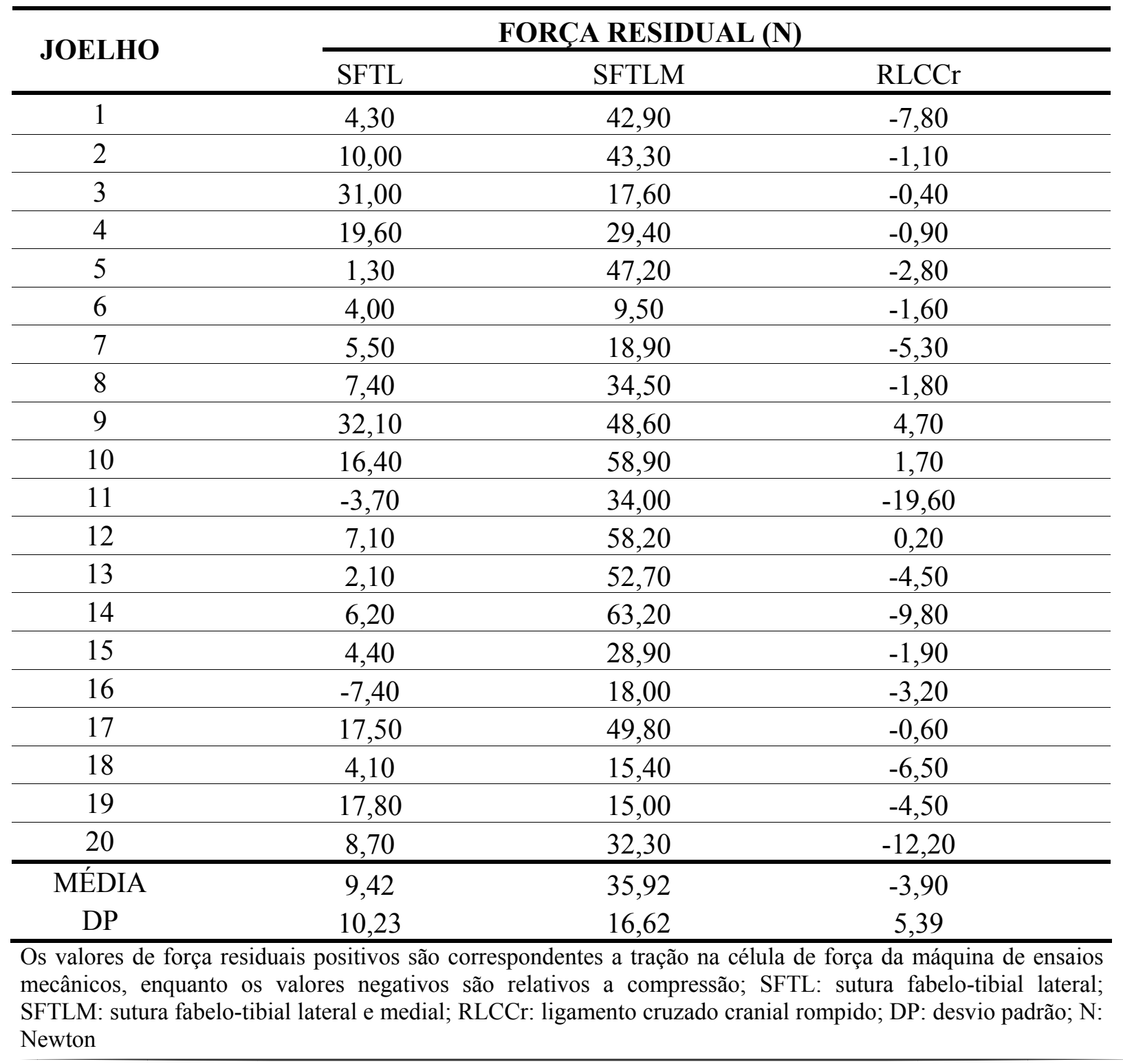




\subsection{COMPARAÇÃO NO MESMO GRUPO}

Seguem-se as representações gráficas da comparação dos valores médios de gaveta e rigidez tanto craniais quanto caudais, nos diferentes grupos, obtidos nos três ciclos de 100 Newtons realizados (Gráfico 22 a 25).

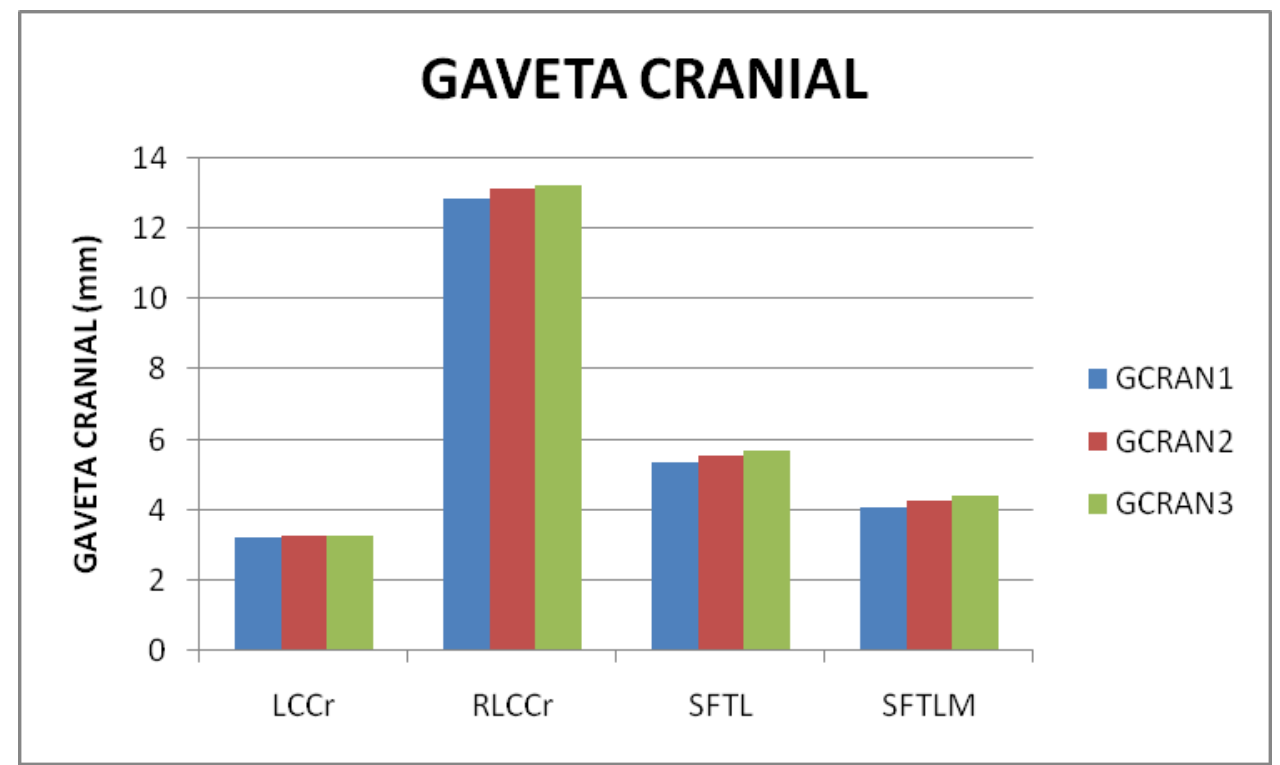

GCRAN1: gaveta cranial do primeiro ciclo; GCRAN2: gaveta cranial do segundo ciclo; GCRAN3: gaveta cranial do terceiro ciclo; LCCr: ligamento cruzado cranial íntegro; RLCCr: ligamento cruzado cranial rompido; SFTL: sutura fabelo-tibial lateral; SFTLM: sutura fabelo-tibial lateral e medial; mm: milímetro

Gráfico 22 - Comparação gráfica dos valores médios de gaveta cranial de cada um dos grupos quando submetidos aos três ciclos de 100 Newtons - São Paulo 2007 


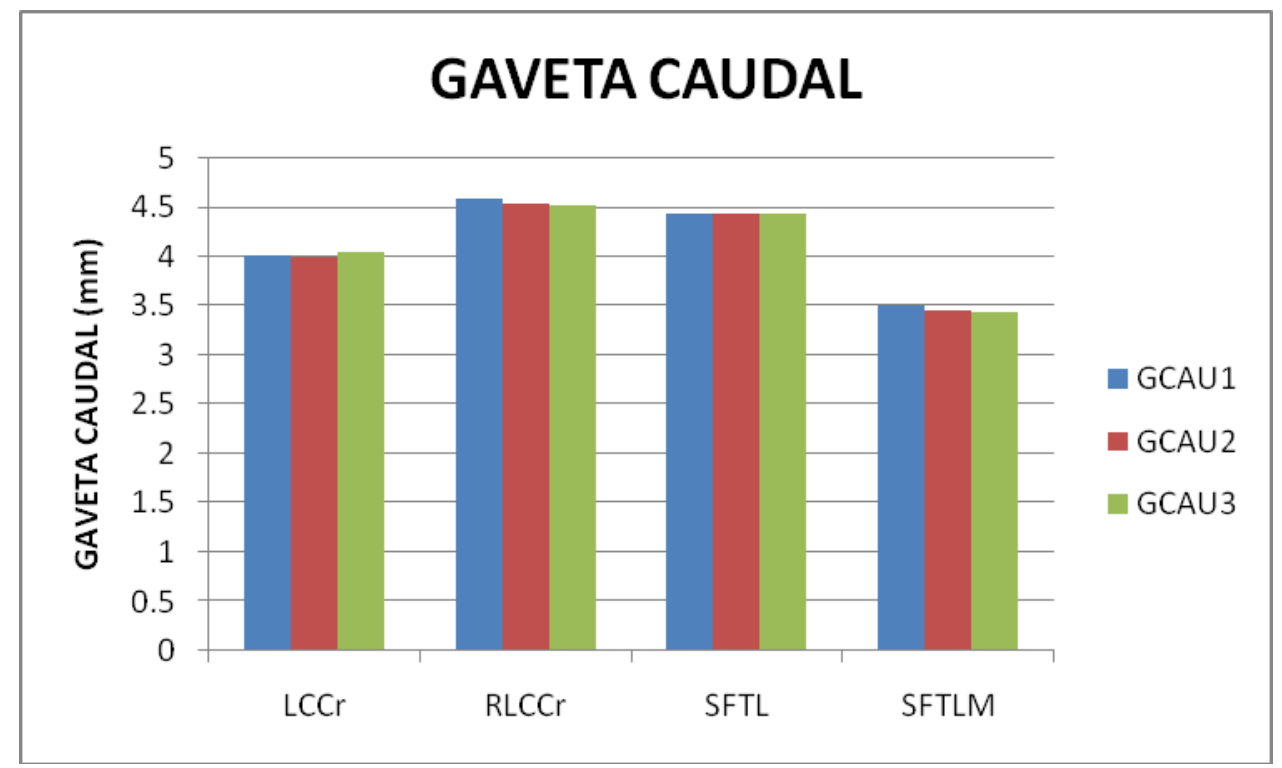

GCAU1: gaveta caudal do primeiro ciclo; GCAU2: gaveta caudal do segundo ciclo; GCAU3: gaveta caudal do terceiro ciclo; LCCr: ligamento cruzado cranial íntegro; RLCCr: ligamento cruzado cranial rompido; SFTL: sutura fabelo-tibial lateral; SFTLM: sutura fabelo-tibial lateral e medial; mm: milímetro

Gráfico 23 - Comparação gráfica dos valores médios de gaveta caudal de cada um dos grupos quando submetidos aos três ciclos de 100 Newtons - São Paulo 2007

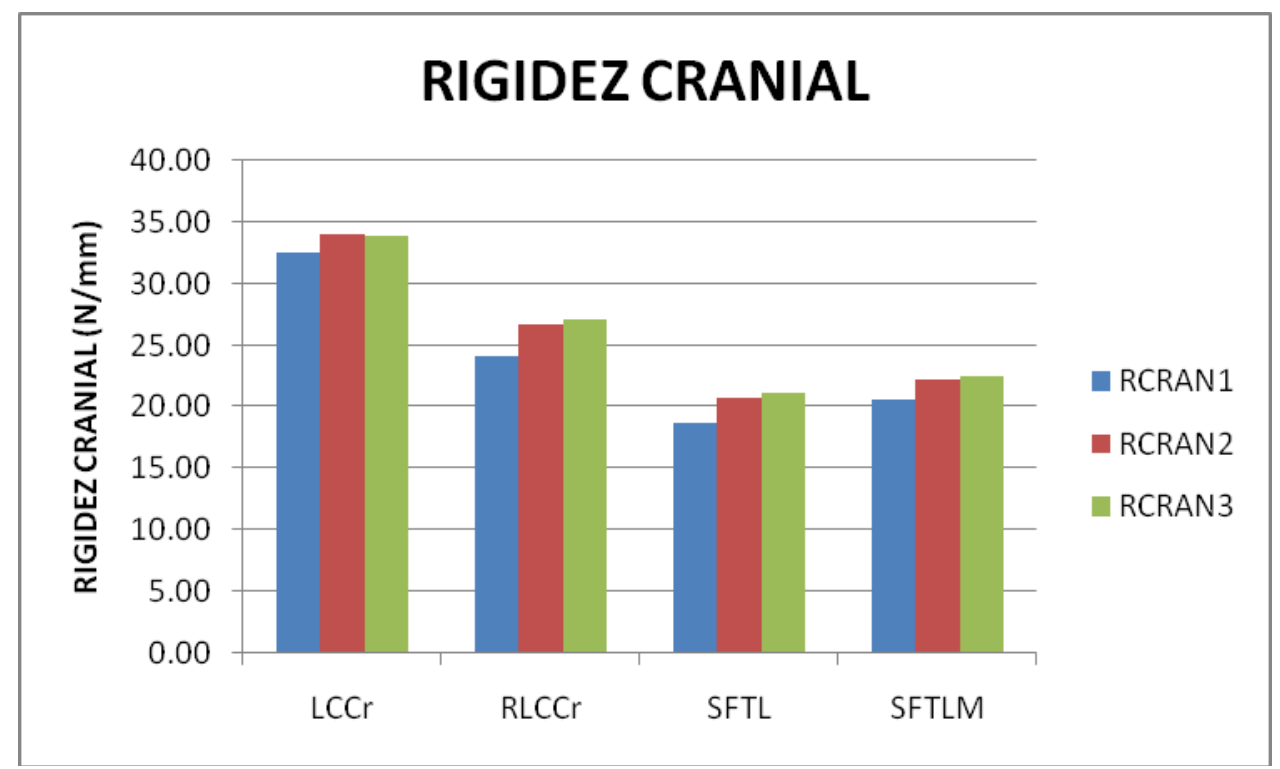

RCRAN1: rigidez cranial do primeiro ciclo; RCRAN2: rigidez cranial do segundo ciclo; RCRAN3: rigidez cranial do terceiro ciclo; LCCr: ligamento cruzado cranial íntegro; RLCCr: ligamento cruzado cranial rompido; SFTL: sutura fabelo-tibial lateral; SFTLM: sutura fabelo-tibial lateral e medial; N/mm: Newton/milímetro

Gráfico 24 - Comparação gráfica dos valores médios de rigidez cranial de cada um dos grupos quando submetidos aos três ciclos de 100 Newtons - São Paulo 2007 


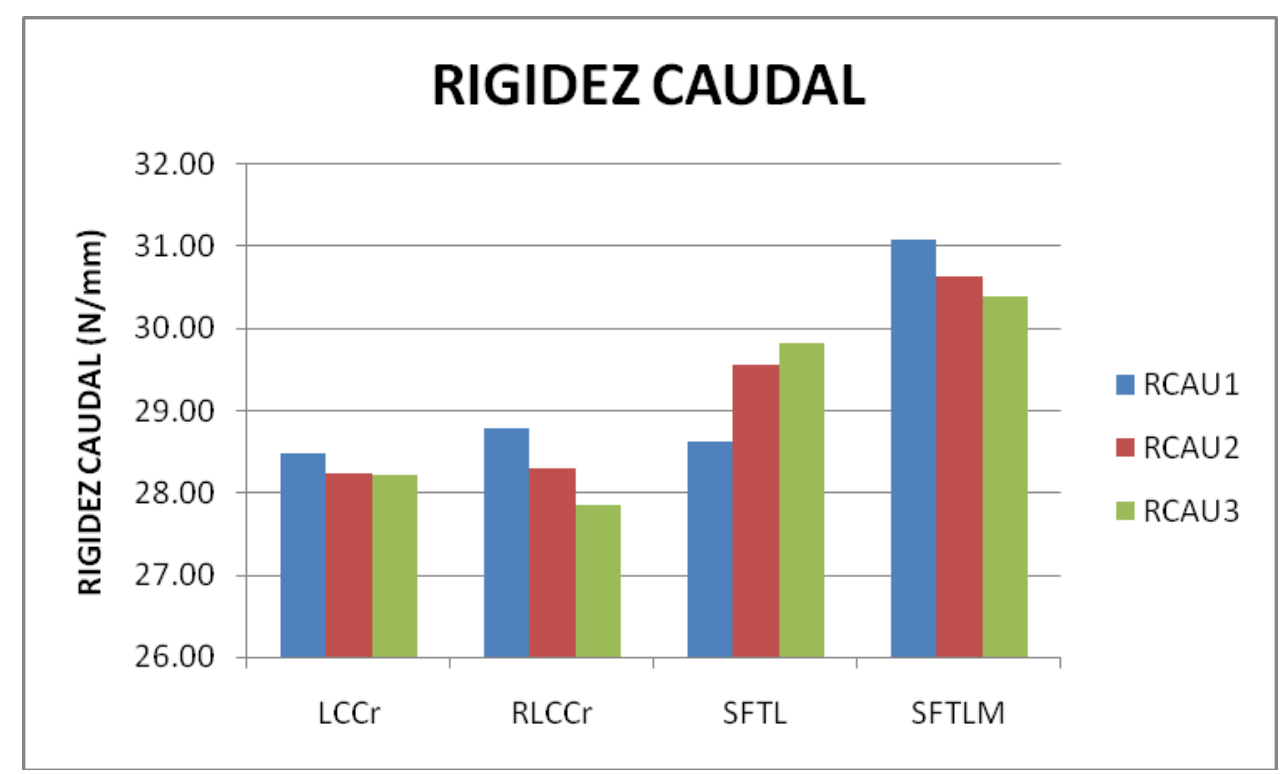

RCAU1: rigidez caudal do primeiro ciclo; RCAU2: rigidez caudal do segundo ciclo; RCAU3: rigidez caudal do terceiro ciclo; LCCr: ligamento cruzado cranial íntegro; RLCCr: ligamento cruzado cranial rompido; SFTL: sutura fabelo-tibial lateral; SFTLM: sutura fabelo-tibial lateral e medial; N/mm: Newton/milímetro

Gráfico 25 - Comparação gráfica dos valores médios de rigidez caudal de cada um dos grupos quando submetidos aos três ciclos de 100 Newtons - São Paulo 2007 


\subsection{COMPARAÇÃO ENTRE OS GRUPOS}

Seguem-se as representações gráficas da comparação dos valores médios de gaveta e rigidez tanto craniais quanto caudais obtidos nas diferentes situações de ensaio biomecânico, bem como seus respectivos desvios padrões (Gráfico 26 a 29).

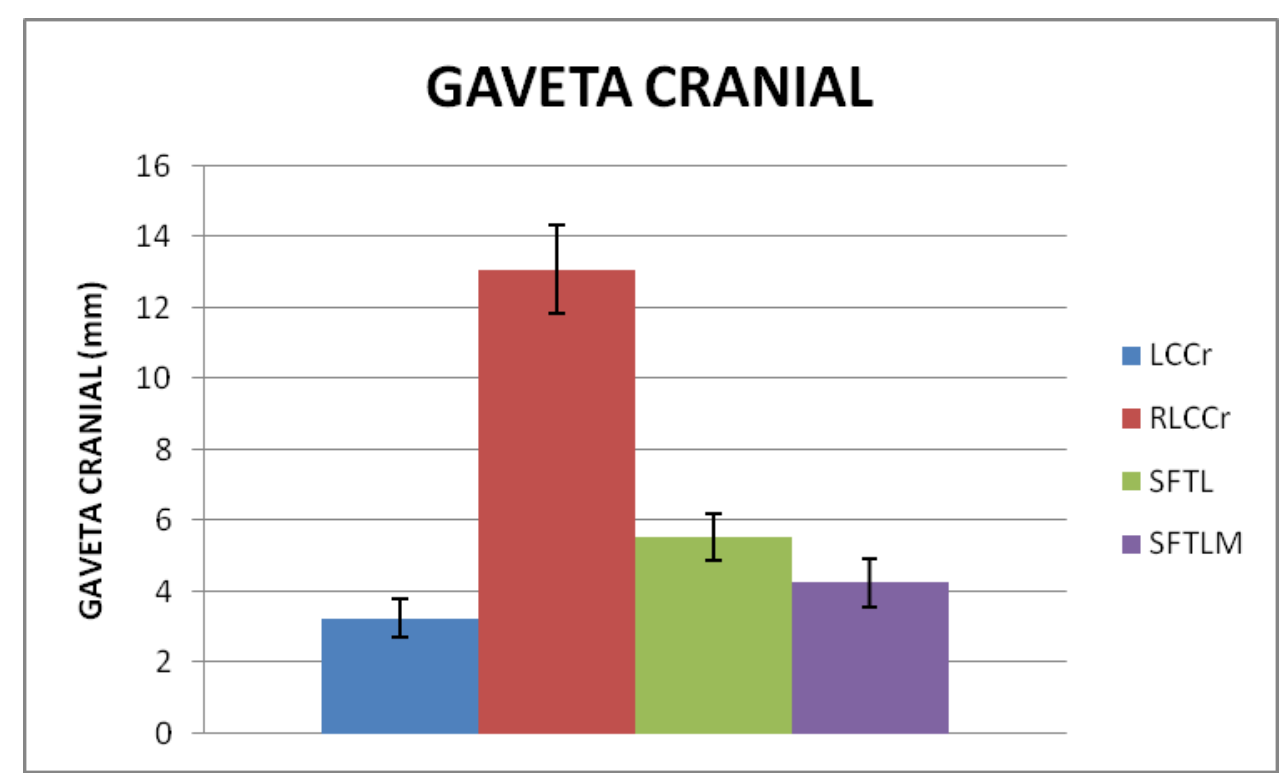

LCCr: ligamento cruzado cranial íntegro; RLCCr: ligamento cruzado cranial rompido; SFTL: sutura fabelo-tibial lateral; SFTLM: sutura fabelo-tibial lateral e medial; mm: milímetro

Gráfico 26- Comparação gráfica da média e desvio padrão da gaveta cranial apresentada pelos diferentes grupos quando submetidos aos ensaios com carga de 100 Newtons - São Paulo - 2007 


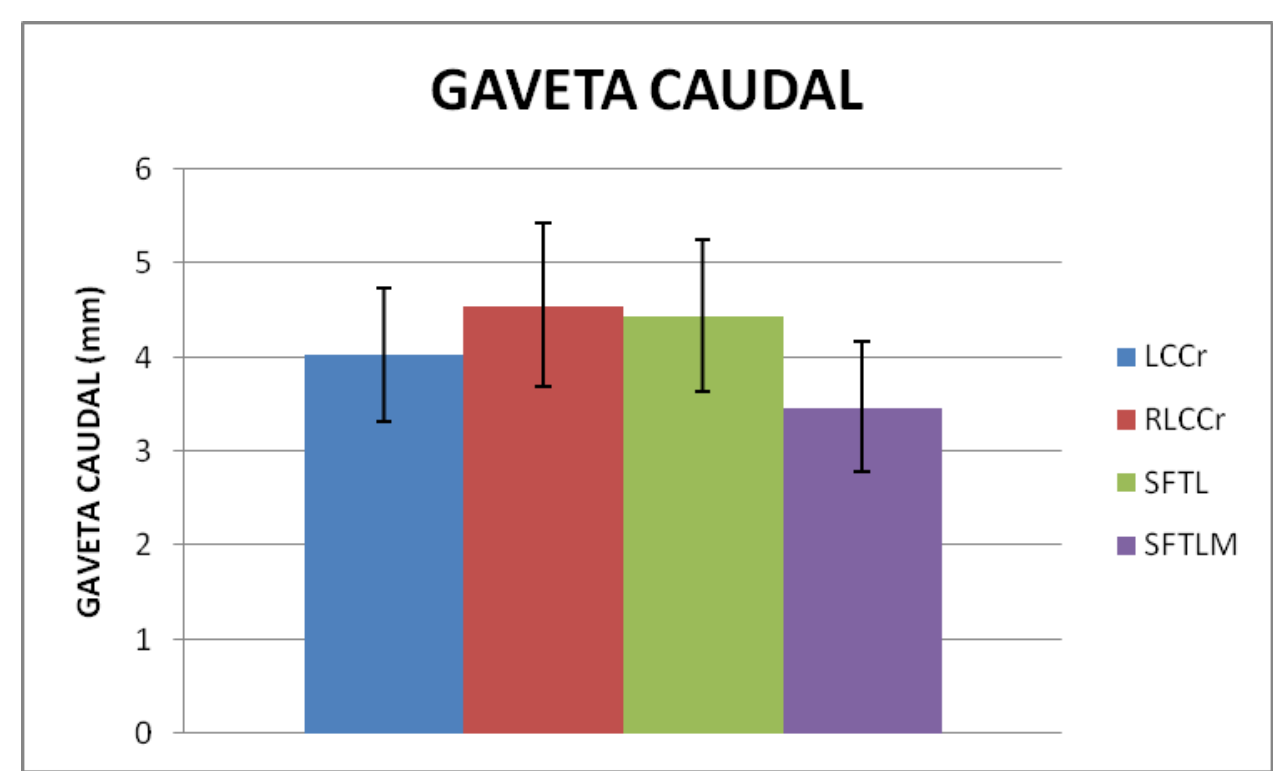

LCCr: ligamento cruzado cranial íntegro; RLCCr: ligamento cruzado cranial rompido; SFTL: sutura fabelo-tibial lateral; SFTLM: sutura fabelo-tibial lateral e medial; mm: milímetro

Gráfico 27 - Comparação gráfica da média e desvio padrão da gaveta caudal apresentada pelos diferentes grupos quando submetidos aos ensaios com carga de 100 Newtons - São Paulo - 2007

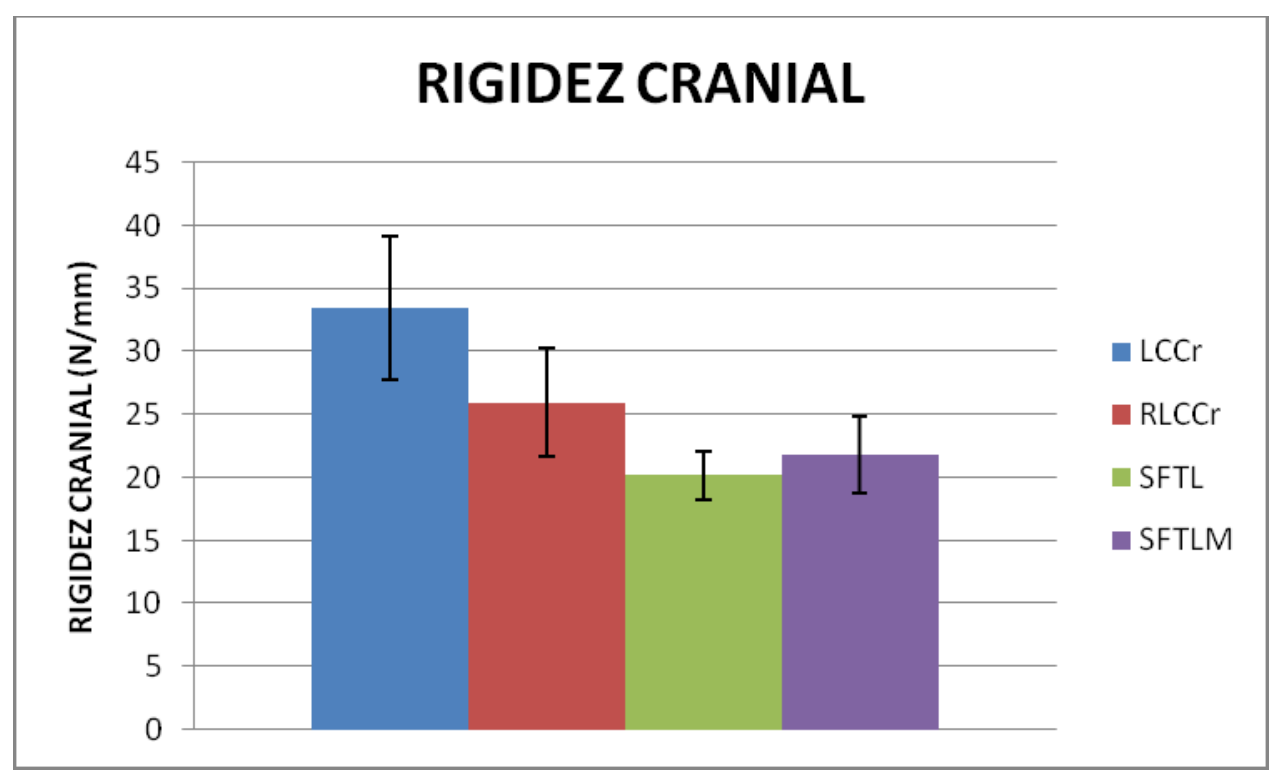

LCCr: ligamento cruzado cranial íntegro; RLCCr: ligamento cruzado cranial rompido; SFTL: sutura fabelo-tibial lateral; SFTLM: sutura fabelo-tibial lateral e medial; N/mm: Newton/milímetro

Gráfico 28 - Comparação gráfica da média e desvio padrão da rigidez cranial apresentada pelos diferentes grupos quando submetidos aos ensaios com carga de 100 Newtons - São Paulo - 2007 


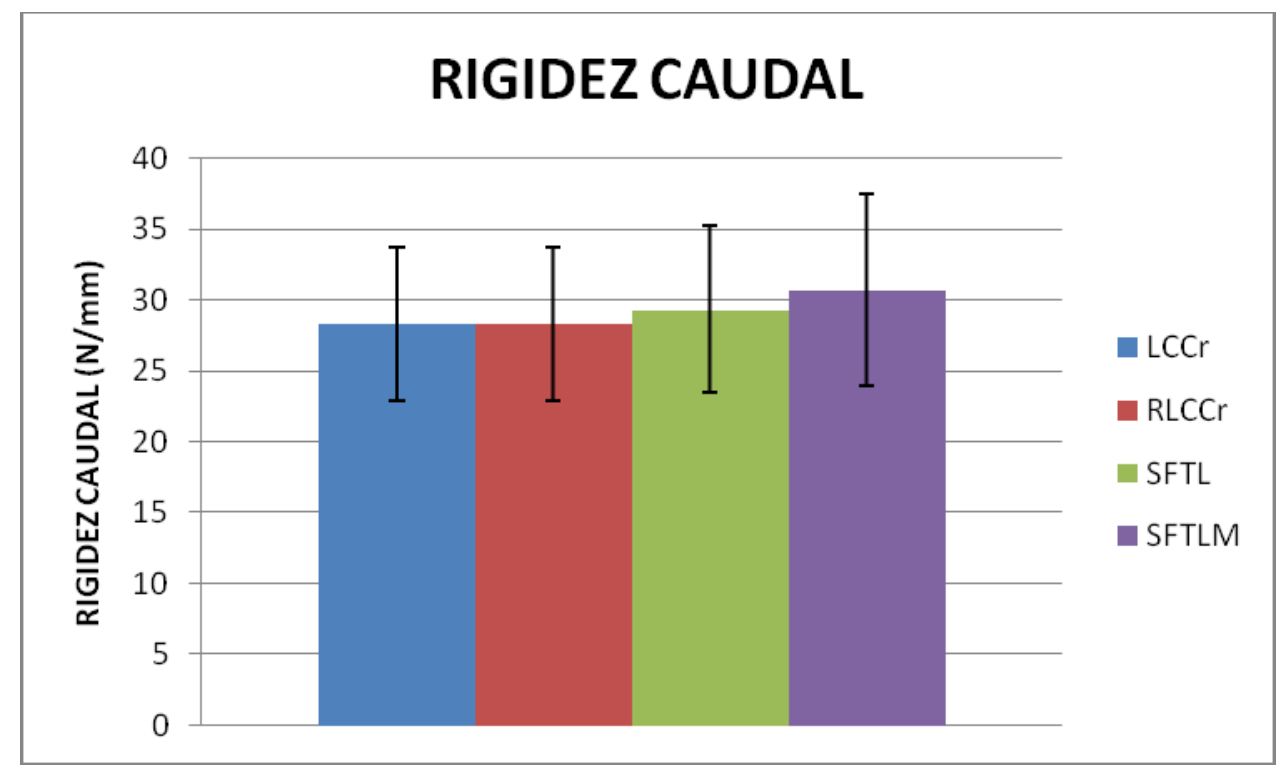

LCCr: ligamento cruzado cranial íntegro; RLCCr: ligamento cruzado cranial rompido; SFTL: sutura fabelo-tibial lateral; SFTLM: sutura fabelo-tibial lateral e medial; N/mm: Newton/milímetro

Gráfico 29 - Comparação gráfica da média e desvio padrão da rigidez caudal apresentada pelos diferentes grupos quando submetidos aos ensaios com carga de 100 Newtons - São Paulo - 2007 


\subsection{ANÁLISE ESTATÍSTICA}

A análise estatística foi dividida realizando a comparação por grupo e entre grupos.

\subsubsection{Comparação por grupo}

Os resultados da análise estatística comparando a gaveta e rigidez tanto craniais quanto caudais dos três ciclos para os diferentes grupos estão dispostos a seguir sob a forma de tabelas (Tabelas 43, 44, 45 e 46).

Tabela 43 - Gaveta cranial (GCRAN) em milímetros apresentada pelos diferentes grupos nos três ciclos de 100 Newtons de carga com respectivas médias, desvios padrões (DP) e probabilidades estatísticas (P) - São Paulo - 2007

\begin{tabular}{lcccccc}
\hline GRUPO & GCRAN1 & GCRAN2 & GCRAN3 & MÉDIA & DV & P \\
\hline LCCr & 3,24 & 3,26 & 3,29 & 3,27 & 0,55 & 0,9653 \\
RLCCr & 12,88 & 13,15 & 13,25 & 13,09 & 1,24 & 0,6317 \\
SFTL & 5,37 & 5,57 & 5,68 & 5,54 & 0,65 & 0,3167 \\
SFTLM & 4,07 & 4,29 & 4,44 & 4,27 & 0,69 & 0,2399 \\
\hline
\end{tabular}

LCCr: ligamento cruzado cranial íntegro; RLCCr: ligamento cruzado cranial rompido; SFTL: sutura fabelo-tibial lateral; SFTLM: sutura fabelo-tibial lateral e medial

Tabela 44 - Gaveta caudal (GCAU) em milímetros apresentada pelos diferentes grupos nos três ciclos de 100 Newtons de carga com respectivas médias, desvios padrões (DP) e probabilidades estatísticas (P) - São Paulo - 2007

\begin{tabular}{lcccccc}
\hline GRUPO & GCAU1 & GCAU2 & GCAU3 & MÉDIA & DP & P \\
\hline LCCr & 4,02 & 4,00 & 4,05 & 4,02 & 0,70 & 0,9790 \\
RLCCr & 4,59 & 4,54 & 4,53 & 4,55 & 0,87 & 0,9762 \\
SFTL & 4,45 & 4,43 & 4,45 & 4,44 & 0,80 & 0,9978 \\
SFTLM & 3,51 & 3,46 & 3,44 & 3,47 & 0,68 & 0,9494 \\
\hline
\end{tabular}

LCCr: ligamento cruzado cranial íntegro; RLCCr: ligamento cruzado cranial rompido; SFTL: sutura fabelo-tibial lateral; SFTLM: sutura fabelo-tibial lateral e medial 
Tabela 45 - Rigidez cranial (RCRAN) em Newton/milímetro apresentada pelos diferentes grupos nos três ciclos de 100 Newtons de carga com respectivas médias, desvios padrões (DP) e probabilidades estatísticas (P) - São Paulo - 2007

\begin{tabular}{lcccccc}
\hline GRUPO & RCRAN1 & RCRAN2 & RCRAN3 & MÉDIA & DP & P \\
\hline LCCr & 32,50 & 33,98 & 33,90 & 33,46 & 5,71 & 0,6581 \\
RLCCr & 24,19 & 26,65 & 27,12 & 25,99 & 4,51 & 0,0871 \\
SFTL & $18,78^{\mathrm{B}}$ & $20,70^{\mathrm{A}}$ & $21,11^{\mathrm{A}}$ & 20,19 & 2,17 & 0,0008 \\
SFTLM & 20,64 & 22,25 & 22,57 & 21,82 & 3,17 & 0,1182 \\
\hline
\end{tabular}

${ }_{\mathrm{A}, \mathrm{B}}$ Médias com sobrescritos diferentes na mesma linha diferem pelo Teste de Tukey $(\mathrm{P}<0,01)$; LCCr: ligamento cruzado cranial íntegro; RLCCr: ligamento cruzado cranial rompido; SFTL: sutura fabelo-tibial lateral; SFTLM: sutura fabelo-tibial lateral e medial

Tabela 46 - Rigidez caudal (RCAU) em Newton/milímetro apresentada pelos diferentes grupos nos três ciclos de 100 Newtons de carga com respectivas médias, desvios padrões (DP) e probabilidades estatísticas (P) - São Paulo - 2007

\begin{tabular}{lcccccc}
\hline GRUPO & RCAU1 & RCAU2 & RCAU3 & MÉDIA & DP & P \\
\hline LCCr & 28,49 & 28,25 & 28,21 & 28,32 & 5,33 & 0,9844 \\
RLCCr & 28,79 & 28,29 & 27,86 & 28,31 & 5,42 & 0,8646 \\
SFTL & 28,63 & 29,56 & 29,83 & 29,34 & 5,83 & 0,7977 \\
SFTLM & 31,09 & 30,64 & 30,39 & 30,71 & 6,67 & 0,9471 \\
\hline
\end{tabular}

LCCr: ligamento cruzado cranial íntegro; RLCCr: ligamento cruzado cranial rompido; SFTL: sutura fabelo-tibial lateral; SFTLM: sutura fabelo-tibial lateral e medial

Observou-se diferença significativa apenas na rigidez cranial do grupo SFTL entre a rigidez do primeiro ciclo e os demais $(\mathrm{P}<0,01)$, porém não houve diferença significativa entre o segundo e terceiro ciclo $(\mathrm{P}>0,05)$. 


\subsubsection{Comparação entre os grupos}

Os resultados da análise estatística comparando as médias da gaveta e rigidez tanto craniais quanto caudais dos diferentes grupos estão dispostos na Tabela 47.

Tabela 47 - Gaveta cranial (GCRAN) e caudal (GCAU) em milímetros e rigidez cranial (RCRAN) e caudal (RCAU) em Newton/milímetro apresentadas pelos diferentes grupos nos ensaios biomecânicos com carga de 100 Newtons com respectivas médias, desvios padrões (DP) e probabilidades estatísticas (P) - São Paulo - 2

\begin{tabular}{lccccccc}
\hline & LCCr & RLCCr & SFTL & SFTLM & MÉDIA & DP & P \\
\hline GCRAN & $3,26^{\mathrm{D}}$ & $13,09^{\mathrm{A}}$ & $5,54^{\mathrm{B}}$ & $4,27^{\mathrm{C}}$ & 6,54 & 3,96 & 0,0001 \\
GCAU & $4,02^{\mathrm{AB}}$ & $4,55^{\mathrm{A}}$ & $4,44^{\mathrm{A}}$ & $3,47^{\mathrm{B}}$ & 4,12 & 0,87 & 0,0001 \\
RCRAN & $33,46^{\mathrm{A}}$ & $25,99^{\mathrm{B}}$ & $20,19^{\mathrm{C}}$ & $21,82^{\mathrm{C}}$ & 25,36 & 6,57 & 0,0001 \\
RCAU & 28,32 & 28,31 & 29,34 & 30,71 & 29,17 & 5,88 & 0,5291 \\
\hline
\end{tabular}

${ }_{\mathrm{A}, \mathrm{B}, \mathrm{C}, \mathrm{D}}$ Médias com sobrescritos diferentes na mesma linha diferem pelo Teste de Tukey $(\mathrm{P}<0,05)$; LCCr: ligamento cruzado cranial íntegro; RLCCr: ligamento cruzado cranial rompido; SFTL: sutura fabelo-tibial lateral; SFTLM: sutura fabelo-tibial lateral e medial

A análise estatística demonstrou diferença significativa entre a média da gaveta cranial de todos os grupos sendo entre o grupo LCCr e RLCCr $(\mathrm{P}<0,001)$, LCCr e SFTL $(\mathrm{P}<0,001)$, LCCr e SFTLM (P < 0,01), RLCCr e SFTL $(\mathrm{P}<0,001)$, RLCCr e SFTLM $(\mathrm{P}<0,001)$ e SFTL e SFTLM $(\mathrm{P}<0,001)$.

Houve diferença significativa entre a média da gaveta caudal entre os grupos RLCCr e SFTLM ( $\mathrm{P}<0,001)$ e SFTL e SFTLM $(\mathrm{P}<0,001)$, sendo $\mathrm{P}>0,05$ na comparação da gaveta caudal entre os demais grupos.

Observou-se também diferença significativa entre a rigidez cranial entre os grupos LCCr e RLCCr ( $<<0,001)$, LCCr e SFTL ( $<<0,001)$, LCCr e SFTLM $(\mathrm{P}<0,001)$, RLCCr e SFTL $(\mathrm{P}<0,001)$ e RLCCr e SFTLM $(\mathrm{P}<0,01)$, sendo $\mathrm{P}>0,05$ entre SFTL e SFTLM.

Não foi encontrada diferença significativa entre os valores médios de rigidez caudal dos diferentes grupos. 


\subsubsection{Força residual}

Ao comparar a força residual encontrada para os diferentes grupos observou-se um valor de $\mathrm{P}<0,0001$ sendo significativa a diferença entre os grupos SFTL e RLCCr $(\mathrm{P}<0,01)$, SFTLM e RLCCr $(\mathrm{P}<0,001)$ e SFTL e SFTLM $(\mathrm{P}<0,001)$.

Ao analisarmos a correlação existente entre os grupos encontramos um $\mathrm{P}$ igual a 0,0111 (r $=0,5546)$ para a correlação de SFTL e RLCCr, sendo esta a única significativa encontrada obtendo P igual a 0,6473 ( $\mathrm{r}=0,1090)$ para a correlação de SFTLM e RLCCr e P igual a $0,7713(r=0,0693)$ para a correlação de SFTL e SFTLM. 
5 DISCUSSÃO 


\section{DISCUSSÃO}

A ruptura do ligamento cruzado cranial (RLCCr) é a principal causa de dor em membros pélvicos de cães. Trata-se de uma afecção de tão elevada freqüência que é relatada uma movimentação econômica de mais de um bilhão de dólares no tratamento de cães portadores da RLCCr (WILKE et al., 2005).

Devido a importância da RLCCr, uma vasta quantidade de estudos a seu respeito vem sendo realizada. São abordados os mais diferentes aspectos da RLCCr sendo alguns já bem estabelecidos enquanto outros não. Existe certo consenso quanto a sua etiopatogênia e epidemiologia, porém quando abordamos, principalmente, os diferentes tipos de tratamento e os respectivos prognósticos podemos observar diferentes condutas e resultados, que em muitos momentos, demonstram-se conflitantes. Desta forma optou-se pela realização deste trabalho com o intuito de avaliar e comparar de forma objetiva as técnicas SFTL e SFTLM com fio de náilon leader line, as quais são utilizadas nos pacientes portadores de RLCCr do Serviço de Cirurgia de Pequenos Animais do HOVET - FMVZ/USP.

Acredita-se que a RLCCr seja, predominantemente, de origem degenerativa podendo também ocorrer de forma traumática (LAMPMAN; LUND; LIPOWITZ, 2003). Foi constatado que o ligamento cruzado cranial (LCCr) de cães sofre, com o decorrer do tempo, uma degeneração, a qual acomete principalmente a sua porção central e que afeta mais precocemente cães de raça grande e gigante (VASSEUR et al., 1985). Tais características foram observadas também em nossa casuística, na qual algumas das raças mais acometidas são o Rottweiler, Labrador, Boxer e o Pit Bul (TATARUNAS et al., 2006; TATARUNAS et al., 2007).

Quanto ao tratamento da RLCCr, basicamente ele é dividido em clínico e cirúrgico. O tratamento clínico apresenta boa resposta para cães de até 15 quilos sendo pouco indicado para os animais de maior porte. Nestes animais a indicação geralmente é cirúrgica, sendo diversas as técnicas e materiais existentes (VASSEUR, 1984). Apesar desta indicação cirúrgica nos animais de maior porte, o estudo retrospectivo realizado por Morais, Tatarunas e Matera (2007) avaliando grau de satisfação dos proprietários quanto ao retorno a função do membro em animais com RLCCr tratados de forma conservadora no HOVET - FMVZ/USP, demonstrou melhora em $77 \%$ dos animais acima de 15 quilos. 
Apesar da diversidade de técnicas existentes ainda não foi possível estabelecer a superioridade de alguma delas baseando-se em evidências (ARAGON; BUDSBERG, 2005). Diversos são os trabalhos comparando biomecânicamente as técnicas, porém os resultados são muito variados, uma vez que os protocolos experimentais também não estão muito bem estabelecidos. Com o intuito de padronizar a metodologia foi utilizado neste estudo um protocolo baseado nas características biomecânicas dos ensaios realizados por Barreto (2000), Maradei Pereira (2004), Romano (2006) e Romano et al. (2006).

São descritos na literatura diversos tipos de materiais para a utilização nestas técnicas de sutura fabelo-tibial. Dentre eles, os mais citados são os fios de polipropileno (MOORE; READ, 1995), náilon (KORVICK; JOHNSON; SCHAEFFER, 1994), náilon leader line (MOORE; READ, 1995), aço (OLMSTEAD, 1993) e flúorcarbono leader line (BANWELL et al., 2004). Utiliza-se também enxerto de fascia lata com ou sem ligamento patelar deixando sua inserção à tuberosidade da tibia e fixando-o proximalmente a fabela lateral (HARPER et al., 2004). O náilon leader line é também utilizado na rotina do Serviço de Cirurgia de Pequenos Animais - HOVET - FMVZ/USP, sendo este um dos motivos pelo qual se optou pela sua utilização no estudo.

A sutura fabelo-tibial lateral, apesar de amplamente utilizada devido a sua relativa facilidade de execução e baixo custo de material apresenta resultados clínicos variáveis, sendo predominantemente classificados como satisfatórios (CHAUVET et al., 1996; CONZEMIUS et al., 2005). Conzemius et al. (2005) sugerem que tal resultado esteja relacionado com o grau de osteoartrose pré-existente à intervenção cirúrgica, apesar de ter sido relatado por Gordon et al. (2003) que o grau de severidade da osteoartrose ao exame radiográfico não possui valor preditivo com relação a função do membro. Segundo Piermattei e Flo (1997) esta sutura deve promover estabilização do joelho por curto período até que a fibrose peri-articular se desenvolva, resultando em estabilidade a longo prazo. Em busca de melhorar seus resultados clínicos com esta técnica muitos autores estudam modificações tanto da técnica quanto dos materiais (HARPER et al., 2004; MOORES et al., 2006; BARAÚNA JÚNIOR et al., 2007; GUÉNÉGO et al., 2007; GILES et al., 2008), fato que nos levou a realizar esta pesquisa.

Levando-se todos estes fatores em consideração, a proposta do presente trabalho foi comparar a técnica de sutura fabelo-tibial lateral, já bem estabelecida e difundida, com a técnica de imbricação do retináculo modificada (suturas fabelo-tibiais lateral e medial) pouco utilizada atualmente, com intuito de verificar, através de ensaio biomecânico, uma possível 
melhora da estabilidade articular com a adição do laço medial, bem como comparar o resultado das duas técnicas com o joelho íntegro.

A utilização de um único joelho nos diferentes grupos realizada neste trabalho, utilizandoo como seu próprio controle é suportada por Chailleux et al. (2007), os quais referem que tal metodologia elimina a influência de diferenças individuais que podem existir até mesmo para joelhos de um mesmo animal.

O pré-tensionamento do laço com aproximadamente $100 \mathrm{~N}$ de força foi estipulado através da análise prévia da força utilizada para a confecção do mesmo em situação clínica. Tal tensão também é citada em alguns estudos relacionados a RLCCr (CAPORN; ROE, 1996; ANDERSON et al., 1998; NWADIKE; ROE, 1998; VIANNA; ROE, 2006). Apenas 16,4 N

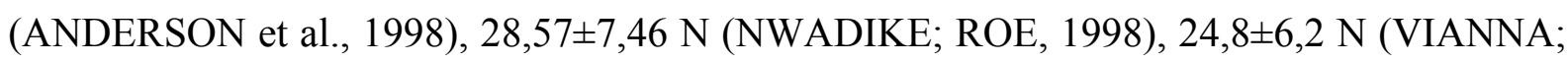
ROE, 2006) e 20\% da tensão inicial (CAPORN; ROE, 1996) são mantidos da tensão inicial de $100 \mathrm{~N}$, a qual é anterior a confecção do nó. Sendo a curva de aprendizado rápida (ANDERSON et al., 1998), concluem que, neste ponto, a habilidade do cirurgião em manter a tensão no laço é de extrema importância na promoção de estabilidade efetiva do joelho restaurado. É sugerido também por estes autores que o atrito do fio com os tecidos moles, quando da aplicação do fio no joelho, ajudam na manutenção da tensão no laço durante a confecção do nó. Apesar de tal propriedade não ter sido o foco deste experimento, acreditamos também que o atrito gerado auxilia na manutenção da tensão.

A utilização da fixação da primeira laçada com porta agulha, utilizada neste estudo, é suportada pelos seus relatos como benéfica na confecção do nó, aumentando a rigidez e tensão inicial do laço, sem comprometimento da força (CAPORN; ROE, 1996; HUBER; EGGER; JAMES, 1999).

Outro ponto que pode influenciar nos resultados é a variação individual na confecção do nó. Huber, Egger e James (1999) padronizaram a confecção do nó com a utilização de dinamômetro, porém neste trabalho, assim como em muitos outros (CAPORN; ROE, 1996), a padronização foi feita através da confecção dos nós por uma única pessoa. Da mesma forma que a força do cirurgião ao apertar o anel de aço influencia na biomecânica do laço (MOORES et al., 2006), acreditamos que variações individuais de tal natureza também afetem a confecção do nó. Sendo assim foi padronizada a tensão inicial do laço com o uso do dinamômetro e a confecção do nó através da execução exclusiva pelo autor deste estudo. 
Apesar de não ter sido aferida a tensão inicial do laço neste estudo, pode-se compactuar com a idéia de perda sensível da tensão inicial do laço na confecção do nó, sendo tomadas as medidas acima descritas para que este efeito fosse minimizado.

O uso da carga de $100 \mathrm{~N}$ de certa forma simula as condições a que o implante é submetido, pois é referida por Caporn e Roe (1996) como sendo semelhante a carga resistida pelo implante no uso do membro no pós-operatório. Porém é sugerido que os tecidos do joelho estão expostos a cargas que variam entre 10 a $25 \%$ de sua carga máxima a falha, sendo esta entre $1279 \mathrm{~N}$ a $2449 \mathrm{~N}$ para o LCCr (HULSE et al., 1983; JOHNSON et al., 1989; PATTERSON et al., 1991). Desta forma o real estresse a que são submetidos os implantes quando no joelho, onde a carga e o número de ciclos por tempo podem ser infinitamente maiores, ainda é desconhecido (NWADIKE; ROE, 1998). Caporn e Roe (1996) ao analisar a necessidade do náilon leader line de suportar tamanha ciclagem, mesmo que sob carga fisiológica, sugere que tal material pode não conseguir manter tensão suficiente durante o período necessário para o estabelecimento da fibrose periarticular. Assim acreditamos que a carga de $100 \mathrm{~N}$ simula condições, a que o implante é submetido quando do animal em repouso ou em atividade leve, sendo muito inferior aos valores atingidos em atividade física vigorosa (CAPORN; ROE, 1996; WEIGEL et al., 2005). Porém, levando-se em conta a proposta do trabalho, tal carga permitiu de forma adequada a avaliação biomecânica das duas técnicas e do joelho íntegro.

Patterson et al. (1991), em seu estudo biomecânico observou que forças de $80 \mathrm{~N}$ no sentido da gaveta cranial e $65 \mathrm{~N}$ no sentido caudal, permitiam avaliação das características biomecânicas dos joelhos sem gerar nenhum tipo de deformação permanente ou plástica. Através dos resultados obtidos neste projeto de pesquisa a carga a ser utilizada para ensaios biomecânicos com joelhos de cães pode ser a de $100 \mathrm{~N}$, tanto no sentido cranial quanto no caudal, sem que seus tecidos sejam submetidos a tal tipo de deformação.

A utilização do nó como método de fechamento do fio pode ter influenciado de forma negativa a biomecânica dos joelhos cirúrgicamente reparados. Vários trabalhos têm demonstrado a superioridade mecânica dos laços de NLL da marca Mason ${ }^{\circledR}$ fechados com o sistema de anel de aço quando confrontados com o nó (ANDERSON et al., 1998; PEYCKE et al., 2002; BANWELL et al., 2005; VIANNA; ROE, 2006). Sicard, Hayashi e Manley (2002) referem superioridade da utilização do nó quando a variável cotejada é a força máxima à falha, porém são inferiores quando da comparação de sua deformação com a apresentada pelo 
método de tubo de aço. Um consenso entre os autores é o de que independentemente do método de fechamento utilizado, gera-se uma deformação e um ponto de concentração de estresse no fio de NLL que o enfraquece, sendo a maior parte das falhas observadas nestes locais (LEWIS; MILTHORPE; BELLENGER, 1997; ANDERSON et al., 1998; PEYCKE et al., 2002; SICARD; HAYASHI; MANLEY, 2002; BANWELL et al., 2005). Outros pontos citados como pontos de estresse são o túnel na tuberosidade da tíbia, o ligamento fabelofemoral e a fabela (ANDERSON et al., 1998). Estes pontos de fraqueza não foram observados neste estudo, talvez devido a sua característica não destrutiva.

Deve-se considerar também a influência do método de esterilização utilizado sobre o desempenho biomecânico dos joelhos reparados, independentemente da técnica, uma vez que ambas utilizaram o mesmo material esterilizado da mesma forma. Sicard et al. (1999) referem aumento significativo da deformação do náilon após a esterilização em autoclave quando comparado com o mesmo material não estéril. Referem também que a deformação do material é uma característica mais relevante que a sua força, já que ela resulta principalmente da carga cíclica exercida sobre o material, representando melhor a situação do material quando aplicado ao joelho in vivo. Tal deformação é resultante do ajuste do nó ou da deformação do próprio material (NWADIKE; ROE, 1998; PEYCKE et al., 2002). Os autores referem também que a escolha do melhor método de esterilização deve ser realizada levando-se em conta a marca do fio e não apenas o material, pois a resposta das diferentes marcas de fios de náilon foi diferente para cada tipo de esterilização (SICARD et al., 1999). Tal consideração é reforçada por Sicard, Hayashi e Manley (2002) ao observar que a esterilização em autoclave gerou menor deformação no náilon leader line da marca Mason ${ }^{\circledR}$ do que em outras marcas testadas. Este estudo verificou também que a esterilização por autoclave aumentou a deformação mantendo a resistência do material quando comparados com a esterilização por óxido de etileno. Peycke et al. (2002) ainda ressalta que o diâmetro do fio deve ser considerado no momento da escolha do método de esterilização, pois observaram que a esterilização pode alterar as propriedades de diferentes tamanhos de NLL de forma diferente.

No entanto os resultados obtidos neste estudo demonstram a viabilidade da utilização do NLL de 60 libras da marca Mason ${ }^{\circledR}$ esterilizado por autoclave, uma vez que o óxido de etileno ainda não é acessível para muitos veterinários, porém não se recomenda a re-esterilização do material (LEWIS; MILTHORPE; BELLENGER, 1997). Ao analizarem os efeitos da esterilização sobre o NLL de 60 libras observaram que um ciclo de $134,5^{\circ} \mathrm{C}, 207 \mathrm{kPa}$ por 3 
minutos não afetou o seu diâmetro, não havendo diferença estatísticamente significante entre a força deste fio, fechado com nó, esterilizado ou não esterilizado (LEWIS; MILTHORPE; BELLENGER, 1997). O ciclo de esterilização utilizado nesta pesquisa de $121,0{ }^{\circ} \mathrm{C}$, pressão de $103,4 \mathrm{kPa}$, durante 20 minutos aparentemente não afetou as características do NLL, demonstrando bons resultados durante os ensaios realizados.

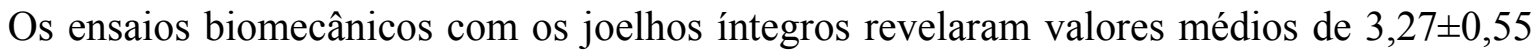
$\mathrm{mm}$ de gaveta cranial, sendo este semelhante aos $3,0 \pm 0,8 \mathrm{~mm}$ encontrados por Lewis, Milthorpe e Bellenger (1997) e 3,46 $\pm 1,08 \mathrm{~mm}$ (ROMANO et al., 2006). A gaveta caudal de 4,02 $\pm 0,71 \mathrm{~mm}$ observada, não é analisada nos demais estudos consultados, apesar de ter sido realizada (PATTERSON et al., 1991; LEWIS; MILTHORPE; BELLENGER, 1997). A rigidez cranial de $33,46 \pm 5,70 \mathrm{~N} / \mathrm{mm}$ é próxima de $37,52 \mathrm{~N} / \mathrm{mm}$ obtida por Romano et al. (2006) em estudo com metodologia semelhante, enquanto Wingfield et al. obtiveram 194,8 e $158,3 \mathrm{~N} / \mathrm{mm}$ de rigidez cranial em ensaio destrutivo do LCCr, em ângulo de $130^{\circ} \mathrm{e}$ velocidade de $1000 \mathrm{~mm} /$ minuto, de cães da raça Rottweiler e Greyhound respectivamente. A rigidez caudal de $28,31 \pm 5,37 \mathrm{~N} / \mathrm{mm}$, da mesma forma que a gaveta caudal não foi analisada nos estudos pesquisados.

Os ensaios biomecânicos dos joelhos com RLCCr revelaram valores médios de 13,09 $\pm 1,25$ $\mathrm{mm}$ de gaveta cranial, sendo este também próximo aos 12,2 $\pm 1,9 \mathrm{~mm}$ encontrados por Lewis,

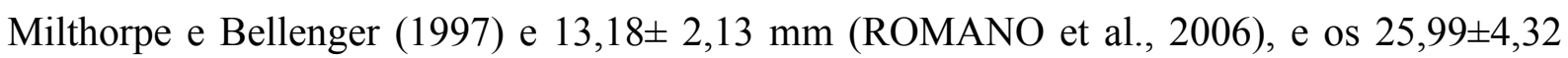
$\mathrm{N} / \mathrm{mm}$ de rigidez cranial próximos dos 23,65 N/mm observados por Romano et al. (2006). A

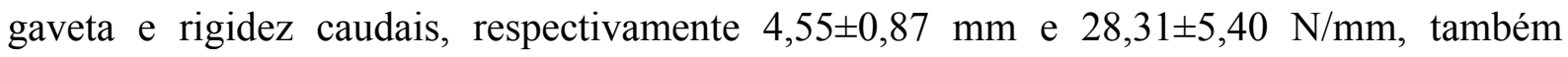
ficaram sem parâmetros para comparação.

Os ensaios biomecânicos dos joelhos recuperados pela SFTL revelaram valores médios de $5,54 \pm 0,65 \mathrm{~mm}$ de gaveta cranial, enquanto Lewis, Milthorpe e Bellenger (1997) obtiveram

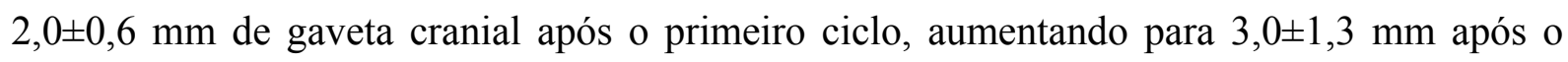
décimo segundo ciclo. Em seu protocolo de pesquisa utilizaram NLL de 80 libras, $80 \mathrm{~N}$ de carga em sentido cranial e $60 \mathrm{~N}$ de carga caudal a uma velocidade de $25 \mathrm{~mm} /$ minuto. Caporn e Roe (1996) obtiveram grande deformação do laço, ao analisarem o desempenho da fixação do fio ao ligamento fabelo-femoral, sugerindo possível ruptura parcial do ligamento quando submetidos a carga de 100 N. Fato este, não observado nos três ciclos consecutivos de $100 \mathrm{~N}$

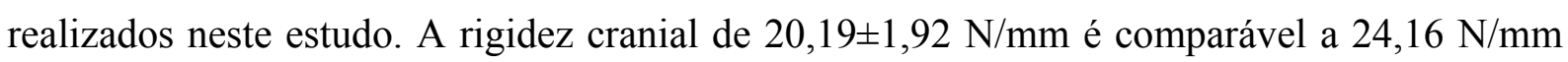


(ROMANO, 2006). A gaveta e rigidez caudais, respectivamente 4,44 $\pm 0.81 \mathrm{~mm}$ e $29,34 \pm 5,87$ $\mathrm{N} / \mathrm{mm}$ não puderam ser comparadas com outros resultados.

Os ensaios biomecânicos dos joelhos recuperados com a SFTLM revelaram valores médios de 4,27 $\pm 0,68 \mathrm{~mm}$ de gaveta cranial, 3,47 $\pm 0,69$ de gaveta caudal, 21,82 $\pm 3,07 \mathrm{~N} / \mathrm{mm}$ de rigidez cranial e $30,70 \pm 6,74 \mathrm{~N} / \mathrm{mm}$ de rigidez caudal, não sendo encontrado nenhum estudo biomecânico com a mesma técnica para comparação dos dados. Porém Chailleux et al. (2007) ao analisarem a cinemática do joelho estabilizado por tal técnica referem não ter notado movimento de gaveta cranial. Os autores discutem que a ausência de gaveta cranial apresentada pela técnica pode ser um reflexo da circunstância em que os joelhos foram testados, já que sua metodologia simulou o membro na fase da marcha sem sustentação do peso. Apesar de não terem estudado a biomecânica desta técnica, Lewis, Milthorpe e Bellenger (1997) relatam seu uso em sua rotina ortopédica.

A análise estatística dos três ciclos de gaveta cranial e caudal de cada grupo (LCCr, RLCCr, SFTL e SFTLM) não demonstrou diferença significativa, diferente de Patterson et al. (1991) que observaram aumento significativo na translação cranial da tibia em relação ao fêmur quando submetida a três ciclos consecutivos com carga de $180 \mathrm{~N}$ e Nwadike e Roe (1998) que referem perda significativa da tensão no laço durante teste cíclico, sendo $90 \%$ desta perda nos primeiros três ciclos dos dez realizados. Apesar da semelhança estatística existe um aumento do deslocamento cranial de um ciclo para outro. Nesta situação, assumindo a citação de Nwadike e Roe (1998) para os três primeiros ciclos, pode-se supor que a eficiência das técnicas testadas em testes cíclicos maiores seria semelhante aos encontrados neste estudo, já que teríamos incluído a faixa de maior variabilidade de tensão no laço. Desta forma, a partir do terceiro ciclo a gaveta cranial pouco se alteraria.

Já na avaliação da rigidez cranial o único grupo em que foi encontrada diferença entre os ciclos foi o grupo da SFTL, no qual a rigidez no primeiro ciclo foi maior que a do segundo e terceiro não havendo diferença entre estes dois últimos. Tal resultado esta de acordo com Patterson et al. (1991) que observaram queda gradativa da rigidez nos três ciclos craniais de $180 \mathrm{~N}$ em joelho com RLCCr reparado com técnica extra-capsular semelhante a SFTL. A diferença apenas entre o primeiro e segundo ciclo pode ser explicada pela acomodação do nó (NWADIKE; ROE, 1998; PEYCKE et al., 2002) durante o primeiro ciclo.

$\mathrm{Na}$ rigidez caudal dos três ciclos nos diferentes grupos não foi encontrada diferença estatística significante. 
Outro fator importante e ausente em nosso estudo é a função da contração muscular dando suporte ao joelho e gerando maior estabilidade (HARPER et al., 2004).

A comparação da gaveta cranial entre os diferentes grupos demonstrou diferenças entre todos eles (LCCr X RLCCr X SFTL X SFTLM). A diferença encontrada entre o grupo LCCr e RLCCr $(\mathrm{P}<0,001)$, e entre RLCCr e SFTL $(\mathrm{P}<0,001)$, confere com os resultados de Lewis, Milthorpe e Bellenger (1997) e Romano et al. (2006), porém o mesmo não pode ser dito na comparação entre o grupo LCCr e SFTL $(\mathrm{P}<0,001)$. No estudo dos autores citados anteriormente não houve diferença entre a gaveta cranial do grupo LCCr quando comparada com o grupo SFTL. O conflito dos nossos resultados com os encontrados por estes autores pode ser decorrente na diferença da metodologia utilizada por Lewis, Milthorpe e Bellenger (1997), o qual usou carga cranial de $80 \mathrm{~N}$ e registrou o movimento de gaveta cranial como o deslocamento produzido até $25 \mathrm{~N}$ de força ou diferença no fio utilizado, não sendo referido o diâmetro e marca do fio por Romano (2006), e fio de NLL da Mason ${ }^{\circledR}$, porém de 80 libras, por Lewis, Milthorpe e Bellenger (1997). A diferença entre o grupo LCCr e SFTLM (P<0.01), RLCCr e SFTLM $(\mathrm{P}<0,001)$ e SFTL e SFTLM $(\mathrm{P}<0,001)$ não econtramos parâmetros para comparação, porém demonstram que a SFTLM registrou valores de gaveta cranial mais próximos de LCCr.

A diferença estatística da gaveta caudal foi encontrada entre o grupo RLCCr e SFTLM $(\mathrm{P}<0,001)$ e entre SFTL e SFTLM $(\mathrm{P}<0,001)$. Apesar de não existir diferença estatística significativa entre a gaveta caudal do grupo LCCr e os demais grupos $(\mathrm{P}>0,05)$, o aumento da gaveta caudal no grupo RLCCr e SFTL, observado em nosso estudo, é citado por Harper et al. (2004), o qual também observou aumento no deslocamento caudal de acordo com a técnica de reconstrução do LCCr utilizada, porém dados de diminuição da gaveta caudal gerada por algum tipo de reconstrução, como a observada para a SFTLM, não foram encontrados na literatura consultada.

A explicação encontrada para esta mudança na biomecânica do ligamento cruzado caudal nas diferentes situações (RLCCr, SFTL e SFTLM) baseia-se na seguinte hipótese: no joelho com os ligamentos cruzados íntegros existe uma relação normal entre as estruturas restritoras e uma distribuição fisiológica das forças pelas mesmas (HARPER et al., 2004) levando a um deslocamento caudal normal, bem como um movimento fisiológico de rotação axial da tíbia. No momento em que o LCCr é rompido estas características de rotação e relação com os restritores se alteram, gerando maior sobrecarga no ligamento cruzado caudal e resultando 
em maior gaveta caudal que no joelho íntegro. Na SFTL, como citado por Arnoczky, Torzilli e Marshall (1977) e Selmi et al. (2003), existe uma restrição da rotação axial da tíbia somada a uma força de compressão entre as superfícies articulares da tíbia e do fêmur, relacionada com a mudança do centro instantâneo de movimento. Sugerimos que esta força de compressão deva aumentar o contato entre as estruturas restritoras do joelho, diminuindo desta forma a gaveta caudal quando comparada com o joelho com RLCCr, sendo mais exuberante para a SFTLM do que para SFTL.

A SFTLM apesar de possuir o laço medial também promove, da mesma forma que a SFTL, a rotação externa da tibia e movimento de abdução no joelho reconstruído (CHAILLEUX et al., 2007). Esta técnica de estabilização extra-capsular reduziu o deslocamento da gaveta caudal a proporções menores do que as observadas até mesmo para o joelho íntegro, não sendo encontrado relato de tal influência na literatura consultada até o presente momento. Acreditamos que a resposta para tal alteração da biomecânica do ligamento cruzado caudal se deva também a restrição da rotação axial da tíbia baseando-se em estudo realizado por Amis et al. (2003). Estes autores referem a importância das estruturas periarticulares na promoção da estabilidade do joelho, sendo estas estruturas em alguns momentos mais importantes que o ligamento cruzado caudal na manutenção da estabilidade caudal do joelho (HARARI et al., 1987). Citam o ligamento cruzado caudal e as estruturas postero-laterais como atuantes na restrição da gaveta posterior dependendo do ângulo de flexão do membro, sendo o ligamento cruzado caudal mais efetivo quando do membro em flexão e as estruturas postero-laterais com o membro em extensão. Ressaltam também que com a limitação da rotação da tíbia existe uma menor contribuição do ligamento cruzado caudal como restitor da gaveta caudal, pois a força aplicada é redistribuída para as estruturas postero-laterais do joelho (AMIS et al., 2003) fato observado também por Fukubayashi et al. (1982) que citam a limitação da rotação da tíbia como responsável por diminuir o movimento de gaveta posterior do joelho em até $30 \%$. Desta forma a rotação externa proporcionada pela SFTL e SFTLM deve tensionar as estruturas postero-laterais aumentando a sua contribuição na restrição da gaveta caudal nos ensaios biomecânicos, justificando assim a menor gaveta caudal observada nos joelhos reconstruídos.

Diferentemente do realizado por Patterson et al. (1991), que seccionou o ligamento colateral medial para avaliação biomecânica de técnicas extra-capsulares, optamos pela manutenção do mesmo durante os ensaios para que agisse em conjunto com o implante na 
restrição da gaveta cranial da mesma forma como agem in vivo. Acreditamos também que tal procedimento tornaria os resultados não representativos da influência das técnicas sobre os joelhos reconstruídos, não apenas pela atuação do ligamento colateral medial na restrição da translação cranial, mas também pela sua atuação e das estruturas postero-mediais (AMIS et al., 2003) na contraposição da abdução gerada pelas técnicas de reconstrução extra-capsulares (CHAILLEUX et al., 2007).

A liberdade de movimento da tibia nos três planos permitiu uma melhor simulação da biomecânica das técnicas in vivo (HARPER et al., 2004), diferentemente de outros estudos onde esta liberdade não existiu (PATTERSON et al., 1991; LEWIS; MILTHORPE; BELLENGER, 1997), não sendo também encontrada interferência na variabilidade dos resultados como citado por Fukubayashi et al. (1982).

Apesar da liberdade de movimento da tibia não foi possível a análise de sua rotação durante os ensaios como o realizado por Harper et al. (2004) e Chailleux et al. (2007). Sendo relatado por Harper et al. (2004) a rotação externa em todos os joelhos reconstruídos por técnicas extra-capsulares e ausência de rotação na maioria dos joelhos íntegros.

Este tipo de influência das duas técnicas extra-capsulares estudadas sobre o ligamento cruzado caudal não foi encontrado na literatura, porém Arnoczky, Torzilli e Marshall em 1977 já relatavam que estes tipos de estabilização adicionam restrições a movimentação normal do joelho, não associadas a função normal do ligamento cruzado, predispondo também a lesões cartilagíneas. Outro ponto de nosso estudo que reforça esta teoria da força de compressão das superfícies articulares é a análise das forças residuais encontradas nos ensaios biomecânicos. De maneira geral a SFTL gerou forças residuais positivas, ou seja, de tração, na célula de carga da máquina de ensaios mecânicos, sendo esta ainda maior para a SFTLM, isso quando comparadas com a posição de força residual zero que é a estabelecida para o grupo LCCr, nossa referência nesta situação. Sugerimos que tal força de tração gerada seja resultante da compressão articular proporcionada pelas técnicas de reconstrução e que pelo fato da tibia estar fixa a garra distal o fêmur é tracionado distalmente gerando tração na célula de carga. $O$ contrário acontece no grupo RLCCr, o qual de maneira geral apresentou forças residuais negativas, ou seja, de compressão, na célula de carga. Nesta situação, como o ponto de referência também é o joelho íntegro, a ausência do LCCr mantendo o equilíbrio das forças na articulação gera a força de compressão na célula de carga. 
$\mathrm{Na}$ avaliação destas forças uma das limitações deste estudo é a possibilidade da avaliação apenas da resultante axial da força residual, ou seja, compressão e tração, devido a célula de carga utilizada. Uma célula de carga que medisse os vetores componentes de força nos três eixos (MARGHERITINI et al., 2004; YAMAMOTO et al., 2004) elucidaria melhor tais forças residuais, contribuindo também para um melhor entendimento das forças atuantes durante os ensaios biomecânicos.

A análise estatística das forças residuais dos grupos SFTL, SFTLM e RLCCr demonstrou diferença estatística significativa entre os grupos $(\mathrm{P}<0,0001)$, sendo a correlação significativa apenas entre o grupo SFTL e $\operatorname{RLCCr}(\mathrm{P}=0,0111)$, porém o fator que relaciona a força residual destes dois grupos não pôde ser estabelecido.

Outra limitação do trabalho é a repetibilidade do reposicionamento dos joelhos na máquina de ensaios mecânicos através da metodologia utilizada, a qual não foi estudada. Apesar do minucioso reposicionamento, auxiliado pelas três medidas (ângulo de rotação, paquímetro inicial e distância da tíbia), pequenas mudanças no reposicionamento podem estar contribuindo na força residual encontrada, bem como interferindo de diferentes formas nos ensaios biomecânicos (PATTERSON et al., 1991).

Houve também diferença significativa entre a rigidez cranial do grupo LCCr e RLCCr $(\mathrm{P}<0,001)$, LCCr e SFTL ( $<<0,001)$, LCCr e SFTLM ( $<<0,001)$, RLCCr e SFTL $(\mathrm{P}<0,001)$ e RLCCr e SFTLM $(P<0,01)$, não sendo a mesma observada entre os dois tipos de reconstrução $(\mathrm{P}>0,05)$. Resultado semelhante ao obtido por Harper et al. (2004) onde a rigidez cranial do grupo LCCr foi maior que a do RLCCr, a qual foi maior que a dos grupos reconstruídos. A rigidez maior no grupo RLCCr do que nos reconstruídos é explicada pela ausência do restritor primário ( $\mathrm{LCCr}$ ), sendo a carga distribuida pelos demais restritores, como por exemplo os ligamentos colaterais e os meniscos (HARPER et al., 2004), os quais possuem rigidez maior que a do NLL. No entanto, segundo Harper et al. (2004) cada técnica de reconstrução gera diferentes forças sobre as estruturas do joelho explicando as diferenças de rigidez das técnicas observadas em seu estudo. Em nosso estudo, apesar de serem utilizadas duas técnicas diferentes, não foi possível observar diferença estatística significativa entre a rigidez cranial e a rigidez caudal dos grupos reconstruídos $(\mathrm{P}>0,05)$.

Os efeitos a longo prazo da restrição da rotação axial normal da tíbia durante a flexão e extensão e a real participação das estruturas postero-laterais do joelho proporcionada por estas duas técnicas ainda não foram totalmente elucidados, porém é sugerido que a perpetuação 
destas forças na articulação promovam forças de compressão excessivas no compartimento lateral da tíbia (CHAILLEUX et al., 2007) e pelo fato das estruturas posterolaterais do joelho e o ligamento cruzado caudal também serem responsáveis pela restrição da rotação externa excessiva da tibia, agindo de forma semelhante a restrição da gaveta caudal, ou seja, o ligamento cruzado caudal mais efetivo na restrição à flexão e as estruturas posterolaterais à extensão (AMIS et al., 2003; YOON et al., 2006), estas podem estar sendo sobrecarregadas no joelho reconstruído.

A possível sobrecarga das estruturas posterolaterais do joelho proporcionanda pela SFTL e SFTLM deve ser levada em consideração nas RLCCr traumáticas, nas quais tais estruturas podem estar lesionadas. Nestas situações de lesões combinadas (WOO et al., 1990) em que existe uma maior complexidade do mecanismo de instabilidade o uso destas técnicas pode não ser recomendado.

Sabe-se que a RLCCr resulta em alteração da morfologia do ligamento cruzado caudal em cães, gerando alteração da matrix extra-celular, caracterizada por metaplasia condróide e perda da arquitetura celular, provavelmente devido a microtraumas e degradação enzimática secundários a instabilidade (ZACHOS et al., 2002). Porém as conseqüências da influência na biomecânica do ligamento cruzado caudal gerada pelas técnicas aqui estudadas não são descritas, sendo esse fato muito citado principalmente nas técnicas de nivelamento do platô tibial, onde pode ocorrer a sobrecarga do ligamento cruzado caudal (WARZEE et al., 2001). 
6 CONCLUSÕES 


\section{CONCLUSÕES}

Face aos resultados obtidos neste estudo biomecânico, pode-se concluir que:

$\checkmark$ A metodologia utilizada permitiu avaliação biomecânica adequada do joelho com ligamento cruzado cranial íntegro, rompido e estabilizado por uma das técnicas estudadas.

$\checkmark$ A RLCCr gera aumento da instabilidade cranial da tíbia em relação ao fêmur sem influenciar na quantidade de movimento de gaveta caudal.

$\checkmark$ A RLCCr promove uma redução significativa na rigidez cranial do joelho sem afetar a sua rigidez caudal.

$\checkmark$ As técnicas SFTL e SFTLM de estabilização do joelho com RLCCr reduzem a quantidade de movimento de gaveta cranial.

A técnica SFTLM é mais efetiva na promoção da estabilidade cranial do joelho quando comparada com a técnica SFTL.

$\checkmark$ A técnica SFTLM influencia na biomecânica do ligamento cruzado caudal quando comparada com o joelho estabilizado por SFTL.

$\checkmark \quad$ A adição da sutura fabelo-tibial medial não aumenta a rigidez cranial do joelho.

$\checkmark$ As duas técnicas extra-capsulares estudadas geram forças de compressão entre as faces articulares da tíbia e do fêmur, sendo esta mais evidente para a técnicas SFTLM.

$\checkmark$ As técnicas SFTL e SFTLM são técnicas de baixo custo e baixa complexidade de execução. 


\section{REFERÊNCIAS}




\section{REFERÊNCIAS}

AMIS, A. A.; BULL, A. M. J.; GUPTE, C. M.; HIJAZI, I.; RACE, A.; ROBINSON, J. R. Biomechanics of the PCL and related structures: posterolateral, posteromedial and meniscofemoral ligaments. Knee Surgery, Sports Traumatology, Arthroscopy: Official Journal of the ESSKA, v. 11, p. 271-281, 2003.

ANDERSON III, C. C.; TOMLINSON, J. L.; DALY, W. R.; CARSON, W. L.; PAYNE, J. T.; WAGNER-MANN, C. C. Biomechanical evaluation of a crimp clamp system for loop fixation of monofilament nylon leader material used for stabilization of the canine stifle joint. Veterinary Surgery, v. 27, p. 533-539, 1998.

ARAGON, C. L.; BUDSBERG, S. C. Applications of evidence-based medicine: cranial cruciate ligament injury repair in the dog. Veterinary Surgery, v. 34, p. 93-98, 2005.

ARNOCZKY, S. P.; MARSHALL, J. L. The cruciate ligaments of the canine stifle: anatomical and functional analysis. American Journal of Veterinary Research, v. 38, p. 1807-1815, 1977.

ARNOCZKY, S. P.; TORZILLI, P. A.; MARSHALL, J. L. Biomechanical evaluation of anterior cruciate ligament repair in the dogs: an analysis of the instant center of motion. Journal of the American Animal Hospital Association, v. 13, p. 553-558, 1977.

ARNOCZKY, S. P. Surgery of the stifle - the cruciate ligaments. Compedium on Continuing Education for the Practicing Veterinarian, v. 11, p. 106-116, 1980.

ARTHURS, G. I.; LANGLEY-HOBBS, S. J. Patellar luxation as a complication of surgical intervention for the management of cranial cruciate ligament rupture in dogs. Veterinary and Comparative Orthopaedics and Traumatology, v. 20, p. 204-210, 2007. 
BANWELL, M. N.; HOSGOOD, G.; KERWIN, S. C.; HEDLUND, C. S.; METCALF, J. B. In vitro evaluation of fluorocarbon leader line for use as a fabella-tibial suture. Veterinary and Comparative Orthopaedics and Traumatology, v. 17, p. 35-40, 2004.

BANWELL, M. N.; KERWIN, S. C.; HOSGOOD, G.; HEDLUND, C. S.; METCALF, J. B. In vitro evaluation of the 18 and $36 \mathrm{~kg}$ securos cranial cruciate ligament repair system.

Veterinary Surgery, v. 34, p. 283-288, 2005.

BARAÚNA JÚNIOR, D.; ROEHSIG, D.; ROCHA, L. B.; CHIORATTO, R.; TUDURY, E. A. Técnica de interligação extra-capsular fêmoro-fabelo-tibial na ruptura do ligamento cruzado cranial em cães: achados clínicos e radiográficos. Ciência Rural, v. 37, n. 3, p. 769 776, 2007.

BARRETO, J. M. Avaliação mecânica da fixação femoral de tendões ísquio-tibiais e do ligamento patelar com parafuso de interferência nas reconstruções do ligamento cruzado anterior. 2000. 103 f. Tese (Doutorado) - Faculdade de Medicina, Universidade de São Paulo, São Paulo, 2000.

BUDSBERG, S. C.; VERSTRAETE, M. C.; SOUTAS-LITTLE, R. W.; FLO, G. L.; PROBST, C. W. Force plate analyses before and after stabilization of canine stifles for cruciate injury. American Journal of Veterinary Research, v. 49, n. 9, p. 1522-1524, 1988.

BUQUERA, L. E. C.; CANOLA, J. C.; PADILHA FILHO, J. G.; FURLANI, J. M.; TALIERI, I. C.; SELMI, A. L. Radiografia e macroscopia do do joleho após estabilização extra-articularutilizando fascia-lata, fio de poliéster trançado ou fio de poliamida para correção da ruptura do ligamento cruzado cranial em cães. Ciência Rural, v. 32, n. 1, p. 7378, 2002. 
CAPORN, T. M.; ROE, S. C. Biomechanical evaluation of the suitability of monofilament nylon fishing and leader line for extra-articular stabilisation of the canine cruciate-deficient stifle. Veterinary and Comparative Orthopaedics and Traumatology, v. 9, p.126-133, 1996.

CHAILLEUX, N.; LUSSIER, B.; DE GUISE, J.; CHEVALIER, Y.; HAGEMEISTER, N. In vitro 3-dimensional kinematic evaluation of 2 corrective operations for cranial cruciate ligament-deficient stifle. The Canadian Journal of Veterinary Research, v. 71, p. 175-180, 2007.

CHAUVET, A. E.; JOHNSON, A. L.; PIJANOWSKI, G. J.; HOMCO, L.; SMITH, R. D. Evaluation of fibular head transposition, lateral fabellar suture, and conservative treatment of cranial cruciate ligament rupture in large dogs: a retrospective study. Journal of the American Animal Hospital Association, v. 32, p. 247-255, 1996.

COETZEE, G. L. An in vitro comparison of two replacement techniques utilizing fascia lata after cranial cruciate ligament transaction in the dog. Veterinary and Comparative Orthopaedics and Traumatology, v. 6, p. 85-92, 1993.

COMERFORD, E. J.; TARLTON, J. F.; INNES, J. F.; JOHNSON, K. A.; AMIS, A. A.; BAILEY, A. J. Metabolism and composition of the canine anterior cruciate ligament relate to differences in knee joint mechanics and predisposition to ligament rupture. Journal of Orthopaedic Research, v. 23, p. 61-66, 2005.

COMERFORD, E. J.; TARLTON, J. F.; WALES, A.; BAILEY, A. J.; INNES, J. F. Ultrastructural differences in cranial cruciate ligaments from dogs of two breeds with differing predisposition to ligament degeneration an rupture. Journal of Comparative Pathology, v.134, p. 8-16, 2006. 
CONZEMIUS, M. G.; EVANS, R. B.; BESANCON, M. F.; GORDON, W. J.; HORSTMAN, C. L.; HOEFLE, W. D.; NIEVES, M. A.; WAGNER, S. D. Effect of surgical technique on limb function after surgery for rupture of the cranial cruciate ligament in dogs. Journal of the American Veterinary Medical Association, v. 226, n. 2, p. 232-236, 2005.

DEANGELIS, M.; LAU, R. E. A lateral retinacular imbrications technique for the surgical correction of anterior cruciate ligament rupture in the dog. Journal of the American Veterinary Medical Association, v. 157, p. 79-84, 1970.

DUPUIS, J.; HARARI, J.; PAPAGEORGES, M.; GALLINA, A. M.; RATZLAFF, M. Evaluation of fibular head transposition for repair of experimental cranial cruciate ligament injury in dogs. Veterinary Surgery, v. 23, p. 1-12, 1994.

FRANCIS, D. A.; MILLIS, D. L.; HEAD, L. L. Bone and lean tissue changes following cranial cruciate ligament transaction and stifle stabilization. Journal of the American Animal Hospital Association, v. 42, p. 127-135, 2006.

FLO, G. Modification of the lateral retinacular imbrication technique for stabilizing cruciate ligament injuries. The Journal of American Animal Hospital Association, v. 11, p. 570574, 1975.

FUKUBAYASHI, T.; TORZILLI, P. A.; SHERMAN, M. F.; WARREN, R. F. An in vitro biomechanical evaluation of anterior-posterior motion of the knee. The Journal of Bone and Joint Surgery, v. 64, p. 258-264, 1982.

GILES III, J. T.; COKER, D.; ROCHAT, M. C.; PAYTON, M. E.; SUBRAMARIAN, V.; BARTELS, K. E. Biomechanical analysis of suture anchors and suture materials in the canine femur. Veterinary Surgery, v. 37, p. 12-21, 2008. 
GORDON, W. J.; CONZEMIUS, M. G.; RIEDESEL, E.; BESANCON, M. F.; EVANS, R.; WILKE, V.; RITTER, M. J. The relationship between limb function and radiographic osteoarthrosis in dogs with stifle osteoarthrosis. Veterinary Surgery, v. 32, p. 451-454, 2003.

GUÉNÉGO, L.; ZAHRA, A.; MADELÉNAT, A.; GAUTIER, R.; MARCELLIN-LITTLE, D. J.; HULSE, D. Cranial cruciate ligament rupture in large and giant dogs. Veterinary and Comparative Orthopaedics and Traumatology, v. 20, p. 43-50, 2007.

HARARI, J.; JOHNSON, A. L.; STEIN, L. E.; KNELLER, S. K.; PIJANOWSKI, G. Evaluation of experimental transaction and partial excision of the caudal cruciate ligament in dogs. Veterinay Surgery, v. 16, n. 2, p. 151-154, 1987.

HARPER, T. A. M.; MARTIN, R. A.; WARD, D. L.; GRANT, J. W. An in vitro study to determine the effectiveness of a patellar ligament/fascia lata graft and new tibial suture anchor points for extracapsular stabilization of the cranial cruciate ligament-deficient stifle in the dog. Veterinary Surgery, v. 33, p. 531-541, 2004.

HAVIG, M. E.; DYCE, J.; KOWALESKI, M. P.; REYNOLDS, L. R.; BUDSBERG, S. C. Relationship of tibial plateau slope to limb function in dogs treated with a lateral suture technique for stabilization of cranial cruciate ligament deficient stifles. Veterinary Surgery, v. 36, p. 245-251, 2007.

HOHN R. B.; NEWTON C. D. Surgical repair of ligamentous structures of the stifle joint. In: BOJRAB, M. J. Current techniques in small animal surgery. Philadelphia: Lea \& Febiger, 1975. p. 470-479.

HUBER, D. J.; EGGER, E. L.; JAMES, S. P. The effect of knotting method on the structural properties of large diameter nonabsorbable monofilament sutures. Veterinary Surgery, v. 28, p. 260-267, 1999. 
HULSE, D. A.; BUTLER, D. L.; KAY, M. D.; NOYES, F. R.; SHIRES, P. K.;

D'AMBROSIA, R.; SHOJI, H. Biomechanics of cranial cruciate ligament reconstruction in the dog. In vitro laxity testing. Veterinary Surgery, v. 12, n. 3, p. 109-112, 1983.

HULSE, D. A.; JOHNSON, A. L. Tratamento da doença articular. In: FOSSUM, T. W. Cirurgia de pequenos animais. São Paulo: Roca, 2001. p. 978-1103.

INNES, J. F.; BACON, D.; LYNCH, C.; POLLARD, A. Long-term outcome of surgery for dogs with cranial cruciate ligament deficiency. The Veterinary Record, v. 147, p. 325-328, 2000 .

JOHNSON, S. G.; HULSE, D. A.; HOGAN, H. A.; NELSON, J. K.; BOOTHE, H. W. System behavior of commonly used cranial cruciate ligament reconstruction autografts. Veterinary Surgery, v. 18, n. 6, p. 459-465, 1989.

KIM, S. E.; POZZI, A.; KOWALESKI, M. P.; LEWIS, D. D. Tibial osteotomies for cranial cruciate ligament insufficiency in dogs. Veterinary Surgery, v. 37, p. 111-125, 2008.

KORVICK, D. L.; JOHNSON, A. L.; SCHAEFFER, D. J. Surgeons' preferences in treating cranial cruciate ligament ruptures in dogs. Journal of the American Veterinary Medical Association, v. 205, n. 9, p. 1318-1324, 1994.

LAMPMAN, T. J.; LUND, E. M.; LIPOWITZ, A. J. Cranial cruciate disease: current status of diagnosis, surgery, and risk for disease. Veterinary and Comparative Orthopaedics and Traumatology, v. 16, p. 122-126, 2003.

LAZAR, T. P.; BERRY, C. R.; DEHAAN, J. J.; PECK, J. N.; CORREA, M. Long-term radiographic comparison of tibial plateau leveling osteotomy versus extracapsular stabilization for cranial cruciate ligament rupture in the dog. Veterinary Surgery, v. 34, p. 133-141, 2005. 
LEOPIZZI, N. Estudo experimental das propriedades mecânicas do ligamento cruzado cranial de cães em diferentes graus de flexão do joelho. 1998. 152 f. Tese (Mestrado em Fisiopatologia Experimental) - Faculdade de Medicina Veterinária e Zootecnia, Universidade de São Paulo, São Paulo, 1998.

LEWIS, D. D.; MILTHORPE, B. K.; BELLENGER, C. R. Mechanical comparison of materials used for extra-capsular stabilization of the stifle joint in dogs. Australian Veterinary Journal, v. 75, n. 12, p. 890-896, 1997.

LOPEZ, M. J.; ROBINSON, S. O.; QUINN, M. M.; HOSGOOD, G.; MARKEL, M. D. In vivo evaluation of intra-articular protection in a novel model of canine cranial cruciate ligament mid-substance elongation injury. Veterinary Surgery, v. 35, p. 711-720, 2006.

MARADEI PEREIRA, J. A. R. Estudo biomecânico da influência da espessura do enxerto e da técnica de dois feixes na reconstrução do ligamento cruzado posterior. $2004.140 \mathrm{f}$. Tese (Doutorado) - Faculdade de Medicina, Universidade de São Paulo, São Paulo, 2004.

MARGHERITINI, F.; MAURO, C. S.; RIHN, J. A.; STABILE, K. J.; WOO, S. L.;

HARNER, C. D. Biomechanical comparison of tibial inlay versus transtibial techniques for posterior cruciate ligament reconstruction: analysis of knee kinematics and graft in situ forces. American Journal of Sports Medicine, v. 32, n. 3, p. 587-593, 2004.

MCCARTNEY, W. T.; O'CONNOR, J. V.; MCCANN, W. M. Incidence of infection and premature crimp failure after repair of cranial cruciate ligament-deficient stifles in 110 dogs. Veterinary Record, v. 161, p. 232-233, 2007.

MOORE, K. W.; READ, R. A. Cranial cruciate ligament rupture in the dog - a retrospective study comparing surgical techniques. Australian Veterinary Journal, v. 72, n. 8, p. 281$285,1995$. 
MOORES, A. P.; BECK, A. L.; JESPERS, K. J. M.; HALFACREE, Z.; WILSON, A. M. Mechanical evaluation of two crimp clamp systems for extracapsular stabilization of the cranial cruciate ligament-deficient canine stifle. Veterinary Surgery, v. 35, p. 470-475, 2006.

MOORES, A. P.; BECK, A. L.; JESPERS, K. J. M.; WILSON, A. M. Mechanical evaluation of two loop tensioning methods for crimp clamp extracapsular stabilization of the cranial cruciate ligament-deficient canine stifle. Veterinary Surgery, v. 35, p. 476-479, 2006.

MORAIS, C. L. M.; TATARUNAS, A. C.; MATERA, J. M. Estudo retrospectivo do tratamento conservativo de ruptura do ligamento cruzado cranial no cão. Pesquisa Veterinária Brasileira, v. 27, p. 50-52, 2007. Suplemento.

MUIR, P.; DANOVA, N. A.; ARGYLE, D. J.; MANLEY, P. A.; HAO, Z. Collagenolytic protease expression in cranial cruciate ligament and stifle synovial fluid in dogs with cranial cruciate ligament rupture. Veterinary Surgery, v. 34, p. 482-490, 2005.

MUIR, P.; MANLEY, P. A; HAO, Z. Collagen fragmentation in ruptured canine cruciate ligament explants. The Veterinary Journal, v. 172, p. 121-128, 2006.

NWADIKE, B. S.; ROE, S. C. Mechanical comparison of suture material and knot type used for fabello-tibial sutures. Veterinary and Comparative Orthopaedics and Traumatology, v. 11, p. 47-52, 1998.

OLMSTEAD, M. L. The use of orthopedic wire as a lateral suture for stifle stabilization. Veterinary Clinics of North America: Smal Animal Practice, v. 23, n. 4, p. 735-753, 1993.

OTT, R. L. An introduction to statistical methods and data analysis. 4. ed. Belmont, CA: Wadsworth Inc., 1993. 
PATTERSON, R. H.; SMITH, G. K.; GREGOR, T. P.; NEWTON, C. D. Biomechanical stability of four cranial cruciate ligament repair techniques in the dog. Veterinary Surgery, v. 20, n. 2, p. 85-90, 1991.

PEYCKE, L. E.; KERWIN, S. C.; HOSGOOD, G.; METCALF, J. B. Mechanical comparison of six loop fixation methods with monofilament nylon leader line. Veterinary and Comparative Orthopaedics and Traumatology, v. 15, p. 210-214, 2002.

PIERMATTEI, D. L. The hind limb. In: . An atlas of surgical approaches to the bones and joints of the dog and cat. $3^{\text {rd }}$ ed. Philadelphia: W.B. Saunders Company, 1993. p. 276-277.

PIERMATTEI, D. L.; FLO, G. L. A articulação fêmuro-tibio-patelar. In: Brinker, Piermattei e Flo manual de ortopedia e tratamento das fraturas dos pequenos animais. 3 ed. São Paulo: Manole, 1997. p. 480-538.

ROMANO, L. Análise biomecânica da articulação femoro-tíbio-patelar quanto à translação cranial da tíbia em relação ao fêmur em milímetros e da técnica extracapsular com nylon e anel de aço para reparação do ligamento cruzado cranial em cães. 2006. 76 f. Dissertação (Mestrado em Medicina Veterinária) - Faculdade de Medicina Veterinária e Zootecnia, Universidade de São Paulo, São Paulo, 2006.

ROMANO, L.; PEREIRA, C. A. M.; SCHMAEDECKE, A.; SAUT, J. P. E.; FERRIGNO, C. R. A. Análise biomecânica do joelho íntegro e com ruptura do ligamento cruzado cranial quanto ao grau de deslocamento cranial e rigidez articular em cães. Acta Cirúrgica Brasileira, v. 21, n. 1, p. 47-51, 2006.

SAS. STATISTICAL ANALISYS SYSTEM. SAS/STAT User's guide. 8. ed. Cary: SAS, 2001. 
SCHAEFER, S. L.; FLO, G. L. Cranial cruciate ligament repair by modified retinacular imbrications technique. In: BOJRAB, M. J. Current techniques in small animal surgery. Baltimore: Williams \& Wilkins, 1998. cap. 62, p. 1206-1209.

SELMI, A. L.; LINS, B. T.; BARBUDO-SELMI, G. R.; MENDES, G. M. Centro instantâneo de movimento, na avaliação ex-vivoda reconstrução extra-articular fabelo-tibial, após transecção do ligamento cruzado cranial em cães. Ciência Rural, v.33, n. 5, p. 875-880, 2003.

SICARD, G. K.; HAYASHI, K.; MANLEY, P. A. Evaluation of 5 types of fishing material, 2 sterilization methods, and a crimp-clamp system for extra-articular stabilization of the canine stifle joint. Veterinary Surgery, v. 31, p. 78-84, 2002.

SICARD, G. K.; MEINEN, T. P.; PHILLIPS, T.; MANLEY, P. A. Comparison of fishing line for repair of the cruciate deficient stifle. Veterinary and Comparative Orthopaedics and Traumatology, v. 12, p. 138-141, 1999.

SLOCUM, B.; SLOCUM, T. D. Algorithm for diagnosis and treatment of the stifle for cranial cruciate ligament rupture. Diagnostic tests. In: BOJRAB, M. J. Current techniques in small animal surgery. $4^{\text {th }}$ ed. Baltimore: Williams \& Wilkins, 1998. cap. 62, p. 1187-1193.

SLOCUM, B.; SLOCUM, T. D. Tibial plateau leveling osteotomy for repair of cranial cruciate ligament rupture in the canine. Veterinary Clinics of North America: Small Animal Practice, v. 23, n. 4, p. 777-705, 1993.

SMITH, B. Viewpoints in surgery - cruciate ligament rupture extracapsular stabilization. Australian Veterinary Journal, v. 78, n. 6, p. 382, 2000.

TATARUNAS, A. C.; MATERA, J. M.; IMAGAWA, V. H.; MASTROCINQUE, S. Arthroscopic study of the dog's knee joint with clinical cranial cruciate ligament injury. Brazilian Journal of Veterinary Research and Animal Science, v. 43, p. 129-136, 2006. Suplemento. 
TATARUNAS, A. C.; MATERA, J. M.; OLIVEIRA, R. M. D.; MACCHIONE, R. F.; BRUGNARO, M. Estudo retrospectivo do tratamento da ruptura de ligamento cruzado cranial no cão por técnica cirúrgica extra-articular. Brazilian Journal of Veterinary Research and Animal Science, v. 44, n. 3, p. 200-207, 2007.

VASSEUR, P. B. Clinical results following non-operative management for rupture of the cranial cruciate ligament in dogs. Veterinary Surgery, v. 13, p. 234-246, 1984.

VASSEUR, P. B. Stifle joint. In: SLATTER, D. Textbook of small animal surgery. Philadelphia: Saunders, 2003. p. 2090-2132.

VASSEUR, P. B.; BERRY, C. R. Progression of stifle osteoarthrosis following reconstruction of the cranial cruciate ligament in 21 dogs. Journal of the American Animal Hospital Association, v. 28, p. 129-136, 1992.

VASSEUR, P. B.; POOL R. R.; ARNOCZKY S. P.; LAU R. E. Correlative biomechanical and histologic study of the cranial cruciate ligament in dogs. American Journal of Veterinary Research, v. 46, n. 2, p.1842-1854, 1985.

VIANNA, M. L.; ROE, S. C. Mechanical comparison of two knots and two crimp systems for securing nylon line used for extra-articular stabilization of the canine stifle. Veterinary Surgery, v. 35, p. 567-572, 2006.

WARZEE, C. C.; DEJARDIN, L. M.; ARNOCZKY, S. P.; PERRY, R. L. Effect of tibial plateau leveling on cranial and caudal tibial thrusts in canine cranial cruciate-deficient stifles: an in vitro experimental study. Veterinary Surgery, v. 30, p. 278-286, 2001.

WEIGEL, J. P.; ARNOLD, G.; HICKS, D. A.; MILLIS, D. L. Biomechanics of rehabilitation. Veterinary Clinics Small Animal Practice, v. 35, p. 1255-1285, 2005. 
WHITEHAIR, J.; VASSEUR, P. B. Epidemiology of cranial cruciate ligament rupture in dogs. Journal of the American Veterinary Medical Association, v. 203, n. 7, p. 10161019, 1993.

WILKE, V. L.; ROBINSON, D. A.; EVANS, R. B.; ROTHSCHILD, M. F.; CONZEMIUS, M. G. Estimate of the annual economic impact of treatment of cranial cruciate ligament injury in dogs in the United States. Journal of the American Veterinary Medical Association, v. 227, n. 10, p. 1604-1607, 2005.

WINGFIELD, C.; AMIS, A. A.; STEAD, A. C.; LAW, H. T. Comparison of the biomechanical properties of rottweiler and racing greyhound cranial cruciate ligaments. Journal of Small Animal Practice, v. 41, p. 303-307, 2000.

WOO, S. L.; YOUNG, E. P.; OHLAND, K. J.; MARCIN, J. P.; HORIBE, S.; LIN, H. C. The effect of transaction of the anterior cruciate ligament on healing of the medial collateral ligament. A biomechanical study of the knee in dogs. The Journal of Bone and Joint Surgery, v. 72, p. 382-392, 1990.

YAMAMOTO, Y.; HSU, W.; WOO, S. L.; VAN SCYOC, A. H.; TAKAKURA, Y.; DEBSKI, R. E. Knee stability and graft function after anterior cruciate ligament reconstruction: a comparison of a lateral and an anatomical femoral tunnel placement. American Journal of Sports Medicine, v. 32, n. 8, p. 1825-1832, 2004.

YOON, K. H.; BAE, D. K.; HA, J. H.; PARK, S. W. Anatomic reconstructive surgery for posterolateral instability of the knee. Arthroscopy: The Journal of Arthroscopic and Related Surgery, v. 22, n. 2, p. 159-165, 2006.

ZACHOS, T. A.; ARNOCZKY, S. P.; LAVAGNINO, M.; TASHMAN, S. The effect of cranial cruciate ligament insufficiency on caudal cruciate ligament morphology: an experimental study in dogs. Veterinary Surgery, v. 31, p. 596-603, 2002. 